\title{
III. DER REVOLUTIONÄRE KRIEG UND DIE KRIEGERISCHE REVOLUTION: MASSENMOBILISIERUNG, RADIKALISIERUNG UND TERROR 1792-1794
}

Der revolutionäre Krieg, lautet eines der so anregenden wie schillernden Urteile von François Furet, habe kein klar bestimmtes Ziel gehabt, er sei vielmehr so tief in der Revolution selbst verwurzelt gewesen, daß er auch nur mit ihr habe enden können'. So richtig es indes ist, die intime Verbindung zwischen der Revolution und ihrem Krieg gegen die Mächte des Ancien Régime hervorzuheben, so wenig vermag die vielsagende Unverbindlichkeit einer solchen Äußerung letztlich zu erklären. Hier wurde im vorhergehenden Kapitel zu zeigen versucht, wie nicht die Revolution an sich, sondern ihre vielfältigen Konflikte mit den Mächten der alten Ordnung den Diskurs über Militär, Krieg und revolutionäre Gesellschaft umgestaltet und sie schließlich in den Krieg geführt haben. Im folgenden soll nun genauer analysiert werden, wie die Revolution sowohl im politischen Diskurs als auch in der davon bestimmten politischen Praxis immer intensiver an ihren Krieg mit den Mächten des Ancien Régime gebunden, ja schließlich mit ihm identifiziert wurde und dadurch selbst spezifisch kriegsbedingte Prägungen erhielt. Die wesentliche Grundlage für diesen Identifikationsprozeß lag in der sich bereits in der Agitation für den Krieg im Winter 1791/92 abzeichnenden, aus der revolutionären Konfrontation mit dem Ancien Régime hervorgehenden und nun die Betrachtung aller wesentlichen gesellschaftspolitischen Ebenen zutiefst prägenden Konzipierung des Krieges als einen revolutionären europäischen Bürgerkrieg mit einer fundamentalen Verschiebung der bisher üblichen Formen der Frontbildung, die nun im Zeichen der Realität des Krieges die Betrachtung aller politischen und gesellschaftlichen Probleme und Konflikte durchdrang. Die traditionellen Grenzen zwischen Innen- und Außenpolitik wurden dabei grundsätzlich aufgelöst. Nicht mehr Staaten schienen gegeneinander Krieg zu führen, sondern die grenzüberschreitende Konfliktlinie schien innerhalb wie außerhalb Frankreichs zwischen den nach Freiheit strebenden Völkern einerseits, ihren tyrannischen, mit allen privilegierten Schichten verbundenen Herrschern andererseits zu verlaufen. Sowohl der Krieg als auch die Revolution gewannen so einen spezifisch doppelten, nach außen wie nach innen gerichteten, sich wechselseitig durchdringenden Charakter: Dem revolutionären 
Krieg entsprach die kriegerische Revolution. Der Krieg wurde dabei zu einem kaum mehr eingrenzbaren Kampf für die Ideale der Revolution und, bald immer deutlicher hervortretend, auch für die Interessen ihrer französischen Inkarnation, während die Revolution selbst gleichzeitig zum kriegerischen Kampf gegen alle ihre realen und möglichen Feinde mutierte.

Die Jahre 1792 bis 1794 gelten allen Schulen der Revolutionsgeschichtsschreibung, unabhängig von den höchst unterschiedlichen Bewertungen, übereinstimmend als Phase der beschleunigten, einem Höhepunkt zustrebenden revolutionären Radikalisierung. Begriffsgeschichtlich betrachtet stand dieser Radikalisierungsprozeß im Zeichen des Kampfes gegen die »ennemis« bzw. "étrangers du dedans«, er war geprägt von "mesures révolutionnaires« und zu seinem eigentlichen Gehalt wurde immer mehr »la terreur«. Im folgenden soll jedoch gezeigt werden, daß die Begrifflichkeit der revolutionären Radikalisierung ihren eigentlich Sinn erst durch einen diskursiven Zusammenhang gewann, der von der Identifikation von Krieg und Revolution geprägt war. »After 1792« so hat Gwynne Lewis die Bedingungen dieser Zeit treffend charakterisiert, »but particularly during the Year II, Mars was the deity who actually presided over the actions of most Frenchmen and women ${ }^{2}$. Nicht um die gewissermaßen objektiven Einflüsse des Krieges, die Probleme etwa der Rekrutierung, der Kriegswirtschaft, des Währungsverfalls oder der Lebensmittelversorgung, soll es hier jedoch vor allem gehen, sondern, selbstverständlich in engem Bezug dazu, um die Deutungsformen der Verbindung von Krieg und Revolution im revolutionären Diskurs. Dabei sind vor allem drei eng miteinander verbundene Deutungsmuster festzustellen, durch die der Radikalisierungsprozeß in seiner Dynamik und Ausformung wesentlich geprägt wurde.

Die Konstruktion des revolutionären Bürgerkrieges führte zum einen dazu, daß die inneren politischen Gegner aufs engste mit den äußeren Kriegsgegnern verbunden wurden. Der als ebenso kriegerisch wie revolutionär begriffene Kampf zielte gegen die »ennemis du dehors et du dedans«, die es gleichermaBen auszuschalten gelte, wenn die Revolution insgesamt siegreich bleiben sollte; mehr noch, die Ausschaltung der sinneren Gegner، wurde als Voraussetzung des militärischen Sieges begriffen, den sie zu hintertreiben schienen. Die zwar auch als rhetorisch-politisches Mittel eingesetzte, wesentlich aber ernstgemeinte Denunziation des politischen Gegners als Verbündeten des feindlichen Auslandes zielte zuerst vor allem auf mehr oder weniger eindeutig konterrevolutionäre Kräfte, die nun generell als feindliche Agenten vor allem der gegenrevolutionären Vormächte, zuerst Österreichs und seit Anfang 1793 dann vor allem Englands, betrachtet wurden. Sie rückte bald aber auch in den

2 G. LEwIS, The French Revolution. Rethinking the Debate, London u. New York 1993, S. 45 . 
Mittelpunkt der politischen Auseinandersetzungen innerhalb des revolutionären Lagers. Zwar wurde gerade in Zeiten der akuten Bedrohung immer wieder die innere Einheit der Revolutionäre beschworen. Doch war in die Konstruktion dieser Beschwörung die Wendung gegen den »ennemis du dedans« bald so unauflöslich eingewoben, daß sie wie selbstverständlich auch zu einer Intensivierung jedes politischen Kampfes an der sinneren Front führte. So war die Zuspitzung der Konflikte im revolutionären Lager, wie sie 1793/94 erst zur Ausschaltung der Girondisten, dann der Hébertisten und Dantonisten führte, keineswegs primär auf die Situation nach dem "Königsmord" und die Notwendigkeit der Neuverteilung der Macht zurückzuführen ${ }^{3}$, sondern in erster Linie auf die Deutung politischer Gegensätze im Rahmen eines Interpretationsmusters, das sich durch Verlängerung des Krieges in die revolutionäre Innenpolitik auszeichnete.

Zum Synonym für alle Feinde der Revolution, die äußeren wie die inneren, die offenen wie die verborgenen, wurde der zunehmend im Kollektivsingular benutzte, untrennbare Verbundenheit zwischen äußerer und innerer Revolutionsfeindschaft suggerierende Begriff $" /$ 'étranger ${ }^{4}$. Die in Frankreich lebenden Ausländer, die die Revolution anfangs gastfreundlich in ihre Reihen aufnehmen wollte, wenn sie sich zu ihr bekannten, gerieten im Krieg prinzipiell unter den Verdacht, feindliche Agenten zu sein. Darüber hinaus aber erfaßte der Begriff von Anfang an auch alle Franzosen, die der Revolution tatsächlich oder vermeintlich ablehnend gegenüberstanden, die somit nicht zur neugeschaffenen revolutionären Nation dazugehörten und die nun im Zeichen des Krieges ebenfalls prinzipiell der direkten, zumindest aber der indirekten $\mathrm{Zu}$ sammenarbeit mit dem feindlichen Ausland verdächtigt wurden. Gerade der als Patriot getarnte sétranger", der Verräter an der revolutionären Nation, schien die weitaus größte Gefahr im Innern darzustellen, und in dieser Denkfigur findet die nunmehr obsessive Beschäftigung der Revolutionäre mit "Verschwörungen«, bzw. mit der jede politische Abweichung im Kollektivsingular vereinheitlichenden »conjuration de l'étranger", ihre eigentliche Wurzel.

Diese Entwicklung gewann eine besondere Qualität durch den zweiten Faktor, durch die wachsende Identifikation von Krieg und Revolution. Schon kurz nach Kriegsbeginn bestimmte Condorcet, daß die französische Revolution "peut être regardée comme la guerre de la raison contre les préjugés «s. Was hier indes noch als eine vom ideellen revolutionären Universalismus geleitete Wortspielerei erscheinen mochte, gewann in der Folgezeit nicht nur an

3 Vgl. L. HUNT, The Family Romance of the French Revolution, Berkeley u. Los Angeles 1992 , bes. S. 53-88.

4 Vgl. S. WAHNICH, L'impossible citoyen: L'étranger dans le discours de la Révolution française, Paris 1997

s Chronique du Mois, Juni 1792, S. 60f. 
diskursiver Zuspitzung, sondern auch an geschichtsprägender Kraft, weil die innere Revolutionierung zum entscheidenden Mittel der Kriegsführung erhoben wurde. In begriffsgeschichtlicher Betrachtung verstand man unter den im Zeichen der drohenden Niederlage bald immer häufiger geforderten »mesures révolutionnaires« erst einmal außerhalb der legalen Verfassungsordnung stehende Maßnahmen, die ihre Rechtfertigung in der außergewöhnlichen Bedrohungssituation der Revolution fand, deren Rettung sie jenseits aller legalistischen Bedenken dienen sollten. Doch diese Betrachtungsweise greift zweifellos zu kurz, denn zugleich waren revolutionäre Maßnahmen im eigentlichen Sinne des Wortes gemeint, sie sollten nicht nur der Sicherung, sondern auch der Fortsetzung der Revolution dienen. Und beide Ziele waren aufs engste mit dem Krieg verbunden.

Da die Revolutionäre von Anfang an übereinstimmend der Auffassung waren, daß ihre revolutionäre Nation den Mächten des Ancien Régime weit überlegen sein müsse, führten militärische Niederlagen mit innerer Logik nicht nur zur verschärften Wendung gegen den sinneren Feind`, sondern auch zu dem Eindruck, daß die Revolution offensichtlich unvollständig sei und weiter vorangetrieben werden müsse, um den Krieg schließlich doch gewinnen zu können. Und da der Feind im Innern der revolutionären Nation, durchaus nicht ohne Grund, mit den priviligierten Mächten der alten Ordnung identifiziert wurde, erschien die fortgesetzte Revolutionierung als einzig geeignete Form des Kampfes an der sinneren Front. Diese innere Revolutionierung um des äußeren Sieges willen prägte dann umgekehrt, wie im folgenden vielfach deutlich werden wird, in kriegsspezifischer Weise die Revolution und ihren Radikalisierungsprozeß, wobei die sich wandelnden Konnotationen zugleich den aufs engste mit dem Krieg verbundenen Weg der Revolution vom politischen Umsturz über die soziale Radikalisierung der revolutionären Bewegung zur revolutionären Diktatur widerspiegeln. "La patrie est en danger, nous rentrons en révolution«, so lautete eine der zentralen Parolen für den Sturz der Monarchie im August $1792^{6}$. Als die revolutionären Armeen im Frühjahr 1793 erneut unter Druck gerieten und die gesetzlichen Grundlagen des Terrors geschaffen wurden, rückte die Forderung nach revolutionären Maßnahmen in den Mittelpunkt der öffentlichen Agitation: "c'est par des mesures véritablement révolutionnaires qu'il faut sauver la patrie; c'est sur la force de la nation qu'il faut s'appuyer«, argumentierte etwa Robespierre im Nationalkonvent für die revolutionäre Radikalisierung?. Diese Entwicklung fand ihren Höhepunkt dann in der Begründung der revolutionären Regierung, $d$. h. der terroristischen Kriegsdiktatur der großen Ausschüsse, die wesentlich darauf beruhte, daß

6 Adresse der Pariser Volksbewegung für den Sturz der Monarchie, 6.8.1792. AP 47, S. $525 f$.

7 AP 61, S. 271, 3.4.1793. 
Krieg und Revolution zu Synonymen wurden; es war wiederum Robespierre, der ihre klarste, mit der eingangs zitierten von Condorcet so oberflächlich übereinstimmende wie in der qualitativen Bedeutung fundamental radikalisierte Formulierung fand: "La révolution«, stellte er in seiner ersten großen Rechtfertigung der revolutionären Diktatur zum Jahresende 1793 in aller Klarheit fest, »est la guerre de la liberté contre ses ennemis»?.

Eine dritte, eng damit verbundene, die Identifikation von Krieg und Revolution spezifizierende diskursive Grundfigur, die die Radikalisierung der Revolution wesentlich geprägt hat, ist schließlich in der Gleichsetzung von kriegerischer und revolutionärer Massenmobilisierung zu sehen, deren diskursive Verbindung zugleich maßgeblich dazu beitrug, den revolutionären Terror hoffähig zu machen. Als die von außen und innen sbelagerte Republikı im Sommer 1793 mit dem Projekt der levée en masse reagierte, war dies zugleich der diskursive Höhepunkt einer Rhetorik der totalen Mobilmachung der gesamten französischen Bevölkerung. Der Begriff beinhaltete eine doppelte Bedeutung, er zielte nicht nur auf die massenhafte, dem Anspruch nach freiwilliger Rekrutierung neuer Soldaten für die militärische Landesverteidigung, sondern er verband damit zugleich, was oft übersehen wird, auch die Vorstellung einer revolutionären Erhebung im Innern. Diese Verbindung war zweifellos bereits in der Konzeption des citoyen soldat angelegt, doch erhielt sie durch die Bedingungen von Krieg und Bürgerkrieg nicht nur eine enorme, die gesamte zivile Gesellschaft einbeziehende Bedeutungserweiterung. Vielmehr transportierte die Rhetorik der levée en masse zugleich spezifisch kriegerisch geprägte Formen des inneren Kampfes gegen die Konterrevolutionäre im eigenen Land, gegen die man schließlich im Zeichen des gleichzeitig inaugurierten Terrors spezifische armées révolutionnaires ins Feld führte.

Ein wesentlicher diskursiver Faktor bleibt noch zu klären, der Begriff la terreur ${ }^{9}$. Ursprünglich war dieser Begriff im revolutionären Diskurs überwiegend mit negativen Konnotationen verwendet worden, Terror wurde demnach in erster Linie von den Konterrevolutionären ausgeübt. Zweifellos hat Gewalt die revolutionäre Bewegung von Anfang an begleitet, und ihre abstoßenden Formen entsprangen keineswegs nur attavistischen Triebstrukturen, sondern sie sollten immer auch die Gegner der Revolution zum Erschrecken bringen. Doch handelte es sich erst einmal um spontane Gewaltakte, nicht um

8 AP 82, S. 300, 25.12.1793.

- Vgl. G. VAN DEN HeUVEL, Terreur, Terroriste, Terrorisme, in: Handbuch politischsozialer Grundbegriffe in Frankreich 1680-1820, H. 3, S. 89-132; H. KESSLER, Terreur. Ideologie und Nomenklatur der revolutionären Gewaltanwendung in Frankreich von 1770 bis 1794, München 1973; P. GUENIFFEY, La Politique de la Terreur. Essais sur la violance révolutionnaire 1789-1794, Paris 2000; A. GEFFROY, Terreur et terrorisme: les mots en héritage, du néologisme au concept, in: A. GERARD (Hg.), La Vendée. Après la terreur, la reconstruction, Paris 1997, S. 144-161. 
eine terroristisch konzipierte revolutionäre Politik. Frühzeitig hat im revolutionären Lager fast nur Marat den Begriff des Terrors positiv gewendet, und bezeichnenderweise hatte er ihn von Anfang an in einen engen Zusammenhang mit seiner Deutung der Revolution als Krieg gegen die Konterrevolution gestellt: „Dans l'état de guerre où nous sommes, il n'y a que le peuple«, stellte er schon 1790 fest, "qui puisse en imposer aux ennemis de la révolution, les contenir dans le devoir, les forcer au silence, les réduire à cet état de terreur salutaire ${ }^{10}$. Doch erst der heranziehende Krieg ließ den politisch konzipierten Terror Eingang in den allgemeineren politischen Diskurs der Revolution finden, vor allem in der Denkfigur eines "rétournement de la terreur«. So formulierte Vergniaud im März 1792, als er für die Anklageerhebung gegen den des Landesverrats bezichtigten Außenminister Delessart plädierte, die an den Hof insgesamt gerichtete Drohung: »Le your est arrivé, Messieurs, où vous pouvez mettre un terme à tant d'audace, à tant d'insolence, et confondre enfin les conspirateurs. L'epouvante et la terreur sont souvent sorties dans les temps antiques, et au nom du despotisme, de ce palais fameux. Qu'elles y rentrent aujourd'hui au nom de la loi. (Applaudissements réitérés.) Qu'elles y pénètrent tous les cœurs «".

Hier wird zum einen deutlich, wie sehr der antizipierte Krieg dazu beitrug, den Terror im revolutionären Diskurs hoffähig zu machen. Zum anderen weist der letzte Satz auf eine wesentliche Differenzierung des Terror-Begriffs an, die Unterscheidung zwischen spontanem und legalem Terror. Im Zeichen der kriegerischen Radikalisierung konnte die spontane njustice du peuple« auch für die revolutionären Bürger durchaus eine situative Berechtigung finden. Doch im Prinzip sollten nach ihrem Verständnis »lois terribles« dafür sorgen, $\mathrm{daB}$ der populare Terror mit seiner unkontrollierbaren Radikalität und seinen grauenhaften Begleiterscheinungen durch staatlich legitimierte, kontrollierte und zielgerichtete Maßnahmen ersetzt werden konnte. Eine Eingrenzung des Terrors war damit allerdings nicht unbedingt verbunden, in Verbindung mit der Ausbildung der revolutionären Kriegsdiktatur war eher das Gegenteil der Fall.

Die kriegerische Aufladung trug schließlich entscheidend dazu bei, daß im Begriff des Terrors Abschreckung und Vernichtung des Feindes zunehmend miteinander verschwammen. So wie die feindlichen Armeen durch die Truppen der Revolution vernichtet werden sollten, sollten bald auch im Innern Frankreichs die Feinde der Revolution nicht nur in die Schranken gewiesen, sondern ausgelöscht werden. "Citoyens, ce n'est qu'en jetant la terreur dans l'âme des traitres que vous assurerez l'indépendance de la patrie«, so verband im Sommer 1793 ein Vertreter der radikalisierten Enragés den Terror gegen

10 Ami du Peuple, 13.6.1790.

1 AP 39, S. 549, 10.3.1792. 
den inneren Feind unmittelbar mit der Landesverteidigung, um dann die diskursive Konstruktion der Revolution als terroristischen Vernichtungskrieg gegen ihre Feinde auf den Punkt zu bringen: „En fait de révolution, le seul moyen de la consolider, c'est d'écraser les traîtres dans la fureur de la guerre $\ll^{12}$.

Bevor wir aber im folgenden den kriegsspezifischen Diskurs des inneren Radikalisierungsprozesses in seinen wichtigsten Etappen: dem Weg zum Sturz der Monarchie, der Auseinandersetzung zwischen Montagne und Gironde, der Verbindung von Massenmobilisierung und Terror und der Ausbildung der terroristischen Kriegsdiktatur, genauer behandeln wollen, soll hier zuerst die weitere revolutionäre Ideologisierung des Krieges und, aufs engste damit verbunden, die äußere Bindung der Revolution an den Krieg analysiert werden. Sie spiegelt sich indirekt darin wieder, da $\beta$ alle Versuche - nach den Feuillants zuerst der Anhänger Brissots, dann der Dantonisten -, die Dynamik der inneren Radikalisierung einzudämmen, zugleich die Eingrenzung oder gar die Beendigung des Krieges $\mathrm{zu}$ ihrer zentralen Voraussetzung machten. Umgekehrt weisen die Abdrängung dieser Versuche in die Geheimdiplomatie und ihr Scheitern darauf hin, wie sehr der revolutionäre Diskurs »la guerre à outrance«, den Kampf bis zur endgültigen Entscheidung, zum Wesenselement der Revolution stilisiert hatte. "Leur cri est: La paix et la royauté; le vôtre doit être: la république et la guerre«, so identifizierte der Konvent im Frühjahr 1793, vor dem Hintergrund des Bürgerkrieges, den Frieden mit dem Königtum und die Republik mit dem Krieg ${ }^{13}$. Der außenpolitische Sprecher des Wohlfahrtsausschusses, Barère, führte diese Identifikation Anfang 1794 noch klarer aus, als er sich vor dem Konvent folgendermaßen gegen die Friedensbestrebungen der Dantonisten wandte: "Il faut la paix aux monarchies, il faut l'énergie guerrière à la République; il faut la paix aux esclaves, il faut la fermentation de la liberté aux républicains; il faut la paix aux gouvernements de l'Europe, il faut l'activité révolutionnaire à la République française « ${ }^{14}$.

12 Le Publiciste de la Révolution française, par l'ombre de Marat, 27.7.1793.

13 Zit. n. Annales Patriotiques, 30.4.1793.

14 AP 83, S. 562, 20.1.1794. 


\section{Revolutionäre Kriegsideologie 1792-1794}

Von Anfang an erschien der Krieg im revolutionären Diskurs, allen offensiven Sinnstiftungen des Winters 1791/92 zum Trotz, als ein gerechter Verteidigungskrieg, den ein um die Bewahrung des Friedens bemühtes Frankreich bis zuletzt zu verhindern versucht habe, der ihm aber durch die äußere Bedrohung aufgezwungen worden sei ${ }^{15}$. Darin lag indes bereits ein erster, über die $\mathrm{Be}$ schwörung der Landesverteidigung hinausweisender Ansatzpunkt für die revolutionäre Ideologisierung des Krieges. Denn er galt so als "la guerre la plus juste et la plus glorieuse dont avaient jamais parlé les fastes du monde«, der Welt wollte man nun beweisen, "que c'est l'amour de la patrie, et non la fureur des conquêtes, la liberté, et non l'ambition qui nous met les armes à la main ${ }^{16}$. Und so wie anfangs die Revolution nicht zuletzt als ein Instrument des Friedens betrachtet worden war, so erschien nun der aufgezwungene Krieg letztlich nur der allgemeinen Durchsetzung des Friedens gegen die mit dem Krieg identifizierten Kräfte der alten Ordnung zu dienen: „Oui, nos saurons nous réduire à une nourriture grossière, à la sauce noire des Spartiates, pour soutenir une guerre qui sera suivie de la paix perpétuelle «"

Mit dem Pathos der moralischen Überlegenheit im gerechten Verteidigungskrieg kündigte sich zugleich eine weitere revolutionäre Neuheit an, die das säkularisierte Kreuzzugspathos des Winters 1791/92 in spezifischer Weise zuspitzte. Denn der Krieg wurde dabei unter der Hand zu einem finalen Entscheidungskampf zwischen fundamental gegensätzlichen, ja unvereinbaren gesellschaftlichen Prinzipien und Werten stilisiert. "La guerre que nous entreprenons est la guerre du genre humain, contre ses oppresseurs«, so war man überzeugt, denn es handelte sich schließlich um "la guerre sacrée des hommes contre les couronnes", die ihrerseits "une guerre impie avec des soldats-serfs et de l'argent exturqué« führten ${ }^{18}$. Schließlich gehe es dem revolutionären Frankreich nicht um Eroberungen, die seine Verfassung doch ausschließe. Der revolutionäre Krieg erschien vielmehr mit den Worten von Brissot als »la guerre de la justice contre l'oppression, de la liberté contre le despotisme; et cette guerre est sacrée; elle est commandée par vos serments, par votre intérêt le plus cher, par l'intérêt même de tous les peuples dont ont veut étouffer la liberté future dans la liberté naissante des Français ( $^{19}$.

is Vgl. Condorcets Begründung der Kriegserklärung in der Nationalversammlung. AP 42, S. 210-213, 20.4.1792.

${ }^{16}$ Patriote Français, 21.4.1792, Bericht über die Sitzung der Nationalversammlung vom 19.4.1792.

17 A. Cloots vor der Nationalversammlung am 21.4.1792. AP 42, S. $252 \mathrm{f}$.

18 Patriote Français, 21.4.1792 bzw. 23.4.1792.

19 J.-P. BRISSOT, Sur la justice de la guerre contre l'Autriche, in: Chronique du Mois, Mai 1792, S. 41-53, hier S. 52. 
Als der im revolutionären Überschwang erwartete schnelle Sieg sich nicht einstellte, die französischen Armeen auf die Verliererstraße gerieten und im Sommer 1792 nach dem Kriegseintritt Preußens die militärische Bedrohung immer näher rückte, verwandelte sich nicht nur der Tonfall, sondern der finale Entscheidungscharakter des Krieges trat zugleich immer stärker in den Vordergrund. Nun führte man " la guerre à mort entre la royauté et la liberté«, einen Krieg also, der nur mit dem totalen Sieg einer Seite enden könne ${ }^{20}$. "Vivre libre ou mourir«, das Motto des Föderationsfestes von 1790, wurde zum Wahlspruch eines Krieges, der bis zur letzten Entscheidung geführt werden müsse. Im Krieg der Freiheit, so brachte Barère diese fundamentale Grundannahme des revolutionären Krieges Anfang 1794 zum Ausdruck, wil n'est qu'un moyen, c'est de ruiner et d'exterminer les despotes. Lorsque l'horreur de la tyrannie et l'instinct de la liberté ont mis les armes dans les mains d'hommes braves, ils ne doivent les poser qu'en dictant la paix: (...) il n'y a ni paix, ni trêve, ni armistice avec les despotes, qu'au nom d'une République affermie, triomphante et dictant la paix aux nations «"'t.

Diese den Ausschluß jedes Verständigungsfriedens beinhaltende, die Revolution de facto auf unabsehbare Zeit an den Krieg bindende, grundsätzliche Orientierung auf einen umfassenden Siegfrieden basierte zweifellos auf der spezifisch revolutionären Grundannahme, daß es sich bei dem Krieg um einen Konflikt zwischen unvereinbaren Werten handele, der nur durch den Sieg eines Prinzips entschieden werden könne. In der konkreten Ausformung indes können dabei zwei verschiedene Ebenen unterschieden werden, die cum grano salis der militärischen Defensive und der militärischen Offensive entsprachen: der Betrachtung jeder Form von Verständigung mit dem Kriegsgegner als den Interessen der Konterrevolution dienende Form des Landesverrats einerseits, der revolutionären Expansion andererseits.

$\mathrm{Da}$ die Offensive die der Revolution angemessene Kriegstaktik sei, diese Auffassung teilten bei Kriegsbeginn alle revolutionären Kräfte. Selbst der entschiedene Kriegsgegner Robespierre forderte nun mit Nachdruck, daß die französischen Truppen ihre Revolution über die Landesgrenzen hinaustragen sollten und "conquérir le Brabant, les Pays Bas, Liège, la Flandre etc. $\aleph^{22}$. Dieses Projekt rückte angesichts der realen Kriegsentwicklung jedoch erst einmal in den Hintergrund und wurde im Zeichen der Defensive durch die fundamentale Ablehnung jeder Verständigung ersetzt. Bemühungen um einen Waffenstillstand oder gar um einen Verständigungsfrieden wurden im revolutionären Diskurs prinzipiell ausgeschlossen. Nachdem er zuvor bereits Gerüchten über einen möglichen Waffenstillstand zur Einleitung von

22 Rede im Jakobinerklub am 20.4.1792, zit. n. Journal des débats, Nr. 183, S. 3. 
Friedensverhandlungen mit dem Argument entgegengetreten war, daß es sich dabei nur um den Versuch der Feinde handeln könne, bessere Ausgangsbedingungen für die Fortsetzung des Krieges zu schaffen ${ }^{23}$, stellte Brissot im Juli 1792 klar, daß ein Verständigungsfrieden aufgrund des prinzipiellen Gegensatzes von Revolution und Ancien Régime prinzipiell ausgeschlossen sei: „C'est donc ici, Messieurs, une guerre à mort entre la royauté et la liberté. Les tyrans de l'Europe veulent nous écraser ou périr. (...) Point de paix à espérer avec eux. Et telle est l'idée profonde qui a déterminé les hommes qui, connaissant la vraie base de cette coalition, ont pensé qu'en la prévenant, on pouvait la renverser; que lui donner le temps de s'accroître, de se consolider, c'était perdre la liberté. La paix, comme la guerre, doit être également funeste aux rois, parce que nos principes, dont la contagion est si séduisante pour les peuples et si rapide, doivent tendre à se propager sans aucun effort et à ruiner la tyrannie $\ll^{24}$. Jean Debry fügte im August die Erweiterung hinzu, alle Friedensbestrebungen auf feindlicher Seite seien doch nur geschickt kaschierte Instrumente der Kriegführung: "Ils nous promettaient la paix que pour vous faire la guerre plus cruelle, après vous avoir desarmé. C'est dans les flots de votre sang qu'ils voudraient à jamais étouffer ces germes de liberté dont le développement les épouvante. Vos femmes, vos enfants imbûs des mêmes principes, seraient avec vous précipités dans la tombe ${ }^{25}$. Angesichts dieser Charakterisierungen war es politisch ein eher zurückhaltender Schritt, als die Revolutionsregierung Ende September 1792 auf ein Waffenstillstandsangebot mit der Erklärung reagierte, daß die Republik »n'entendrait aucune proposition, qu'au préalable les ennemis n'eussent évacué son territoire ${ }^{26}$.

$\mathrm{Zu}$ diesem Zeitpunkt begann sich indes nach Valmy bereits der militärische Vormarsch der revolutionären Truppen abzuzeichnen, der nun ganz selbstverständlich nicht nur über die Landesgrenzen hinaustrieb, sondern auch das Projekt des Revolutionsexports wieder in den Vordergrund rückte. Schon die zweite, zum Sturz der Monarchie führende Revolution vom 10. August 1792 hatte erneut den Eindruck erweckt, es gehe nun endlich auch im Krieg nach außen wieder um das offensiv anzustrebende Ziel, "que tous les trônes soient transformés en autels de la patrie. La dernière guerre des tyrans sera suivie de la grande paix du genre humain: courte guerre, paix perpétuelle! $\aleph^{27}$. Der neugewählte Konvent sollte nach dieser Logik dazu dienen, "d'assurer votre li-

23 Patriote Français, 15.6.1792.

${ }^{24}$ Rede in der Nationalversammlung am 9.7.1792, AP 46, S. 261-273, hier S. 262. Vgl. auch Patriote Français, 12.7.1792.

${ }_{25}$ Zit. n. La Sentinelle, 31.8.1792, abgedr. in: J.-B. LOUVET, La Sentinelle 1792, Nachdr. Paris 1981. Vgl. auch AP 49, S. 12f., 26.8.1792, ohne vollständigen Abdr. der Rede.

${ }_{26}$ Zit. n. Journal de la République Française, 30.9.1792.

27 Aufruf von Cloots, abgedr. in: Patriote Français, 11.8.1792. 
berté toute entière et de préparer celle de l'Europe $\aleph^{28}$. Und als die französischen Armeen dann im Herbst 1792 tatsächlich fremde Territorien zu besetzen begannen, griffen auch ihre Generäle wie selbstverständlich die Parolen des revolutionären Befreiungskrieges auf. "Guerre aux châteaux, paix aux chaumettes«, so hatte Condorcet das Befreiungspathos bei Kriegsbeginn auf eine griffige Formel gebracht, die nun auch das Selbstbild und die Selbstdarstellung der französischen Armeen prägte. "Au nom de la nation française, guerre aux despotes, paix et liberté aux peuples«, proklamierte General Montesquiou in Savoyen, und einige Tage später erließ General Custine im Rheinland eine Proklamation, in der es hieß: "Guerre aux tyrans, paix aux hommes justes, voilà le manifeste de la république française $\aleph^{29}$. General Dumouriez teilte schließlich Ende Oktober 1792 den Belgiern mit: "Nous entrons incessamment sur votre territoire; nous y entrons pour vous aider à planter l'arbre de la liberté, sans nous mêler en rien de la Constitution que vous voudrez adopter $\wedge^{30}$.

Vieles spricht dafür, daß nicht nur die tatsächlich anfangs oft als Befreier bejubelten französischen Soldaten von diesen revolutionären Befreiungsparolen überzeugt waren, sondern auch weite Teile der öffentlichen Meinung in Frankreich. In Paris schlug nun die Stunde der politischen Emigranten, die ihre politischen Ziele unmittelbar mit dem Vormarsch der französischen Truppen verbunden sahen. Nicht nur der bereits seit langem als universeller norateur du genre humain " hervorgetretene, auf eine starke Fraktion batavischer Emigranten gestützte niederländische Preuße Cloots ${ }^{31}$ tat sich dabei besonders hervor, sondern auch weniger schwärmerische Geister wie etwa der Genfer Clavière oder der Engländer Thomas Paine, beide ausgestattet mit französischem Bürgerrecht und als Finanzminister bzw. als Konventsabgeordneter auch mit beträchtlichem politischem Einfluß. Die Revolutionierung Europas lag im Interesse aller politischen Emigranten, und ihre führenden Vertreter traten nachdrücklich dafür ein. "La liberté et l'égalité«, stellte etwa Paine fest, "sont des bienfaits trop grands pour n'appartenir qu'à la France; c'est assez d'honneur pour elle d'en être le premier apôtre. Qu'elle dise donc à ses ennemis, d'une voix imposante: $O$ vous, Autrichiens; o vous, Prussiens, qui tournent à présente vos bayonnettes contre nous; c'est pour vous, c'est pour toute l'Europe, c'est pour tout le genre humain, et non pour la France seul que nous levons l'étendard de la liberté et de l'égalité « ${ }^{32}$.

28 La Sentinelle, 25.8.1792.

29 Zit. n. Patriote Français, 29.9. bzw 14.10.1792.

30 AP 53, S. 103, 1.11.1792.

31 Vgl. M. Duval (Hg.), Anacharsis Cloots, Ecrits révolutionnaires, 1790-1794, Paris 1979.

${ }^{32}$ Lettre au peuple français, 25.9.1792, abgedr, in: Patriote Français, 15.10.1792. 
Hiermit wurde die Ideologie des revolutionären Kreuzzuges geradezu in Reinkultur formuliert, und doch legen sowohl der Adressat, der Nationalkonvent, als auch der beschwörende Charakter die Vermutung nahe, daß Paine zugleich den auch schon von einer gewissen Skepsis geleiteten Versuch unternahm, die sich entwickelnde militärische Expansion tatsächlich auf die vielbeschworenen revolutionären Befreiungsziele festzulegen. Bald sollte sich jedenfalls zeigen, daß eine solche Skepsis mehr als berechtigt gewesen wäre. Doch vorerst dominierte auch unter den französischen Revolutionären die universelle revolutionäre Befreiungsideologie so sehr, da $B$ der Konvent in seinem berühmten "Propagandadekret« vom 19. November 1792 nicht nur den bereits sbefreiten`, sondern gleich allen um ihre Freiheit kämpfenden Völkern den Beistand der französischen Armeen versprach: "La Convention nationale déclare, au nom de la nation française, qu'elle accordera fraternité et secours à tous les peuples qui voudront recouvrer leur liberté, et charge le pouvoir exécutif de donner aux généraux les ordres nécessaires pour porter secours à ses peuples, et défendre les citoyens qui auraient été vexés, ou qui pourraient l'être pour la cause de la liberté ( $^{33}$.

Mit diesem Dekret verpflichtete sich die Revolution offiziell, Freiheitsbewegungen auf der ganzen Welt militärisch zu unterstützen. Es implizierte somit die Kriegserklärung an alle Mächte des Ancien Régime, und es lag in der Logik dieses Beistandsangebotes, einen universellen Befreiungskrieg für das Selbstbestimmungsrecht der Völker zu führen. Und doch wäre es zu einfach, darin bereits die definitive Bindung der Revolution an einen nahezu unendlichen Krieg zu sehen. Denn zum einen hat Frank L. Kidner überzeugend nachweisen können, wie wenig die reale französische Kriegspolitik vom "Propagandakrieg» de facto beeinflußt wurde ${ }^{34}$. Und zum anderen zeigt gerade die politische Diskursanalyse, daß sich die außenpolitische Bindung der Revolution an den Krieg nicht allein durch Ideologie und Propaganda vollzog, sondern vielmehr durch die spezifischen Formen ihrer Verbindung mit den realen, wesentlich kriegspolitisch begründeten Eigen- und Herrschaftsinteressen der französischen Nation ${ }^{35}$. Diese Verbindung war von Anfang an angelegt, und nicht zuletzt in enthusiasmierten Formulierungen wurde immer wieder deutlich, wie sehr das nationale Interesse des revolutionären Frankreich in die Ideologie der revolutionären Expansion eingewoben war. Schon im Winter 1791/92 hatte das Pathos des revolutionären Kreuzzugs letztlich doch

33 AP 53, S. 474.

34 Vgl. F. L. KIDNER, The Girondists and the »Propaganda War« of 1792: A Re-Evalutation of French Revolutionary Foreign Policy from 1791 to 1793, Ph. D. Princeton 1971.

35 Vgl. hierzu auch H. LeUVERS, Révolution et guerre de conquête. Les origines d'une nouvelle raison d'Etat (1789-1795), in: Revue du Nord, Bd. LXXV, 1993, S. 31-40. 
vor allem dazu gedient, die kriegspolitische Stärke der französischen Nation zu beschwören. Und dieser Selbstbezug schimmerte auch in der Folgezeit im revolutionären Diskurs immer wieder durch, so etwa wenn Brissot gegenüber Kriegsminister Servan die Auffassung vertrat, Frankreich werde erst Ruhe finden, "que lorsque l'Europe, et toute l'Europe, sera en feu ${ }^{36}$; oder wenn Chaumette begeistert ausrief, alle Gebiete zwischen Frankreich und Rußland würden »bientôt francisé, municipalisé, jacobinisé« $\operatorname{sein}^{37}$.

Die Auseinandersetzungen über das Problem des Revolutionsexports waren sehr komplex und verbanden verschiedene Ebenen miteinander. Wesentlich aber können zwei Grundprobleme unterschieden werden, nämlich die Stellung zu Befreiungsbewegungen außerhalb des unmittelbaren französischen Einflußbereiches einerseits, die konkrete Praxis in militärisch besetzten Gebieten andererseits. In bezug auf den ersten Fall wurde bald deutlich, daß die Propaganda des Revolutionsexports reine Ideologie blieb. Zwar war man zeitweise von der Hoffnung, teilweise sogar von der Erwartung erfullt, daß sich nun endlich auch andere Völker dem siegreichen Beispiel der französischen Revolution anschließen würden. "Des révolutions nationales se préparent de tous côtés, et vont offrir à l'histoire des tableaux variés en tout sens et un ordre de choses absolument nouveau", so brachte Carra in den Annales Patriotiques diese Auffassung zum Ausdruck ${ }^{38}$. Zugleich versuchte man nachdrücklich, die Nachbarvölker zur Revolution zu ermuntern. ${ }^{39}$ Doch an konkrete militärische Unterstützung außerhalb des unmittelbaren Einflußbereiches der französischen Armeen dachte dabei kaum jemand. Politisch ging es der Revolutionsführung im Herbst 1792 vielmehr darum, den Krieg zu begrenzen und bislang neutrale Länder wie England und die Schweiz nicht zu provozieren. Dementsprechend ist es auch für die Kriegszeit nicht mehr hinreichend, allein die Girondisten für einen revolutionären Expansionismus verantwortlich zu machen, der sich aus der Logik des revolutionären Krieges insgesamt ergab ${ }^{40}$. Gerade girondistische Vertreter des revolutionären Kreuzzuges wie Brissot oder Lasource hatten demgegenüber schon am 19. November versucht, die Verabschiedung des

${ }^{36}$ Brissot an Servan, 26.11.1792, abgedr. in: Ch. PERROUd (Hg.), J.-P. Brissot. Correspondance et papiers, Paris 1912, S. 312f.

37 Zit. n. FURET, RICHET, La Révolution, Bd. 1, S. 268.

38 Annales Patriotiques, 9.12.1792.

39 Vgl. etwa Condorcets Adressen an die Spanier, die Holländer die Deutschen und die Engländer sowie an alle freien Menschen, abgedr. in: CONDORCET, Guvres. Nouvelle impression en facsimilé de l'édition Paris 1847-1849, Bd. XII, Stuttgart - Bad Cannstadt 1968, S. 107-166.

40 So durchgehend GODECHOT, La Grande Nation. Die wesentlichen Übereinstimmungen zwischen Girondisten, Dantonisten und Robespierristen betont demgegenüber treffend KIDNER, The Girondists and the »Propaganda War«, bes. App. A, Bd. 2, S. 691-705. 
Propagandadekrets mit seiner impliziten Kriegserklärung an alle europäischen Mächte zu verhindern, "car il offre une généralité qui serait ridicule « ${ }^{41}$.

Vorerst aber war es im revolutionären Überschwang kaum möglich, die Beistandserklärung offiziell wieder zurückzunehmen. Die Auseinandersetzungen konzentrierten sich so vor allem auf das eng mit dem Propagandakrieg verbundene, vor allem von Cloots vertretene Programm der "République universelle«, das ins Zentrum der Debatten rückte. Schnell wurde dabei deutlich, daß die große Mehrheit der Revolutionäre darin bestenfalls eine »douce chimère (...), impossible à réaliser ${ }^{42}$, in der Regel aber schlicht »une maladie bizarre $\star^{43}$ erkannte. Von realer Bedeutung war es tatsächlich nicht, ob »la Chine et le Monomotaba soient des départements de France«, wie Brissot spottete, sondern wie sich die französischen Truppen konkret in den besetzten Gebieten Belgiens, des Rheinlandes oder Savoyens verhalten sollten, auf welche Weise der Revolutionsexport hier nun konkret durchgeführt werden und wie Frankreich auf Integrationswünsche sbefreiter Völker reagieren sollte.

Bei kritischer Betrachtung erscheint die Universalität des Dekrets vom 19. November so eher als eine Flucht aus den realen Problemen der französischen Besatzungspolitik, die am 19. November eigentlich auf der Tagesordnung des Konvents standen. Ihre Schwierigkeit lag wesentlich darin begründet, daß man sich zwischen zwei revolutionären Werten entscheiden mußte, die zunehmend in Widerspruch miteinander traten: dem Selbstbestimmungsrecht der Völker einerseits, den demokratisch-egalitären Zielen der französischen Revolution andererseits. Hinzu trat das ja gerade im Zeichen des Krieges unabweisbar pressierende Eigeninteresse Frankreichs, das schließlich als Ferment zur Vermittlung des Widerspruchs diente. "Comment pourriezvous, sans porter atteinte à leurs droits les plus sacrés, les forcer à recevoir de vous la Constitution que vous allez vous donner, et qui peut-être ne leur conviendrait pas? «, charakterisierte Louvet treffend die innere Problematik des Revolutionsexports, als am 28. September 1792 erstmals über die Zukunft der >befreiten` Bevölkerung Savoyens diskutiert wurde ${ }^{44}$. Nicht nur Girondisten wie Louvet oder Bancal waren in diesem Konflikt der zuerst noch generell dominierenden Auffassung, daß das Selbstbestimmungsrecht prinzipiell den

41 So Brissots Kritik im Patriote Français, 20.11.1792. Vgl, auch AP 53, S. 472f., 19.11.1791; eine moderatere Form der Ablehnung vertraten die Révolutions de Paris, 29.12.1792-5.1.1793, Bd. 15, S. 63-70, wenn sie ein Eingreifen der französischen Armeen davon abhängig machen wollten, daß die Freiheitsbewegung, ggf. unter Hilfestellung französischer »missionaires patriotes qui préparent la révolution«, zu revolutionärer Reife herangewachsen seien.

${ }_{42}$ Révolutions de Paris, 1.-8.12.1792, Bd. 14, S. 489.

${ }_{43}$ Patriote Français, 24.11.1792; hier auch das folgende Zitat. Vgl. auch andere in den vorhergehenden Ausgaben veröffentlichte Kritiken führender Brissotins.

4 AP 52, S. 190, 28.9.1792; hier auch die folgenden Zitate. 
Vorrang haben müsse. Auch ein Montagnard wie Desmoulins argumentierte: "La Convention nationale ne doit pas restreindre la souveraineté des peuples; elle doit laisser le peuple savoisien libre de se choisir le gouvernement qui lui convient. (...) Craignons de ressembler aux rois en enchaînant la Savoie à la République«.

Doch zugleich traten bereits hier auch andere, stärker die spezifischen revolutionären Werte und, eng damit verbunden, die Interessen Frankreichs in den Mittelpunkt rückende Stimmen hervor, die in der Folgezeit zu dominieren begannen. Danton versuchte den Widerspruch zwischen Selbstbestimmungsrecht und Demokratisierung aufzulösen, indem er die Abschaffung des Königtums zur Vorbedingung der nationalen Selbständigkeit erhob. Doch wenn er den Konvent nun zu einem "grand comité d'insurrection générale des peuples contre tous les rois de l'univers « erklärte, war darin nicht nur ein deutlicher französischer Führungsanspruch enthalten, sondern auch das nationale Eigeninteresse Frankreichs: „En même temps que nous devons donner aux peuples voisins la liberté, je déclare que nous avons le droit de leur dire: >Vous n'aurez plus de rois ; car tant que vous serez entourés de tyrans, leur coalition pourra mettre votre propre liberté en danger«. Dantons Vertrauter Delacroix hatte zuvor bereits nachdrücklich darauf hingewiesen, $\mathrm{da}$ es im Interesse Frankreichs notwendig sei, dafür Sorge zu tragen, "que la propagation des principes de la liberté soit sûre et stable«. Und er hatte darüber hinaus eine Frage aufgeworfen, deren Brisanz bald immer deutlicher hervortreten sollte: "Qui paiera les frais de la guerre?«.

In der Tat wurde die französische Kriegspolitik keineswegs nur von politisch-ideologischen Grundsätzen und ihren inneren Widersprüchen bestimmt. Unmittelbar damit verbunden waren auch die militärischen und kriegspolitischen Interessen Frankreichs, die nicht nur dazu fuihren konnten, für eine Begrenzung des militärischen Vormarsches einzutreten ${ }^{45}$, sondern die das ideelle Projekt der revolutionären Völkerbefreiung auch mit innerer Logik in die reale Praxis der französischen Herrschaft verwandelten. Sie führten etwa am Beispiel Belgiens bald zu der Frage, ob es nicht notwendig sei, »à faire ordonner à nos généraux de traiter les provinces belgiques comme un pays conquis sur le

45 So argumentierte etwa Marat im Herbst 1792 gegen die Fortsetzung des militärischen Vormarsches, dieser diene letztlich nur den Feinden Frankreichs, weil er ihren Gegenschlag erst möglich mache. Journal de la République Française, 22.11.1792. Und die Révolutions de Paris, 29.12.1792-5.1.1793, Bd. 15, S. 70, wandten gegen die offensive Fortsetzung des Krieges nicht nur ein, Revolutionen könnten nicht durch die bewaffnete Macht ausgeführt werden, sondern sie fügten zugleich das Argument hinzu, daß ein zu weiter Vormarsch nur die Versorgungsmöglichkeiten und damit auch die Kampffähigkeit der französischen Truppen gefährde: "Donnons six semaines ou deux mois de tranquillité à nos troupes, si nous voulons repousser plus aisément, à la saison prochaine, la confédération des rois \& de leurs esclaves«. 
tyran autrichien, jusqu'à ce que les Belges aient organisé leur gouvernement et dissipé les partisans de l'Autriche et des ci-devants états? « ${ }^{46}$.

Damit soll keineswegs die Auffassung vertreten werden, die revolutionären Werte und Ziele seien nur Staffage, blanke Ideologie gewesen. Vielmehr spricht alles dafür, daß es den Revolutionären mit ihrem Anspruch, ihre Nachbarvölker auf der Basis des Selbstbestimmungsrechts der Völker zu befreien, durchaus ernst war. So pochten sie etwa lange nachdrücklich darauf, >befreite Gebiete selbst über ihre politische Zukunft entscheiden zu lassen und sie ggf. nur nach wirklich glaubwürdigen Volksabstimmungen in die französische Nation zu integrieren; selbst der Erlaß von Gesetzten durch die französischen Besatzungsarmeen wurde abgelehnt, weil er dem "principe éternel et sacré de la souveraineté des peuples« widerspreche, wie es in einem von Lasource eingebrachten Dektret des Konvents hieß: "Donner des lois, c'est conquérir! Faites donc que les généraux français ne puissent jamais déployer un pouvoir tyrannique $\ll^{47}$. Und als Savoyen einen Monat später aufgrund eines überzeugenden Votums der "Allobrogen" tatsächlich integriert wurde, handelte es sich wirklich nicht um eine gewaltsame Annexion, sondern die Revolutionäre konnten durchaus mit Recht "le premier exemple d'un contrat diplomatique passé entre deux vrais et légitimes souverains « feiern ${ }^{48}$.

Diese Idylle des nationalen Selbstbestimmungsrechts konnte jedoch nur dort funktionieren, wo die Interessen und Ziele einer Mehrheit der ১befreiten` Völker mit denjenigen Frankreichs übereinstimmten. Anders sah es aus, wenn diese Kongruenz nicht vorhanden war. Wenn, wie in Belgien, eine selbständige, eigenstaatliche Entwicklung angestrebt wurde, deren politische Tendenz darüber hinaus nicht den Vorstellungen der Franzosen entsprach, dann wurde es problematisch, denn dann wurde schnell deutlich, daß in der praktischen Umsetzung mit dem Selbstbestimmungsrecht der Völker einerseits, und den demokratisch-egalitären Idealen der französischen Republik andererseits zwei revolutionäre Grundwerte in einen so oder so zu entscheidenden Konflikt miteinander geraten würden.

Es ist hier nicht der Ort, die konkreten Probleme und Ausformungen der französischen Besatzungs- und Expansionspolitik im einzelnen darzustellen. Vielmehr soll im folgenden am Beispiel von zwei grundlegenden Richtungsentscheidungen der revolutionären Kriegspolitik gezeigt werden, wie sich revolutionäre Befreiungsideologie und nationales Eigen- und Herrschaftsin-

46 Annales Patriotiques, 15.12.1792, Supplément.

47 So Lasource als Vertreter des diplomatischen Komitees zur Politik von General Montesquiou und zur Frage der Integration Savoyens am 24.10.1792 im Konvent, AP 52, S. 551-555.

${ }^{48}$ Aus der Rede von Oberstleutnant Doppet zur Integration Savoyens im Nationalkonvent. AP 53, S. 617, 27.11.1792. Vgl. auch Annales Patriotiques, 29.11.1792. 
teresse unter den Bedingungen des Krieges zu einem Expansionsprogramm zusammenfügten, das die Revolution schließlich in weit fundamentalerer Weise an den Krieg band, als es Propaganda und Ideologie allein jemals gekonnt hätten.

Am 19. November hatte das erste Propagandadekret die Diskussion über die konkreten Verfahrensweisen in besetzten Ländern unterbrochen. Die Problematik indes blieb bestehen, und am 15. Dezember schließlich folgte ein zweites, die französische Praxis der Revolutionierung in den tatsächlich besetzten Gebieten konkret gestaltendes Dekret, das hier Klarheit schaffen sollte. Eingebracht und begründet wurde es von Cambon, der für die vereinigten Finanz-, Kriegs- und Diplomatiekomitees sprach. In seiner Rede kamen die Widersprüche und Konsequenzen der revolutionären Expansion so deutlich wie selten zum Ausdruck ${ }^{49}$. Der revolutionäre Messianismus wurde dabei seines ideellen Charakters entkleidet und enthüllte sich im Kern als imperialistisches Herrschaftsprogramm.

Cambon ging in revolutionärer Manier davon aus, daß das Hauptziel des Krieges die Abschaffung aller Privilegien sei. Dieses Ziel stehe indes, so stellte er treffend fest, in einem Spannungsverhältnis zum ebenfalls proklamierten Selbstbestimmungrecht der Völker. Wenn man, wie Dumouriez in Belgien, davon ausgehend die lokalen Bedingungen akzeptiere und ihre Regelung den >befreiten Völkern selbst überlasse, würden die bislang privilegierten Schichten weiterherrschen. Diese seien tatsächlich jedoch die wahren Feinde der französischen Revolution, die es zu vernichten gelte. Da die Bevölkerung in den besetzten Ländern aber nicht die nötige Erfahrung besitze, ihre Rechte selbst zu schaffen, sei es unabdingbar notwendig, daß Frankreich für sie die revolutionäre Neuordnung nach französischem Muster anleite: "Les peuples chez lesquels les armées de la République ont porté la liberté, n'ayant pas l'expérience nécessaire pour établir leurs droits, il faut que nous nous déclarions pouvoir révolutionnaire et que nous détruisons l'ancien régime qui les tenait asservis. (Applaudissement) (...) Ainsi donc, si nous sommes pouvoir révolutionnaire, tout ce qui existe de contraire aux droits du peuple doit être abattu dès que nous entrons dans le pays. (Applaudissments): en conséquence, il faut que nous proclamons nos principes, que nous détruisons toutes les tyrannies et que rien de ce qui existait ne résiste au pouvoir que nous exerçons«.

Aus diesem letztlich die Herrschaft der revolutionären Sieger proklamierenden Versuch zur Lösung des Widerspruchs zwischen Revolutionierung und Selbstbestimmung folgte nun mit innerer kriegspolitischer Logik, daß diejenigen Völker, die sich dem französischen Gestaltungsanspruch, wie etwa die

$49 \mathrm{Vgl}$. AP 55, 70-73, 19.12.1792; hier auch die im folgenden nicht angemerkten Zitate und das schließlich beschlossene Dekret. 
Belgier, nicht unterwerfen wollten, zu Feinden der Revolution erklärt wurden: "Vous voulez que les peuples chez qui vous portez vos armes, soient libres. S'ils se réconcilient avec les castes priviligiées, vous ne devez pas souffrir cette transaction honteuse avec les tyrans. Il faut donc dire aux peuples qui voudraient conserver des castes privilegiées: vous êtes nos ennemis; alors on les traitera comme tels, puisqu'ils ne voudront ni liberté, ni égalité«. Als Finanzexperte fügte Cambon diesem Programm der revolutionären Herrschaftsexpansion schließlich einen weiteren zentralen Aspekt hinzu. Bereits wenige Tage zuvor hatte er nachdrücklich darauf hingewiesen, "que plus nous avançons dans le pays ennemi, plus la guerre devient ruineuse, surtout avec nos principes de philosophie et de générosité $\varkappa^{50}$. Nun zog er daraus die Konsequenz, daß die sbefreiten` Völker das doch schließlich ihren Interessen dienende militärische Engagement Frankreichs auch bezahlen sollten. "Conséquentement, en entrant dans un pays, en supprimant ses contributions, en offrant au peuple une partie de nos trésors pour l'aider à reconquérir sa liberté, nous lui offrirons notre monnaie révolutionnaire«. Doch ging es beileibe nicht nur darum, die Menge der in Frankreich zirkulierenden Assignaten zur Stabilisierung ihres Wertes zu verringern. Cambon deutete vielmehr zugleich an, daß am Ende noch weitere finanzielle Ausgleichszahlungen gefordert würden; ganz beiläufig war in seinen Formulierungen außerdem der offenbar selbstverständliche Anspruch enthalten, daß die französischen Besatzungstruppen von den besetzten Ländern versorgt werden müßten: "A la fin de la guerre vous aurez des comptes à régler; vous compterez avec les représentants de chaque peuple, et des dépenses que vous aurez faites, et des approvisionnements qu'on vous aura fournis«.

Nach diesem Programm wurde in den folgenden Jahren tatsächlich verfahren. Es blieb aber noch zu entscheiden, in welchen staatlichen Formen die sbefreiten`Völker sich unter französischer Anleitung organisieren, ob sie formal selbständig bleiben oder in die französische Republik integriert bzw. annektiert werden sollten. Hier wurden die entscheidenden Festlegungen im Februar 1793 getroffen, als Carnot allgemeine Maßstäbe zur Beurteilung dieser Frage entwickelte, die die Interessen Frankreichs noch eindeutiger in den Mittelpunkt rückten. Carnot unterschied nicht mehr zwischen den konkurrierenden revolutionären Werten des Selbstbestimmungsrechts der Völker einerseits, der republikanischen Demokratisierung andererseits, sondern er ging nunmehr von zwei etwas anders gelagerten politischen Grundprinzipien aus, nämlich dem Staatsinteresse und der Gerechtigkeit; er proklamierte: 
»1. Toute mesure politique est légitime, dès qu'elle est commandée par le salut de l'Etat;

2. Tout acte qui blesse les intérêts d'autrui, sans nécessité indispensable pour soi-même, est injuster.

In bezug auf die konkrete Frage nach den Entscheidungskriterien für die Integration oder Annexion bedeutete dies,

"1. que cette mutation n'a rien de contraire aux intérêts de l'Etat;

2. que les communes que regarde cette mutation, l'ont demandée par l'émission d'un vœux libre et formel ou que la sûreté générale de la République la rend indispensable $\ll$.

Nicht nur mit den Zusätzen zu den jeweils zweiten Paragraphen machte Carnot deutlich, daß nach seiner schließlich vom Konvent angenommenen Auffassung die Interessen des französischen Staates denen der Gerechtigkeit bzw. dem Selbstbestimmungsrecht anderer Nationen prinzipiell übergeordnet seien. Das nationale Interesse sei, so betonte er nachdrücklich, stoujours le premier des principes«. Dabei legte er schließlich das nationale Interesse der französischen Republik als Hauptgrundlage der revolutionären Expansionspolitik so weit aus, daß, zumal in Kriegszeiten, fast jede Vergewaltigung des nationalen Selbstbestimmungsrechts anderer Völker damit zu begründen war: "Cet intérêt peut résulter d'une augmentation de forces, de richesses, de prospérité nationale, d'une plus grande sûreté des frontières ou d'une simplification de moyens de défense, de la gloire enfin qu'il peut y avoir, de la part d'une nation puissante, à agréger un peuple faible, mais digne du bienfait de la liberté $\ll^{s_{1}}$.

Es lag in der Logik einer solchen Sichtweise, wenn etwa Danton die Besetzung der Republik Genf aus militärischen Erwägungen nicht ausgeschlossen sehen wollte, oder wenn Chabot gar die Eroberung von Amsterdam und Madrid forderte, um genügend Finanzmittel für die Fortsetzung des revolutionären Krieges zu erbeuten, die doch schließlich auch im Interesse der dortigen Bevölkerung liege: „Où trouverons-nous de l'or pour faire la guerre? A Amsterdam et à Madrid. (...) Portez la liberté en Hollande, elle vous tend encore les bras, elle vous offre son or et ses vaisseaux ${ }^{52}$. Carnot aber ging es erst einmal um die Grenzen des unmittelbaren französischen Machtbereiches, und deshalb leitete er aus diesen allgemeinen Voraussetzungen schließlich ein konsistentes Annexionsprogramm ab, das die Integration aller Territorien zwischen dem Rhein, den Alpen und den Pyrenäen in das französische Staatsgebiet zum Inhalt hatte: "Les limites anciennes et naturelles de la France sont le Rhin, les Alpes et les Pyrénées; les parties qui en ont été démembrées ne l'ont

52 AULARD, Société des Jacobins, Bd. 5, S. 9, 25.1.1793. 
été que par usurpation; il n'y aurait donc, suivant les règles ordinaires, nulle injustice à les reprendre«.

Hier haben wir nun das berühmte Programm der »natürlichen Grenzen« vor uns, das die Revolutionshistoriogaphie immer wieder nachhaltig beschäftigt hat. Die konkrete Formulierung Carnots von den naturelles« bestätigt dabei nur oberflächlich Sorels These, daß dieses Programm in direkter Kontinuität zu den machtstaatlichen Ziele des absolutistischen Frankreichs gestanden habe ${ }^{53}$. Vielmehr machte sich Carnot hier eine verbreitete Vorstellung $\mathrm{zu}$ eigen, die mit der Politik des Ancien Régime wenig zu tun hatte, nun gleichwohl aber geschichtsmächtige Kraft erlangte, weil sie in besonderem Maße geeignet war, die inneren Widersprüche der revolutionären Expansion durch den Bezug auf das nationale Interesse Frankreichs zu überwinden. Bereits zwei Wochen vorher hatte Lasource, der noch im Oktober 1792 das Selbstbestimmungsrecht der Völker zum alleinigen Grundprinzip der französischen Außenpolitik erklärt hatte, die Annexion Nizzas nicht nur mit dem Verweis auf den Willen der Bevölkerung gefordert, sondern auch mit Handelsinteressen und vor allem mit der machtpolitischen Feststellung: "Là finissent les Alpes, et vous avez voulu, en réunissant la Savoie, mettre cette barrière entre vous et le despote de Turin, ou pour mieux dire, de l'Italie ${ }^{54}$. Danton nahm diesen Gedanken auf, übertrug ihn auf Belgien und forderte eine Annexionspolitik, die stout aux intérêts de la République française« gestützt sein sollte und sich deshalb an den Grenzen orientieren solle, die von der Natur vorgezeichnet seien. "Nous les atteindrons toutes des quatre points de l'horizon; du côté du Rhin, du côté de l'Océan, du côté des Alpes. Là doivent finir les bornes de notre République, et nulle puissance humaine ne pourra nous empêcher de les étendre «ss. Zuerst entwikkelt aber hatte diese Perspektive Brissot, und bezeichnenderweise war es ihm ursprünglich nicht darum gegangen, die revolutionäre Expansion zu propagieren, sondern vielmehr sie auf ein realistisches $\mathrm{MaB}$ zu begrenzen. Die snatürlichen Grenzen w waren seine Antwort auf Cloots universelles Projekt der ২République universelle<, der er schon im November 1792 das Programm entgegensetzte: „Unité des départements de la France, extention jusqu'au bornes que lui proscrit la nature (...) le Rhin, les Alpes, les Pyrénées et l'Océan « ${ }^{56}$.

Auch wenn die snatürlichen Grenzen` so ihrem Ursprung nach nicht primär ein militärisches Expansionsprogramm bezeichneten, sondern vielmehr ein Versuch waren, die Expansion Frankreichs zu begrenzen und die inneren Wi-

53 Vgl. A. SOREL, L'Europe et la Révolution française, hier bes. Bd. 3.

54 AP 58, S. 102, 31.1.1793.

ss Ebd., S. 102f. Danton griff dabei ein Argument auf, das Lasource unmittelbar vorher in bezug auf die Annexion Nizzas vorgetragen hatte.

so Patriote Français, 24.11.1792. 
dersprüche der revolutionären Besatzungsherrschaft zu lösen, beinhaltete eine daran orientierte Politik mit den damit verbundenen Verstößen gegen das nationale Selbstbestimmungsrecht der Völker einerseits, gegen die traditionellen Herrschaftsrechte der benachbarten Mächte andererseits, doch eine ungleich festere Bindung der Revolution an den Krieg, als es die ideellen Formulierungen des Propagandakrieges je vermocht hätten. Erschwerend trat hinzu, daß auch die Gebiete jenseits der snatürlichen Grenzen keineswegs aus der Verbindung von Revolutionsexport und Herrschaftsinteresse ausgeschlossen wurden, wenn der militärische Vormarsch die revolutionären Truppen dorthin führen würde. Brissot sah für diesen Fall die Schaffung von Schwesterrepubliken, von >Républiques fédératives` vor, für die selbstverständlich auch die Bestimmungen des Dekrets vom 15. Dezember 1792 gelten würden, nach dem die französische Besatzung die Einführung von Verfassungen anleiten sollte. Diese, die expansive Politik der zweiten Hälfte der 1790er Jahre vorzeichnende Perspektive aber unterlag zweifellos im Prinzip denselben inneren Widersprüchen, wie sie hier bereits herausgearbeitet worden sind, und ihre Lösung sollte in ähnlicher Weise von den Herrschaftsinteressen der Grande Nation bestimmt werden. 1793 indes führte die Bildung der ersten Koalition unter Führung Englands die Republik erst einmal wieder in die Defensive.

In dieser Situation wurde deutlich, daß sowohl die revolutionären Wertbezüge als auch die nationalen Interessen Frankreichs nun jedem Versuch, die 'natürlichen Grenzen` wieder in Frage zu stellen, grundsätzlich entgegenstanden. Es erschien selbstverständlich als wun devoir indispensable de la part de la République française, de protéger par nos armes la liberté que nous avons donnée ${ }^{57}$. Wie ernst das im Dekret vom 15. Dezember 1792 ausgesprochene Versprechen einer >protection durable` aller `befreiten` Völker tatsächlich gemeint war, wurde deutlich, als das nunmehr als Department Mont-Blanc zu Frankreich gehörende Savoyen im Sommer 1793 militärisch unter Druck geriet. "Disons franchement aux hommes de Mont-Blanc«, so trat Hérault im Namen des Wohlfahrtsausschusses für die Entsendung von Truppen in das neugeschaffene Departement ein: »Frères et amis, vous vous êtes rangés sous l'étendard tricolore, nous ne vous abandonnerons jamais; nous vous protègerons de toutes nos forces contre vos cruels oppresseurs, nous reconstruirons sans cesse de nos mains la digue que vous nous avons donnée contre les inondations de la tyrannie! $\aleph^{58}$. Zugleich allerdings hatte Hérault erneut die Verbindung von nationalem Interesse und snatürlichen Grenzen ( mobilisiert: "Si vous ne consultiez que vos intérêts«, erklärte er den Abgeordneten, »on vous dirait: la nature en dessinant le globe a tracé nos limites sur les confins de la

58 AP 73, S. 21, 25.8.1793; hier auch das folgende Zitat. 
Savoie. Ce département seul, par ses rochers, ses montagnes, ses défilés en protège quatre des nôtres et les garantit bien plus solidement par sa position que vous ne pouvez l'être par aucune considération contre l'insatiable cupidité des despotes qui ne s'arrêtent et ne se rassasient jamais dans l'ivresse de leurs premiers succès $\ll$. Barère beendete schließlich die aufkommende Diskussion, ob es wirklich einen Anspruch auf militärischen Schutz für Savoyen und damit auch für alle im Winter 1792/93 integrierten Gebiete gebe, indem er nicht nur beide Aspekte verbindend erklärte, "la nature et le vœu de ses habitants« habe zur Integration Savoyens geführt, sondern damit zugleich eine Absage an die "vieille diplomatie« verband, die erneut die fundamentale Bindung der Revolution an den Krieg zum Ausdruck brachte: "Citoyens, loin de nous cette diplomatie, la nôtre doit être la diplomatie des canons et de la victoire «"

Vor dem Hintergrund einer so bellizistisch konzipierten revolutionären Kriegspolitik war es im Grunde nur von begrenzter Bedeutung, daß die Republik 1793 offiziell wieder von einem Propagandakrieg Abstand nahm, den sie de facto nie ernsthaft geführt hatte. Die vor allem von Mathiez als Ausdruck einer von seinem Héros Robespierre geprägten, qualitativen Neuorientierung der Kriegspolitik gewertete Freundschaftserklärung des Konvents an neutrale Staaten, insbesondere an die Schweiz und die USA, vom 17. November 1793 vermag jedoch kaum einen fundamentalen Wechsel der revolutionären $\mathrm{Au}$ Benpolitik zu belegen ${ }^{60}$. Vielmehr hatte der Konvent schon im April auf Initiative Dantons das Propagandadekret vom 19. November 1792 ohne jede Diskussion offiziell aufgehoben. Es entsprach wesentlich der vom Kriegsverlauf vorgezeichneten Umstellung der revolutionären Außenpolitik von der Offensive auf die Defensive, wenn der Konvent nun die außenpolitische Thematik des Sommers 1792 wieder aufgriff und sie zugleich extrem zuspitzte; auf Antrag Robespierres wurde der fundamental gegen die von Danton vorgenommenen Friedenssondierungen gerichtete Beschluß gefaßt, die Todesstrafe zu verhängen gegen "quiconque proposerait de négocier ou de traiter avec des puissances ennemis, qui n'auraient pas préalablement reconnu solennellement l'indépendance de la nation française, sa souverainité, l'indivisibilité et l'unité de la République, fondée sur la liberté et l'égalité « ${ }^{61}$.

Im weiteren Verlauf des Jahres 1793 dominierte die Vorstellung von einem "guerre à outrance« zwischen Revolution und Tyrannei den öffentlichen Diskurs und die Politik der Republik. In erster Linie ging es darum, jede Form der

59 Ebd., S. 22. A. MATHIEZ, Danton et la paix, Paris 1919, S. 186, urteilt treffend: »Si la République s'engageait solennellement à ne déposer les armes qu'après avoir délivré de nouveau de la domination étrangère tous les peuples réunis au moment des victoires de l'automne précédent, la guerre s'éterniserait«.

${ }_{60}$ Vgl. AP 79, S. 377-385, 17.11.1793; zur Deutung vgl. MATHIEZ, Danton et la paix, S. 213f;; GoDECHOT, La Grande Nation, S. 77-79.

61 AP 62, S. 2f., 13.4.1793. 
Verständigung mit den Kriegsgegnern als Revolutions- und Landesverrat zu denunzieren und so auszuschließen. Dementsprechend wurde am 18. Juni 1793 eine Verfassungsbestimmung verabschiedet, nach der die Republik »ne fait point la paix avec un ennemi qui occupe son territoire«. Als Mercier dagegen einwandte, eine solche Festlegung sei unpolitisch, und in ironischer Manier die Frage aufwarf: "Avez-vous fait un traité avec la victoire?«, zeigte die berühmte Replik von Basire erneut die revolutionäre Zuspitzung des Krieges zu einem unabweisbaren Entscheidungskampf zwischen gegensätzlichen Prinzipien an, die das revolutionäre Verständnis vom Krieg auszeichnete: "Nous en avons fait un avec la mort ${ }^{62}$. Dementsprechend verabschiedete der Wohlfahrtsausschuß im September 1793 außenpolitische Prinzipien, nach denen die Republik weder mit Vertretern noch mit Ministern ausländischer Mächte in Verhandlungen treten durfte, "qui n'auront pas un caractère positif auprès de la République française ${ }^{63}$. Und Barère, nach dem Sturz Héraults außenpolitischer Sprecher des Wohlfahrtsausschusses, lehnte Anfang Februar 1794, schon im Übergang zur militärischen Offensive, weiterhin jeden Waffenstillstand grundsätzlich ab, weil er doch nur den Interessen des Königtums dienlich sei: "Une trêve avec douze cents mille républicains sous les armes! (...) Deux ans de trêve pour laisser respirer le crime et la royauté, pour donner le temps d'incarcérer, de vexer, d'égorger les vrais républicains et pour avoir ensuite un de ces mangeurs d'hommes sur un trône usurpé! $\aleph^{64}$.

Die prinzipielle Ablehnung jedes Verständigungsfriedens galt nun tatsächlich keineswegs nur für die Defensive. Vielmehr entsprach es der inneren Logik des revolutionären Krieges, daß die militärischen Erfolge der französischen Armeen wie selbstverständlich erneut $z u$ einer, nun allerdings offen nationalistisch konzipierten, Politik des Revolutionsexports führten. Die robespierristische Geschichtsschreibung hat demgegenüber nachdrücklich die Auffassung vertreten, der Wohlfahrtsausschuß habe im Frühsommer 1794 eine antiannexionistische Politik verfolgt und die Beendigung des Krieges ins Auge gefaßt ${ }^{65}$. Tatsächlich erklärten seine Vertreter nun wiederholte Male, sie würden keine Annexionen anstreben. "L'expérience des siècles nous a suffisamment prouvé qu'un peuple guerrier apprête pour lui-même le joug qu'il impose aux autres nations«, so argumentierte etwa Billaud schon zu Beginn der Früh-

${ }^{62}$ AP 66, S. 676, 18.6.1793.

${ }^{63}$ Die fünf Prinzipien sind abgedruckt in: MATHIEZ, Danton et la paix, S. 191f.

64 AP 84, S. 173, 1.2.1794.

65 Vgl. grundlegend E. HAMEL, Histoire de Robespierre et du coup d'état du 9 thermidor, 2 Bde., Paris 1987 (Orig. 1865/67); ähnlich A. MATHIEZ, La Révolution française, 3 Bde., Paris 1938, hier Bd. 3, S. 180-193. 
jahrskampagne $\mathrm{e}^{\sigma 6}$. Zurecht jedoch hat Richard R. Palmer demgegenüber eingewendet, daß mit "quotations of its anti-annexionist intentions" nichts bewiesen sei, denn Intentionen $» d o$ not determine the course of events ${ }^{67}$. Zweifellos war es wesentlich der Vormarsch der französischen Truppen, der erneut zur Herrschaftsexpansion drängte. Doch war diese zugleich in der Logik eines revolutionären Diskurses angelegt, der den Krieg zu einem finalen Entscheidungskampf zwischen antagonistischen Prinzipien erklärt hatte und damit maßgeblich dazu beitrug, daß der Krieg auch in der Offensive kein Ende finden konnte.

An die Stelle der kriegerischen Völkerbefreiung trat nun im Zeichen des immer wieder beschworenen, unauflöslichen Gegensatzes von Revolution und Ancien Régime der Wille zum totalen, den Gegner vernichtenden Sieg: »Mais, dans les guerres de liberté«, so argumentierte Barère schon Anfang 1794, »il n'est qu'un moyen, c'est de ruiner et d'exterminer les despotes. Lorsque l'horreur de la tyrannie et l'instinct de la liberté ont mis les armes dans les mains d'hommes braves, ils ne doivent les poser qu'en dictant la paix; et lorsque des républicains ont formé quinze armées, il n'y a ni paix, ni trêve, ni armistice avec des despotes, qu'au nom d'une République affermie, triomphante et dictant la paix aux nations ( $^{68}$. Als sich im Frühjahr 1794 das Kriegsglück immer deutlicher der Republik zuzuwenden schien, erhob Billaud die scheinbar auf einen dauerhaften Frieden abzielende, angesichts der realen Kräfteverhältnisse tatsächlich aber die dauerhafte Fortsetzung des Krieges implizierende Zielvorstellung, "que les deux maisons d'Autriche et de Bourbon s'écroulent jusque dans leurs fondements, pour construire de leurs décombres un temple à la Paix, qui soit indestructible. Et toi aussi, tremble, Albion! L'heure de la décadence n'est pas éloignée. (...) Nous marchons, non pour conquérir, mais pour vaincre, non pour nous laisser entraîner par l'ivresse des triomphes, mais pour cesser de frapper à l'instant où la mort d'un soldat ennemi serait inutile à la liberté ${ }^{69}$. Und auch nach dem vorerst entscheidenden Sieg bei Fleurus wandte sich wiederum Barère vehement gegen »cette pensée dangereuse que tout est terminé lorsque le territoire français est évacué. (...) Transigez aujourd'hui, ils vous attaqueront demain avec audace; endormezvous un instant sur vos lauriers, ils vous massacreront sans pitié. (...) Les tyrans sont incorrigibles; (...) il faut donc mettre à profit la victoire; il faut utiliser le courage, il faut immortaliser cette campagne. (...) Les rois ne

66 AP 89, S. 99, 1. Flor. II/20.4.1794.

67 R. R. PALMER, Twelve who Ruled. The Year of the Terror in the French Revolution, Princeton 1970 (Orig. 1941), S. 357.

68 AP 83, S. 561, 22.1.1794.

69 AP 89, S. 94-100, hier S. 98f., 1. Flor. II/20.4.1797. 
conspirent plus contre la liberté quand ils ne seront plus; ils ne seront plus quand leurs armées seront anéanties, car ils n'auront plus ni impôts, ni pouvoir, quand ils n'auront plus de soldats. Faisons-leur donc une guerre vigoureuse, une guerre d'extermination ${ }^{70}$.

Wie ernst das hier proklamierte Ziel der Vernichtung des Gegners tatsächlich gemeint war, hatte der Konvent schon einige Zeit vorher klargemacht, als er »la guerre à mort contre les Anglais« beschlossen hatte, die man nun, nachdem man sie ursprünglich zu den freiheitlichen Völkern gerechnet hatte, des Verbrechens des Menschheitsverrats (lèze-humanité) bezichtigte. "Guerre, donc, guerre à mort à tous les sanguinaires et vils défenseurs du gouvernement anglais (...); que pas un seul ne reste pour porter à leur chef la nouvelle de leur anéantissement «, proklamierte die revolutionäre Presse ${ }^{\eta}$. Und Barère bejubelte nun die Tatsache, daß in der Schlacht von Fleurus nur ein lebender englischer Soldat gefangengenommen worden sei, und kündigte an, diese mörderische Kriegspraxis werde nun auch gegen alle anderen Truppen angewendet werden, die nicht innerhalb von zwei Tagen das französische Staatsgebiet verlassen hätten. Hierin wurde auch deutlich, daß die revolutionäre Offensive inzwischen eine ganz andere Konzeption gewonnen hatte. Während der völkerbefreiende Idealismus des revolutionären Kreuzzugsgedankens abgelegt worden war, rückte das nationale Eigeninteresse des französischen Volkes, das in der gesellschaftlichen Entwicklung "semble avoir devancé de deux mille ans le reste de l'espèce humain « $^{72}$, nun ganz unverhohlen in den Vordergrund. "Quand nous tiendrons la Belgique«, so brachte Robespierre dies gegenüber den Revolutionsexportwünschen holländischer Patrioten kühl zum Ausdruck, "nous verrons ce que nous ferons ${ }^{73} \ll$.

Die französischen Revolutionäre hatten spätestens angesichts der Bildung der ersten Koalition Anfang 1793 feststellen müssen, daß es sich bei ihrem Krieg doch nicht um einen Krieg der Völker gegen die Tyrannen handelte, sondern, mit den Worten Brissots, eher um wune guerre (...) de dix peuples esclaves contre un peuple libre ${ }^{74}$. Vor diesem Hintergrund: "Seule dans l'univers la France libre, luttant contre tous les orages conjurés du despotisme ${ }^{\prime s}$, richtete sich die Feindschaft der Revolutionäre nicht mehr nur gegen

70 AP 92, S. 391-393, 4.7.1794.

71 Journal des hommes libres, 13. Prair. II/1.6.1794. Zum revolutionären Englandbild vgl. N. HAMPSON, The Perfidies of Albion. French Perceptions of England during the French Revolution, London u. New York 1998.

72 So Robespierre vor dem Konvent am 7.5.1794. AP 90, S. 132.

73 Zit. n. Godechot, La Grande Nation, S. 79.

${ }^{74}$ Patriote Français, 5.4.93.

75 Garnier de Saintes, Begründung für ein Gesetz gegen die Ausländer. AP 70, S. 107, 1.8.1793. 
die monarchische Ordnung und ihre priviligierten Stände, sondern bald auch gegen alle Völker, die den Krieg gegen das revolutionäre Frankreich schließlich unterstützen würden. "Ce n'est que quand les peuples ligués contre nous viendront, à genoux, nous demander la paix, que nous pourrons consentir à leur accorder«, so brachte Bentabole diese Grundhaltung in einer großen Rede vor dem Pariser Jakobinerklub zum Ausdruck. Ein anderer Jakobiner, möglicherweise Robespierre, wollte diese Passage in einer Form verändert sehen, die deutlich werden ließ, wie sich die Ideologie des revolutionären Befreiungskrieges in die Rechtfertigung des universellen Krieges gegen alle unfreien Völker verwandelt hatte: "A genoux comme debout, nous n'accorderons la paix aux peuples que quand ils auront brisés leurs chaînes. Il n'est ni paix, ni trêve avec les peuples corrompus et avilis« ${ }^{76}$.

Es lag auch in der Logik einer solchen, den Krieg letztlich verewigenden Denkweise, wenn die revolutionäre Expansion des Sommers 1794 nicht mehr in erster Linie dem Revolutionsexport im Interesse >befreiter، Völker, sondern erst einmal den Interessen des revolutionären Frankreich selbst dienen sollte. Das vom Wohlfahrtsausschuß im Juli 1794 angenommen Annexionsprogramm in Belgien und den Niederlanden orientierte sich dementsprechend in erster Linie an der Schaffung von sicheren Grenzen, »bien couvert par des rivières«; und die Bestimmungen über die Militärverwaltung in den besetzten Gebieten zielten nun ganz offen auf die von den Armeen de facto schon lange praktizierte Ausbeutung im Interesse des revolutionären Frankreich und seiner Kriegsführung: „Hâtez-vous, chers collègues«, so forderte der Wohlfahrtsausschuß am 20. Juli seine Repräsentanten bei den nach Belgien vordringenden

76 AULARD, Société des Jacobins, Bd. 5, S. 630, 28.1.1794. In derselben Sitzung ließ sich Robespierre wenig später, in Reaktion auf Verständigungstendenzen der Dantonisten, zu der folgenden, so revolutionär begründeten wie chauvinistischen Haßtirade gegen das englische Volk hinreißen: "Pourquoi veut-on que je distingue un peuple qui se rend complice des crimes de son gouvernement, de ce gouvernement si perfide? Je n'aime pas les Anglais, moi (applaudissement), parce que ce mot me rappelle l'idée d'un peuple insolent osant faire la guerre au peuple généreux qui a reconquis sa liberté. Je n'aime pas les Anglais, parce qu'ils ont osé entrer dans Toulon pour y proclamer un roi; ce que n'a pas voulu souffrir le peuple qui a reconquis ses droits. Je n'aime pas les Anglais, parce que leur gouvernement, perfidement machiavélique envers le peuple même, qui le souffre, parce que ce même gouvernement a osé dire et proclamer qu'il ne fallait garder aucune foi, aucune règle d'honneur avec les Français dans cette guerre, parce que c'était un peuple de rebelles qui avait foulé aux pieds les lois les plus saintes; parce qu'une partie du peuple, les matelots, les soldats, a soutenu par les armes cette odieuse proclamation. En qualité de Français, de représentant du peuple, je déclare que je hais le peuple anglais. (Applaudi.) etc.«. Ebd., S. 633f. Zum revolutionären Feindbild vgl. auch JeISMANN, Vaterland der Feinde, S. 133146. 
Armeen auf, "de faire rentrer de même en France toutes les richesses de la Belgique ${ }^{7}$.

Die Radikalisierung und Verewigung des Krieges hatte allerdings keineswegs nur eine außenpolitische Komponente. Im Zeichen der Konzeption des revolutionären Bürgerkrieges entsprach ihr vielmehr eine immer aggressivere, zunehmend terroristisch konzipierte Radikalisierung der Revolution.

77 Aufruf des Wohlfahrtsausschusses, 20.7.1794, abgedr. in: A. AULARD (Hg.), Recueil des Actes du Comité du Salut Publique. Avec la correspondance officielle des Représentants en Mission et le registre du Conseil Exécutif Provisoire, 25. Bde., Paris 1889-1918, hier Bd. 15, S. 317f; konkret sah das von Carnot vorgeschlagene Annexionsprogramm folgendermaßen aus: »à gauche toute la Ouest-Flandre et la Flandre hollandaise, à droite le pays d'entre Sambre-et-Meuse, et, au milieu, seulement tout ce que est de deça de l'Escaut et de la Haisie, de manière qu'Anvers et Namur soient les deux points d'appui et que la frontière fasse un cercle tentant, bien couvert par les rivières«. Das Programm für die Militärverwaltung ebd., S. 261-267, 18.7.1794. Vgl. auch M. BouloiseaU, La République jacobine, Paris 1972, S. 167; PALMER, Twelve who Ruled, S. 357. 


\section{Krieg und revolutionäre Radikalisierung I: Der Sturz der Monarchie 1792}

«Junge Klassen lernen schnell«, urteilte Walter Markov mit der ihm eigenen Fähigkeit zur prägnanten Formulierung, wund die Wechselbeziehungen zwischen Innen- und Außenressort gingen den revolutionären Führern niemals glatter ein als 1792. Ihre Differenzen betrafen das Verfahren « ${ }^{78}$. Sieht man einmal von der allzu rationalen und vor allem viel zu optimistischen Einschätzung als Lernprozeß $a b$, wird diese Beurteilung durch die Analyse des politischen Diskurses und seiner kriegspolitischen Prägungen grundsätzlich bestätigt. Zwar spitzten sich nach der Kriegserklärung die inneren Gegensätze im revolutionären Lager noch einmal weiter $\mathbf{z u}^{79}$, doch jenseits der in den Vordergrund tretenden Gegensätze zeichnete sich der nun durchgängig von der Konzeption des revolutionären Bürgerkrieges geprägte politische Diskurs doch durch eine Reihe grundlegender, oft kaum erkannter Gemeinsamkeiten aus, die schließlich sogar den immer unversöhnlicheren Kampf gegeneinander prägen sollten. Vor allem folgten die gegenseitigen Vorhaltungen und Verdächtigungen im Grunde demselben, äußeren und inneren Feind, Krieg und Revolution miteinander verbindenden Deutungsmuster, daß den revolutionären Diskurs durchgängig prägte; und die Auseinandersetzungen bezogen sich, wenn man sie auf ihren politischen Kern reduziert, in der Tat wesentlich auf unterschiedliche taktische Varianten, die durch kriegsspezifische Deutungsmuster jedoch eine weit darüber hinausgehende Bedeutung gewannen ${ }^{80}$. Diese Auseinandersetzungen verdeckten so trotz ihrer Schärfe nur oberflächlich grundlegende Übereinstimmungen des revolutionären Diskurses, die vor allem in der Konzeption des Verhältnisses von Außen- und Innenpolitik, von äußerer, kriegerischer Bedrohung und innerer Revolutionsfeindschaft $z u$ finden waren und schließlich in gleichartiger, den Widerstand gegen die äußere Bedrohung und den revolutionären Kampf gegen den inneren Feind verbindender

78 W. MARKov, Die Freiheiten des Priesters Roux, Berlin/DDR 1967, S. 126.

79 Bezeichnend für die kriegsbedingte Zuspitzung der inneren Auseinandersetzungen war es, daß der Kriegsbeginn zu einer Reihe wichtiger neuer Zeitungsgründungen führte. Finanziert von Innenminister Roland, gab Jean-Baptiste Louvet seit Mai 1792 die regelmäßig erscheinende, weit verbreitete Wandzeitung $L a$ Sentinelle heraus, während auf der regienungskritischen Seite der revolutionären Bewegung Robespierre mit dem Défenseur de la Constitution an die Öffentlichkeit trat und Desmoulins zusammen mit Fréron die fast ausschließlich der Agitation gegen die Brissotins gewidmete Wochenschrift La Tribune des Patriotes als Nachfolgeorgan der Révolutions de France et de Brabant ins Leben rief. Und nicht zuletzt in diesen vom Krieg inspirierten Neugründungen wurde bald deutlich, daß die innenpolitischen Gegensätze auch im revolutionären Lager nun immer enger mit den Kriegsfronten verbunden wurden.

${ }_{80} \mathrm{Vgl}$. hierzu das folgende Kapitel. 
Form handlungsrelevant wurden. Der Krieg wurde nicht nur durchgängig in einem unauflöslichen Zusammenhang mit den inneren Problemen der Revolution interpretiert, sondern er wurde auch weniger als äußere denn als innere Bedrohung aufgefaßt. Im Entscheidungskampf zwischen Revolution und Despotie, gegen die den Krieg betreibenden "autrichiens du dehors et du dedans", schien der innere Feind, der »esprit autrichien«, dessen Ziel es sei, »d'allumer en France la guerre civile et d'y introduire des troupes étrangères«, die eigentliche Bedrohung darzustellen ${ }^{81}$. Dagegen wendeten sich die Träger der revolutionären Bewegung, die mit der Identifizierung des äußeren und des inneren Feindes in Parallelität zur Revolutionierung des Krieges zugleich auch eine innere Radikalisierung der Revolution propagierten, die dabei zunehmend auch militarisierte Züge gewann. Die erste wesentliche Folge davon war die von allen Kräften im revolutionären Lager vollzogene, nun wesentlich kriegspolitisch begründete und dadurch erst ihre eigentliche Überzeugungskraft und Massenwirksamkeit gewinnende Wendung gegen den Hof und sein "comité autrichien«, die alle taktischen Unterschiede in den Hintergrund drängte und schließlich am 10. August zum Sturz des Königs und der Monarchie führte. Damit verband sich allerdings schon zu diesem Zeitpunkt eine weitertreibende revolutionäre Dynamik, wie sie in den folgenden Septembermassakem ihren ersten Ausdruck fand und sehr schnell wieder zur Spaltung des revolutionären Lagers führen sollte.

$\mathrm{Da}$ der Sturz der Monarchie in Verbindung mit dem Krieg stand, ist ein geschichtswissenschaftlicher Allgemeinplatz, der in jeder Darstellung über die Französische Revolution zu finden ist. Doch gehen die Analysen über diese allgemeine Charakterisierung zumeist kaum hinaus, das genaue Wirkungsverhältnis zwischen Krieg und revolutionärer Radikalisierung wird selten in den Blick genommen. So finden sich darüber in der den Forschungsstand prägenden, marxistisch-strukturgeschichtlich angelegten Darstellung des Sturzes der Monarchie von Michel Vauvelle nur einige wenige Zeilen, und kaum anders verhält es sich in den grundlegenden revisionistischen Revolutionsdarstellungen von Denis Richet und François Furet ${ }^{82}$. Die konkreten empirischen Untersuchungen der politischen Vorgänge im Sommer 1792, insbesondere von Frédéric Braesch und Marcel Reinhard, sind demgegenüber eher positivistisch angelegt und thematisieren vor allem die politische Organisierung der Pariser Volksbewegung, so daß auch hier die Bedeutung des Krieges analytisch an

${ }^{81}$ La Sentinelle, Nr. 9, 11, o. D.

${ }^{82}$ Vovelle, La Chute de la monarchie, S. 254-265; FURET, RICHET, La Révolution, Bd. 1, S. 212-230; FURET, La Révolution Française, Bd. 1, S. 192-196. Vgl. etwa auch J. SOLE, La Révolution en question, Paris 1988, wo dem Sturz der Monarchie gar kein Kapitel gewidmet ist. 
den Rand rückt ${ }^{83}$. Die Analyse des politischen Diskurses zeigt indes, wie sehr der Krieg in seiner Konzeption als grenzüberschreitender revolutionärer Bürgerkrieg im Zentrum der politischen Konzeptionen stand und zur Antriebskraft der revolutionären Radikalisierung wurde.

Ein revolutionärer Krieg der französischen Nation gegen monarchische Söldnerheere könne eigentlich nur, so lautete eine grundlegende, verbindende Überzeugung aller revolutionären Kräfte, mit einem raschen Sieg enden. "Vous leur opposez pour le moins autant d'hommes libres, le combat ne devait donc pas être long«, hieß es etwa in La Sentinelle ${ }^{24}$, und der Patriote Français argumentierte, ganz in der Logik der bisherigen Propaganda für die Kriegserklärung: »La guerre d'un peuple libre contre un despote doit toujours finir à l'avantage du premier, parce que le despote a besoin d'acheter des armées, et que le peuple libre est tout entier une armée; ses ressources ne finissent qu'avec lui même «" ${ }^{85}$. Doch waren keineswegs nur die Propagandisten des revolutionären Kreuzzuges geprägt von der Vorstellung, daß das revolutionäre Frankreich mit seinen unermeßlichen Ressourcen den monarchischen Gegnern grundsätzlich überlegen sei. Auch bislang kriegsgegnerische und sich am linken Rand der revolutionären Bewegung formierende Stimmen teilten im Grunde diese Überzeugung. Robespierre etwa charakterisierte »la guerre de la liberté« der revolutionären Nation mit Worten, die aus einer Rede Brissots für den Krieg hätten stammen können: "Son objet est sublime; sa face est invincible; ses mesures sont sages et grandes; ses attaques prompts et irrésistibles. Elle veut; et la foudre tombe au milieu de ses ennemis; tous les tyrans pâlissent sur leurs trônes ébranlés, et se hâtent de prévenir leur ruine, en désarmant sa colère; tous les ennemis du dedans ont caché leurs fronts dans la poussière. (...) Une telle guerre est terminée presqu'aussitôt que commencée; elle ne coûte aucune alarme qu'aux despotes; elle ne fait point acheter de pénibles succès, par des torrents de sang. Voilà la guerre de la liberté $\iota^{86}$. Und in den Révolutions de Paris hieß es ähnlich: »Il paraît qu'un grand peuple, un peuple magnamine \& fort de la justice de ses droits ne peut longtemps laisser la victoire incertaine, sur-tout alors qu'il ne combat contre une autre nation, mais contre un roi, \& cela est vrai une thèse générale: tous les fois qu'une nation

83 F. BRAESCH, La Commune du dix août 1792. Etude sur l'histoire de Paris du 20 juin au 2 décembre 1792, Genf 1978 (Nachdr. d. Ausgabe Paris 1911); die Entwicklung seit Sommer 1791 behandelt M. REINHARD, La Chute de la royauté. 10 août 1792, Paris 1969; zuletzt M. SLAVIN, The Making of an Insurrection. Parisian Sections and the Gironde, Cambridge/Mass. 1986.

84 La Sentinelle, Nr. 2.

85 Patriote Français, 6.5.1792.

86 Défenseur de la Constitution, Nr. 8, S. 225-233: Réflexions sur la manière dont on fait la guerre, S. 226. Die Seitenangaben hier wie im folgenden nach dem Abdruck in ROBESPIERRE, Euvres complètes, Bd. 4. 
parfaitement libre n'aura à combattre qu'un roi ou des rois, elle les écrasera comme des insectes « ${ }^{87}$.

Und doch gestaltete sich die kriegspolitische Situation nicht nur de facto keineswegs in so eindeutiger Weise; sie stellte sich auch für die radikalen Revolutionäre tatsächlich von Anfang an, wesentlich angesichts der innenpolitischen Verhältnisse, ganz anders dar. Die Differenzen im revolutionären Lager entwickelten sich vor allem über die Frage, ob der Krieg denn eigentlich ein revolutionärer Krieg sei. Während die gemäßigten Kräfte dies anfangs bejahten, gelangten die Radikalen zu einem ganz anderen Urteil, wobei der Vergleich zwischen dem Ideal des revolutionären Krieges und der französischen Realität zu besonders schroffen Urteilen führte: "mais peut-on dire la même chose d'une nation qui n'est pas entièrement libre, qui conserve en son sein le germe de la tyrannie«, mit dieser rhetorischen Frage setzten die Révolutions de Paris höchst skeptisch die oben angeführten Äußerungen fort, denn gerade "dans un pays moitié libre, moitié esclave, dans un pays où la nation a son intérêt, \& le gouvernement un intérêt contraire, nous croyons que dans un tel pays la guerre ne peut avoir de succès heureux, à moins que la nation ne se mette au-dessus de son gouvernement, \& le constitue dans l'impuissance de traverser la marche des événements, quels qu'ils soient«. Während Prudhomme und seine Mitautoren hier die spezifischen kriegspolitischen Probleme einer steckengebliebenen, unabgeschlossenen Revolution in den Mittelpunkt rückten, ging Robespierre mit seinem ganz ähnlich konzipierten Gegensatz zwischen Ideal und Realität des revolutionären Krieges noch einen Schritt weiter. Er ließ im Défenseur de la Constitution keinen Zweifel daran, daß die reale französische Kriegspolitik in keiner Weise der für einen revolutionären Freiheitskrieg notwendigen Offensive entspreche. Doch vor allem kritisierte Robespierre einen nicht nur mit innerer Notwendigkeit militärisch desaströsen, sondern auch innenpolitisch bedrohlichen »guerre du despotisme«, zu dem sich zwei Herrscher, der österreichische Kaiser und der französische König, gegen ihre Völker verbunden hätten ${ }^{88}$. Die logische Konsequenz daraus war die von Robespierre schon in der ersten Ausgabe seiner Zeitung entwickelte Vorstellung vom Krieg an zwei Fronten, der wesentlich im Innern Frankreichs entschieden werden müsse: „Mais, pour faire la guerre utilement aux ennemis du dehors, il est une mesure générale absolument indispensable; c'est de faire la guerre aux ennemis du dedans, c'est-à-dire à l'injustice, à l'aristocratie, à la perfidie, à la tyrannie. Si ce dernier système est fidèlement suivi«, so war auch Robespierre überzeugt, "vous pourrez regarder la guerre comme un bienfait; mais si vous voyez régner dans

87 Révolutions de Paris, 5.-12.5.1792, Bd. 12, S. 238; hier auch die folgenden zwei Zitate.

${ }^{88}$ Défenseur de la Constitution, Nr. 8, S. 215-232: Réflexions sur la manière dont on fait la guerre. 
l'intérieur le despotisme militaire et une tyrannie cruelle déguisée sous le voile de la loi et sous les apparences de la sûreté public«, und so sah er die politische Realität, "scroyez que vous avez été trompez ${ }^{89}$.

Während Robespierre sich aber in seiner Zeitschrift als Défenseur de la Constitution zum Bewahrer der Verfassung stilisierte und damit seiner in der Analyse eigentlich angelegten revolutionären Wendung gegen den inneren Feind politisch die Fesseln der Verfassung und der Gesetzmäßigkeit anlegte, verfochten einige Stimmen am linken Rand des revolutionären Spektrums von Kriegsbeginn an die aggressive, zunehmend terroristisch konzipierte Wendung gegen alle privilegierten Gruppen des alten Systems als Verbündete des äußeren Feindes. Insbesondere der Ami du Peuple tat sich dabei besonders hervor. Marat trat schon im April dem herrschenden nationalen Überschwang schroff entgegen und prognostizierte ähnlich wie Robespierre gravierende Niederlagen der nicht genügend gerüsteten französischen Armeen, die erst nach einem "guerre longue et désastreuse« am Ende den Sieg davontragen könnten. Um jedoch überhaupt erfolgreich Krieg führen zu können, schien es ihm, wie schon während der Flucht des Königs im Juni 1791, notwendig, gegen die inneren Feinde der Revolution endlich die von ihm schon lange geforderte "terreur salutaire« zu praktizieren und dafür die Staatsgewalt an eine kriegsdiktatorisch agierende Revolutionsführung zu übertragen ${ }^{\circ}$. Eine solche terroristisch-diktatorische Politik fand jedoch zu diesem Zeitpunkt noch kaum einen öffentlichen Widerhall; allein der Orateur du peuple von Fréron und Roux als Sprecher der entstehenden Gruppe der radikalen sog. Enragés forderten schon so früh ähnlich extreme, terroristische Maßnahmen ${ }^{91}$. Einflußreicher war Héberts Père Duchesne, dessen Linie insgesamt weniger eindeutig war, der sich jedoch in manchen allgemeineren Formulierungen bereits ebenfalls einer umfassenderen terroristischen Konzeption annäherte. So begriff er den Krieg als »le tour aux aristocrats \& aux Autrichiens« und proklamierte »la guerre ouverte « der Sansculotten gegen alle inneren Feinde der Revolution: »il faut que les braves sans culottes qui sont maintenant les plus forts, se servent de leurs piques, qu'ils exterminent quiconque voudra sortir du cercle qui lui a été tracé par la loi «"

Dies blieben im revolutionären Diskurs vorerst jedoch marginalisierte Stimmen, die oft auf die Verachtung der führenden Kräfte nicht nur in der Na-

89 Défenseur de la Constitution, Nr. 1, S. 15-27: Observations sur les moyens de faire utilement la guerre, hier S. 26.

${ }_{90}$ Ami du Peuple, 19.4.1792; vgl. auch ebd., 22.6.1791.

91 So Roux in seinem vielfach gehaltenen "Discours sur les moyens de sauver la France et la Liberté«, der uns schriftlich allerdings nur in einer im Herbst 1792 überarbeiteten, zweifellos unter den neuen politischen Bedingungen veränderten Fassung überliefert ist. J. Roux, Scripta et acta. Textes présentés par W. MARKOV, Berlin/DDR 1969, S. 49-78.

92 Père Duchesne, Nr. 126. 
tionalversammlung, sondern auch im Jakobinerklub und in den großen patriotischen Blättern trafen. Im grundsätzlichen Ansatz aber unterschieden sie sich doch nur graduell von den gemäßigteren Tendenzen im revolutionären Lager, denn der Kampf gegen die inneren Feinde wurde von allen als zentrale Voraussetzung für eine erfolgreiche Kriegspolitik begriffen. Im volkstümlichen Diskurs blieb dabei Ludwig XVI vorerst weitgehend von der Kritik ausgenommen, auch wenn die im Père Duchesne formulierte Perspektive, »renverser les trônes de tous les tyrans, pas un autrichien, pas un aristocrate n'échappera à votre vengeance«, implizit auch schon die Wendung gegen den eigenen König beinhaltete. Die intellektuelleren Köpfe des Pariser Radikalismus in den Révolutions de Paris gingen darüber aber schon bald weit hinaus. Zwar beschworen sie bei Kriegsbeginn, ähnlich wie Robespierre ${ }^{93}$, angesichts der möglichen militaristischen oder aristokratischen Herrschaftsalternativen trotz aller bisherigen Kritik die aktuelle Verfassungsordnung. Doch schnell setzte sich hier eine ganz andere, offen gegen den König als inneren Hauptfeind gerichtete, zugleich auch die konstitutionelle Staatsform fundamental kritisierende politische Tendenz durch, deren Konzeption aufs engste mit dem Krieg verbunden war: "La nation n'est pas en guerre avec les rois étrangers, elle est en guerre avec Louis XVI, \& c'est lui qu'il faut vaincre le premier, si l'on veut vaincre (...) les tyrans et ses alliés $\iota^{94}$.

Diese offene Wendung gegen die innere Konterrevolution und besonders gegen die monarchische Exekutive entsprach eigentlich auch den politischen Perspektiven der weiterhin die Nationalversammlung und die politische Öffentlichkeit dominierenden gemäßigten Jakobiner um Brissot, die, wie wir gesehen haben, den Krieg ja nicht zuletzt als Herausforderung für die nationale Loyalität des Hofes und als Instrument der revolutionären Konsolidierung konzipiert und betrieben hatten. Nun durch drei ihnen nahestehende Minister mehr oder weniger direkt eingebunden in die Regierungsverantwortung, kam diese Perspektive hier vorerst jedoch nur in abgeschwächter Form zum Ausdruck. Ins Zentrum rückte zum einen die generalisierende, aber unspezifische Kritik an der konterrevolutionären wnoblesse«, die durch ihre Intrigen den Krieg herbeigefürt bzw. unvermeidlich gemacht habe ${ }^{95}$. Zum anderen und vor allem aber wandte man sich gegen das von der Königin gebildete «comité autrichien«, das nach Auffassung der revolutionären Öffentlichkeit in Konkurrenz zum jakobinischen Ministerium den scheinbar schwankenden König beeinflussen und gegen die Revolution einnehmen würde. Die Tätigkeit dieses "comité autrichien« hatte Brissot schon in der ersten Kriegswoche so charakterisiert: "Le comité des Tuileries ne cesse de s'agiter en tout sens pour se-

95 Vgl. La Sentinelle, Nr. 1. 
mer la division, et allumer la guerre civile. Anéantir les sociétés patriotiques, diffamer les meilleurs citoyens, élever des soupçons sur les députés les plus purs, et amener ainsi la dissolution de l'assemblée nationale elle-même; voilà à quoi il travaille tous les jours (...), ébranlent la confiance due aux représentants du peuple et le nouveaux ministère, déclament contre une guerre inévitable, et s'efforcent d'inspirer la méfiance et le découragement $\aleph^{96}$.

In Gegensatz zum Skeptizismus der radikaleren Blätter des Pariser Populismus und der entstehenden Bergpartei gingen die gemäßigteren Revolutionäre jedoch zuerst einmal prinzipiell davon aus, daß der Krieg auf französischer Seite tatsächlich bereits ein revolutionärer Krieg sei, der aus diesem Grunde mit innerer Notwendigkeit zu einem erfolgreichen Abschluß führen werde und darin nicht zuletzt durch die von den Radikalen betriebene, zur Anarchie führende Auflösung der inneren Einheit gefährdet werde. Während jene alle legalen Autoritäten, insbesondere die Militärführung unter Generalverdacht stellten, sah man genau darin eine sinnlose Untergrabung der nationalen Kriegsmoral, forderte erst einmal Vertrauen in die gesetzmäßigen Autoritäten und kritisierte in schroffer Form die demagogischen Tendenzen im Pariser Radikalismus, die ebenso gefährlich erschienen wie der sogenannte Moderantismus. "Rien n'est plus vrai que le vieil adage, qui dit que les deux extrêmes se touchent. Le démagogisme furieux et l'hypocrite modérantisme se sont réunis pour déclarer contre l'indispensable mesure de la guerre«, hieß es in Brissots Patriote Français, der sich zugleich gegen die "efforts multipliés de l'aristocratie et du démagogisme pour désorganiser l'armée, en décourageant les généraux et en excitant les soldats à d'horribles excès « wandte ${ }^{97}$.

Die letzte Äußerung bezog sich auf die Massakrierung von General Arthur de Dillon durch seine Soldaten, die besonders von Marat unter der Rubrik "grands examples de la justice populaire qui peuvent sauver la patrie« als beispielhafte Maßnahme gegen den Defaitismus der Generäle gefeiert wurde ${ }^{\text {s }}$. Die gemäßigten Revolutionäre sahen darin umgekehrt eine fundamentale Bedrohung für die Kampffähigkeit der französischen Armeen. Ihre Agitation für die Bewahrung der militärischen Disziplin gipfelte in einem Aufruf der Nationalversammlung an die Soldaten, in dem die Notwendigkeiten der militärischen Disziplin von den Grundsätzen der zivilen Gesellschaft unterschieden wurden: „Mais pour (...) la victoire, il faut que la discipline règle les mouvements du courage, et que jamais la défiance ne les suspende ou ne les égare.

96 Patriote Français, 26.4.1792.

97 Patriote Français, 2.5. und 6.5. 1792.

98 Ami du Peuple, 6.5.1792. Der Vorfall ereignete sich während des ungeordneten Rückzugs nach einem Angriff auf Tournai, dessen Scheitern von den Soldaten auf die Inkompetenz des adeligen Militärführers zurückgeführt wurde. 
Point de triomphe sans l'obéissance absolue du soldat à l'officier, de l'officier au général, sans leur union constante et fraternelle «".

In der Unterordnung unter die Generäle sahen die radikaleren Blätter dagegen einen Bruch mit der Konzeption des selbstbestimmten soldat citoyen, dem allein sie eine erfolgreiche Kriegsfuihrung zutrauten ${ }^{100}$. Und auch im Innern interpretierten sie alle Initiativen der Brissotins als Maßnahmen zur Bekämpfung der revolutionären Kräfte, obwohl diese selbst zunehmend auf deren Aktivierung setzten. Denn sowohl der Kriegsverlauf als auch die innenpolitische Entwicklung bestätigten den Skeptizismus der Radikalen, und unter diesen Voraussetzungen führte auch die politische Konzeption der gemäßigteren Kräfte im revolutionären Lager unausweichlich zu einer immer schärferen Wendung gegen die »Autrichiens du dedans«. Die entscheidenden Voraussetzungen für die Entstehung einer breiten, trotz aller Gegensätze, Verdächtigungen und Anfeindungen von allen revolutionären Kräften getragenen Massenbewegung gegen den Hof, den König und schließlich auch gegen die Monarchie wurden wesentlich durch die realpolitischen Entwicklungen geschaffen. Ihre revolutionäre Wirkung indes basierte vor allem darauf, daß sie die gemeinsamen Grundelemente des revolutionären Diskurses zu bestätigen schien, insbesondere den Verdacht, die inneren Gegner der Revolution würden mit den äußeren Kriegsgegnern im Bunde stehen und müßten, weil sie den militärischen Erfolg gezielt verhindern würden, als erste ausgeschaltet werden, bevor der Krieg selbst zu einem siegreichen Ende gebracht werden könne.

Die innenpolitische Situation begann sich zuzuspitzen, als im Laufe des Mai die Loyalität der Militärführung immer fragwürdiger wurde. Mehrere Regimenter liefen zum Feind über, etliche Offiziere reichten ihren Rücktritt ein, vor allem aber verweigerten die kommandierenden Generäle die von der $\mathrm{Na}$ tionalversammlung beschlossene offensive Kriegsführung und verharten nach den ersten Rückschlägen in einer attentistischen Defensive, die den weiteren gegnerischen Truppenaufmarsch zu begünstigen schien. Diese Situation nahm Brissot zum Anlaß, in einer großen Rede vor der Nationalversammlung das "comité autrichien« als Drahtzieher einer Verschwörung zu denunzieren, deren Ziel es sei, mit Hilfe des militärischen Drucks von außen eine die Position von Adel und Krone stärkende Verfassungsrevision im Innern durchzusetzen. »Messieurs, à qui profitent et les débats sur la guerre offensive, et ces lenteurs dans les préparatifs, et ces échecs, et ces trahisons? A l'Autriche et à ses partisans. Quel est le but de ces démissions combinées, qui sont un véritable crime, puisque déserter, sous le prétexte qu'on ne veut point de guerre offensive, c'est renverser le système d'obéissance qu'on prêche avec

99 Zit. n. Annales Patriotiques, 14.5.1792.

${ }^{100}$ Vgl. Défenseur de la Constitution, Nr. 1, S. 15-27: Observations sur les moyens de faire utilement la guerre. 
tant de zèle aux soldats, sans doute pour s'en dispenser? (...) C'est de désorganiser, de dissoudre l'armée, de réduire la France à un état d'impuissance qui la force de recevoir la loi des puissances étrangères, et (...) d'amener le fatal système des 2 chambres. Oui, Messieurs, tel est le but où l'on tend. Ouvrez un registre d'informations sur le Comité autrichien et la lumière la plus vive éclairera bientôt tous ces forfaits « $^{101}$.

Im Anschluß an diese scharfe Wendung gegen den »conseil clandestin, lequel dirige le roi ${ }^{102}$, verabschiedete die Nationalversammlung auf Initiative der Brissotins mehrere Gesetze gegen den sinneren Feind, die für die weitere revolutionäre Radikalisienung im Sommer 1792 auch deshalb eine zentrale Bedeutung gewannen, weil der König sie überwiegend durch sein Veto zu blockieren versuchte und damit seine Position nur noch weiter untergrub. Am 27. Mai wurde die Deportation aller Priester angeordnet, die den Eid auf die Verfassung verweigert hatten und deshalb als Agenten der Konterrevolution galten, da sie durch das Schüren der inneren Unzufriedenheit die Verteidigung gegen den äußeren Feind behindern wollten. "Suivez le fil des trames ourdies par les ennemis du dehors et du dedans«, so hatte der jakobinische Abgeordnete Ichon diese Initiative in der Nationalversammlung begründet, wrecherchez l'origine des mouvements qui ont provoqué la violation de la loi, et donné lieu à des scènes de sang; combinez la marche des rebelles qui ont déserté leur patrie pour aller dans une terre étrangère s'armer contre elle, et méditer des complots funestes; remontez à la source de tous les maux qui ont infesté la France depuis l'époque de la fameuse loi de l'Assemblée constituante sur le serment civique (...) et partout vous verrez les orages se former à l'ombre des autels, et éclater ensuite dans le sein des familles, et sur la place publique. Détruisez l'idée menaçante d'un schisme malicieusement controuvé pour porter l'épouvante dans les consciences faibles; arrachez des mains du prêtre insermenté l'arme redoutable du fanatisme, destinée à diviser les citoyens, et à frapper l'Empire du fléau d'une guerre civile; que partout le sacerdoce courbe sa tête avec franchise devant la majesté de la loi, et dès lors la paix s'établit dans l'intérieure (...) les espérances des émigrés, qui ne fondent leurs succès que sur nos dissensions intestines, s'évanouissent; et les puissances étrangères, inquiètes sur les destinées de leurs propres Etats, restent dans l'éloignement, simples spectatrices des débats d'un grand peuple, qui s'agite majestueusement sur les ruines du despotisme, pour consolider l'édifice de sa liberté $\ll^{103}$.

${ }^{101}$ AP 44, S.43, 23.5.1792; vgl. allg. M. HochEDLINGER, "La cause de tous maux de la France«. Die ,Austrophopier im revolutionären Frankreich und der Sturz des Königtums 1789-1792, in: Francia, 24/2 (1997), S. 75-120.

${ }^{102}$ Patriote Français, 25.5.1792.

${ }^{103}$ AP 44, S. 61f., 24.5.1792. 
Zwei Tage später schaffte die Nationalversammlung per Dekret die königliche Garde ab, weil sie als bewaffnete konterrevolutionäre Kraft angesehen wurde, die offen mit dem Feind sympathisiere. Am 8. Juni schließlich ging die Legislative noch einen Schritt weiter und schuf die Voraussetzungen für die Bildung einer eigenen militärischen Schutztruppe: Auf Anregung des neuen Kriegsministers Servan dekretierte sie die Aushebung von 20.000 Freiwilligen, die als "nouvelle armée de l'élite des citoyens de tous les cantons « ${ }^{104}$ anläßlich der Feierlichkeiten zum 14. Juli nach Paris kommen, in der Nähe der Hauptstadt in einem Militärlager ausgebildet und auf unbestimmte Zeit dort stationiert werden sollten. Die Fédérés, wie diese organisierten und bewaffneten Revolutionäre aus ganz Frankreich nun genannt wurden, erwiesen sich nicht nur tatsächlich als ein wesentlicher Faktor beim Sturz der Monarchie. Sie waren zugleich auch der sichtbarste Ausdruck einer weit umfassenderen, revolutionäre Radikalisierung und kriegerische Militarisierung miteinander verbindenden Form der Massenmobilisierung, die im politischen Diskurs vorbereitet wurde und die gesellschaftliche Realität des revolutionären Frankreich bald in wachsendem Maße prägte. Die allgemeine bürgerliche Mobilmachung in einer levée en masse, wie sie erst ein Jahr später formell dekretiert wurde, wurde bereits im Sommer 1792 umfassend diskutiert und begann, sowohl die äußere Kriegsführung als auch die innenpolitischen Auseinandersetzungen immer deutlicher zu prägen. In durchaus ähnlicher Form wie 1793 zielte sie keineswegs nur gegen den äußeren Kriegsgegner, sondern sie richtete sich wesentlich gegen den sinneren Feind,, dessen Überwindung in der Konzeption des revolutionären Bürgerkrieges nun als grundlegende Voraussetzung für eine erfolgreiche Kriegspolitik erschien.

Die Tendenzen zur revolutionären Militarisierung der innenpolitischen Auseinandersetzung fanden ihren ersten deutlichen Ausdruck schon Anfang Mai 1792, als Carnot in der Nationalversammlung während einer Diskussion über die Überwachung der sich in Paris sammelnden Revolutionsgegner mit ihren "cœurs autrichiens" die Verhängung einer Art Kriegsrecht forderte ${ }^{105}$. Zwar lehnte Marat diese Initiative ebenso wie die geforderte Schaffung einer Schutztruppe der Nationalversammlung und später dann, gemeinsam mit Robespierre, das »camp des fédérés « ab, weil er darin de facto eine bewaffnete Kampftruppe gegen den Pariser Radikalismus sah. Doch in der Grundstruktur folgten auch seine politischen Vorschläge dieser Militarisierungstendenz, wenn er immer wieder die Einsetzung eines Kriegsdiktators mit unbegrenzten Vollmachten für den Kampf gegen den inneren Feind forderte ${ }^{106}$.

${ }^{104}$ So M. Coustard für das Militärkomitee, AP 44, S. 640, 6.6.1792.

105 AP 43, S. 422f., 5.5.1792: »Il faut que la Police de Paris ait les mêmes droits, la même surveillance qu'un général a dans son camp. Il faut déléguer à un magistrat de Paris, les mêmes droits qu'à un commandant dans une ville de guerre«.

${ }^{106}$ Vgl. Ami du Peuple, 18.7.1792. 
Da die große Mehrheit der Revolutionäre jedoch allen militärischen Organisationsformen, die dem traditionellen »despotisme militaire« zu ähneln schienen, grundsätzlich ablehnend gegenüberstand, konnte für sie nur eine Militarisierung svon unten', in Absetzung oder sogar in Gegnerschaft zu den überkommenen Formen der Militärherrschaft in Frage kommen, die ja weiterhin und mit Recht als Bedrohung der Revolution erschienen. Es gehe nun nicht um "la guerre de la cour", sondern um "la guerre du peuple», hatte Robespierre schon bei Kriegsbeginn argumentiert, um davon ausgehend die Perspektive zu weisen: "Il faut que le peuple français se lève désormais et s'arme tout entier, soit pour combattre au-dehors, soit pour veiller le despotisme au-dedans $\aleph^{107}$. Konkretisierung und breitere Wirksamkeit konnten solche Ansätze jedoch erst in Verbindung mit der wachsenden äußeren Bedrohung gewinnen. Der erste wichtige, zugleich für die weitere Entwicklung symptomatische Anstoß zu einer allgemeinen, so kriegerischen wie revolutionären Massenmobilisierung der zivilen Gesellschaft stammte von Lasource, der am 19. Mai 1792 vor der Nationalversammlung angesichts der politischen und militärischen Lage die Forderung erhob, "que la France entière soit transformée tout à coup en une forêt de baionnettes (...) En donnant à toute la France un mouvement militaire, vous portez dans le cœur de tous les citoyens cet esprit fier et belliqueux qui, dangereux dans un temps de calme, est essentiellement salutaire dans le moment actuel ${ }^{108}$.

Auch wenn Lasource seinen Gesetzesvorschlag angesichts des vehementen Widerstandes der Abgeordneten gegen die von ihm zur Finanzierung ins Spiel gebrachte Abholzung der "forêts nationales" in der Nationalversammlung nicht einmal vortragen konnte, zeichnete er doch die weitere Entwicklung vor. Vor allem zeigte seine Initiative bereits deutlich an, daß nach der Logik eines revolutionären Diskurses, der äußere und innere Feinde zum Projekt einer umfassenden Konterrevolution miteinander verschmolz, die militärische Massenmobilisierung gegen die äußere Bedrohung sich zugleich nach innen richten, ja hier sogar ihre Hauptstoßrichtung finden würde. Lasource ging davon aus, $\mathrm{da} B$ angesichts der militärischen Bedrohung die Kriegsanstrengungen Frankreichs »d'une insuffisance ridicule et d'une faiblesse ignominieuse « seien, und er forderte dagegen, "que les Français se lèvent, mais qu'ils se lèvent en masse«. Konkret schlug er neben der Bildung von »bataillons de vétérans« zur Aufrechterhaltung der inneren Ordnung und der Intensivierung der Waffen-

${ }^{107}$ Robespierre am 20.4.1792 im Jakobinerklub, zit. n. Journal des débats, 181, S. 3.

${ }^{108}$ AP 43, S. 560-562, das Zitat S. 560, die folgenden S. 560, 572f.; vgl. auch den zustimmenden Bericht im Patriote Français, 20.5.1792 sowie später, den hier angelegten Grundsatz der Rotation weiterentwickelnd, F. LANTHENAS, Nécessité et moyens d'établir la force publique. Sur la rotation continuelle du service militaire, et la Représentation Nationale, sur la proportion exacte du nombre des citoyens, in: Chronique du Mois, September 1792. 
produktion vor, daß alle Nationalgardisten wöchentlich exerzieren und im Wechsel aus ihren Reihen besetzte, dauerhaft eingerichtete "camps dans l'intérieur" vor allem in grenznahen Gebieten gebildet werden sollten. Das größte dieser Heerlager allerdings sollte zwischen der Nordfront und Paris stationiert werden, und hier rückte nun bereits eindeutig die Wirkung nach innen in den Mittelpunkt, wenn Lasource die Frage stellte, ob nicht "wne force assez considérable, assez prochaine de la capitale, pût y contenir dans l'inaction, la terreur, les factieux, les intrigants, les traîtres qui trament dans son sein des projets perfides, coincidants aux mancuvres des ennemis du dehors?«. Die Einleitung des Dekrets, das Lasource nicht mehr vortragen konnte, zielte dann explizit gegen den sinneren Feind،: "L'Assemblée nationale, considérant qu'il importe au salut de l'Etat de prendre de promptes mesures pour contenir les ennemis intérieurs par l'appareil de la force; considérant qu'il est, à la fois, de l'intérêt et de l'honneur de la nation française de déployer, dans la guerre qu'elle a été forcée d'entreprendre des moyens si imposants qu'ils intimident leurs ennemis secrets qui pourraient former des projets hostiles et des forces puissantes, si puissantes qu'elles contraignent bientôt à la paix l'ennemi ouvert qui combat contre elle décrèter.

Auf dieses Projekt griff Kriegsminister Servan zweifellos zurück, als er wenige Tage später die Forderung erhob, "que la nation doit se lever tout entière $\ll^{109}$, und angesichts der noch geringen Resonanz dann erfolgreicher die Bildung eines "camp des fédérés« anregte. Dieses Heerlager sollte nach seinem Konzept zweifellos an erster Stelle die Möglichkeiten der äußeren Kriegsführung verbessern. "Nous n'avions que des ennemis au dedans, nous en avons actuellement au dehors", argumentierte Servan, die Fédérés sollten es vor allem ermöglichen, die in Paris stationierten Truppen an die Front zu verlegen ${ }^{110}$. Im öffentlichen Diskurs aber verschob sich die Zielsetzungen wie selbstverständlich gegen den sinneren Feind،. Schon als der Pariser Jakobinerklub Servans Anstoß zur levée en masse aufgriff, gab er ihr eine eindeutig nach innen zielende Bedeutung: "La cause de tous nos maux, frères et amis, est dans ce comité autrichien, ennemi né de la nation française (...) Réveillez-

${ }^{109}$ AP 44, S. $188,28.5 .1792$.

110 AP 44, S. 550, 4.6.1792. Allerdings blieb die Bindung an die innere Revolution eindeutig erhalten: $»$ La nation entière s'arma pour faire la Révolution, il faut qu'elle s'arme pour l'assurer«. Zwei Tage später griff Coustard als Sprecher des Militärkomitees diese Auffassung auf: "La liberté a été conquise en France sur les ennemis intérieurs par l'armement simultané de tous les Français; elle ne peut être assurée contre les ennemis extérieurs que par le developpement d'une puissance imposante«, um dann mit einer unauflöslichen Verbindung von Soldat und Bürger fortzufahren: "Autrefois tout était esclave, tout était nul; aujourd'hui tout est soldat, tout est citoyen (Applaudissement); et tel est l'heureux accord établi par notre Constitution dans les divers emplois de la société, que ces 2 titres se confondent dans la qualité d'homme libre et de Français«. AP 44, S. 640, 6.6.1792. 
vous donc, citoyens, que la nation se lève toute entière (...) Guerre aux tyrans, guerre aux partisans des deux chambres, guerre à ceux qui voudraient rétablir la noblesse, sous quelques forme que ce soit (...) Préparons dans l'intérieur nos moyens de défense, instruisons nos concitoyens; prémunissons-les contre les suggestions perfides des prêtres fanatiques et de tous les autres ennemis de la liberté «" erhielt in der revolutionären Öffentlichkeit dann ebenfalls generell eine zweifache, sowohl nach außen als auch nach innen gerichtete, bzw. beides in einen engen Zusammenhang bindende Stoßrichtung, in der letztere schließlich dominierte. Das Militärlager war »destiné à la défense de l'extérieur et à la protection de l'intérieur«, »à opposer aux ennemis extérieurs et à faire trembler ceux du dédans«, man wollte damit »protéger la patrie et la constitution«, »assurer (...) contre les ennemis du dehors et les ennemis du dedans, le règne de la volonté générale ${ }^{112}$.

Konkret ging es darum, eine loyale revolutionäre Armee zu schaffen, die zum einen als Verteidigungsreserve von Paris gegen die sich immer drohender abzeichnende feindliche Invasion, zum anderen und zunehmend vor allem der Verteidigung der Hauptstadt und der Nationalversammlung gegen die vom sinneren Feind ( ausgehenden, die äußeren Gefahren erst heraufbeschwörenden Bedrohungen dienen sollte. "Braves Parisiens«, argumentierte etwa Louvet, „c'est pour vous protéger contre des lâches conspirateurs qui, pour vous égorger, attendaient les ténèbres de la nuit (...) c'est pour vous protéger contre leur fureur, c'est pour vous préserver de la tranquillité de l'esclavage que la majorité de vos représentants a décreté qu'on augmenterait la force publique par 20 mille de vos frères pris dans les départements, et qui se trouveront dans vos murs en 14 juillet ${ }^{113}$. Der Père Duchesne verkündete seine "grande joie (...) de voir arriver vingt mille bougres à Paris, de tous les Départements pour tenir en bride les jean-foutres de Feuillants qui veulent rétablir le despotisme et la noblesse ${ }^{114}$. Und die Annales Patriotiques sahen in dem Heerlager bei

'I' Les citoyens composant la société des amis de la constitution, séante aux jacobins à Paris, à leurs frères des départements, 6.6.1792, abgedr. in: Annales Patriotiques, 13.6.1792, supplément.

${ }_{112}$ In der Reihenfolge: Jean Débry am 6.6.1792 in der Nationalversammlung, AP 44, S. 644; Adresse der von den radikalen Cordeliers beherrschten Sektion Théatre Français (Chaumette, Momoro u.a.), abgedr. in Patriote Français, 14.6.1792; ebd.; Coustard für das Militärkomitee in der Nationalversammlung, 6.6.1792; AP 44, S. 640.

${ }^{113} \mathrm{La}$ Sentinelle, Nr. 12, mit Berufung auf Berichte aus den Départements über ein konterrevolutionäres Projekt: »Leur nombre doit être considérable; cependant vous n'avez que quarante mille hommes de gardes-nationales dont la moitié n'est pas aguerrie. Sie vous n'y prenez garde, vous aurez un massacre (...) Quand il n'y aura plus l'assemblée nationale, quand les meilleurs patriotes sont égorgés, chaque chef aura son parti, la guerre civil éclatera dans tout le royaume, et les étrangers y entreront«.

${ }^{114}$ Père Duchesne, Nr. 140. 
Paris, dem Carra "camps partiels« in den Départements beiseite stellen wollte, »le centre de l'espoir et de ralliement de tous les patriotes des 83 départements«, das sich im Fall einer befürchteten "grande trahison« erweisen solle als »la mort de tous les aristocrates et de tous les conjurés du dedans et du dehors «; gegen das königliche Veto gerichtet, mobilisierte Carra dann das mit der Vorstellung einer Massenerhebung verbundene revolutionäre Pathos und rief auf: "Levez-vous donc tous ensemble, et que votre masse imposante, équipée de piques, de bayonnettes et de flammes tricolores, fasse rentrer dans la poussière les tyrans et les traîtres «"1".

Zwar gab es mit der konterrevolutionären Agitation und einer wachsenden Zahl lokaler Aufstände in der Tat genügend Hinweise auf den Versuch, parallel zum Krieg den inneren Bürgerkrieg zu entfachen. Doch eine noch weit größere Bedrohung schien von der bewaffneten Macht selbst auszugehen, und gerade die Bindung der Föderationsbewegung an den Jahrestag des Sturms auf die Bastille konnte die Stoßrichtung gegen das monarchische Militär ebenso nur bestärken wie den revolutionären Charakter der militarisierten Massenmobilisierung. So wie man sich 1789 der Pariser Waffenarsenale versichert hatte, um für die Auseinandersetzung mit den Truppen des Königs gerüstet zu sein, so schien es nun notwendig zu sein, sich zum Kampf gegen illoyale Militärführer und eventuell auch gegen die weiterhin von La Fayette beeinflußte Pariser Nationalgarde zu rüsten. Die Befürchtung, daß die Militärführer die absolute Macht des Monarchen wiederherstellen könnten, hatte die revolutionäre Bewegung seit 1789 begleitet, und sie hatte sich spätestens seit dem Marsfeldmassaker von 1791 auf La Fayette konzentriert. Daß unter den Bedingungen des Krieges nicht nur diese Gefahr zunehmen würde, sondern auch die Möglichkeiten der Militärfuhrer, gestützt auf die Macht der Bajonette einen offenen "despotisme militaire« zu errichten, war vor allem von Robespierre und Desmoulins seit den Diskussionen über den Krieg zu Jahresbeginn immer wieder beschworen worden ${ }^{116}$. Und die Angst vor einem »neuen Cromwell« trieb nun angesichts der politischen Realitäten nicht nur die Radikalen um. Als sich der Generalstab der Pariser Nationalgarde in einer Eingabe mit 8.000 Unterschriften gegen das "camp des fédérés« wandte, wuchs auch im Kreise der gemäßigteren Revolutionäre die Angst vor der Militärherrschaft: "Par tout l'esprit de corps étouffe l'esprit public« stellte etwa Louvet alarmiert fest, "dans un corps armé sur-tout il menacerait la liberté générale; et de tous les gouvernements le plus absolu, le plus despotique, le plus intolérable, serait le gouvernement militaire « ${ }^{117}$.

${ }^{115}$ Annales Patriotiques, 14.6.1792.

${ }^{116}$ Vgl. hier Kap. II.1.

$117 \mathrm{Vgl}$. La Sentinelle, Nr. 15. 
Diese bedrohliche Perspektive erhielt eine nachhaltige Bestärkung durch das Verhalten des früheren Generals der Pariser Nationalgarde, der von den Jakobinern schon seit langem militärdiktatorischer Neigungen verdächtigt wurde. Als La Fayette dann auch selbst mit einem gegen jakobinische Tendenzen gerichteten Brief an die Nationalversammlung in die Pariser Innenpolitik einzugreifen versuchte, schien sich die Gefahr der Militärdiktatur immer deutlicher abzuzeichnen. "Est-ce Cromwell où vous qui parle dans cette lettre«, fragte Robespierre, um dann die Ähnlichkeit der Forderungen La Fayettes mit denen des österreichischen Kaisers Leopold zu Jahresbeginn herauszustellen und den inneren Feind zu denunzieren: "Léopold n'est point mort pour nous, il vit dans tous les ennemis du peuple français, qui respirent au milieu de nous; de tous les factieux qui menacent la constitution et l'assemblée nationale ${ }^{118}$. Es schien nun völling unzweifelhaft, "que La Fayette ne soit le chef de cette noblesse coalisé avec tous les tyrans de l'Europe«, wie Danton argumentierte ${ }^{119}$. Brissot hatte zuvor zwar immer wieder den Vergleich zwischen La Fayette und Cromwell verworfen, doch nun reagierte er ähnlich alarmiert. "C'est le coup le plus violent qu'on ait encore porté à la liberté«, stellte der Patriote Français fest, "coup d'autant plus dangereux, qu'il est porté par un général qui se vante d'avoir une armée à lui, de ne faire qu'un avec son armée; d'autant plus dangereux encore, que cet homme a su, par sa modération et par ses artifices, se conserver un parti, même parmi les hommes qui aiment vivement la liberté: sa lettre le démasque. (...) Ah, s'il est des vrais factieux, je les vois dans ceux qui veulent rendre la force armée déliberante, arbitre de la législative, et par là établir la domination militaire que tant de pages d'histoire ont appris à redouter ${ }^{120}$.

Auch wenn Brissot hier zugleich noch die optimistische Auffassung vertrat, daß der revolutionäre soldat citoyen La Fayette niemals in den Kampf gegen "sa propre patrie« folgen würde ${ }^{121}$, gewannen die Drohungen des Generals eine besonders allarmierende Qualität im Zusammenhang mit der Politik des Königs. Denn nur wenige Tage vorher, am 12. Juni, hatte Ludwig XVI. die jakobinischen Minister Roland, Servan und Clavière entlassen. Vorangegangen war das königliche Veto gegen die Dekrete der Nationalversammlung zur Deportation der eidverweigernden Priester und zur Bildung des »camp des fédérés« sowie, in Reaktion darauf, der berühmte Brief von Innenminister

118 Défenseur de la Constitution, Nr. 7, S. 159-219: Deuxième lettre de M. Robespierre à M. Lafayette sur les lettres de M. Lafayette à l'Assemblée nationale et au roi, hier S. 212.

119 AULARD, Société des Jacobins, Bd. 4, S. 12, 18.6.1792.

${ }^{120}$ Patriote Français, 19.6., 20.6.1792; weiter hieß es hier, ähnlich wie bereits früher in den Révolutions de Paris: "Vaincre est bon, mais vivre libre est meilleur; et si la France ne peut être libre que par M. Lafayette (...) elle est et sera esclave«.

121 Vgl. auch La Sentinelle, Nr. 19: "parler des soldats de la patrie, comme de soldats à lui, d'une armée nationale, comme d'une armée qui lui appartenait!«. 
Roland, in dem er den König einerseits zur Aufhebung dieser Entscheidung gedrängt, ihm andererseits aber auch mit der Revolution gedroht hatte. "Le salut de l'état et le bonheur de votre majesté sont intimement liés«, so verband Roland das Schicksal des Königs mit seiner Kriegspolitik ${ }^{122}$. Die Entlassung der Minister wies nun auch den bisher gouvernemental orientierten Revolutionären eindeutig den Weg zur Radikalisierung. Die Nationalversammlung setzte eine Zwölferkommission zur Überwachung der Aktivitäten der neuen, wieder von den Feuillants geprägten Regierung ein, und während Robespierre weiterhin unter der Parole "Frappez La Fayette, et la nation est sauvée« die Wendung gegen den General propagierte ${ }^{123}$, rückte nun die Kritik am König immer nachdrücklicher in den Mittelpunkt der allgemeinen politischen Agitation.

"Si quelque chose peut démontrer l'existence d'un comité autrichien, c'est à dire d'un comité secret qui dirige le roi au profit de nos ennemis public, et contre le vœu de la nation, c'est bien le renvoi de son ministère patriote«, stellte Brissot fest: "Mais le peuple n'est pas dupe de cette manœuvre, il connaîtra sans doute un jour les traitres qui se jouent ainsi de ses intérêts dans des moments de crise, et leur châtiment sera terrible $\ll^{124}$. Auch Louvet wandte sich erneut gegen das "comité autrichien«, das den König hintergehe und die Regierungstätigkeit paralysiere, doch ließ er die Unterscheidung zugleich in einer allgemeinen Kritik an "la cour ennemie " verschwimmen, die "la guerre la plus opiniâtre à nos représentants« führe, und beschwor die Erinnerung an die revolutionäre Bedrohungssituation im Juli 1789, die zum Sturm auf die Bastille geführt hatte ${ }^{125}$. Carra stellte angesichts des Briefes von La Fayette die Erinnerung an die Flucht des Königs 1791 in den Mittelpunkt seiner Kritik: "Cette lettre est peut-être encore le préliminaire d'une seconde évasion du roi, et un moyen d'excuse préparé d'avance pour justifier auprès des puissances coalisés, et peut-être auprès des troupes nationales même, cette seconde fuite ${ }^{126}$. Und die Révolutions de Paris zogen bereits die radikale Konsequenz aus dem Vergleich zum Juli 1789 und proklamierten offen den Aufstand gegen den König. Die Nationalversammlung solle dem Volk erklären, hieß es dort, "que la patrie est dans le plus imminent danger; que les pouvoirs qu'elle a réçus ne sont point allés étendus pour la sauver (...) tous vos maux viennent de votre roi, \& vos représentants n'ont aucun pouvoir sur le roi. Toi seule, nation grande \& souveraine, toi seule as le droit \& la puissance de le faire rentrer dans la poussière ${ }^{127}$.

${ }^{122}$ Vgl. Patriote Français, 18.6.1792.

${ }^{123}$ AULARD, Société des Jacobins, Bd. 4, S. 11, 18.6.1792.

${ }^{124}$ Patriote Français, 18.6.1792.

125 La Sentinelle, Nr. 17.

126 Annales Patriotiques, 21.6.1792.

${ }^{127}$ Révolutions de Paris, 9.-16.6.1792, Bd. 12, S. $491 \mathrm{f}$. 
Damit war eine kriegsbezogene Formel geprägt, die die auf den Sturz der Monarchie abzielende Radikalisienung des Sommers 1792 prägen sollte. Auch im Pariser Jakobinerklub wurden Mitte Juni immer deutlichere Stimmen laut, die angesichts einer mit der äußeren Bedrohung verbündeten Monarchie eine zweite Revolution forderten. So hielt Robert im Jakobinerklub Robespierre entgegen: »M. Robespierre et plusieurs autres orateurs se sont élévés contre tous les moyens qui sembleraient contredire la constitution; mais il sont dans l'erreur, car à la fin du chapitre IV de la constitution il est dit que le corps législatif en est le gardien«. Und Fabre d'Eglantine griff die bereits in den Révolutions de Paris formulierte Forderung auf: "Il faut que l'Assemblée nationale déclare que la chose publique est en danger, engage le peuple a soutenir les armes à la main sa constitution « $^{128}$.

Während die Jakobiner indes mehrheitlich noch Zurückhaltung wahrten, wendete sich die Pariser Volksbewegung nun immer eindeutiger gegen einen König, der im Einklang mit den äußeren Feinden zu handeln schien. Auch der mit Kritik am König bislang ausgesprochen zurückhaltende Père Duchesne Héberts begann nun offen gegen Ludwig XVI zu agitieren. "Avant de vouloir foutre un coup de peigne aux ennemis du dehors, il faut exterminer ceux du dedans«, so interpretierte er wie üblich den Kampf gegen den inneren Feind als Voraussetzung militärischer Erfolge, um dann das Verhalten des Königs in den Mittelpunkt der politischen Problematik zu rücken: "... il faut que le Roi fasse éxécuter la constitution, il faut le forcer à être heureux, car on ne peut l'être tant qu'on ne fait pas le bien: tant qu'on est entouré de scélérats. Quand il n'y aura plus en France ni prêtres, ni ci-devant nobles, ni robins, ni financiers, par conséquent plus de Feuillants; car c'est tout un ${ }^{129}$. Wenig später, nachdem Hébert erneut ein Komplott der Generäle saufgedeckt` hatte, spitzte er die Entscheidungssituation für den König noch einmal zu: »Il faut pourtant que cela ait une fin. Il faut que le roi s'explique clairement, qu'il le

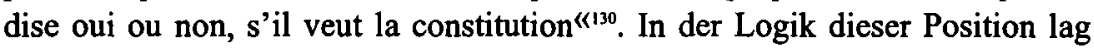
die von den radikalen Kräften im Cordeliers-Klub und in der sich bildenden Pariser Kommune vorbereitete, vom Kreis um Brissot unterstützte Massendemonstration, die sich zum Jahrestag der Flucht nach Varennes am 20. Juni Einla $\beta$ in die Tuilerien verschaffte und vom König unter dem Motto: "Quand la patrie est en danger, tous les sans-culottes sont levés « ${ }^{131}$, die Aufhebung seiner Vetos und die Wiedereinsetzung der jakobinischen Minister forderte.

${ }^{128}$ AULARD, Société des Jacobins, Bd. 4, S. 13f., 18.6.1792; der Redebeitrag von Robert hier S. 16.

129 Père Duchesne, Nr. 141.

130 Père Duchesne, Nr. 145.

${ }^{131}$ Plakataufschrift, zit. n. Révolutions de Paris, 16.6.-23.6.1792, Bd. 14, S. 549. 
Noch gelang es Ludwig durch symbolische Gesten, die Forderungen sauszusitzen<, doch unter dem Eindruck weiter anwachsender militärischer Bedrohungen durch die äußere und die innere Konterrevolution griff die revolutionäre Radikalisierung gegen den König und die Monarchie trotz der Angst, dies könne als Vorwand für einen konterrevolutionären Gegenschlag dienen, immer weiter um sich. "C'est ici un combat à mort de la liberté contre le despotisme«, so wurde in der Pariser Volksbewegung die Frontstellung des Krieges auf die Innenpolitik übertragen: "Il faut que Louis XVI succombe ou la liberté « ${ }^{32}$. Zuerst einmal rückte aber noch einmal La Fayette als mächtiges Symbol der Verbindung von äußerer und innerer Bedrohung in den Vordergrund, als er unter dem Eindruck der Geschehnisse des 20. Juni von seinem Armeekommando nach Paris kam und am 28. Juni vor der Nationalversammlung die Auflösung der Klubs und Volksgesellschaften forderte; nicht ohne Wirkung, denn Bürgermeister Pétion und Prokurator Manuel wurden als vermeintliche Rädelsführer ihrer Ämter enthoben. "Léopold n'était que le précurseur de La Fayette«, so zog Robespierre erneut die kriegsbezogene Parallele zwischen dem äußeren Feind und dem konterrevolutionären General, um beide dann mit dem Hof zu verbinden: „François, Fréderic-Guillaume, ne sont que ses auxiliaires; tous ne sont que les agents de la cour des Tuileries ${ }^{133}$. Louvet agitierte in seiner Wandzeitschrift nun bereits für die noch defensiv begründete Vorbereitung einer Volkserhebung: "O vous tous, parents, amis, quelques soient vos armes, de quelque habit qu'on vous ait revêtus, vous qu'au jour de votre invincible force j'ai vu ne composer qu'une famille, ouvrez les yeux sur les complôts d'une cour profondément perverse. Vous tous, Parisiens, arrêtez, n'avancez plus sur l'abime entre'ouvert. Peuple de la ville remets tes bayonnettes; peuple des fauxbourgs renverse tes piques; peuple tout entier, prends-garde, ils ont soif de ton sang ( $^{134}$.

Im Jakobinerklub kam es angesichts dieser Bedrohung sogar zu einer Verbrüderungsszene zwischen Brissot und Robespierre, deren Kern die gemeinsame Wendung gegen La Fayette und den mit ihm verbundenen König war. "Ce dont il est important de se persuader, c'est que voilà le vrai moment où la Révolution va commencer. Réunissons-nous donc autour de la constitution«, so faßte Lasource den Geist der Versammlung in Worte, und Chabot wies die allgemeinere, revolutionäre Perspektive: »Dans cette crise fatale, l'Assemblée nationale, garrottée par la constitution, ne peut pas vous sauver, car le roi veut vous perdre. Oui, Messieurs, l'Assemblée nationale pourrait vous sauver, si le

${ }^{132}$ Von Pàris am 22. oder 23.6.1792 in der Generalversammlung der Sektion Observatoire verlesene Erklärung, zit. n. BRAESCH, La Commune du dix août 1792, S. 63.

${ }^{133}$ Défenseur de la Constitution, Nr. 8, S. 233-243: Sur la tactique du général Lafayette, hier S. 238.

${ }^{134}$ La Sentinelle, Nr. 23. 
roi était assez scélérat pour marcher hautement, ouvertement contre la constitution; mais, tant qu'il affectera des discours conformes à cette constitution et qu'il se contentera d'agir en sens contraire, nous ne pouvons rien; le peuple, seul souverain, peut seul agir et nous intimer sa volonté. (...) Quand la cour se trouve appuyée d'un nouveau Cromwell qui conspire contre elle comme contre la liberté, quand la cour, dis-je, est appuyée par un tel conspirateur, il est impossible que l'Assemblée nationale sauve la nation; elle ne peut que dire au peuple: ,Venez, accourez tous.ı Je conclus à ce que la Société écrive à toutes les affiliées, et plus encore à ce que l'Assemblée nationale écrive à tous les départements, qu'elle leur crie à nue-tête: /La patrie est en danger! « « ${ }^{135}$.

Die revolutionäre Radikalisierung des Sommers 1792 wurde in der Tat vor allem von zwei aufs engste mit dem Krieg verbundenen Antriebskräften geprägt, die sich im politischen Diskurs spiegelten, durch ihn aber auch gestaltet wurden. Dies war zum einen die Parallelität zwischen der kriegerischen und der politischen Massenmobilisierung, die im Innern dazu führte, daß die revolutionären Massenbewegungen zunehmend einen kriegerischen, militarisierten Charakter gewannen. Wie sehr dieser Prozeß bereits am 20. Juni fortgeschritten war, wurde in der Würdigung der Massendemonstration durch den Jakobinerklub deutlich, in dem zuvor eine ablehnende Haltung gegen "toute insurrection partielle« vorgeherrscht hatte ${ }^{136}$, der nun aber unter dem Einfluß seines Präsidenten Hérault von dem Schwung der Bewegung mitgerissen wurde. Die zwei Vorstädte Saint-Antoine und Saint-Michel hätten sich, so hieß es dort, "levées pour aller saluer les représentants de la nation; précédés de leurs canons, au bruit d'une musique militaire qui répétait le refrain national, ils se sont avancés dans le meilleur ordre et avec la contenance de la plus courageuse sévérité (...) Les fusils fraternisaient avec les piques, avec les armes de toutes les formes; les jeunes élèves de la patrie, le bataillon des vétérans, une portion considérable de la garde nationale, des soldats des troupes de lignes, les braves invalides, des gardes-françaises avec leur ancien uniforme, des officiers municipaux des communes de la campagne, des femmes en grande nombre et toutes armées, des groupes portant diverses inscriptions au milieu desquelles se faisait remarquer la déclaration des droits, tout présentait le spectacle imposant du grand atelier de la Révolution, tout offrait l'image de la force générale qui va se joindre à la volonté générale, dont elle partage le sentiment et l'impulsion, et à laquelle elle tend sans cesse à s'unir, à travers les vetos redoublés que les séparent ( $^{137}$.

Die sich hier abzeichnende Militarisierung der innenpolitischen Auseinan-

135 AULARD, Société des Jacobins, Bd. 4, S. 51f., 28.6.1792; das vorhergehende Zitat S. 56.

136 So Desmoulins am 18.6.1792. AULARD, Société des Jacobins, Bd. 4, S. 20.

${ }^{137}$ Rundschreiben an die angeschlossenen Gesellschaften, 21.6.1792, abgedr. in: AULARD, Société des Jacobins, Bd. 4, S. 33-35. 
dersetzungen fand dann in den Fédérés ihren deutlichsten Ausdruck, deren Sendung nach Paris von den Führern der zukünftigen Gironde im Zusammenhang mit den Vorbereitungen zum Föderationsfest am 14. Juli auch gegen das königliche Veto organisiert wurde und die sich selbst dann an erster Stelle gegen den der Komplizenschaft mit dem äußeren Feind verdächtigen König wandten. Hinzu trat, zum zweiten, die Erklärung der Nationalversammlung, "que la patrie est en danger«, die als Außerkraftsetzung der Verfassung interpretiert wurde und so die Verteidigung des Vaterlandes in die Hände des souveränen, selbstbestimmten Volkes zu legen schien. Sie war zugleich so allgemein gehalten, daß sowohl die äußere als auch die innere Bedrohung angesprochen waren, $\mathrm{ja}$ beides zu einem allgemeinen Bedrohungsszenarium verbunden werden konnte, in dem Krieg und Revolution zu einem allgemeinen, radikalisierten Kampf gegen den inneren und äußeren Feind miteinander zu verschwimmen begannen. "La patrie est en danger", so rückten die Révolutions de Paris Landesverteidigung und Revolution in einen engen revolutionären Zusammenhang, "ce cri s'est fait entendre dans les 83 départements, \& les patriotes n'ont pas attendu le décret $\&$ la sanction pour se lever. Ils arrivent, tous en armes (...) Le vœu des 83 départements est manifesté; \& lorsque 200 mille fédérés entoureront le corps législatif, ce sera à lui qu'il appartiendra de décréter les grandes mesures qui peuvent seules opérer le salut de la patrie. Nous en sommes au point de ne pouvoir plus nous dissimuler qu'une seconde révolution est devenue indispensable, une révolution toute entière $\ll^{138}$.

Als der Jakobiner Delaunay Ende Juni 1792 erstmals in der Nationalversammlung die Forderung aufstellte, man solle das Vaterland in Gefahr erklären, ging die Identifikation von Krieg und Revolution bereits noch weiter. "La révolution n'est pas faite«, stellte Delaunay fest, um dann den Antrag zu stellen, "que l'assemblée nationale déclare que, jusqu'à ce qu'elle ait jugé que l'empire est en état de paix, et que la révolution est définitivement close et terminée, les représentants de la nation, dans les mesures de surveillance ou de répression à déterminer contre les conspirateurs, les perturbateurs et tous les ennemis de la liberté, ne consulteront que l'imminence du danger public et la loi suprême du salut du peuple ${ }^{139}{ }^{19}$. Und angesichts der als "déclaration de la guerre« gewerteten Abreise von La Fayette griff Louvet Anfang Juli diese Forderung auf: "Vous déclarez dès le troisième jour", so schlug er vor, "que l'état est en péril; et par cette mesure préliminaire, vous vous préparez aux mesures plus fortes, que le salut du peuple exige impérieusement«. Ein paar Tage später stellte Louvet in einem Rückblick auf die vorangegangenen Bedrohungen noch einmal den Zusammenhang zwischen den äußeren Gefahren

${ }^{138}$ Révolutions de Paris, 30.6.-7.7.1792, Bd. 13, S. 3, 29.

${ }^{139}$ AP 45, S. 711f., 30.6.1792. 
und der Notwendigkeit revolutionärer Massenmobilisierung her: "La patrie était en danger. Un général était venu dicter des lois aux Représentants de la Nation; un ministère perfide faisait rétrogarder nos armées et cherchait à souffler le feu de la guerre civile; un roi, tant de fois parjure, paralysait de son veto des décrets nécessaires, il renvoyait des ministres dont le crime était de vouloir faire marcher la constitution; il s'environnait d'hommes vendus à la coalition qui tendent évidemment à l'altérer (...) Le peuple s'éveille, il s'inquiète; il se place dans une attitude fière, il accourt des différentes parties de l'empire, il s'adresse à ces Représentants, il leur parle de ses périls, les avertit de son courage. Ceux-ci étaient prêts de le séconder; déjà, ils avaient assuré la sainte Fédération, et la cour alarmée avait bien voulu oublier le veto dont l'usage aurait achevé de la perdre; ils allaient déclarer les dangers de la patrie. La Nation n'attendait que ce cri terrible pour se lever toute entière ${ }^{140}$.

Die erste, konzeptionell auf den erfolgreichen Kampf gegen die militärische Bedrohung abzielende Konsequenz dieser Vorstellung war die revolutionäre Wendung gegen den König als Personifizierung des mit den Kriegsgegnern im Bunde stehenden sinneren Feindesı, wie sie im Juli 1792 die revolutionäre Öffentlichkeit beherrschte. "Tous les maux qu'on s'efforce d'accumuler sur nos têtes, tous ceux que nous avons à redouter, c'est le nom seul du roi qui en est le prétexte ou la cause «, analysierte Vergniaud in der Nationalversammlung ${ }^{141}$. Dieses Deutungsmuster fand seinen klarsten politischen Ausdruck schließlich am 9. Juli, kurz nach dem Kriegseintritt Preußens, als Brissot vor der Nationalversammlung nun offiziell den Antrag stellte, das Vaterland in Gefahr zu erklären; die Begründung wies eindeutig den Weg zum revolutionären Sturz der Monarchie: "La patrie est en danger: non pas qu'elle puisse manquer de troupes, non pas que ses troupes soient peu courageuses, les frontières peu fortifiées ses ressources peu abondantes: non; elle est en danger parce qu'on a paralysé ses forces. Et qui les paralyse? Un seul homme; celui-là même que la constitution appelle son chef, et que des conseillers perfides faisaient son ennemi. On vous dit de craindre les rois de Hongrie et de Prusse; et moi je vous dis que la force principale de ces rois est la cour, et que c'est là qu'il faut les vaincre d'abord. (...) Je vais prouver que tous nos dangers, intérieurs et extérieurs tiennent à ce point de conspiration du pouvoir exécutif; enfin je prouverai que les dangers disparaîtront en frappant sur les auteurs, instruments et complices de ce plan de conspiration (142. $^{14}$.

Dementsprechend erkannte Carra in seinem Aufruf an die Fédérés wenig später: »Louis XVI n'est plus aujourd'hui qu'un autrichien, c'est-à-dire le plus cruel de nos ennemis«, und deshalb sei es die wichtigste Aufgabe der bewaff-

${ }^{140}$ La Sentinelle, 8.7.1792.

141 AP 46, S. 78-83, 3.7.1792.

${ }^{142}$ AP 46, S. 261-273, hier S. 264, 9.7.1972; vgl. auch diverse andere Redebeiträge vom selben Tag. 
neten Vertreter der Nation zu fordern, "que l'Assemblée nationale se hâte de suspendre de ses fonctions ce chef indigne du pouvoir exécutif, en attendant qu'il soit destitué dans les formes; car la patrie est dans le plus pressant danger, et il n'y a plus que ce moyen de la sauver. Suspendons le tyran!!! ${ }^{143}$. Louvet sah das Vaterland der Freiheit in seinem Weckruf an die Nation bedroht "par la guerre étrangère que la majorité de votre noblesse veut susciter«, »par la guerre civile que la minorité de votre noblesse veut allumer«, und schließlich, beides zusammenfügend, "par une cour perfide qui favorise également vos ennemis du dehors et vos ennemis de l'intérieur«. Daraus folgte die Aufforderung an die Nationalversammlung: "Si l'assemblée nationale le veut, le remède à nos dangers est dans la constitution. C'est-là qu'il est écrit, le décret d'accusation contre un général à ce que des pères ne verront plus leurs enfants, pour qu'il les trompe ou qu'il les sacrifie. C'est-là qu'elle est prononcée, la déchéance d'un roi qui ne se serait pas opposé à l'invasion du territoire français par des troupes étrangères. Mais s'il était possible que la majorité des représentants du peuple continuât plus long-temps à ne lire dans l'acte constitutionnel que les articles favorables aux intentions de quiconque veut le détruire, alors, Français, il n'y auront plus de salut pour vous que dans une convention nationale $\ll^{144}$.

Während Brissot und seine Anhänger diese Wendung gegen den König zugleich mit dem Aufruf verbanden, die innere Ordnung zu bewahren, und den sich entwickelnden Basisdruck immer auch zu nutzen versuchten, um wieder in die von den Feuillants schon am 10. Juli erneut geräumten Regierungsämter zu gelangen, zielte der Pariser Radikalismus nun nicht nur direkt auf den Sturz der Monarchie, sondern auch auf eine weit darüber hinausweisende, umfassende Revolutionierung von Politik und Gesellschaft, der nicht nur die Legislative zum Opfer fallen sollte, sondern die schließlich auch explizit terroristische Züge gewann. So forderte der sich radikalisierende Père Duchesne, das Vaterland solle in Gefahr erklärt werden, „pour exterminer tous les traitres et les aristocrates«; es sei notwendig, »que la nation toute entière se réveille; il faut que tous les citoyens soient unis, que tous les traîtres soient exterminés, si vous voulez sauver la constitution et la liberté. (...) tout est foutu, si nous ne montrons pas les dents aux ennemis du dedans et du dehors. La nation entière se lève! Législateurs, dites un mot, et nous allons purger la France de tous les

${ }^{143} \mathrm{~J}$. L. Carra à ses frères et amis les fédérés des quatre-vingt-trois départements: Salut!, 13.7.1792, abgedr. in: Annales Patriotiques, 14.7.1792.

${ }^{144}$ La Sentinelle, 23.7.1792; das vorhergehende Zitat am 15.7.1792. Inhaltlich bezog sich Louvet, wie vor ihm bereits Vergniaud, auf Kapitel II, erste Sektion, Art. 6 der Verfassung: "Si le roi se met à la tête d'une armée et en dirige les forces contre la nation, ou s'il ne s'oppose pas par un acte formel à une telle entreprise qui s'exécuterait en son nom, il sera censé avoir abdiqué la royauté». 
excréments du despotisme et de l'aristocratie «145. Und die Révolutions de Paris jubelten einige Tage später, nachdem die Erklärung verabschiedet war: »La patrie est en danger, \& les députés extraordinaires de tous les départements sont à Paris; la patrie est en danger, le peuple est en insurrection. Quel beau moment! Que sommes-nous? un peuple en révolution, un peuple en guerre pour la révolution. Quel est le germe de cette guerre? C'est la guerre de tous les amis de la liberté contre tous les ennemis de la liberté « ${ }^{146}$.

Den Köpfen der späteren Bergpartei fiel es allerdings schwer, sich in diese Bewegung zu integrieren. Der $A m i d u$ peuple, der schon lange offen für den Sturz der Monarchie agitiert hatte, verzweifelte im Juli 1792 an den revolutionären Qualitäten des französischen Volkes und stellte seine Zeitung zeitweilig $e{ }^{147}$, und auch dem Défenseur de la Constitution gelang es erst im letzten Moment, seinen bis dahin streng verfassungstreuen Standpunkt aufzugeben und sich an die Spitze der revolutionären Bewegung zu stellen. Robespierre und Marat hatten das "camp des fédérés « lange vehement abgelehnt weil sie befürchteten, die bewaffneten Vertreter der Départements sollten dazu dienen, den Pariser Radikalismus zu bekämpfen ${ }^{148}$. Und noch am 9. Juli agitierte Robespierre im Jakobinerklub gegen die nun doch zweifellos auf eine revolutionäre Erhebung abzielende Initiative, das Vaterland in Gefahr zu erklären. "Nous avons deux guerres à soutenir; l'une intérieure, l'autre extérieure. L'une et l'autre peuvent, suivant moi, être terminées en peu de temps et sans effusion de sang«, argumentierte er im Jakobinerklub: "Pourquoi voulez-vous que le peuple se lève, quand, d'un mot, vous pouvez faire cesser les dangers de la patrie en terrassant celui qui est la cause de ces dangers«. Anstelle der geforderten "mesures extraordinaires" sei es nur notwendig, so meinte Robespierre, einen Wechsel in der Armeeführung herbeizuführen: „Frappez un général perfide; nommez un patriote; entrez dans le Brabant, et la guerre extérieure est finie (149. $^{149}$.

Von dieser durchaus naiv anmutendenden Position rückte Robespierre erst ab, als die Erklärung in der Nationalversammlung verabschiedet worden war und zugleich die ersten in Paris eintreffenden Fédérés deutlich werden ließen,

\footnotetext{
145 Père Duchesne, Nr. 153.

${ }^{146}$ Révolutions de Paris, 7.-14.7.1792, Bd. 13, S. 59. Damit verbunden war auch die Vorstellung, daß »le corps législatif, après avoir déclaré que la patrie est en danger, n'a plus le droit d'interpréter cette déclaration«.

${ }^{147} \mathrm{Vgl}$. Ami du Peuple, 22.7.1792.

148 Ami du Peuple, 15.6.1792: "... ce camp, m'en doutez point, est destitué à seconder les opérations contre-révolutionnaires de la capitale, puis celles des armées nationales ou étrangères, appelées à rétablir le despotisme». Ähnlich Défenseur de la Constitution, Nr. 5 , S. 137-144: Sur le projet de rassembler une armée de vingt-trois mille hommes à Paris.

149 Aulard, Société des Jacobins, Bd. 4, S. 85, 9.7.1792; das folgende ebd., S. 90, 11.7.1792.
} 
daß es sich hier keineswegs um Instrumente der Konterrevolution, sondern um radikale Revolutionäre handelte. "Lorsque l'Assemblée nationale a prononcé cette formule, elle a voulu dire: En vain nous faisons de bonnes lois, si le le pouvoir exécutif ne les fait pas exécuter, s'il les entrave par des veto perfides, si des administrateurs corrompus conspirent avec la cour pour tuer la constitution par la constitution«, über diese argumentative Brücke gelang es Robespierre, auf den revolutionären Zug aufzuspringen und sich dann mit einer Adresse an die Fédérés geschickt auch gleich an seine Spitze zu stellen. "Vous n'êtes point venus pour donner un vain spectacle à la capitale et à la France; votre mission est de sauver l'état«, so wies er ihnen ähnlich wie Marat ihre revolutionäre Aufgabe im Kampf gegen den inneren Feind zu, den er wiederum ganz kriegsbezogen bestimmte: »Les tyrans de la France ont feint de déclarer la guerre à leurs complices et à leurs alliés, pour la faire de concert au peuple français; et les traîtres demeurent impunis! « ${ }^{150}$.

Diese Anstöße fielen bei den Fédérés auf fruchtbaren Boden, und schon einen Tag später gaben auf einer außerordentlichen Sitzung des Jakobinerklubs ihre Vertreter die revolutionäre Parole aus: "Aucun de nous n'ira sur les frontières, si le roi n'est pas suspendu, si l'Assemblée nationale ne met pas en activité le pouvoir exécutif national $\aleph^{151}$. Damit folgten sie den Vorgaben eines in Kooperation mit den Jakobinern gebildeten Zentralkomitees, dessen erste Aufgabe darin bestand, die immer zahlreicher nach Paris strömenden Fédérés davon abzuhalten, gemäß einem angesichts der Unaufhaltsamkeit der Bewegung erlassenen Dekret der Regierung unmittelbar nach dem 14. Juli die Hauptstadt wieder zu verlassen und sich in einem Heerlager bei Soissons zu sammeln. Unter dem Einfluß von Anthoine, Danton und vor allem von Robespierre, dem es nun gelang, »le professeur de politique et le porte-parole des fédérés « zu werden ${ }^{152}$, entstand dann am 13. Juli die erste, vier Tage später eingebrachte Petition der Fédérés an die Nationalversammlung, in der die Abgeordneten unter Berufung auf die Erklärung, daß das Vaterland in Gefahr sei, aufgefordert wurden, gegen den Verrat durch den sinneren Feind vorzugehen, ohne den die äußere Bedrohung gar nicht existieren würde, und den König, in dessen Namen die ausländischen Mächte den Krieg führten, zu suspendieren: "Vous nous avez déclarez que la patrie est en danger (...) nous savons, nous sentons que sans la trahison de nos ennemis intérieurs les autres ne seraient point à craindre, ou plutôt nous savons qu'ils n'existeraient pas. (...) Qu'elle est, en effet, la cause de tous nos dangers, si ce n'est la perfidie de la cour et

${ }^{150}$ Défenseur de la Constitution, Nr. 9, S. 255-260: Aux Fédérés, hier S. 257-259. Vgl. auch "Conseil de l'Ami du Peuple aux Fédérés des Départements" und "Lettre de l'Ami du Peuple aux Fédérés«, in: Ami du Peuple, 18.7. bzw. 20.7.1792.

I51 AULARD, Société des Jacobins, Bd. 4, S. 94f., 12.7.1792.

${ }^{152}$ BRAESCH, La Commune du dix août 1792, S. 141. 
de ses agents et de tous les fonctionnaires publics qu'elle a corrompus. (...) On nous parle de faire la guerre à l'Autriche, et l'Autriche est dans nos camps et dans le conseil du roi, et l'Autriche est à la tête de nos armées. (Vifs applaudissement à gauche et acclamations réitérés des tribunes) (...) Pères de la patrie, suspendez provisoirement le pouvoir exécutif dans la personne du roi. Le salut de l'état l'exige, et vous commande cette mesure. Mettez en état d'accusation la Fayette, la constitution et le salut public vous l'ordonne. Décrétez le licenciement des état-majors, des fonctionnaires militaires nommés par le roi ${ }^{133}$.

Während sich hier schon die von Robespierre und den radikalen Kräften der Volksbewegung angestrebte, weit über den Sturz des Königs hinausweisende, allgemeine Revolutionierung andeutete, richteten sich die Fédérés wenige Tage später in einer wiederum von Robespierre redigierten Adresse an die Franzosen nun noch eindeutiger gegen den König als inneren Hauptfeind, den es an erster Stelle zu bekämpfen und vor allem nun nicht mehr nur, wie im Juni 1791, zu suspendieren, sondern auf revolutionärem Wege abzusetzen gelte: "... voilà les ennemis de la patrie et c'est à Paris qu'il faut les combattre. C'est à Paris, que le conseil secret du roi commande les armées autrichiennes, prépare l'invasion de notre territoire, et les horreurs de la guerre étrangère et civile (...) C'est à Paris que nous devons vaincre ou mourir, et nous avons juré d'y rester«. Und da die Nationalversammlung nicht aktiv geworden sei, müsse sich nun das Volk erheben. "... nous avons vaincu, si nos frères de tous le départements se lèvent tous ensemble, s'ils jurent, comme nous, d'anéantir jusqu'au dernier vestige l'aristocratie, et de ne plus souffrir, à la tête des armées, de la législation et du gouvernement, ceux contre lesquels nous avons fait la révolution « ${ }^{154}$.

In den Pariser Sektionen entwickelte sich zu diesem Zeitpunkt mit der Permanenzerklärung und der Aufhebung der Unterscheidung zwischen Aktivbürgern und Passivbürgern (am 25. bzw. 30.7. von der Nationalversammlung autorisiert) längst eine umfassende revolutionäre Massenbewegung. "Suspendrat-on le roi? destituera-t-on le roi? Telles sont les questions qui occupent

${ }^{153}$ Pétition des Fédérés à l'assemblée nationale, abgedr. in: AP 46, S. 560f., 17.7.1792.

${ }^{154}$ Les Citoyens réunis à Paris au mois de juillet 1792. Aux Français des quatre-vingt-trois départements, abgedr. In : Défenseur de la Constitution, Nr. 10, S. 307-309; Vgl. auch die zweite Adresse vom 23.7. an die Nationalversammlung, in der ebenfalls ihre Untätigkeit beklagt und nunmehr die vorläufige Suspendierung des Königs, verbunden mit dem längerfristigen Ziel der Absetzung gefordert wurde: „Nous vous disons que la source de nos maux est dans l'abus qu'a fait de son autorité le chef du pouvoir exécutif; nous vous disons qu'elle est encore dans les états-majors de l'armée, dans une grande partie des directoires des départements et des districts, et dans les tribunaux. Nous vous disons enfin ... qu'elle existe en partie dans votre sein. ... Suspendez le pouvoir exécutif, comme il le fut l'année dernière (nach der Flucht des Königs, WK); par là vous couperez la racine de tous nos maux «. AP 47, S. 69f., 23.7.1792. 
maintenant tous les français, telle est la matière que tous les partis mettent à l'ordre du joun, so kennzeichneten die Révolutions de Paris die Stimmung in der Hauptstadt, um dann mit der folgenden, wiederum ausgesprochen kriegsbezogenen Begründung fortzufahren: "Si la cause des émigrés est intimement liée à celle du roi; si les nobles, les prêtres et tous les rois de l'Europe font la guerre à tous les peuples de l'Europe, dans la seule personne du peuple français, le peuple français ne serait-il pas stupide, imbécile et lâche s'il allait combattre contre les rois et les nobles, sous le commandement des nobles et sous la direction d'un roi?«. Auch hier rückten dann die Fédérés in den Mittelpunkt der revolutionären Perspektive, sie wurden aufgefordert: „Fédérés! que cette grande vérité pénètre dans tous vos pores; ne quittez donc Paris qu'après vous serez sûrs de l'anéantissement de tous les partis politiques ennemis du peuple, \& de la dispersion des intrigues traîtresses dont le palais des Tuileries est le foyer principal « ${ }^{155}$.

Die Erklärung »la patrie est en danger« und die Ankunft der Fédérés in Paris gaben der Pariser Politik nicht nur durch den davon ausgelösten, auch in der Forschung immer immer wieder betonten "enthousiasme patriotique « einen neuen, revolutionierend wirkenden Charakter ${ }^{156}$. Von mindestens ebenso großer Bedeutung für den Sturz der Monarchie wie für die schnell darüber hinaustreibende Radikalisierung war die damit verbundene, aus der kriegerischen Massenmobilisierung hervorgehende, durch die Angst vor dem "despotisme militaire « bestärkte und im Pathos der "levée en masse « vorgezeichnete revolutionäre Form der politischen Militarisierung im Innern. Nachdem "la patrie en danger" erklärt worden war, in der Folge die Aushebung neuer Freiwilligenregimenter allein in Paris binnen weniger Tage Tausende unter Waffen stellte, die soldatisch ausgerüsteten Fédérés zu großen Teilen auch nach dem 14. Juli in der Stadt blieben und in den folgenden Tagen und Wochen noch weitere Fédérés einrückten, verwandelte sich Paris tatsächlich zunehmend in eine Art Heerlager. Diese Entwicklung spiegelte sich im politischen Diskurs und wurde zugleich durch ihn geformt. Das Föderationsfest am 14. Juli, durchgeführt »au son d'une musique guerrière, et au bruit de l'artillerie«, erschien nun als betont kämpferisch, aber keineswegs im traditionellen Sinne militärisch inszenierte, eben revolutionäre »union de tous les citoyens; les piques mêlés aux fusils, et les uniformes aux habits grossiers des laboureurs et des artisans ${ }^{157}$. Als die äußere Bedrohung immer näher rückte, nahm auch die Beschwörung des inneren Heerlagers an Schärfe

${ }^{155}$ Révolutions de Paris, 21.-27. 7. 1792, Bd. 13, S. 142, 148.

${ }^{156}$ Vgl. u. a. BRAESCH, La commune du dix août 1792, S. 105; Vovelle, La Chute de la monarchie, S. 159; FURET, RICHET, La Révolution Française, Bd. 1, S. 199.

${ }^{157}$ Patriote Français, 17.7.1792; Défenseur de la Constitution, Nr. 10, S. 294-300, hier S. 295. 
zu, zumal nachdem die Nationalversammlung am 30. Juli den zuvor schon begonnenen Eintritt von Passivbürgern in die Nationalgarde legalisiert hatte. Die Einrichtung von "camps des fédérés « solle, so griff Réal im Jakobinerklub eine zuvor schon von Lasource und Carra vertretene Forderung auf, auf ganz Frankreich ausgedehnt werden: »Quand la patrie est en danger tous les citoyens doivent être sous les armes; quand nos frères sont en présence de l'ennemi (...) devons nous reposer un moment dans nos maisons? Que toute la France ne soit qu'un camp, que tous les Français soient sous la toile; que chaque citoyen ait sa pique ou son fusil, que chaque famille ait sa tente ${ }^{138}$. Und unmittelbar vor dem Sturm auf die Tuilerien forderte La Sentinelle die Pariser Bevölkerung alarmiert auf: "Prépare tes armes, faits des retranchements, apprends les évolutions militaires, forge, forge des piques! et des piques encore! et toyons des piques! couvre-toi de fer « $^{\text {s9 }}$.

Die "piques« waren längst zu einem Symbol der allgemeinen Volksbewaffnung geworden, und ihre 'Stoßrichtungs war ohne Zweifel mindestens ebenso sehr gegen den inneren wie gegen den äußeren Feind gerichtet. Vor allem in der Agitation der radikaleren Kräfte gewann die kriegerische Massenmobilisierung angesichts der Identifikation von äußerem und innerem Feind und der Vorbereitungen des Hofes auf eine bewaffnete Auseinandersetzung schnell einen primär nach innen gerichteten Charakter: ")... déployer la loi martiale du peuple souverain contre la rebellion du pouvoir exécutif $«$, forderte Carra in den Annales Patriotiques vom 3. August, denn das sei "le seul moyen de rompre le talisman fatal des conspirations du dedans et des coalitions du dehors $\aleph^{160}$. Und Billaud-Varenne erhob im Jakobinerklub am selben Tag die Forderung, auf den Champs Elysées ein Heerlager einzurichten, dessen Patrouillen die Pariser Bevölkerung überwachen sollten: wun camp sera une sauve garde permanente contre toute surprise nocturne. Un camp protégera les opérations de l'assemblée nationale contre la malveillance de la cour. Un camp donnera la force qui parôit manquer au corps législatif, et pour prononcer la déchéance et pour appeler la convention nationale, et enfin pour frapper du glaive de la loi le scélérat la Fayette«. Zwar sah Billaud darin selbst eine problematische Maßnahme, die den "esprit militaire qui nous a déjà fait tant de mal« propagiere, doch sei dies, ganz kriegsbezogen, ein "malheur qui tient aux circonstances. Enthourés, pressés de toutes parts par les phalanges des potentats de l'Europe, si vous ne devenez une nation de héros (...), la servitude vous attend, la mort vous menace, et après avoir goûté les

\footnotetext{
${ }^{158}$ Rede vom 6.8.1792, zit. n. Journal des débats, 8.8.1792.

159 La Sentinelle, 8.8.1792.

160 Annales Patriotiques, 3.8.1792.
} 
jouissances de la liberté, il ne restera plus aux survivants que le désespoir de l'avoir perdue sans retour ${ }^{161}$.

Schließlich kam es nicht zur Einrichtung eines solchen Heerlagers, de facto jedoch entwickelten sich die Pariser Sektionen selbst zu bewaffneten Versammlungen, in denen die militärische Auseinandersetzung mit den um den Hof zusammengezogenen Schweizergarden vorbereitet wurde. Es war schließlich die immer näherrückende Invasionsdrohung, verbunden mit der Unterstützung für den König und den Drohungen des preußischen Oberkommandieren gegen die Pariser Bevölkerung, die den letzten Anstoß zum Aufstand gab. Als das Manifest des Herzogs von Braunschweig in den ersten Augusttagen in Paris bekannt wurde, faßte die Pariser Stadtverwaltung angesichts der so massiven wie realen Drohungen eines machtvollen, im Auftrag von zwei Großmächten agierenden Heerführers, der seine Ziele darüber hinaus noch im Einklang mit »ceux de nos généraux, de nos ministres et des contre-révolutionnaires de l'intérieur" verfolge, den Beschluß, von der Nationalversammlung die von Marat seit langem geforderte Geiselnahme des Königs und seiner Familie zu verlangen und alle Maßnahmen zur Verhinderung einer erneuten Flucht zu ergreifen ${ }^{162}$.

Nachdem mit der kriegsbezogenen Wendung gegen den Hof als Exponent des inneren Feindes, der bewaffneten Massenmobilisierung und ihrer institutionellen Verankerung in den Sektionen sowie der Bildung eines Aufstandskomitees in der Pariser Kommune die wesentlichen Voraussetzungen für eine zweite Revolution geschaffen waren, ist die weitere Entwicklung schnell zusammengefaßt. Am 31. Juli erkennt die Sektion Mauconseil in ihrer berühmten Beschlußfassung die Autorität des Königs nicht mehr an, auf ihre Initiative wird am 3. August namens 47 der 48 Sektionen der Pariser Kommune von Bürgermeister Pétion in der Nationalversammlung die Absetzung eines Königs (und auch der ganzen Dynastie) gefordert, in dessen Namen feindliche Armeen französisches Territorium bedrohen: "... pour guérir les maux de la France, il faut les attaquer dans leur source, et ne pas perdre un moment. C'est avec douleur qu'elle vous dénonce, par notre organe, le chef du pouvoir exécutif«. Einen Tag später kündigt die Sektion Quinze-Vingts für den 10. August einen Aufstand an, wenn die Nationalversammlung den König bis dahin nicht abgesetzt habe. Hier wird deutlich, daß der Sturz der Monarchie von langer Hand vorbereitet war, auch wenn die leitenden Akteure bis heute weitgehend im Dunkel geblieben sind. Vor allem aber tritt immer wieder hervor, wie sehr die kriegsbezogene Gleichsetzung von innerem und äußerem Feind, von Krieg und Revolution die Radikalisienung vorantrieb. "La patrie est en danger: ces mots terribles signifient nous sommes trahis«, so lautete, als ob

161 Rede vom 3.8., zit. n. Journal des débats, 21.8.1792.

${ }^{162} \mathrm{Vgl}$. die Wiedergabe im Jakobinerklub am 5.8.1792, AULARD, Société des Jacobins, Bd. 4, S.180f. 
nur der innere Verrat überhaupt eine äußere Bedrohung der Revolution möglich machen könne, der Ausgangspunkt eines Manifestes, in dem Delegierte der Pariser Volksbewegung am 6. August von der Nationalversammlung die Absetzung des Königs forderten. Die revolutionäre Schlußfolgerung daraus lautete: »La patrie est en danger, nous rentrons en révolution ${ }^{163}$.

Trotz mancher die radikalen Kräfte verstörenden Taktiererei und der Orientierung auf den verfassungsgemäßen, angesichts des Vertrauensvotums der Legislative für La Fayette wenig erfolgversprechenden Weg zur Absetzung des Königs über Anklageerhebung, Suspendierung und Gerichtsverfahren bewegten sich auch die Brissotins auf diesem Kurs: "La déchéance où la suspension du roi: telles sont les mesures généralement réclamées«, stellte der Patriote Français fest, denn schließlich sehe man den Hof »comme un foyer de contre-révolution; le château des Tuileries (...) comme un autre Coblentz ${ }^{164}$. Die Annales Patriotiques von Carra forderten offen die Absetzung des Königs, denn »la guerre étrangère finira bientôt, et toutes les craintes d'une guerre civile seront dissipées, parce que les germes combinés de l'une et de l'autre seront entièrement détruits par-là « ${ }^{165}$. In der Nationalversammlung trat Gensonné am 6. August für die Suspendierung des Königs ein, während Brissot darauf setzte, daß der König nach einer Untersuchung seines Verhaltens durch einen Kommission der Legislative abgesetzt werden könne. Dementsprechend votierte Condorcet als Berichterstatter des Konvents am 9. August für die Einsetzung einer Untersuchungskommission, und am folgenden Tag verabschiedete die Versammlung auf seinen Vorschlag hin die Suspendierung eines Königs, der die Schuld für Krieg und Bürgerkrieg trage ${ }^{166}$. Brissot begrüßte im Patriote Français den Sturz des Königs, auf den seine Kriegspolitik von Anfang an abgezielt hatte, schließlich voller Zustimmung: „Le vœu de la France était remplie. Un roi, chef de toutes les conjurations dont nous avons été jusqu'ici les victimes, était suspendu; une cour conspiratrice était dispersée; une convention nationale, objet des désirs de tous ceux qui ont sondé les profondes plaies du corps social, était convoquée; le pouvoir exécutif était confié à des mains pures et habiles; des commissaires avaient été nommés pour attacher à une seconde, à une inévitable, à une plus complette révolution, nos armées dont le patriotisme avait assuré le sort de la première « ${ }^{167}$.

Die hier erneut hervortretende Unsicherheit über die Stellung des Militärs rückte tatsächlich schnell wieder in den Mittelpunkt der Debatten und Aktivi-

\footnotetext{
${ }^{163}$ AP 47, S. 525f.

164 Patriote Français, 7.8.1792, 11.8.1792.

${ }^{165}$ Annales Patriotiques, 4.8.1792.

$106 \mathrm{Vgl}$. L. WhaleY, Political Factions and the Second Revolution, in: French History, 7. Jg. 1993, S. 133-157; zu Condorcet L. CAHEN, Condorcet et la Révolution Française, New York 1971 (Orig 1904), S. $380-422$.

${ }^{167}$ Patriote Français, 12.8.1792.
} 
täten. Die Nationalversammlung entsandt auf der Stelle Kommissare zu den Armeen, um ihre Loyalität zu sichern, und der Konflikt zwischen Revolution und Militärführung schien seinem Höhepunkt entgegenzusteuern, als La Fayette, längst zu einer »figure du discours jacobin « verkommen ${ }^{168}$, die zu seiner Moselarmee geschickten Kommissare der Nationalversammlung verhaften ließ und seinen Marsch auf Paris beginnen wollte, der schließlich an der Weigerung der »soldats citoyens« scheiterte.

Obwohl die revolutionären Kräfte in der Abwehr der militärischen Reaktion grundsätzlich einig waren, verschärften sich schon unmittelbar nach dem 10. August die Konflikte zwischen den gemäßigten, überwiegend die Übergangsregierung bildenden, nun auf die Konsolidierung der Revolution hinwirkenden Kräften um Brissot einerseits, der neuen Pariser Kommune als Zentrum der revolutionären Volksbewegung andererseits. Angesichts der sich weiter verschärfenden äußeren Bedrohung blieb die militärische Massenmobilisierung jedoch erst einmal im Mittelpunkt der revolutionären Propaganda, und damit war wiederum wie selbstverständlich auch eine weitere Militarisierung der innenpolitischen Konflikte verbunden. "Peuple de Paris« so forderte La Sentinelle angesichts der Bedrohungen durch die feindliche Invasion ebenso wie durch französische Generäle zur allgemeinen Mobilmachung auf, whâte toi de devenir un peuple guerrier. Prépare tes armes, forge des piques, des piques de douze pieds, demande à grands cris de la poudre et des boulets, élève des retranchements, et dans un camp tous les jours rempli exerce aux évolutions militaires tes généreuses légions«. Wenn es an Gewehren fehle, stellte Louvet fest, dann müsse die Nationalversammlung anordnen, «qu'on prenne ceux des gens suspects qu'il est instant de désarmer ${ }^{169}$. Auch Marat blies in dieses Horn, verschärfte aber die innenpolitische Stoßrichtung, als er die Öffnung aller Waffenarsenale und, erneut, die Einrichtung eines Heerlagers forderte, um sich militärisch auf den befürchteten Gegenschlag des inneren Feindes vorzubereiten: "C'est à la commune à faire armer immédiatement tous les bons citoyens de la capitale, et à les faire exercer au maniement des armes, pour mettre Paris en état de défense contre les coups de désespoir des ennemis $\aleph^{170}$.

Als die militärische Bedrohung trotz des Sturzes der Monarchie immer näher rückte, führte die damit einhergehende Radikalisierung der revolutionären Bewegung nach der Logik der diskursiven Verbindung von äußerer und innerer Bedrohung unmittelbar zu Maßnahmen gegen die sinneren Feinde،. "La victoire des Tuileries, la destitution de quelques généraux, la stupeur des

${ }^{168}$ P. GUINIFFEY, La Fayette, in: FURET, Ozouf, Dictionnaire critique, S. 258-267, hier S. 266.

${ }^{169}$ La Sentinelle, 12.8.1792.

${ }^{170}$ Ami du Peuple, 16.8.1792. 
conjurés, tout semblait annoncer un avenir riant, tout présageait la fin prochaine de la guerre«, so brachten die Révolutions de Paris die naive, nach dem 10. August aber angesichts der vorhergehenden Konzentration auf den inneren Feind dominierende Vorstellung zum Ausdruck, daß mit dem Sieg über die »autrichiens du dedans« nun auch die militärische Bedrohung quasi überwunden sei, um dann umso alarmierter festzustellen, daß der Fall von Longwy am 27. August nun auch »le courage abattu des vils partisans de la royauté« wieder bestärkt habe ${ }^{171}$. "L'ennemi est sur notre terrain; déjà il s'est rendu maitre par trahison de plusieurs villes de guerre«, so stellte der Père Duchesne erneut die Verbindung zwischen äußerer Bedrohung und innerem Verrat her ${ }^{172}$.

Die revolutionäre Militarisierung strebte nun einem neuen Höhepunkt zu, und sie richtete sich weiterhin ebenso nach außen wie nach innen. "Prépare tes armes, exerce-toi dans les camps, élève des remparts, couvre-toi de fer", rief Louvet am 29. August das französische Volk auf ${ }^{73}$. Bereits einen Tag vorher war die Pariser Kommune auf Antrag von Justizminister Danton ermächtigt worden, für die Massenerhebung gegen die Feinde des Volkes in der Stadt nach verborgenen Waffen zu fahnden. "Quand un vaisseau fait naufrage«, so hatte Danton die Wendung gegen den inneren Feind begründet, "l'équipage jette à la mer tout se qui l'exposait à périr. De même tout ce qui peut nuire à la nation, doit être rejeté de son sein et tout ce qui peut lui servir, doit être mis à la disposition des municipalités « ${ }^{174}$. Und die Révolutions de Paris propagierten dementsprechend, "qu'avant de quitter leurs foyers les habitants de chaque commune mettent en lieu de sûreté \& sous la sauvegarde de la loi tous ceux qui sont suspectés de ne pas aimer la liberté, qu'on les tienne enfermés jusqu'à la fin de la guerre, \& qu'on les garde avec des piques, c'est ainsi que se fera desormais le service de l'intérieur " $^{175}$.

In der Nacht zum 30. August kam es daraufhin zu systematischen Hausdurchsuchungen, in deren Verlauf etwa 3.000 Verdächtige zeitweilig festgenommen wurden, von denen mehr als 1.000 in Haft blieben. "Die Hauptstadt glitt in einen Ausnahmezustand", urteilt Walter Markov treffend ${ }^{176}$. Und diese Entwicklung gewann noch eine deutliche Beschleunigung, als kurze Zeit später die Meldung von der Belagerung, schließlich vom Fall der Grenzfeste Verdun in Paris umlief. Nun schien die Invasion unmittelbar bevorzustehen, der Weg nach Paris schien frei. „Aux armes! aux armes! L'insolent étranger

${ }^{171}$ Révolutions de Paris, 25.8.-1.9.1792, Bd. 13, S. 377.

172 Père Duchesne, Nr. 168.

${ }^{173}$ La Sentinelle, 29.8.1792.

174 AP 49, S. 78, 28.8.1792.

${ }^{173}$ Révolutions de Paris, 164, 25.8.-1.9.1792, Bd. 13, S. $381 \mathrm{f}$

${ }^{176}$ W. MARKOV, Die Revolution im Zeugenstand. Frankreich 1789-1799, Bd. 1, Leipzig 1982, S. 243. 
ravage nos frontières, l'insolent étranger s'avance dans l'intérieure «"7, proklamierte $\mathrm{La}$ Sentinelle, und Danton nahm in seiner wohl berühmtesten Rede am 2. September das Pathos der »levée en masse« von 1793 ebenso wie die damit verbundene terroristische Wendung gegen den inneren Feind vorweg, als er an die Kühnheit der Nationalversammlung appellierte: "Une partie du peuple va se porter aux frontières; une autre va creuser des retranchements, et la troisième, avec des piques, défendra l'intérieur de nos villes (...) Nous demandons que vous concouriez avec nous à diriger ce mouvement sublime du peuple, en nommant des commissaires qui nous seconderont dans ces grandes mesures. Nous demandons que quiconque refusera de servir de sa personne, ou de remettre ses armes, soit puni de mort ${ }^{178}$.

Paris machte nun vollständig mobil. Die Stadt wurde unter Läuten der Sturmglocken mit Gräben und Wällen befestigt, es wurden weitere Piken geschmiedet und neue Freiwilligenregimenter ausgehoben. Diese defensiv begründete, in einer ungeheuer hektischen, von Gerüchten begleiteten Atmosphäre sich vollziehende Massenmobilmachung aber wurde zugleich zur Geburtsstunde des revolutionären Terrors, denn der von radikalen Agitatoren wie Marat und Fréron schon lange geforderte vterreur salutaire" gegen den inneren Feind wurde nun spontan in die Tat umgesetzt. "Des groupes considérables se sont formés«, so schilderte der Patriote Français die zu den Septembermassakern vom 2. September 1792 führende Entwicklung, »des hommes y ont répandu qu'en partant pour aller battre les ennemis extérieurs, il fallait se délivrer des ennemis de l'intérieur; ils ont dit, qu'il faillait tomber sur les prisons, et principalement sur l'Abbaye, qui renfermait les conspirateurs. Cette idée est répandue « ${ }^{179}$. Auch im Bericht der Révolutions de Paris wurde die hier gefeierte Volksjustiz mit dem Hinweis auf ein Komplott in den Gefängnissen begründet, das im Zusammenhang mit der äußeren Bedrohung gestanden habe und tatsächlich der gefährlichere Feind gewesen sei: »l'ennemi du nord n'est pas à nos portes; mais nous en avons un au milieu de nous dont la mine infernale doit éclater la nuit prochaine. Avant d'aller au-devant des ennemis du dehors, déjouons le complot terrible des scélérats, qui ce soir peutêtre incendieront Paris, après l'avoir mis au pillage ${ }^{180}$. Und Gorsas stellte im Courrier des Départements, Krieg und Revolution zu »la guerre ouverte contre les ennemis de notre liberté« verbindend fest: "La connaissance de ce nouvel attentat a produit le plus terrible mouvement, dont les fastes de

${ }_{178}$ AP 49, S. 209, 2.9.1792.

179 Patriote Français, 3.9.1792; zum Zusammenhang vgl. P. CARRON, Les Massacres de septembre, Paris 1935; F. BLUCHE, Septembre 1792. Logique d'un massacre, Paris 1986; zuletzt J. GUILHAUMOU, Les Massacres de septembre: agents terroristes et juges improvisés, in: DERS., L'Avènement des porte-parole de la république, Lille 1998, S. 235-248.

${ }^{180}$ Révolutions de Paris, 1.-8.9.1792, Bd. 13, S. 418. 
l'histoire puissent fournir l'exemple; \& pendant que plus de 100 mille citoyens volaient aux armes pour se porter aux frontières, 100 mille autre, ou plutôt tout Paris, s'est rendu aux prisons encombrées de brigands, avec l'intention de tout sacrifier à la sûreté publique ${ }^{181}$.

Zwar waren nach dem überraschenden Sieg der französischen Freiwilligenbataillone bei Valmy und dem Rückzug der feindlichen Invasionstruppen alle Vertreter der Revolution überzeugt, daß der Sturz der Monarchie maßgeblich dazu beigetragen hatte, die Verteidigungsanstrengungen zu optimieren und die Nation zu retten: "Sans la journée du 10, il est évident que nous étions perdus; la cour préparée depuis long-temps, attendait l'heure de combler toutes ses trahisons, de déployer sur Paris l'étendard de la mort, et d'y régner par la terreur«, stellte Brissot fest, und Marat betonte: "Le 10 août, la municipalité provisoire de la commune Parisienne à sauvé l'empire « ${ }^{182}$. Doch der Patriote Français zog daraus, ähnlich wie die anderen Vertreter der nun bald so genannten Gironde, genau die gegenteilige Konsequenz zum Ami du Peuple, der für den Fortbestand der Kommune eintrat, denn "son comité de surveillance a dès-lors assuré le salut publique: aussi est-ce contre lui, contr'elle que les contre-révolutionnaires font jouer toutes leurs perfidies pour la destituer et l'anéantir«. Brissot dagegen rückte mit seiner kriegspolitischen Begründung nun den Kampf gegen die unkontrollierten revolutionären Gewalten und die davon ausgehende Infragestellung der angestrebten revolutionären Konsolidierung in den Mittelpunkt, als er die politischen Konfliktlinien im Herbst 1792 so bestimmte: "Jamais l'unité d'action ne fut plus nécessaire. Des ennemis aguerris et nombreux se sont établis sur notre territoire, ils menacent la capitale (...) Sans doute l'énergie du peuple, bien dirigé, leur opposera des barrières insurmontables; mais c'est précisément pour cette direction qu'il faut de l'ensemble et de l'activité: l'une et l'autre sont impossibles, lorsque tout le monde commande $\aleph^{183}$.

\footnotetext{
${ }^{181}$ Courrier des Départements, 4.9.1792.

182 Ami du Peuple, 20.9.1792.

${ }^{183}$ Patriote Français, 5.9.1792.
} 


\section{Krieg und revolutionäre Politik: Der Konflikt Montagne - Gironde 1792/93}

Der Konflikt zwischen den verfeindeten jakobinischen Brüdern der Montagne und der Gironde, wie die vormaligen Brissotins wegen der Herkunft vieler ihrer Führungspersönlichkeiten nun zunehmend genannt wurden, hat in der Revolutionsforschung einen geradezu legendären Charakter gewonnen. Auch wenn Zusammenhalt und Charakter dieser beiden Gruppierungen angesichts eines noch gar nicht ausgebildeten Systems von Parteien und Fraktionen nicht präzise bestimmt werden können und die genauen Gruppenzugehörigkeiten weiterhin umstritten bleiben, handelt es sich dabei doch zweifellos nicht nur um eine Chimäre ${ }^{124}$, sondern um einen realen Konflikt im Lager des revolutionären Bürgertums, der den Verlauf der Revolution maßgeblich beeinflußt hat. Die Deutungen dieses Konfliktes sind dagegen vielfältig und widersprüchlich ausgefallen, zumal sie oft ins Zentrum der allgemeinen Revolutionsdeutungen der verschiedenen Schulen der Revolutionsgeschichtsschreibung gerückt worden sind. Faßt man sehr allgemein zusammen, so lassen sich dennoch zwei grundlegende, gegensätzliche Deutungsmuster ausmachen, die auf unterschiedliche Weise miteinander verbunden werden können, über die hier aber einen Schritt hinausgegangen werden soll.

Für die marxistisch-jakobinische Revolutionsgeschichtsschreibung handelte es sich bei dem Konflikt zwischen Gironde und Montagne wesentlich um den Ausdruck eines sozialen Klassenkonfliktes. Nach der stilbildenden Analyse von Albert Mathiez vertraten Montagne und Gironde zwei klar unterscheidbare Gruppierungen im revolutionären Bürgertum. Während die erste, cum grano salis die Interessenvertretung des besitzenden Großbürgertums, prinzipiell alle Eigentumsrechte gegen die sozialen Interessen der sich radikalisierenden Volksbewegung der Sansculotten verteidigt und deshalb mit innerer Logik zunehmend antirevolutionäre Positionen bezogen habe, sei es der eher den weniger begüterten bürgerlichen Schichten zuzurechnenden Montagne gelungen, im Gesamtinteresse der bürgerlichen Revolution ihren ideologischen Bezug auf die schichtenspezifischen Eigentumsinteressen zu lockern und die Interessen und Forderungen der klein- und unterbürgerlichen Volks-

${ }^{184}$ Vgl. die Deutung von M. J. SydenHaM, The Girondins, London 1961, der in der Gironde wesentlich ein Produkt der Propaganda in der Kritik der Bergpartei sieht. 
massen aufzunehmen ${ }^{185}$. Allerdings konnten tatsächlich bedeutende soziale Unterschiede zwischen den beiden Gruppen kaum ausgemacht werden, und der Versuch, die Infragestellung bzw. die Verteidigung des Eigentums in das Zentrum des Konfliktes zu rücken, kann empirisch ebenfalls nicht überzeugen ${ }^{186}$. Gary Kates hat sogar zeigen können, daß die später zur Führungsgruppe der Gironde zählenden, im Circle Social zusammengeschlossenen Protagonisten der Pariser Kommunalrevolution mit Brissot, Condorcet und Fauchet als Führungspersönlichkeiten, einmal abgesehen von ihrer republikanischen und die Sklavenemanzipation betreibenden Politik, lange Zeit auch den sozialen Problemen der unteren Bevölkerungsschichten sehr aufgeschlossen gegenübergestanden und mit den radikalen Cordeliers oft enger zusammengearbeitet haben als die späteren Montagnards ${ }^{187}$. Die Ursache für die kaum bestreitbare Tatsache, daß die Bergpartei während der Republik tatsächlich den sozialen und zunehmend auch terroristischen Forderungen der Sansculotten aufgeschlossener gegenüberstand als die Gironde, kann so kaum in grundlegenden sozialen oder sozialpolitischen Divergenzen gefunden werden.

Das gegenläufige, dem sogenannten Revisionismus zugehörige Deutungsmuster hat demgegenüber, nicht zuletzt im Rückgriff auf ältere Interpretationen, wesentlich politisch-ideologische Gegensätze zwischen Montagne und Gironde in den Mittelpunkt der Betrachtung gerückt. Doch auch der Bezug auf gegensätzliche Prinzipien wie Zentralismus und Föderalismus, direkte und repräsentative Demokratie oder auf unterschiedliche Grundhaltungen zu Religiosität, Legalität und politischer Gewalt ist kaum in der Lage, den Konflikt überzeugend zu begründen, denn wie auf sozialem Gebiet scheinen auch hier die grundsätzlichen Übereinstimmungen weit zu überwiegen. Wenn man etwa von den Führungspersönlichkeiten Brissot und Robespierre ausgeht, kann man allerdings trotzdem sehr unterschiedliche politische Stile ausmachen, denn während Brissot zweifellos zum politischen Taktieren neigte, war Robespierre um ideologisch klare, gewissermaßen stugendhafte, in jedem Fall aber das Taktieren unter Generalverdacht stellende Grundlinien bemüht, deren puristische Rigorosität von der anderen Seite wiederum als unpolitisch, ja schädlich

${ }^{185}$ Vgl. grundlegend A. MATHIEZ, Girondins et Montagnards, Paris 1988 (Orig. 1930); den Klassenkampfgedanken weiter zuspitzend, dabei zugleich aber die Gegensätze zwischen Gironde und Montagne auf mehr oder weniger geschickte Formen bürgerlicher Interessenvertretung gegen ein entstehendes Proletariat nivellierend, D. GUERIN, La lutte des classes sous la première république, 1793-1797, 2 Bde., Paris 1968 (zuerst 1946), ferner zusammenfassend M. Bouloiseau, La République jacobine; A. Soboul (Hg.), Actes du colloque >Girondins et montagnards‘, Paris 1980.

${ }^{186}$ Vgl. etwa Pétions oft als Beleg angeführten »Lettre aux Parisiens«, dessen eher beiläufige Passagen zur Verteidigung des Eigentums immer wieder zitiert werden, der sich im wesentlichen jedoch gegen den ranarchistischen Terrorismus richtet. Vgl. den Abdruck in MARKOV, Revolution im Zeugenstand, Bd. 2, S. 391-403.

${ }^{187}$ G. KATES, The Cercle Social, the Girondins and the French Revolution, Princeton 1984. 
begriffen wurde. Doch es dürfte schwerfallen, diese persönlichen Unterschiede auf den Konflikt zwischen Gironde und Montagne insgesamt zu übertragen, wenn man etwa nur die keineswegs tugendgeleitete politische Praxis Dantons in den Blick nimmt.

Vor diesem Hintergrund spricht manches dafür, mit Patrice Higonnet vor allem die unterschiedliche Entwicklungsdynamik von zwei ursprünglich durch persönliche Beziehungen und gegenseitige Abgrenzungen entstandene Gruppierungen derselben politischen Klasse zu betrachten, die zu unterschiedlichen Zeitpunkten an die Macht gelangten und dann jeweils die revolutionäre Dynamik anzuhalten versuchten ${ }^{188}$. Die letztlich tödliche Zuspitzung des Konfliktes könnte dann, mit Norman Hampson, auf den philosophisch bedingten "claim of each to be the custodian of the general will« zurückgeführt werden ${ }^{189}$. In einer Verbindung beider Ansätze kommt auch Lucien Jaume auf der Basis seiner Analyse des jakobinischen Diskurses zu dem Schluß, der Sturz der Gironde erscheine sen dernier analyse comme une victoire du courant montagnard et jacobin à l'intérieur de la grande question posée depuis 1789: stabilisation de la Révolution ou radicalisation? ${ }^{190}$. Doch dieser zur Zeit sehr einflußreiche Ansatz vermag trotz einiger Erklärungskraft letztlich auch nicht ganz zu überzeugen, vor allem weil die Problematik des Gegensatzes von revolutionärer Stabilisierung oder Radikalisierung viel zu sehr in einem politisch luftleeren Raum angesiedelt und die tatsächlich den Konflikt entscheidend zuspitzende, grundlegende Bindung an den Krieg weitgehend übergangen wird. Schon der Urvater der sozialistischen Revolutionsgeschichtsschreibung Jean Jaurès hat in seiner kritischen Auseinandersetzung mit der Gironde darauf hingewiesen, daß die differierenden, unterschiedliche Haltungen gegenüber der Pariser Volksbewegung implizierenden Zielvorstellungen: Stabilisierung oder Radikalisierung, 1793 wesentlich kriegspolitisch begründet waren und nicht zuletzt als konkurrierende Methoden für eine erfolgversprechende Kriegsführung begriffen wurden ${ }^{19}$. Tatsächlich aber gingen die kriegsspezifischen Wirkungen im Zusammenhang eines Diskurses, der Außen- und Innenpolitik in der Konzeption des revolutionären Bürgerkrieges zu einem allgemeinen Kampf zwischen Revolution und Konterrevolution verband, weit über rationale taktische Divergenzen hinaus. Der Konflikt zwischen den bei-

${ }^{188}$ P. HIGONNET, The Social and Cultural Antecedents of Revolutionary Discontinuity: Montagnards and Girondins, in: English Historical Review, 1985, S. 513-544.

${ }^{189}$ N. HAMPSON, From Regeneration to Terror: the Ideology of the French Revolution, in: N. O'Sullivan (Hg.), Terrorism, Ideology, and Revolution, Brighton 1986, S. 49-66, hier S. 61; vgl. allg. DERS., Will and Circumstance: Montesquieu, Rousseau and the French Revolution, Duckworth 1983.

${ }^{190}$ L. JAUME, Le Discours jacobin et la démocratie, Paris 1989, S. 96.

191 J. JAURES, Histoire Socialiste de la Révolution française, Bd. 7, S. $527 f$. 
den Gruppierungen entwickelte sich tatsächlich nicht primär in Abhängigkeit von den "péripéties de la Révolution ${ }^{192}$, sondern er folgte vor allen den Wechselfällen des Krieges.

Eine wesentliche Schwäche aller Formen der bisherigen Sichtweise auf den Konflikt zwischen Montagne und Gironde ist in der fast ausschließlichen Konzentration auf die Entwicklungen nach dem Sturz der Monarchie zu sehen. Zwar trieben die Auseinandersetzungen im Konvent ihrem Höhepunkt zu, doch zwischen den führenden Persönlichkeiten und ihren Anhängern hatten sich bis zu diesem Zeitpunkt längst so tiefgehende Vorurteile und Gegensätze gebildet, da $@$ die weitere Entwicklung dadurch maßgeblich vorgeprägt wurde. Es wurde oben bereits gezeigt, wie sich die Gegensätze im republikanisch-jakobinischen Lager zuerst in den Diskussionen über Krieg und Frieden im Winter 1791/92 herausgebildet haben. Dieser Punkt ist selbstverständlich auch vielen anderen Historikern nicht entgangen. Doch da sie die weitere Entwicklung nicht wesentlich unter kriegsspezifischen Gesichtspunkten analysiert haben, ist die Bedeutung des Krieges, abgesehen von zumeist eher beiläufigen Erwähnungen und der möglicherweise für diese Unterlassung bezeichnenden Tatsache, daß die Historiker stattdessen, dem zeitgenössischen Diskurs folgend, den innenpolitischen Konflikt häufig wie selbstverständlich als "guerre« bezeichnet haben, kaum in den Mittelpunkt der Untersuchungen und Erklärungsversuche gerückt worden.

Im Zentrum der nach Kriegsbeginn forcierten, aber noch von beiden Richtungen in einen dynamischen Revolutionsverlauf eingeordneten Konflikte standen zweifellos nicht zuletzt unterschiedliche Vorstellungen über die Frage, ob und wie sich eigentlich republikanisch orientierte Kräfte in der Legislative auf die Beteiligung an einer monarchischen Exekutive einlassen dürften; während die Brissotins darin einen Fortschritt und Machtgewinn sahen, beschworen Robespierre und seine Anhänger die Korruptionsgefahr und beharrten darauf, daß die Legislative nur der Kontrolle der Regierung zu dienen habe. Doch vor allem ging es bei diesen Auseinandersetzungen, wie oben bereits deutlich wurde, wesentlich um unterschiedliche taktische Konzeptionen des Verhältnisses von Außen- und Innenpolitik unter den Bedingungen des Krieges, um unterschiedlich konzipierte Verbindungen der äußeren und der inneren Konterrevolution sowie der sich daraus ergebenden innenpolitischen Perspektiven. Mathiez, der durchaus Gespür und Interesse für die Probleme des revolutionären Krieges besaß, läßt diese Problematik zwar immer wieder deutlich anklingen, doch ordnet er sie zugleich in wenig überzeugender Manier seinem marxistisch geprägten Interpretationsschema unter; so etwa wenn er die rückblickenden Äußerungen des Montagnard Baudot zitiert, der doch

192 M. Ozouf, Girondins, in: DIES., Furet, Dictionnaire critique de la Révolution française, Paris 1988, S. 374-385, hier S. 384. 
zweifellos nicht den Primat materieller Interessen, sondern den Primat der Kriegspolitik in den Mittelpunkt der Konflikte gerückt hat: »Les Girondins voulaient arrêter la Révolution sur la bourgeoisie, mais cette résolution était alors impossible et impolitique dans le temps. La guerre était flagrante au dehors, menaçante au dedans. Les hordes étrangères ne pouvaient être repoussées que par les masses. Il fallait donc les soulever et les intéresser au succès. La bourgeoisie est paisible de sa nature, et d'ailleurs pas assez nombreuse pour de si grands mouvements. La Montagne seule comprit donc bien sa mission, qui était d'abord d'empêcher l'invasion étrangère «' 193 .

Mit dieser kriegspolitischen Begründung ist trotz ihres zweifellos selbstrechtfertigenden Charakters doch ein wichtiger Aspekt angesprochen, der auch die zeitgenössischen Auseinandersetzung geprägt hat. Die eine Partei des Konvents, so die treffende Unterscheidung von Vergniaud im März 1793, betreibe die Radikalisierung als vermeintlich notwendigen Beitrag »à l'énergie de notre défense«, während er selbst mit der anderen Partei die umgekehrte Auffassung vertrat, es sei notwendig »d'arrêter le mouvement révolutionnaire«, um durch das Beispiel einer glücklichen Republik die Völker auf die Seite Frankreichs zu ziehen und auf diese Weise den revolutionären Krieg siegreich zu beenden: "... fondons la liberté sur les lois et une sage Constitution. Bientôt vous verrez les trônes s'écrouler, les sceptres se briser, et les peuples, étendant leurs bras vers nous, proclamer par des cris de joie la fraternité universelle «194. Doch so fundamental gegensätzlich diese beiden Optionen in taktischer und kriegspolitischer Hinsicht tatsächlich waren, die schließlich zum fundamentalen Bruch treibende Schärfe des Konflikts zwischen Montagne und Gironde kann mit Vergniauds noch immer um Einheit bemühten Rationalisierungen, die mit ihrer Unterschätzung der militärischen Bedrohung in der Tat das Urteil Baudots zu bestätigen scheinen, allein nicht erfaßt werden. Sie resultierte vor allem aus einer beiden Parteien gemeinsamen Sichtweise, die nicht nur viel stärker die Verbindung zwischen dem äußeren und dem inneren Feind in den Mittelpunkt rückte, sondern auch die jeweilige Gegenposition, der gemeinsamen Logik des revolutionären Diskurses folgend, wie selbstverständlich als Revolutions- und Landesverrat im Interesse der konterrevolutionären Bedrohung denunzierte.

Eine analytische Grenze der politischen Diskursanalyse tritt hier zweifellos deutlich hervor, denn der weiterhin offenen Frage nach den allgemeineren sozialen oder politisch-ideologischen Ursachen für die Konstituierung der gegensätzlichen Gruppen vermag sie kaum nachzugehen. Doch wenn man davon ausgeht, daß der Krieg seit dem Frühjahr 1792 tatsächlich zu dem oder zumin-

${ }^{193}$ Zit. n. MATHIEZ, Girondins et Montagnards, S.11; vgl. auch M. SLAVIN, The Making of an Insurrection.

${ }^{194}$ AP 60, S. 161-166, hier S. 162, 166, 13.3.1793. 
dest $\mathrm{zu}$ einem wesentlichen Inhalt der Revolution selbst geworden war, dann muß es doch als ein wesentlicher Fortschritt erscheinen, wenn der Konflikt zwischen Montagne und Gironde nach seinem Inhalt wesentlich als ein Kriegskonflikt gedeutet werden kann.

Hauptkriegsschauplatz war anfangs der Pariser Jakobinerklub, in dem sich bereits kurz nach der Kriegserklärung führende Girondisten und führende zukünftige Montagnards in Fortsetzung der vorhergehenden Konflikte über die Kriegsfrage gegenseitig beschuldigten, Agenten der Konterrevolution zu sein ${ }^{195}$. Trotz eindeutigem Bezug auf die Kriegspolitik ging es dabei allerdings noch nicht um den Vorwurf der Zusammenarbeit mit dem auswärtigen Feind. Fauchet, Guadet und Brissot wurden hier vielmehr von Vertretern des radikalen Flügels verdächtigt, durch ihre Agitation für den Krieg das Projekt bzw. die Projekte der Militärführer La Fayette oder Narbonne zur Etablierung eines Protektorats zu befördern. Die von Robespierre schon lange vorher zum Ausdruck gebrachte Befürchtung, ein Krieg werde zur Aufwertung der Militärführung und schließlich zur Militärdiktatur führen, wurde dabei mit einer Kritik an der Politik der Brissotins verbunden, die wesentlich die Ähnlichkeiten der jeweiligen Option für den Krieg in Betracht zog, ohne indes die höchst unterschiedlichen damit verbundenen politischen Konzeptionen und Interessen zu berücksichtigen.

Was so der einen Seite als Konspiration erschien, wurde von der anderen Seite als völlig absurde Anschuldigung wahrgenommen, die hier wiederum den Verdacht erweckte, daß die Kritiker mit dem Schüren der inneren Zwietracht letztlich im Dienste des Hofes und der Konterrevolution stehen würden. "Prenez y garde, vous suivez vous même les impulsions de la cour", so die Retourkutsche von Brissot, der dann zumindest beiläufig auf den tatsächlichen Kern des Konflikts einging, als er den "Agitatoren« vorwarf: "Leur conduite est la même; comme les amis de la cour, les agitateurs dénoncent et cherchent à diviser les patriotes; comme les amis de la cour, ils crient contre la guerre, lorsque la guerre est voulue par la majorité des patriotes ${ }^{19 \%}$.

Dies war zweifellos ein geschickter rhetorischer Schachzug, denn noch war der Krieg so populär, daß Brissots mit vielen »Ah« und »Oh« aufgenommene Äußerung eine große, im Applaus ablesbare Wirkung erzielte und die Angreifer generell in die Defensive gerieten, wobei insbesondere Robespierre es nun allerdings seinerseits in höchst geschickter Form verstand, sich selbst als Opfer von Intrigen und Denunziationen hinzustellen ${ }^{197}$. Und doch ging es um mehr als um bloße Rhetorik. Tatsächlich wurden die in den politischen

\footnotetext{
$195 \mathrm{Vgl}$. AulaRD, Société des Jacobins, Bd. 3, 25.4.1792, S. 524-536.

${ }^{196}$ Ebd., S. 530.

197 Vgl. seine Rede im Jakobinerklub vom 27.4.1792, Ebd., S. $614 f$.
} 
Positionen eindeutigen, in den realen oder möglichen Bündnispartnem aber höchst verwickelten Konfliktlinien der Diskussion über Krieg und Frieden nun durch die Übertragung auf den Krieg selbst noch einmal enorm zugespitzt. Ob man nun für oder gegen den Krieg gewesen war, in jedem Fall befand man sich damit immer auch in Übereinstimmung mit einem Teil der gegenrevolutionären Kräfte und konnte so als ihr Agent denunziert werden. Mehr noch: Wer den Krieg betrieben hatte, mußte angesichts der militärischen Schwäche Frankreichs und des desaströsen Kriegsverlaufs nicht nur mit dem Hof und der Militärführung im Bunde stehen, sondern auch mit den äußeren Feinden. Und während die gegenseitigen Denunziationen vor dem kritischen, auf Beweis und Gegenrede pochenden Auditorium des Jakobinerklubs zu diesem frühen Zeitpunkt eher noch in zurückhaltender Form vorgebracht wurden, ging man in der allgemeinen politischen Öffentlichkeit bald schon sehr viel weiter.

Es war nicht der vorsichtig formulierende, vor allem seinen Ruf als nicht korrumpierbarer Kämpfer gegen jede "faction« wahrende Robespierre, der hierbei voranschritt, sondern es waren zwei andere Führer der späteren Bergpartei, die vor allem als Journalisten Einfluß ausübten, nämlich Robespierres Vertrauter Desmoulins und Marat. Der Volksfreund hatte schon den Kriegsbeginn unter der Überschrift "Conjuration de la faction Brissot avec les royalistes, le cabinet ministeriel et la cour, pour faire décréter la guerre« gemeldet, um dann etwas später zu präzisieren: "Enfin la fusée se démêle, les complots de la cour et ses suppôts paraissent à découvert; le ministre actuel commence à se démasquer, sa coalition avec les députés de Paris et de la Gironde, coalisés eux-mêmes avec les royalistes le plus gangrenés n'est plus un mystère; tous les fléaux de la guerre extérieure et de la guerre civile que les cabinets des Tuileries appellent depuis si long-temps sur la patrie, sont prêt à fondre à la fois sur nous « ${ }^{198}$. Ganz ähnlich argumentierte Desmoulins, der seit Ende April gemeinsam mit Fréron die Zeitschrift La Tribune des Patriotes herausgab, deren vier Ausgaben geradezu als denunziatorische Kampfschriften gegen Brissot als Mitverschworenen La Fayettes konzipiert waren. "Aussi l'at-on appellé très bien de Warwick des ministres«, so lautete die zentrale, auf die Vorgeschichte des Krieges zielende Anklage: "C'est par lui que les nouveaux ont été nommés, et c'est pour lui qu'ils ont été nommés. Ils ont été nommés pour faire la guerre; et ils font la guerre pour l'élever à la dictature $\ll^{199}$.

${ }^{198}$ Ami du Peuple, 24. bzw. 29.4.1792.

199 La Tribune des Patriotes, ou Journal de la Majorité, Nr. 1, 30.4.1792, S. 21; vgl. zuvor bereits Desmoulins Flugschrift "Jean-Pierre (sic) Brissot démasqué«, abgedr. in: DESMOULINS, CEuvres, Bd. 1, S. 349-408; "Warwick" ist vermutlich eine Verbindung von Brissots Namenszusatz Warwille und dem Namen des Oberkommandierenden der feindlichen Invasionstruppen von 1792, des Herzogs von Brunswick. 
Der Vorwurf, daß Brissot und seine Anhänger durch die Kriegspolitik nicht nur ihre eigenen Machtinteressen verfolgen würden, sondern diese auch noch mit der inneren Konterrevolution verbunden hätten, wurde durch die mit dem Krieg untrennbar verbundene Identifikation von innerer und äußerer Konterrevolution wie selbstverständlich auch auf die Komplizenschaft mit dem äußeren Feind übertragen. So stellten selbst die im innerjakobinischen Konflikt weitgehend neutralen Révolutions de Paris schon bald eine beunruhigende "parallèle de la conduite du gouvernement autrichien avec celle du gouvernement français, relativement à la guerre fest $^{200}$. Während Prudhomme und seine Mitautoren jedoch darauf beharrten, daß die Brissotins solange als Opfer, nicht aber als Verschwörer zu gelten hätten, wie es keine Beweise gegen sie gäbe, und kurz danach, spätestens nach der Entlassung der jakobinischen Minister, trotz weiterbestehender Antipathien den durchaus revolutionären Charakter ihrer Maßnahmen erkannten, spitzte sich die Kritik bei Robespierre und anderen radikalen Jakobinern weiter $z u$.

"N'est ce pas vous enfin«, so lautete nun im Rahmen seiner Betrachtungen "sur l'une des principales causes de nos maux" die Anklage von Robespierre gegen Brissot, "qui, après avoir rejeté tous les moyens proposés pour faire heureusement la guerre, de réprimer tous nos ennemis intérieurs, même de pourvoir à l'armement complet de nos troupes et de nos gardes nationales, en remplacement de nos officiers, et à la défense de toutes nos frontières, vous êtes appliqués chaque jour à introduire au milieu de nous le despotisme militaire dans toute son étendue?«. In jedem Fall sei dies, so fuhr L'Incorruptible in typisch denunziatorischer Manier fort, eine Politik, die sich "point au bien public et à la cause du peuple« orientiere, "mais à un système d'intrigues, et à l'intérêt d'un parti. Je n'ai pas besoin de savoir si c'est la cour ou une autre faction que vous servez; il suffit de voir que ce n'est point la liberté. Il est clair même que votre conduite ne peut que favoriser le triomphe de la cour $\aleph^{201}$. Wie immer man sich zu den mehr oder weniger offen angedeuteten Unterstellungen Robespierres stellen mochte, in einem Punkt war die Argumentation der früheren Kriegsgegner kaum zu widerlegen: »Rien de ce que je vous annonçais sur la guerre désastreuse que nous avons eu la folie d'entreprende, n'a manqué d'arriver «, stellte Marat zutreffend fest ${ }^{202}$. Und Robespierre hielt den Brissotins voller Sarkasmus entgegen: "Et vous voulez que M. Lafayette fasse la guerre aux Autrichiens! « ${ }^{203}$.

${ }^{200}$ Révolutions de Paris, 5.-12.5.1792, Bd. 12, S. 237. Vgl. auch die Ausgaben vom 12.19.5.1792, 9.-16.6. und 16.6.-23.6.1792.

${ }^{201}$ Défenseur de la Constitution, Nr. 3, S. 77-99, hier S. 97-99.

${ }^{202}$ Ami du Peuple, 18.7.1792.

${ }^{203}$ Défenseur de la Constitution, Nr. 8, S. 233-243: Sur la tactique du général Lafayette, hier S. 238. 
In seinen Argumenten war der allgemeinere, von Marat und Desmoulins offen ausgesprochene Vorwurf der Kriegstreiberei im Interesse auch der äußeren Konterrevolution bzw. der Verbindung von äußerer und innerer Konterrevolution zwar noch nicht explizit enthalten, implizit aber doch immer angelegt, wenn er einerseits das Zusammenwirken zwischen Österreich und La Fayette denunzierte, anderseits die Verbindung zwischen La Fayette und Brissot. Dies wurde besonders deutlich, als im unmittelbaren Vorfeld des 10. August die Konflikte zwischen den werdenden Fraktionen der Montagne und der Gironde noch einmal eine krasse Zuspitzung erfuhren. Während Brissot und seine Anhänger angesichts der revolutionären Dynamik die Bewegung abbremsen wollten, mit dem Hof über die Neubesetzung des Ministeriums verhandelten, öffentlich nur die Anklageerhebung und Suspendierung, noch nicht aber die definitive Absetzung des Königs forderten und der Ausschreibung von Konventswahlen kritisch gegenüberstanden, sahen die radikaleren Kräfte in diesem Taktieren erneut nur einen Verrat, zumal nach ihrer Deutung Brissot sein Versprechen, in der Nationalversammlung die Anklageerhebung gegen La Fayette zu fordern, nicht erfüllt hatte. Verschärfend trat hinzu, daß die linksstehenden Abgeordneten der Nationalversammlung einen La Réunion genannten Klub eingerichtet hatten, der vielen Jakobinern als Konkurrenzorganisation erschien, obwohl er de facto wohl vor allem der Absprache gemeinsamer parlamentarischer Vorgehensweisen durchaus unter Einschluß radikaler Abgeordneter diente und schließlich am Sturz der Monarchie mitwirkte ${ }^{204}$. Vor diesem Hintergrund wurde im Jakobinerklub am 1. August 1792 über den Ausschluß von Brissot diskutiert. Die schärfste Attacke ritt Anthoine: "Je dénonce (...) J.-P. Brissot et la compagnie qui l'entoure, qui a fait déclarer la guerre avant que rien fût prêt pour la guerre; (...) qui, ayant pris ici l'engagement formel de perdre La Fayette, n'a pas même ouvert la bouche sur son compte; (...) qui, après la proclamation des dangers de la patrie, veut nous boucher les yeux au point de nous faire croire que le rappel des ministres, patriotes sans doute, soit la seule mesure suffisante pour faire cesser ces dangers et sauver la patrie ${ }^{205}$.

Auch die Angriffe von Brissot und seiner Umgebung gegen den radikalen Flügel des Jakobinismus blieben nicht auf die Kritik an politischen Zielen und Methoden begrenzt. Sie gewannen ihre Schärfe vielmehr ebenfalls, nur in gewissermaßen spiegelverkehrter Form, durch die Denunziation der politischen Gegner als Agenten des Hofes wie des äußeren Feindes. Es handele sich bei den Denunzianten, so hetzte der Patriote Français bereits Ende April angesichts der Auseinandersetzungen im Jakobinerklub, um winstruments du

${ }^{204}$ Vgl. A. MathIEZ, Un Club révolutionnaire inconnu: le club de la Réunion, in: DERS., Girondins et Montagnards, S. 70-81; REINHARD, Chute de la Royauté, S. $351 \mathrm{f}$.

${ }^{205}$ AULARD, Société des Jacobins, Bd. 4, S.168. 
comité autrichien«, angestellt um den inneren Bürgerkrieg zu entfachen: "voilà à quoi il travaille tous les jours, aux moyens des nombreux journaux qu'il soudoie, sous toutes les formes et dans tous les genres, au moyen d'une foule d'émissaires, dont les masques sont nuancés à l'infini, et qui se répand dans les clubs, dans les assemblées politiques, dans les groupes et dans les cafés, ébranlant la confiance aux représentants du peuple, décriant le nouveaux ministère, déclarant contre une guerre inévitable, et s'efforçant d'inspirer la méfiance et le découragement $\kappa^{206}$.

Mit dieser Denkfigur versuchte vor allem Brissot, die linke und die rechte Kritik an seiner Politik gleichzusetzen und die von ihm so bezeichneten "enragés« gemeinsam mit den "modérés" als letztlich den Interessen des Hofes dienende »instruments dans la main du pouvoir exécutif» zu denunzieren ${ }^{207}$. Doch auch andere zukünftige Girondisten stimmten in diese Angriffe ein. Es gebe einen "vaste plan de conjuration« mit dem Ziel, die innere Einheit zu zerstören, stellte etwa Louvet fest; auch wenn er sich zuerst vor allem gegen die "meneurs-feuillantins" wandte, agitierte er nach der Ablehnung des "camp des fédérés» auch immer schärfer gegen den inneren Feind im patriotischen Gewand: "1... et les sociétés patriotiques elles-mêmes sont déchirées par des agitateurs d'autant plus dangereux que quelques personnes veulent encore les croire patriotes $\aleph^{208}$. Vor allem aber ging es immer wieder um den Krieg, denn »le démagogisme furieux et l'hypocrite modérantisme se sont réunis pour déclarer contre l'indispensable mesure de la guerre ${ }^{209}$. Wenn die radikaleren Kräfte für die rigorose Säuberung des adeligen Offizierscorps agitierten, so handelte es sich dabei für manche um Irrtümer, doch in der scharfen Diktion von Brissot waren das Maßnahmen "pour désorganiser l'armée, en décourageant les généraux et en excitant les soldats à d'horribles excès « ${ }^{210}$.

Vermittelt über die unterschiedlichen Auffassungen über die Notwendigkeiten der Landesverteidigung ergab sich auch hier im Zusammenhang der allgemeinen Tendenz zur Identifikation des äußeren und des inneren Feindes wie selbstverständlich der Verdacht, die Kritik Robespierres und anderer radikaler Jakobiner diene letztlich dem Landesverrat. »Pourquoi la conduite de $\mathrm{M}$. Robespierre est-elle toujours telle qu'elle ne pourrait être autrement si elle était tracée par le comité autrichien?«, fragte der Patriote Français angesichts der ersten ablehnenden Äußerungen Robespierres zu dem von Kriegsminister

\footnotetext{
${ }^{206}$ Patriote Français, 25.4., 26.4.1792.

${ }^{207}$ Entwicklung dieser Einteilung im Patriote Français, 10.5.1792.

${ }^{208}$ La Sentinelle, Nr. 4, Nr. 14.

${ }^{209}$ Patriote Français, 2.5.1792.

${ }^{210}$ Patriote Français, 6.5.1792.
} 
Servan projektierten "camp des fédérés $\aleph^{211}$, um dann einige Tage später festzustellen: $» \mathrm{M}$. Robespierre a entièrement levé le masque. Digne émule des meneurs autrichiens du côté droit de l'assemblée nationale, il a déclaré à la tribune des jacobins, avec sa virulence ordinaire, contre le décret qui ordonne la levée des vingt milles hommes qui doivent se rendre à Paris pour le 14 juillet $\ll^{212}$.

Nach dem Sturz der Monarchie ging es dann in der Tat wesentlich um eine Wiederauflage der schon 1791, nach dem Abschluß der Verfassung, im Konflikt zwischen Feuillants und Jakobinern in den Mittelpunkt gerückten Frage, ob die Revolution nun beendet sei, oder eigentlich erst begonnen habe und weiter vorangetrieben werden müsse. Spätestens jetzt war mit der in der neuen Stadtverwaltung organisierten Pariser Volksbewegung ein neuer, die Konfliktlinien verändernder Machtfaktor auf die Bühne getreten, der im Einklang mit den Montagnards die Legitimität der bis zum Zusammentritt des neu zu wählenden Konvents weiteramtierenden Legislative und der von ihr gebildeten, mehrheitlich girondistischen Regierung bestritt, während diese in der dauerhaften Etablierung einer revolutionären Gegenregierung eine die Prinzipien von Volkssouveränität und Repräsentation verletztende Machtanmaßung sahen. Der Konflikt zwischen der direkten Demokratie der Pariser Sansculotten und der Nationalversammlung reichte weit über den Konflikt zwischen Montagne und Gironde hinaus. Er wird im folgenden Kapitel über den Zusammenhang von Massenmobilisierung und Terror analysiert, während es an dieser Stelle zunächst noch um die Fortsetzung der Analyse des Konfliktes innerhalb des jakobinisch geprägten revolutionären Bürgertums gehen soll, der zweifellos vor dem Hintergrund der Sansculotten-Bewegung einen neuen Charakter gewann. Der mit der Doppelherrschaft verbundene Konflikt zwischen der mehrheitlich girondistischen Übergangsregierung und der Mehrheit der Nationalversammlung auf der einen Seite, der Pariser Kommune und der sie unterstützenden Montagne auf der anderen Seite war zweifellos wesentlich getragen von dem wechselseitigen Vorwurf, eine Diktatur anzustreben. Im Folgenden soll indes gezeigt werden, wie stark die Kriegsproblematik auch in diese Auseinandersetzungen eingeschrieben blieb und den Konfliktverlauf letztlich immer wieder entscheidend beeinflußt hat.

"Si nous sommes calmes et fermes«, so formulierte Kriegsminister Servan im September 1792 die auf innere Stabilisierung als Voraussetzung einer erfolgreichen Kriegspolitik abzielende Position der gemäßigten Kräfte, wla cause de la liberté triomphera dans la lutte des hommes libres contre le tyrans $\ll^{213}$. Die Radikalen betonten dagegen weiterhin den Zusammenhang von innerer

${ }^{211}$ Patriote Français, 7.6.1792.

${ }^{212}$ Patriote Français, 10.6.1792.

${ }^{213}$ Brief an die Nationalversammlung, abgedr. in: Annales Patriotiques, 19.9.1792. 
Revolutionierung und äußerer Kriegspolitik, beschworen die Notwendigkeit einer "nouvelle insurrection « und attackierten die Gironde, "cette faction si long-temps prostitué à Mottié (La Fayette, WK), que nous devons la guerre avec les puissances liguées, la fatale sécurité où elle nous a entretenu par l'étalage imposteur des forces que nous avions point, l'aveugle confiance que nous avions en nos généraux perfides, et les malheurs qui ont été la suite inévitable $\ll^{214}$. Diese Agitation wiederum nährte unter den gemäßigten Kräften den umgekehrten Verdacht, gerade die Radikalen würden tatsächlich mit der Krone und dem feindlichen Ausland im Bunde stehen und die Niederlage der Republik betreiben. "Cependant quelque attention que mérite l'ennemi du déhors«, warnte etwa Louvet, "ne perdez pas de vue l'ennemi du dedans. (...) Presque toujours au moment où le despotisme est abattu, des agitateurs s'élèvent, qui fermentent l'anarchie pour dominer, régner, tyranniser à leur tout. (...) Peuple de Paris, tu a terrassé le despotisme: prends garde à l'anarchie, c'est la mère des tyrans « $\varkappa^{215}$.

Der Konflikt zwischen Montagne und Gironde spitzte sich nach dem Sturz der Monarchie wesentlich in drei aufeinanderfolgenden Schritten zu. Am Anfang standen die Auseinandersetzung über die Septembermassaker von 1792, es folgte zum Jahreswechsel der Prozeß gegen den König, und schließlich kam es im Frühjahr 1793 vor dem Hintergrund der erneut anwachsenden, nunmehr nicht nur von außen, sondern auch vom inneren Bürgerkrieg ausgehenden militärischen Bedrohungen zu einer erneuten revolutionären Radikalisierung der Pariser Volksmassen, die schließlich Anfang Juni zum Sturz der Gironde führte.

Mona Ozouf hat die Auffassung vertreten, das gesamte revolutionäre Bürgertum habe nach den Septembermassakern geglaubt, man müsse nun über die schrecklichen Ereignisse, wie es zeitgenössisch in der Tat öfters hieß, »einen Schleier werfen«; erst Ende September habe die Gironde daraus Anklagen im Kampf gegen die radikale Pariser Stadtverwaltung und gegen die Bergpartei

${ }^{214}$ Ami du Peuple, 21.9.1792, 25.9.1792. Bereits im Wahlkampf hatte Marat argumentiert: »Je ne parle ici des Brissot, ni des Guadet, Lasource, Condorcet, Vergniaud, Pastoret et autres députés infidèles, que leurs suppôts ci-dessus dénommés veulent porter à la Convention. Pour les en exclure, il suffit de ne pas oublier que ce sont eux qui ont fait déclarer la guerre pour servir Motier, et que ce sont eux qui ont déstitué la Commune pour usurper l'autorité suprême». Ami du peuple, 5.9.1792, "Liste des sujets déméritants proposés par l'auteur de la Sentinelle, dans la vue de servir la faction des ennemis de la libertér. Louvet hatte zuvor, am 21.8.1792, eine Liste von Kandidaten publiziert, in der sich Girondisten und Montagnards in etwa die Waage hielten. Vgl. auch E. CHARAVAY (Hg.), Assemblée Electorale de Paris, 3 Bde., hier Bd. 3: 2 Septembre 1792 - 17 Frimaire an II, Paris 1905, S. 593ff.

${ }^{215}$ La Sentinelle, 20.10.1792. 
entwickelt ${ }^{216}$. Doch auch wenn sich die Massaker zweifellos spontan, ohne erkennbare politische Führung abgespielt hatten und sich das Mitleid mit den überwiegend kriminellen Opfern bei vielen durchaus in Grenzen hielt, stand für die führenden gemäßigten Revolutionsführer die Antwort auf die Frage nach der Verantwortung von Anfang an fest. Ein wesentlicher Grund hierfür lag darin, daß die radikale Agitation gegen den sinneren Feind, den die Pariser Sansculotten in den Gefängnissen abzuschlachten meinten, auch sie selbst einbezogen hatte. Brissot veröffentlichte infolgedessen schon am 4. September einen Brief $" A$ ses concitoyens $«$, in dem er die durchaus glaubwürdige Behauptung aufstellte, daß er selbst und andere gemäßigte Revolutionsführer als vermeintliche Landesverräter den Massakern hatten zum Opfer fallen sollen: »On nous accusait de vouloir livrer la France au duc de Brunswick, d'en avoir reçu des millions, et de nous être concertés pour nous sauver en Angleterre«. Diese im Überwachungsausschuß der Pariser Kommune geäußerten Vorwürfe erschienen Brissot, nachdem er nur knapp einer Verhaftung entkommen war, angesichts der Vorfälle in den Gefängnissen quasi als Mordversuch, denn »on me dénonçait à dix heures du soir, et à cette heure on égorgeait dans les prisons! $\aleph^{217}$.

Bereits einen Tag vorher hatte sich Innenminister Roland, der nach der Auffassung seiner Frau ebenfalls nur knapp dem Gemetzel entkommen war, in ähnlicher Weise nicht nur gegen die Massaker gewendet, sondern zugleich auch Verräter in der Pariser Kommune angeklagt, deren Versuche, das Volk zu mißbrauchen, gestoppt werden müßten, wenn man die militärisch bedrohte Nation noch retten wolle: "Jamais l'unité d'action ne fut plus nécessaire. Des ennemis aguerris et nombreux se sont établis sur notre territoire, ils menacent la capitale; c'est vers elle que se dirigent leur rage et leur désespoir; c'est-là qu'ils ont à exercer des vengeances; c'est-là qu'ils espèrent dissoudre le gouvernement et profiter de leurs avantages. Sans doute l'énergie du peuple, bien dirigé, leur opposera des barrières insurmontables; mais c'est précisément pour cette direction qu'il faut de l'ensemble et de l'activité; l'un et l'autre sont impossibles, lorsque tout le monde commande $\ll^{218}$. Und auch die Nationalversammlung drehte in ihrer Reaktion auf die Massaker die kriegspolitisch begründeten Vorwürfe gegen ihrer Führung um und wandte sich gegen »les plus dangereux ennemis du peuple«, die den Bürgerkrieg entfachen wollten, um das Volk von den notwendigen Verteidigungsmaßnahmen abzuhalten: „Citoyens, c'est par le mensonge que des Français parjurés ont excité contre leur patrie les armes de l'Autriche et de la Prusse; c'est à force de mensonges

${ }^{216} \mathrm{M}$. OzoUf, Guerre et terreur dans le discours révolutionnaire, 1792-1794, in: DIES., L'école de France. Essais sur la Révolution, l'utopie et l'enseignement, Paris 1984, S. 113127; GuILlaUMOU, Les massacres de septembre.

${ }^{217}$ Abgedr. in: Patriote Français, 4.9.1792.

${ }^{218}$ Lettre de M. Roland, ministre de l'intérieur, à l'assemblée nationale, imprimée par ordre de l'assemblée nationale, zit. n. Patriote Français, 5.9.1792. 
qu'une cour conspiratrice était parvenue à cacher la sourde destruction ou la destination perfide des moyens que vos représentants avaient préparés pour la défense des frontières; c'est aussi en employant le mensonge, que ceux de vos ennemis qui sont encore au milieu de vous, se flattent d'égarer votre patriotisme, ou de refroidir votre valeur, et qu'ils espèrent de répandre parmi vous, ou le découragement, ou la défiance ${ }^{219}$.

Die Kritik an der "Anarchie» der Pariser Kommune verschärfte sich in der Folgezeit. Die gemäßigten, eine Stabilisierung der inneren Verhältnisse anstrebenden Kräfte wandten sich nun, gestützt auf die moralische Kritik an den "monstres sanguilantes" und ihren Verteidigern, um so heftiger gegen die "nouveaux dominateurs«, gegen die in Danton, Marat und Robespierre personifizierte "tyrannie triumvirale «, die im Dienste des feindlichen Auslandes handele, "pour répandre la terreur dans l'âme des citoyens, et semer l'anarchie; car c'est-là le seul moyen que nos ennemis puissent employer pour ramener le despotisme«, wie Vergniaud urteilte ${ }^{20}$. Bürgermeister Pétion fügte hinzu: "Nous avons parmi nous, et je ne cesserai de le dire, des agents payés par nos ennemis pour amener l'anarchie, car c'est un sur moyen pour parvenir au despotisme « ${ }^{221}$. Und La Sentinelle argumentierte: $» A$ mesure que votre gloire s'accroît, que votre puissance se consolide, et que vos ennemis extérieurs s'abaissent devant vous, le plan des ennemis de l'intérieur développe des dimensions nouvelles. La discorde, dont le masque varie avec les époques, a troqué l'habit de cour qu'elle portait il y a quelques mois, contre le costume populaire, et se flatte sous le déguisement de mieux vous désunir $\aleph^{222}$.

Mit dem Sieg der französischen Truppen bei Valmy, der damit verbundenen Konsolidierung auch der innenpolitischen Situation nach dem Zusammentritt des Konvents und nicht zuletzt mit dem Beginn der französischen Expansion rückte dieser Konflikt allerdings eher in den Hintergrund, auch wenn der Pariser Radikalismus sich nun in immer eindeutiger kriegsbezogener Weise gegen die "canaille Brissotine" wandte, "qui, foutre, était grassement payée par nos ennemis pour nous jetter dans le labyrinthe $\aleph^{223}$. Eine wesentliche Vorentscheidungen für den weiteren Verlauf fiel jedoch bereits im Oktober 1792

219 Adresse der Nationalversammlung »Aux Français« vom 5. September, zit. n. Patriote Français, 6.9.1792; auch hier hieß es weiter: »Ils ont dit à ceux qu'ils voulaient irriter, que l'assemblée nationale se préparait à rétablir Louis XVI; ils ont dit à ceux dont ils voulaient décourager la résistance contre les soldats de la tyrannie, que l'assemblée nationale avait le projet d'élever sur le trône un prince étranger, et même le général des armées ennemies, le duc de Brunswick«. Die vorhergehenden Wendungen aus einem Dekret der Nacht vom 3.9. zum 4.9.1792, ebd.

${ }_{220}$ Zit. n. Patriote Français, 19.9.1792; vgl. auch AP 50, S. 93f., 17.9.1792

${ }^{221}$ Ebd.

${ }^{222}$ La Sentinelle, 20.10.1792.

${ }^{223}$ Père Duchesne, Nr. 189. 
im Pariser Jakobinerklub, aus dem Brissot und seine Anhänger nach und nach ausgeschlossen wurden. Die Anklagen bezogen sich wesentlich auf ihr wankelmütiges Verhalten unmittelbar vor dem 10. August, doch als die Jakobiner den Ausschluß von Brissot gegenüber den angeschlossenen Volksgesellschaften begründeten, stand am Anfang wiedenum der mit dem Krieg verbundene Vorwurf: "Ils brusquèrent la déclaration de guerre, sans aucune mesure préparatoire pour détourner l'influence du tyran des Tuileries sur le sort de nos armées, dirigées contre ses parents, ou pour rompre sa coalition avec tous les despotes, avec nos propres généraux, et surtout La Fayette $\ll^{224}$. Welche zentrale Bedeutung dieser Punkt tatsächlich besaß, zeigt die Reaktion von Brissot, der in seiner öffentlichen Rechtfertigung entgegnete: "C'était l'abolition de la royauté que j'avais en vue en faisant déclarer la guerre«, um dann umgekehrt seine Gegner im Jakobinerklub in die Nähe des auswärtigen Feindes zu rükken: "Quand le duc de Brunswick y aurait présidé, aurait-il pu mieux manœuvrer, pour perdre, et cette société et la chose publique? Ces débats, ou ridicules, ou grossiers, ou absurdes, n'étaient-ils pas recherchés, répandus, avec soin, dans toute l'Europe par les aristocrates, les émigrés, le comité autrichien? N'ont-ils pas fait plus de prosélytes à la contre révolution, que les actes des apôtres? Ne sont-ce pas ces débats qui nous ont attiré le mépris des puissances étrangères, qui ont consolidé la coalition des couronnes, qui les ont confirmées dans l'espoir de conquérir la France « ${ }^{225}$.

Es war dann der Prozeß gegen den König, der wesentlich zur genaueren Klärung der Abgrenzungen und der Kräfteverhältnisse zwischen Montagne und Gironde beitrug. Es ging in diesem Prozeß um eine Fülle von verfassungsrechtlichen und politischen Problemen, die hier im einzelnen nicht diskutiert werden können ${ }^{226}$. Eindeutig aber ist, daß die Frontlinie zwischen der auf die Verurteilung und Hinrichtung des Königs abzielenden, besonders von Robespierre und Saint-Just entwickelten Position der Montagne auf der einen, und der unschärferen, dilatorischen, tendenziell aber doch deutlich die persönlich Schonung des längst abgesetzten Königs anstrebenden Position der Gironde auf der anderen Seite verlief. Dies ließ die Girondisten zum einen als verkappte Royalisten erscheinen, zum anderen verstärkte ihre Option für den Appell an die Urwählerversammlungen noch den bereits seit der Initiative zur Bildung einer Schutztruppe des Konvents aus den Departements schwelenden Vorwurf des Föderalismus. Nicht zuletzt aber ging es im Konflikt um das Schicksal des Königs auch wesentlich um die in der Literatur zumeist an den

${ }^{224}$ Circulaire de la société, 15.10.1792, abgedr. in: AULARD, Société des Jacobins, Bd. 4, S. 394-398, hier S. 395.

${ }^{225}$ J.-P. BRISSOT, A tous les républicains de France; sur la société des Jacobins de Paris, abgedr. in: La Chronique du Mois, November 1792, supplément, S. 42-80, hier S. 43, 68.

${ }^{226} \mathrm{Vgl}$. zusammenfassend M. OZOUF, Procès du Roi, in: DIES., FURET, Dictionnaire critique, S. 134-145; das folgende Zitat S. 142. 
Rand gedrängte Frage nach der kriegspolitischen Bedeutung, die beide Seiten gleichermaßen heraufbeschworen, aber ganz unterschiedlich beantworteten. Dies verlieh ihren Argumenten keineswegs nur eine "note d'urgence tragique«, sondern es prägte die Zuspitzung des Konfliktes, zumal deshalb, weil im Dezember der Höhenflug der militärischen Erfolge zu verblassen und die Gefahr einer sich anbahnenden, erweiterten antifranzösischen Allianz aufzuscheinen begann ${ }^{227}$.

"La guerre actuelle est un combat à mort entre la liberté française et la tyrannie universelle«, so stimmte Brissot in seiner großen Rede vom 1. Januar 1793 die Konventsabgeordneten auf den Zusammenhang von Krieg und Königsprozeß ein ${ }^{228}$, um dann erst einmal die moralische Stärke und Unabhängigkeit eines Volkes zu betonen, das im Angesicht des Feindes die Monarchie gestürzt, einen Nationalkonvent gewählt und die Republik etabliert habe. Vor diesem Hintergrund sei die erneute Einberufung der Urwählerversammlung zur Entscheidung über das Schicksal des Königs »le pendant de l'immortel 10 août; il produira le même effet sur l'esprit des nations étrangères«. Die gegnerischen Mächte indes würden die Hinrichtung des Königs wünschen, weil es dann leichter sei, eine antirepublikanische Partei als Sammelbecken aller Unzufriedenen in Frankreich zu schaffen und die antifranzösische Kriegskoalition auszuweiten: »Elles veulent sa mort, parce qu'elle semble un garant de la restauration de la royauté«. Als es zwei Wochen später nicht mehr um die Verurteilung, sondern nur noch um einen möglichen Aufschub der Vollstreckung des Todesurteils ging, spitzte Brissot diese Argumentation noch einmal zu. Der Verzicht auf die Hinrichtung werde die Völker Europas für die Revolution einnehmen und so zur Beendigung des Krieges und der Revolution führen: "Donnez un grand exemple de modération, et la révolution est faite, dans toute l'Europe, avant peu«. Die Hinrichtung dagegen werde, so argumentierte Brissot trotz der gegensätzlichen Stoßrichtung weiterhin in der ursprünglich zum Krieg treibenden Logik der Verbindung von Krieg und Revolution, $\mathrm{zu}$ einem "guerre universelle» gegen die Revolution führen, auf den Frankreich nicht vorbereitet sei; sie werde alle auswärtigen Freunde von Frankreich entfremden, die Bemühungen der Regierungen um die Unterstützung ihrer Völker erleichtern, den Krieg gegen die Revolution nationalisieren und vor allem der antirevolutionären Allianz neue Partner hinzufügen: "Si Louis est exécuté, il faut dès demain voter la guerre contre l'Angleterre, la Hollande et l'Espagne, contre tous les tyrans de l'Europe, parce qu'elle est inévitable de leur part (...), parce que tous ces tyrans, résolus à écraser notre

${ }^{227}$ Vgl. etwa Sitzung der Nationalversammlung vom 24.12.1792, Redebeiträge von Bréard, Jean Debry und Barère. AP 55, S. 377-386.

${ }^{228}$ AP 56, S. 124-131, 1.1.1793. 
liberté, et dans cette liberté, celle de toute l'Europe, croiront avoir trouvé dans cette mort un prétexte séduisant aux yeux de leurs peuples «229.

Die Gegenposition verhielt sich zu dieser Argumentation im Grunde spiegelverkehrt, doch basierte sie dabei ebenfalls auf der Verbindung von Krieg und Revolution. Folgen wir der Argumentation von Robespierre, ihrem nicht nur klarsten, sondern nunmehr zweifellos auch einflußreichsten Vertreter, der schon am 3. Dezember mit dem Argument für eine schnelle Aburteilung des Königs eintrat, jede Verzögerung werde nur den konzertierten äußeren und inneren Konterrevolutionären nützen: "Et quelle carrière ouverte aux conspirateurs! Quel aliment à l'intrigue et à l'aristocratie! Ainsi, tous les partisans de la tyrannie pourront espérer encore dans le secours de leurs alliés; et les armées étrangères pourront encourager l'audace des contre-révolutionnaires, en même temps que leur or tentera la fidélité du tribunal qui doit prononcer sur son sort. Juste ciel! toutes les hordes féroces du despotisme, s'apprêtent à déchirer de nouveau le sein de nôtre patrie, au nom de Louis XVI! (...) Je veux bien croire encore que la république n'est point un vain nom dont on nous amuse; mais, quels autres moyens pourrait-on employer, si l'on voulait rétablir la royauté $\aleph^{230}$. Ende Dezember sah Robespierre dann in der Einberufung der Urwählerversammlungen, für die er selbst noch wenige Monate vorher im Kampf gegen den König und die Legislative vehement eingetreten war, nur noch ein Kampfmittel der Konspiration gegen die Revolution: »Ainsi la guerre civile unira ses fureurs au fléau de la guerre étrangère; et les intrigants ambitieux transigeront avec les ennemis du peuple, sur les ruines de la patrie, et sur les cadavres sanglants de ses défenseurs ' $^{231}$. Als Robespierre dann am 16. Januar im Konvent für die Todesstrafe plädierte, hielt er den Argumenten Brissots die Auffassung entgegen, daß gerade ein entschlossenes Auftreten die kriegerische Kampfbereitschaft der Nation erhöhen werde: $» J e$ ne cherche point non plus, comme plusieurs autres, des motifs de sauver le ci-devant roi dans les menaces ou dans les effort des despotes de l'Europe, car je les méprise tous, et mon intention n'est pas d'engager les représentants du peuple à capituler avec eux. Je sais que le seul moyen de les vaincre, c'est d'élever le caractère français à la hauteur des principes républicains, et d'exercer sur les rois et sur les esclaves des rois l'ascendant des âmes fières et libres sur les âmes serviles et insolentes « ${ }^{232}$.

${ }^{229}$ AP 57, S. 451-453, 19.1.1793. Zum Hintergrund vgl. A. MATHIEZ, Danton, Talon, Pitt et la mort de Louis XVI, in: DERS., Études robespierristes, Bd. 2, S. 104-119.

${ }^{230}$ AP 54, S. 74-77, hier S. 76, 3.12.1792.

231 AP 56, 28.12.1792. Auf Antrag von Léonhard Bourdon hielt Robespierre die Rede im Jakobinerklub noch einmal, und es wurde beschlossen, sie zu drucken und an alle angeschlossenen Gesellschaften zu schicken. Vgl. AULARD, Société des Jacobins, Bd. 4, S. $627,30.12 .1792$.

${ }^{232}$ AP 57, S. 363, 16.-17.1.1792. 
Zweifellos ging Robespierre nun in Verkehrung der Fronten des Jahreswechsels 1791/92 davon aus, daß die Fortsetzung und Ausweitung des revolutionären Krieges sowieso unvermeidlich sei. Gegen die Verschiebung der Hinrichtung wandte er, wiederum mit Bezug auf die Argumente Brissots, ein, da $\beta$ alle Hoffnungen auf einen Ausgleich mit den Despoten nicht nur vergeblich, sondern auch ebenso wimpurs comme la politique des cours« seien, deren Interesse sie letztlich diene: "Si nous pensions seulement à composer avec la tyrannie, nous serions déjà vaincus, notre liberté serait ébranlée ou anéantie par ce caractère honteux de servitude et de pusillanimité. Eh! si Louis n'est pas destiné à ce criminel usage, quel rapport existe-t-il donc entre les puissances étrangères et l'exécution de Louis? « ${ }^{233}$.

Als der Konvent nur acht Tage nach der Hinrichtung des Königs England und Holland, einen Monat später auch Spanien den Krieg erklärte, konnten sich beide Seiten fraglos bestätigt sehen. Was für Brissot und seine Anhänger die vorhergesagte Folge der Exekution des Königs war ${ }^{234}$, diente ihren radikalen Kritikern als Bestätigung der seit längerem schwelenden Vermutung, daB es sich bei ihnen in Wahrheit um englische Agenten handele, die im Auftrag Pitts zuerst den König zu retten versucht hätten und nun die französische Niederlage vorbereiten würden. Sie müßten, so forderte Robespierre, nun auch aus den lokalen Volksgesellschaften ausgeschlossen werden, denn wil y a une coalition criminelle entre les intrigants et les cabinets étrangers. Faisons apercevoir que Brissot s'est exprimé, sur la mort du tyran des Français, comme Pitt et ses partisans de Londres. Prouvons que les mêmes hommes qui excitent des troubles affament le peuple, qu'ils disposent de tous les trésors de la République, dont ils tiennent les destinées dans leurs mains « ${ }^{233}$.

Als unter der Pariser Bevölkerung im Spätwinter 1792/93 Subsistenzunruhen ausbrachen, standen die ökonomischen und sozialen Ursachen von »la vie chère $\aleph^{236}$ keineswegs im Mittelpunkt des Interesses der Revolutionsführer, der Montagnards ebensowenig wie der Girondins. Die Sichtweise beider Seiten war vielmehr gleichermaßen geprägt von kriegspolitischen, den inneren Feind in den Mittelpunkt rückenden Deutungsmustern, die Barère als Vertreter der fraktionell ungebundenen Plaine mit der Frage nach einem von London nach Paris führenden "fil d'or conducteur de ces drames contre-révolutionnaires«

\footnotetext{
${ }^{233}$ AP, 18.1.1792.

234 "Que le jugement de Louis ait été, sinon la cause, au moins le prétexte des hostilités des Anglais et des Espagnols, c'est ce qui n'est pas douteux, puisque c'est à partir de ce moment où ils ont rompu, d'une manière outrageante, toute communication avec la France«. Patriote Français, 28.3.1793. Der Artikel setzt zugleich den Krieg gegen Österreich als sinnvolle revolutionäre Maßnahme vom Krieg gegen England und Spanien ab.

${ }^{235}$ AULARD, Société des Jacobins, Bd. 5, S. 46f., 27.2.1793.

${ }^{236} \mathrm{Vgl}$. zu den Ursachen A. MATHIEZ, La Vie chère et le mouvement social sous la Terreur, 2 Bde., Paris 1973 (Orig. 1927), hier Bd. 1, S. 109-182.
} 
zum Ausdruck brachte ${ }^{237}$; nur in der Spezifizierung des inneren Feindes unterschieden sich Gironde und Montagne diametral. Robespierre sah hinter den Unruhen »les desseins perfides des ennemis de la liberté, des ennemis du peuple, bien convaincus que le seul moyen de nous livrer aux puissances étrangères est d'alarmer le peuple sur les subsistances et de le rendre victime des excès qui en résultent $\aleph^{238}$, und gemeint war damit eindeutig der in Regierung und Nationalversammlung dominierende Kreis um Brissot, wie die unmittelbar folgende Ankündigung von Collot d'Herbois zeigt, er werde »démasquer les Brissotins" und beweisen, daß Innenminister Roland in England viele Millionen gehortet habe. Für die Brissotins waren es umgekehrt ihre radikalen jakobinischen Widersacher, die sie als Hintermänner und Provokateure von Unruhen ansahen, welche nur dazu dienen könnten, die innere Ordnung der jungen Republik zu zerstören und so ihre Verteidigungsanstrengungen zu untergraben. Sie forderten deshalb die Anklageerhebung gegen Marat, weil er die Plünderungen gerechtfertigt habe und zu denen zähle, »qui veulent faire régner l'anarchie, parce que l'anarchie conduit à la royauté «"29.

Die nicht nur von außen, sondern mit dem beginnenden Aufstand der Vendée auch im Innern wachsende militärische Bedrohung, die mit Dumouriez einmal mehr in einem frondierenden General ihre deutlichste Verbindung fand, führte ähnlich wie im Sommer 1792 auch im Frühjahr 1793 zu einer allgemeinen, immer terroristischere Züge annehmenden Radikalisierung des Kampfes gegen die äußere und innere Konterrevolution. Eine wichtige Etappe auf dem Weg zur vollständigen Etablierung der terroristischen Diktatur, der hier wesentlich in den folgenden Kapiteln behandelt wird, war der Sturz der Gironde Ende Mai bzw. Anfang Juni 1793. Ihre Vertreter hatten sich seit dem vergangenen Herbst um eine Konsolidierung der neuen Republik bemüht und den terroristischen Radikalismus der Pariser Volksbewegung und ihrer Fürsprecher in Jakobinerklub und Bergpartei bekämpft. Als nun die militärische Bedrohung in der Logik des revolutionären Diskurses emeut zu einer verschärften Wendung gegen den inneren Feind führte, geriet auch die Gironde immer stärker unter Druck, weil sie in den vorangegangenen politischen Debatten »avec les puissances coalisées, avec les émigrés, avec tous les royalistes, ennemis ligués de la République«, gestimmt habe ${ }^{240}$. Ihre Führer mochten noch so sehr die kriegspolitische Geschlossenheit der Nation beschwören, wenn sie nun forderten, »que la grande famille des Français ne

${ }^{237}$ AP 59, S. 272f., 26.2.1793.

${ }^{238}$ AULARD, Société des Jacobins, Bd. 5, S. 44, 25.2.1793; das folgende ebd., S. 45.

${ }^{239}$ So Buzot am 26.2.1793 im Konvent, nachdem Salle gefordert hatte, Marat unter Anklage zu stellen. AP 59, S. 276.

${ }^{240}$ Adresse der Sektion Quatre-Nations an die anderen Pariser Sektionen, abgedr. in: Patriote Français, 14.3.1793. 
soit plus qu'une armée, que la France ne soit plus qu'un camp où l'on ne parle que de guerre, où tout tend à la guerre, où tous les travaux n'ayent pour objet que la guerre $\aleph^{241}$. Doch Unterstützung für ihre Politik konnten sie damit kaum noch mobilisieren. Viel zu stark war die kriegspolitische Beschwörung der nationalen Einheit längst unauflöslich verbunden mit der revolutionären Wendung gegen den inneren Feind, die die Führer der Gironde angesichts der terroristischen, nicht zuletzt sie selbst bedrohenden Tendenzen nicht bedienen wollten und wohl auch kaum noch konnten.

Vergeblich versuchten die Girondisten demgegenüber beschwichtigend zu betonen, da $\beta$ die permanente Beschwörung des "mystère de cette exagération des dangers de la patrie« nur dazu diene, eine Rechtfertigung für die von den Jakobinem angestrebte terroristische Diktatur zu bieten, während das Geheimnis des militärischen Erfolges "dans la constitution promptement descertée» liege: „Qui veut la retarder, combat pour le Prussiens $\aleph^{242}$. Ihre Wendung gegen die "orateurs, dont les uns sont évidement soudoyés par les puissances étrangères, dont les autres veulent marcher à la tyrannie par la popularité $\ll^{243}$, gegen die "agents des puissances ennemies«, die die französische Armee desorganisieren und gemeinsam mit den Aristokraten "le signal de la guerre civile " geben wollten, die schließlich durch »la mort de Louis et les massacres et les pillages de Paris, ont seul fanatisé les têtes anglaises, allemandes et espagnoles, et par conséquent nationalisé cette guerre ${ }^{244}$, gegen die in jedem Fall angesichts der "correspondance entre les ennemis du dehors et ceux du dedans ${ }^{245}$ als "gens des rois $"$ unnachsichtig vorgegangen werden müsse: $» D e ́-$ truisez cette avant-garde de l'armée de Coblentz: nos braves soldats ferront le reste. Douteriez-vous de l'intelligence qui règne entre les traîtres que je vous dénonce et les rois coalisés contre nous? examinez leur conduite depuis six mois, voyez-les semant la division et la haine entre les patriotes, entre les vrais républicains; séparant la nation en deux classes, afin d'affaiblir d'autant sa puissance $\ldots \mathrm{N}^{246}$. Alle diese gegen die innere Radikalisierung als Instrument der äußeren Aggression zielenden Angriffe konnten keine durchschlagende Wirkung erzielen. Zwar wiesen die weiterhin auf ihre Selbständigkeit bedachten Révolutions de Paris darauf hin, daß auch die Gironde letztlich zum Opfer einer von Pitt angestifteten, von Agenten der Konterrevolution in allen politi-

${ }^{241}$ So Brissot im Konvent, 1.2.1793. AP 58, S. 113.

242 Patriote Français, 10.3.1793.

${ }^{243}$ So der Patriote Français, 14.3.1793, über die Rede von Isnard im Konvent am 12.3.1793; hier auch die folgenden Zitate. Isnard hatte sich vor allem gegen einen Aufruf zur Erhebung gegen den Konvent gewendet und hingewiesen auf »l'analogie qui se trouve entre ce que nos ennemis doivent désirer, et ce que l'on a cherché à persuader au peuple; il est clair que, pour opérer la contre-révolution, il faut dissoudre la Convention«. AP 60, S. $123 f$.

${ }^{244}$ Patriote Français, 28.3.1793.

${ }^{245}$ So Lasource am 30.3.1793 im Konvent. AP 60, S. 717.

${ }^{246}$ So Guadet in einer Rede gegen die Jakobiner, die er im Konvent nicht beenden konnte. Zit. n. Patriote Français, 7.5.1793. 
schen Lagern getragenen Verschwörung werden solle ${ }^{24}$. Doch da angesichts einer allseits wachsenden militärischen Bedrohung nun jede Mäßigung im Kampf gegen die Konterrevolution als Verrat erschien, rückte in umgekehrter, aber ebenso kriegspolitisch begründeter Weise der undifferenzierte Kampf gegen die "parti qui veut la perte de la République ${ }^{248}$ immer stärker und erfolgreicher ins Zentrum der radikalen Agitation.

Es war in der Tat nicht so, wie die jakobinische Legende Glauben machen will, daß die Montagne ihre liberalen Prinzipien und die Gironde der Pariser Volksbewegung geopfert hätte, allein um notwendige Voraussetzungen für eine effiziente militärische Verteidigung zu schaffen. Wohl waren die Montagnards schließlich eher bereit zu Maßnahmen der staatlichen Wirtschaftsregulierung im Interesse der Lebensmittelversorgung, und zweifellos besaß die Pariser Volksbewegung in ihrem Kampf gegen die Gironde ein hohes $\mathrm{Ma} B$ an Autonomie ${ }^{249}$. Doch die Wendung der Montagnards gegen die Gironde entsprang, unabhängig davon, eigenen Antrieben, und sie war wesentlich bedingt durch die Interpretation innenpolitischer Gegensätze auf der Basis der Identifikation von innerer und äußerer Konterrevolution, die die Gironde schließlich als »Vaterlandsverräter« auf das Schafott führte.

Zwar lamentierte Robespierre angesichts der ersten militärischen Rückschläge in Belgien im Konvent noch vorsichtig, "que c'est dans l'intérieur qu'est la source du mal, que le gouvernement n'est pas assez firme, que la Convention nationale n'exerce pas une surveillance assez active contre les ennemis de la liberté, qu'elle ne protège point assez les patriotes opprimés, qu'elle ne surveille point assez les agents du pouvoir exécutif $\ll^{250}$. Doch in der breiteren Öffentlichkeit war es schon lange nicht mehr nur die zögerliche Wendung gegen den inneren Feind, die ins Zentrum der Kritik rückte, sondern die girondistische Führung von Regierung und Konvent wurde selbst zum inneren Feind erklärt, der Frankreich an die Koalition der monarchischen Mächte ausliefern wolle. »Nous savons bien«, so hieß es im Jakobinerklub, »que la déclaration de guerre que nous avons notifiée à l'Angleterre, est une nouvelle perfidie de la part de Brissot $\aleph^{251}$.

Im Rahmen der allgemeinen Beschwörung des Kampfes gegen den äußeren

${ }^{247}$ Vgl. Révolutions de Paris, 9.-16. und 16.-23.3.1793, Bd. 15; hier S. 526 die umfassende verschwörungstheoretische Wertung: »Pitt $\&$ ses agents profitaient pour égarer nos armées de la défiance que quelques chefs avaient inspirée au soldat; \& pour égarer les départements de l'intérieur, il ajoutait à la haine que les chauds patriotes avaient pour le parti de la Gironde $\&$ de Brissot; mais leur projet était d'écraser à la fois \& les généraux \& les armées, d'égorger \& le côté droit \& la montagne«.

${ }^{248}$ So Robespierre im Jakobinerklub, 17.4.1793. AULARD, Société des Jacobins, Bd. 5, S. 173.

${ }^{249} \mathrm{Vgl}$. SLAVIN, The Making of an Insurrection.

${ }^{250}$ Rede vom 10.3.1793, abgedr. in: ROBESPIERRE, CEuvres complètes, Bd. 9, S. 306-313, hier S. 313; etwas anders die Wiedergabe in AP 60, S. 55-57, nach dem Logotachigraphe.

${ }^{251}$ So Desfieux, 9.3.1793, in: AULARD, Société des Jacobins, Bd. 5, S. 80. 
und inneren Feind rückte nun tatsächlich nicht mehr die Kritik an, sondern die physische Ausschaltung der Gironde in den Mittelpunkt der Agitation. "Non, je le jure «, hatte Robespierre schon Mitte März unter großem Beifall im Jakobinerklub erklärt, "ma patrie ne sera pas esclave d'un Brissot, d'un Brunswick, et de quelques hommes que je ne veux pas nommer. Nous savons mourir, nos mourrons tous«. Noch beeindruckender aber war die Korrektur von Marrat, der die kriegerische Konsequenz aus der beschworenen Bereitschaft zum Sterben zog: "Non, nous ne mourrons point; nous donnerons la mort à nos ennemis, nous les écraserons ${ }^{252}$. Das war ganz ernst gemeint, und es richtete sich explizit gegen den innenpolitischen Gegner, der die französische Politik vermeintlich im Interesse des feindlichen Auslandes führte. "Dans l'intérieur, nos maux ne viennent point du peuple; ils ne viennent point des Sociétés populaires, comme osent le dire les traîtres qui nous livrent à nos ennemis«, stellte Robesbierre am 29. März im Jakobinerklub fest: »Ils viennent des corps administratifs, du gouvernement et des scélérats qui se liguent avec les cabinets de Londres ou de Berlin pour leur livrer nos frontières $\aleph^{253}$.

Als zwei Tage später die Nachricht von Dumouriez' Abfall Paris erreichte und die Hauptstadt unmittelbar bedroht zu sein schien, wurde die Position der Gironde, die vor allem von Marat schon seit Monaten der Komplizenschaft mit einer konterrevolutionären Militärführung beschuldigt worden war, immer schwieriger. Vorangegangen waren tiefgehende, mit grundlegenden Fragen des Verhältnisses zwischen Parlament, Regierung und Militärführung verbundene Auseinandersetzungen über die Politik des Generals im besetzten Belgien, in deren Verlauf die Girondisten Dumouriez noch gegen scharfe Kritik aus den Reihen der Montagne verteidigt hatte. Schon dabei war nicht nur die allgemeine Gefahr beschworen worden, "qu'un général habile et vainqueur revient en France sans avoir besoin de vous donner ses comptes, et passât enfin le Rubicon«, sondern die Montagnards hatten auch die Militärführung und die girondistische Regierung in einen engen Zusammenhang gerückt und vor Strukturen gewarnt, die »entre les mains du ministère et des généraux une véritable dictature« ermöglichen könnten. Vor diesem Hintergrund richtete sich die Wendung Öffentlichkeit gegen den rebellierenden General zugleich auch gegen die Gironde ${ }^{24}$. Nun gelang es zwar dem eigentlich durch seine erst

${ }^{252}$ AULARD, Société des Jakobins, Bd. 5, S. 89, 13.3.1793.

${ }^{253}$ Ebd., S. 111, 29.3.1793.

${ }^{254}$ Vgl. M. BELOSSO, Pouvoir Exécutif, Centralité Législative. Le débat sur l'organisation du ministère de la Guerre (janvier - février 1793), in: Annales Historiques de la Révolution Française, 70. Jg. 1998, S. 699-718. Während die Gironde tendenziell für eine starke Stellung der Generalität gegenüber den Soldaten einerseits, ihre Unterordnung unter eine starke Regierung andererseits eintrat, verfochten die Montagnards die Selbständigkeit der Soldaten gegenüber den Offizieren und die Unterordnung von Armeeführung und Kriegspolitik unter den Konvent. Die Zitate Buzot, AP 57, S. 745, 21.1.1793; ROBESPIERRE, Lettre à mes commettans, deuxième série, No 5, in: DERS., Euvres complètes, Bd. 5, S. 272. 
wenige Tage zurückliegende persönliche Zusammenarbeit mit dem General in Belgien am meisten kompromittierten Danton, sich ohne größere Probleme zu rechtfertigen, indem er vehement den Kampf gegen den inneren Feind beschwor und im Konvent seine berühmte Kriegserklärung an die von ihm bislang insgeheim umworbene Gironde vortrug ${ }^{2 s 5}$. Diese aber rückte sich mit der halbherzigen, weiterhin "l'anarchie ..., la cause de tous nos maux " kritisierenden Wendung "contre Dumouriez et contre tous les autres ennemis ${ }^{256}$ selbst ins Abseits, zumal sie nicht bereit zu sein schien, die geforderten "mesures véritablement révolutionnaires « ${ }^{257} \mathrm{zu}$ beschließen.

„Vous voyez dans quels pièges la bande brissotine et la clique de la Gironde vous a conduis. Levez vous«, so lautete die Situationsanalyse des Père Duchesne ${ }^{2 s 8}$, die unter den Pariser Volksmassen nun immer weiter um sich griff. "Un général, à la tête d'une faction scélérate, fort des traîtres qu'il a rangés dans son parti, menace notre liberté«, erklärte Chaumette als Vertreter der Pariser Kommune im Konvent. "Nous serions ses complices, si dans une position aussi critique, nous n'adhérions aux mesures vigoureuses qui nous sont proposées (...) Citoyens, il faut abattre les auteurs de cette guerre qui nous a coûté tant de sang «'s9. Damit waren die Girondisten gemeint, die nun ganz explizit auf die Anklagebank und damit auf die Vorstufe zum Schafott gerückt wurden. »Dumouriez est la créature de cette faction scélérate qui a provoqué la déclaration de guerre«, stellte Marat im Jakobinerklub unter großem Beifall fest, »il me faut des faits, et je ne serai jamais satisfait que lorsque la tête des traîtres roulera sur l'échafaud火. Dies war nun offensichtlich die Meinung der Mehrheit der Jakobiner, denn nachdem auch Robespierre noch einmal gegen die Komplizen von Dumouriez an der Spitze von Regienung, Verwaltung und Konvent gehetzt hatte, die die Revolution unverantwortlicherweise in den Krieg geführt hätten, verabschiedeten die Jakobiner nun eine Aufforderung zur revolutionären Massenmobilisierung, in der es hieß: „Oui, la contre-révolution est dans le gouvernement (...), dans la Convention nationale! C'est là, c'est au centre de votre sûreté et de vos espérances que des criminels délégués tiennent les fils de la trame qu'ils ont ourdie avec la horde des despotes qui viennent nous égorger! (...) Levons-nous! Oui, levons-nous tous! Mettons en état d'arrestation tous les

${ }^{255}$ Vgl. AP 61, S. 59, 1.4.1793.

${ }^{256}$ Patriote Français, 5.4.1793; das zweite Zitat ist eine Wiedergabe aus der Rede Brissots im Konvent, 3.4.1793, in der er sich gegen die von Robespierre geforderte Anklageerhebung verteidigte und dabei wesentlich seine Kriegspolitik rechtfertigte. Vgl. später auch Brissots Erwiderung "Sur la dénonciation de Robespierre, et sur l'adresse prêtée aux 48 sections de Paris«, in der er die Anklage, ein englischer Agent zu sein, umdrehte: "Si Pitt paie quelqu'un, ce sont les anarchistes; voilà ses alliés les plus utiles«. Patriote Français, 20.4.1793.

${ }^{257}$ So Robespierre am 3. April in seiner Anklage gegen das Comité de défense générale und speziell gegen Brissot. AP 61, S. 271.

${ }^{258}$ Père Duchesne, Nr. 226.

259 Zit. n. Patriote Français, 4.4.1793. 
ennemis de notre révolution et toutes les personnes suspectes. Exterminons sans pitié les conspirateurs, si nous ne voulons être exterminés nous-mêmes $\aleph^{200}$.

Damit war bereits das Drehbuch für den Aufstand gegen die Gironde geschrieben, der knapp zwei Monate später dann tatsächlich zu ihrer Ausschaltung führte. Noch war die Stimmung dafür allerdings nicht aufgeladen genug, vor allem wohl weil Dumouriez mit dem Versuch, sseines Truppen gegen Paris zu fuihren, ebenso an der Weigerung der soldats citoyens scheiterte wie vor ihm La Fayette. Doch in den folgenden Wochen spitzte sich der Konflikt zwischen Gironde und Montagne immer weiter zu. Dies fand seinen ersten öffentlichen Ausdruck am 10. April im Konvent, als sich Robespierre und Vergniaud, der nun an die Spitze der Gironde rückte, eine große Redeschlacht lieferten. Robespierre attackierte, anstatt sich mit dem eigentlich zur Diskussionen anstehenden Antrag Pétions auf Verurteilung einer zur Insurrektion aufrufenden Adresse zu befassen, erneut die Konspiration der »ennemis intérieurs et extérieurs" und besonders "Brissot! combien de faits n'aurais-je pas à rappeler sur lui et sur la faction dont il est le chef? Brissot! dont les discours, dont les harangues ne sont que des manifestes de Brunswick, et ressemblent par tout, pour l'esprit et pour le style, au langage des cours étrangères et des ministres hypocrites, et au discours de Coblentz (Murmures), que n'aurais-je point à dire si je voulais relater son rôle néfaste dans cette guerre (nicht: in dieser Revolution!, WK), si je voulais montrer comment après nous avoir fait déclarer la guerre à l'Europe au nom de l'émancipation des peuples, il ne cessa de nous inspirer, dès que nous y fûmes engagés « ${ }^{261}$. Vergniaud wandte sich in seiner Antwort umgekehrt gegen alle Angriffe auf den Konvent und forderte, daß die Unterzeichner der von Pétion denunzierten Adresse vor das Revolutionstribunal gestellt werden müßten; den Abgeordneten erklärte er schlicht: »Tout homme qui conspire contre vous est l'allié de l'Autriche «'262.

Während die gemäßigten Kräfte weiterhin primär die Pariser Anarchie zu bekämpfen versuchten und erst Marat als Unterzeichner der jakobinischen Erklärung vom 5. April und im Mai dann Hébert für seine "grande dénonciation du Père Duchesne (...) au sujet des complots formés par les brissotins, les girondins, les rolandins, les buzotins, les pétionistes et toute la foutue séquelle des complices de Capet et de Dumouriez (263 $^{263}$ letztlich erfolglos unter Anklage stellten, konnte die Agitation für ihre Ausschaltung eine immer größere Wirkung erzielen, vor allem als zuerst in Marseille, später dann auch in Lyon die Jakobinerherrschaft gestürzt wurde. Von besonderem Einfluß war

${ }^{260}$ Circulaire de la Société des Amis de la Liberté et de l'Egalité, 5.4.1793, abgedr. in: AULARD, Société des Jacobins, Bd. 5, S. 126-128.

${ }^{261}$ AP 61, S. 530-541 (mit Unterbrechungen), hier S. 540; vgl. allg. A. MATHIEZ, Robespierre et Vergniaud, in: DERS, Girondins et Montagnards, S. 20-69.

${ }^{262}$ AP 61, S. 542-549 (mit Unterbrechungen), hier S. 549.

${ }^{263}$ Zit. n. L. JACOB, Hébert. Le Père Duchesne, chef des sans-culottes, Paris 1960, S. 153. 
dabei eine Flugschrift von Desmoulins, in der erneut auch die allgemeine fundamentale Bedeutung des Krieges für die innenpolitischen Konflikte hervortrat: "Je vais établir contre Brissot et Gensonné l'existence d'un comité Anglo-Prussien, par un ensemble d'indices cent fois plus forts que ceux par lesquels eux, Brissot et Gensonné prouvaient l'existence du comité autrichien. Je mets en fait que le côté droit de la Convention, et principalement les meneurs, sont presque tous partisans de la royauté, complices des trahisons de Dumouriez et Beurnonville, dirigés par les agents de Pitt, de d'Orléans et de la Prusse $\ll^{264}$.

Es war durchaus zutreffend, wenn Desmoulins die Auffassung vertrat, jeder Leser seiner Denunziationsschrift werde sich die Frage stellen: „Où est la chafotte?«. Je näher die militärische Bedrohung rückte, desto eindeutiger trat nun der Kampf gegen die Brissotins als Voraussetzung des militärischen Erfolges in den Mittelpunkt der radikalen Agitation. "Vous allez combattre les fanatiques de la Vendée«, so forderte der Vizepräsident des Jakobinerklubs Desfieux die Freiwilligenregimenter, ganz nach dem Muster vom Vorjahr, zur revolutionären Erhebung auf, "leurs chefs sont à Paris, les brigands de la Vendée ne sont que leurs instruments. Détruisez la cause, et l'effet cessera ${ }^{205}$. Marat erklärte noch eindeutiger, "c'est au sein de la Convention qu'est le foyer de la contre-révolution!«, um dann unter großem Lärm fortzufahren: "Leur plan de machination, concerté avec des ministres perfides et des généraux conspirateurs, tend à retarder le recrutement et à faciliter l'entrée des hordes étrangères ${ }^{266}$. Nachdem Isnard nun den Fehler gemacht hatte, in der Diktion des Herzogs von Brauschweig die Vernichtung von Paris anzudrohen, wenn die Bevölkerung sich gegen den Konvent wende, war der Aufstand "Contre Brissot et les $\curlywedge$ hommes criminels ${ }^{207}{ }^{26}$ nicht mehr aufzuhalten. Am 31. Mai marschierten die Pariser Sektionen in militärisch formierten, nicht nur mit Gewehren und Piken, sondern auch mit Kanonen bewaffneten Marschkolonnen zum Konvent und forderten die Inhaftierung von 29 girondistischen Abgeordneten, die schon seit Anfang Mai auf einer von der Pariser Sektionsversammlung aufgestellten Proskriptionsliste namentlich verzeichnet waren, und der ihnen nahestehenden Minister Clavière und Lebrun. Zuerst weigerte sich die ja keineswegs aus Mitgliedern der Bergpartei zusammengesetzte Konventsmehrheit, nach der Aufhebung der besonders verhaßten, zur Untersuchung von Vorwürfen gegen die Pariser Kommune gebildeten Zwöl-

${ }^{264}$ C. Desmoulins, Histoire des Brissotins ou Fragment de l'histoire secrète de la Révolution, et des six premiers mois de la République, abgedr. in: Guvres, Bd. I, S. 509 590, hier S. 515.

${ }^{265}$ AULARD, Société des Jacobins, Bd. 5, S. 195, 17.5.1793.

${ }^{266}$ Ebd., S. 190, 19.5.1793; im Publiciste de la République française vom 9.5.1793 hatte Marat eine »liste d'épurement" präsentiert, nach der mehr als 100 Abgeordnete aus dem Konvent ausgeschlossen werden sollten.

${ }^{267}$ So Robespierre am 28.5. im Konvent. AP 65, S. 495. 
ferkommission, den Forderungen der Massen weiter nachzugeben. Doch als der Aufstand sich fortsetzte, wurde schließlich, nach einer von Marat vorgeschlagenen Abänderung der Proskriptionsliste, die Arretierung der führenden Girondisten beschlossen.

Die Führer der Montagne fügten sich dabei keineswegs nur dem Massendruck. Sie hatten den Aufstand agitatorisch vorbereitet, und im Konvent übernahm Robespierre schon am 31. April offen die Forderung nach einer Anklageerhebung »contre tous les complices de Dumouriez et contre tous ceux qui ont été désignés par les pétitionnaires ( $^{268}$. Im Jakobinerklub traten Montagnards wie Billaud und Chabot ebenfalls schon am 31. Mai für die Fortsetzung des Aufstandes bis zur völligen Zerschlagung der Gironde ein; es gebe "quarante membres dans la Convention qui sont d'intelligence avec les puissances étrangères«, so war man hier überzeugt, »trente ou quarante membres qui sont salariés par les ennemis et qui s'opposent au mesures du salut public. Si ces membres gangrenés restent, il sera impossible de sauver le peuple ${ }{ }^{269}$. Und am 2. Juni, als die Abgeordneten nach dem Scheitem des Versuchs, den Konvent kollektiv zu verlassen, angesichts der anhaltenden bewaffneten Bedrohung auf einmal in hektischer Weise nach Kompromißformen suchten und Barère als Vertreter der Plaine die vorläufige Suspendierung der Inkriminierten anregte, war es schließlich der Montagnard Levasseur, der als erster offen die dann durchgeführte Inhaftnahme und Anklageerhebung forderte, denn, wie er wieder ganz kriegsbezogen argumentierte, "ceux-là sont bien suspects, qui nous on fait déclarer la guerre à tous les puissances sans avoir préparé les moyens de défense $\aleph^{270}$.

Der Konflikt war damit noch nicht endgültig ausgestanden. Nachdem 77 Abgeordnete öffentlich den Verstoß gegen die Souveränität des Parlaments und gegen die Abgeordnetenimmunität kritisiert hatten, wurden sie ebenfalls aus dem Konvent ausgeschlossen. Und während einige der Inhaftierten Girondisten fliehen konnten und sich nun tatsächlich teilweise an der sogenannten föderalistischen Erhebung gegen Paris beteiligten, folgte in der Hauptstadt die keineswegs problemlose juristische Abwicklung. "Les vrais coupables sont ceux qui ont fui«, so versuchte Saint-Just am 8. Juli als Vertreter des Wohlfahrtsausschusses die Konventsabgeordneten im Namen der Meinungsfreiheit zur Milde anzuhalten, "proscrivez ceux qui nous ont fui pour prendre les armes (...) et pardonnez au plus grand nombre « ${ }^{271}$. Doch während es tatsächlich ganz selbstverständlich erschien, die am Aufstand beteiligten Ex-Abgeordneten zu "traîtres à la patrie» zu erklären, wollte sich die

${ }^{268}$ AP 65, S. 655, 31.5.1793.

${ }^{269}$ So die Äußerungen von Militärs am 31.5. bzw. am 1.6., abgedr. in AULARD, Société des Jacobins, Bd. 5, S. 221; die Diskussionen insgesamt, unter anderem die Stimmen von Billaud und Chabot, ebd., S. 220-225.

${ }^{270}$ AP 65, S. 702, 2.6.1793.

${ }^{271}$ AP 68, S. 426-436, 8.7.1793. 
Konventsmehrheit unter dem Druck der allgemeinen Radikalisierung nun keineswegs darauf einlassen, die Mehrheit der Ausgeschlossenen, wie von Saint-Just gefordert, wieder in ihre Reihen aufzunehmen. Schließlich schien die Politik der Gironde insgesamt das Ziel verfolgt zu haben, "la coalition de tous les despotes de l'Europe contre la République« zu schaffen, wie Billaud eine Woche später hetzte, "pour anéantir la République, pour proscrire à jamais le règne de la liberté, pour livrer toutes les parties de la France aux horreurs d'une guerre générale, pour abandonner le peuple au pillage et aux fureurs sanguinaires d'une soldatesque indigène et étrangère; en un mot, pour établir, ou un duc d'York, roi de France, si Brunswick et Cobourg eussent triomphé, ou le fils de Louis Capet, si l'empereur fût resté maître du champ de bataille $\aleph^{272}$.

Als Amar schließlich am 3. Oktober namens des Sicherheitsausschusses die dann offiziell angenommene Anklageerhebung vortrug, waren aus den neun Landesverrätern und fünf Verdächtigen, die Saint-Just benannt hatte, nunmehr 46 Angeklagte geworden. Ihnen wurde nun wesentlich eine Kriegspolitik zur Last gelegt, die sie im Interesse des äußeren Feindes konzipiert und durchgeführt hätten ${ }^{273}$. "La Cour et tous les ennemis de la France se servaient de leur influence pour faire déclarer la guerre dans le temps où nos armées, nos places fortes, étaient dans un état de dénuement absolu, et confiés à des traîtres choisis par un roi parjure«, hieß es in bezug auf den Kriegsbeginn noch zurückhaltend, um dann vor allem die Verbindung mit England in den Mittelpunkt zu stellen: "La marche des conjurés fut en tout confirmé à celle des ennemis de la France, et surtout des Anglais. Pitt voulait déshonorer dans l'Europe la République naissante: Brissot et ces complices ont pris à tâche de la calomnier (...) Pitt voulait avilir et dissoudre la Convention; ils ont mis tant en cuvre pour l'avilir et pour la dissoudre. Pitt voulait assassiner les fidèles représentants du peuple; ils ont tenté plusieurs fois de faire égorger une partie de leurs collègues; ils ont assassiné Marat et Lepelletier«. Neben einer Reihe weiterer gemeinsamer Projekte wie der Zerstörung von Paris, der Wegnahme der Kolonien, der Entfachung des Bürgerkrieges oder der Einsetzung eines ausländischen Herzogs als Stadthalter ging es auch weiterhin wesentlich um kriegspolitische Zusammenhänge der Verschwörung: "Pitt voulait armer toutes les puissances contre la France; ils ont déclaré la guerre à toutes les puissances. Pitt voulait faire conduire les soldats de la République à la boucherie par des généraux perfides; ils ont mis à la tête de nos armées tous les généraux qui nous ont trahis pendant le cours de deux années«.

${ }^{272}$ AP 69, S. 21-31, hier S. 25, 29, 15.7.1793.

${ }^{273}$ AP 75, S. 520-535, 3.10.1793, die Zitate S. 522, 533. Vgl. auch die das Todesurteil fordernde Agitation des Père Duchesne, Nr. 303, mit dem Argument: »c'est vous, foutre, et c'est là le plus grand de tous vos crimes, c'est vous qui nous avez mis sur le dos toutes les puissances de l'Europe, et qui avez allumé la guerre universelle«. 
Das reichte in einer inzwischen vom offiziellen Terror der revolutionären Regierung geprägten politischen Situation nun endlich aus, die Girondisten am 31. Oktober 1793 auf das Schafott zu bringen. 


\section{Krieg und revolutionäre Radikalisierung II: Massenmobilisierung und Terror 1793}

Am 12. August 1793 ergriff im Nationalkonvent Charles Royer als Sprecher einer Delegation der zur Verabschiedung der neuen Verfassung nach Paris entsandten Urwählervertreter das Wort und brachte angesichts der von außen und innen bedrohten "république assiégée ${ }^{274}$ zwei miteinander verbundene Forderungen vor, die nicht nur den revolutionären Diskurs im Sommer 1793, sondern auch den weiteren Verlauf der Revolution prägen sollten. Der Konvent solle, so Royer, dekretieren, »que le peuple se lève en masse« und gleichzeitig dafür sorgen, "que l'aristocratie devienne entre nos mains l'instrument de sa propre destruction ${ }^{273}$. Gemeint war damit, daß die früheren Aristokraten und darüber hinaus alle der Revolutionsfeindschaft Verdächtigen verhaftet und im Zusammenhang der allgemeinen Erhebung von der wmasse terrible de tous les sans-culottes de la République « in der ersten Frontlinie gegen die feindlichen Heere getrieben werden sollten; ihre Angehörigen sollten derweil als Geiseln gehalten werden. Die »levée en masse« wurde vom Konvent angenommen und nur wenig später, am 23. August, offiziell erklärt. Anfang September setzte der Konvent, wiederum auf Initiative von Royer und auf Druck der Pariser Volksbewegung, auch den Terror »à l'ordre de jour«, so daß es naheliegt, beide Maßnahmen in einem engen Zusammenhang zu sehen. Die politische Diskursanalyse vermag in der Tat zu zeigen, wie Massenmobilisierung und Terror in den gesellschaftspolitischen Entwicklungen des Jahres 1793 sowie in ihrer sprachlichen Verarbeitung und Gestaltung zu einer zwar nicht an und für sich notwendigen, in der konkreten diskursiven Entwicklung aber untrennbaren Einheit miteinander verbunden wurden.

"Catastrophie, Circumstance or Cancer?«. Mit diesen drei Begriffen hat Hugh Gough treffend die divergierenden Grundpositionen der Forschung zur Erklärung des Terrors gekennzeichnet ${ }^{276}$. Für die erste, die konservative Deutungsweise stellt bereits die Revolution selbst eine fundamentale Katastrophe

${ }^{274}$ BOULOISEAU, République jacobine, S. 81.

${ }^{275}$ AP 72, S. 101; zur Interpretation vgl. W. KRUSE, Massenmobilisierung und Terror in der Französischen Revolution. Eine Quelleninterpretation zum Verständnis der revolutionären Radikalisierung des Jahres 1793, in: Geschichte in Wissenschaft und Unterricht. 52. Jg. 2001, S. 111-121.

${ }^{276} \mathrm{H}$. GoUGH, The Terror in the French Revolution, London u.a. 1988, S. 2. Zur allgemeinen Analyse des Terrors vgl. P. GUENIFFEY, La Politique de la terreur; K. M. BAKER (Hg.), The French Revolution an the Creation of a Modern Political Culture, Bd. 4: The Terror, Oxford 1994; C. LuCAS, The Structure of the Terror. The Example of Javogues an the Loire, Oxford 1973; H. BLONECKE, Revolutionsregierung und Volksbewegung (17931794). Die "Terreur« im Departement Seine-et-Marne (Frankreich), Frankf./M. 1989. 
dar, die mit innerer Notwendigkeit neben vielem anderen Bösen auch zum Terror führen mußte. Diese Sichtweise ist jedoch nicht nur höchst pejorativ, sie kann auch nicht erklären, wieso die Revolution von 1789 bis 1792 innenpolitisch einen höchst liberalen Charakter hatte und bis zum Beginn des Krieges kaum terroristische Tendenzen aufwies. Die jakobinisch-marxistische Orthodoxie hat demgegenüber mit guten Gründen nicht die Revolution, sondern den Krieg für den Terror verantwortlich gemacht. Sie ist dabei allerdings immer wieder der Gefahr erlegen, den Terror wesentlich als einen notwendigen Bestandteil der Verteidigungsanstrengungen einer von innen und außen belagerten Republik zu deuten und damit zugleich zu rechtfertigen. An dieser apologetischen Sichtweise hat schließlich die revisionistische Kritik angesetzt. Während Furet und Richet das terroristische >Ausschleudernı einer ursprünglich liberalen Revolution zuerst allerdings noch eng mit dem Krieg verbunden haben, hat die zunehmend dominierende revisionistische Tendenz zur Ideologiekritik trotz mancher Anleihen beim jungen Marx eine Annäherung an die konservative Sichtweise bewirkt, nach der der Terror in der revolutionären, besonders der jakobinischen Ideologie von Anfang an angelegt war. Er erscheint so wesentlich als Ergebnis ideologischer Prägungen, die mit ihrem Tugendbegriff und ihrer Orientierung an der "volonté générale« in der Tat eine starke Tendenz zu einem antipluralistischen, abweichende Meinungen und partikulare Interessen stigmatisierenden Politikverständnis beinhalteten ${ }^{27}$.

Indes waren dies lange Zeit doch eher untergeordnete Tendenzen neben wichtigen anderen, gegenläufigen, und der Revisionismus ist zweifellos immer wieder der Versuchung erlegen, sie aus dem historischen Kontext zu lösen und in übersteigerter Form zu generalisieren. Will man dagegen die Entwicklung des Jakobinismus und die terroristische Radikalisierung der Französischen Revolution konkret im Rahmen des historischen Kontextes analysieren, drängt sich die Frage nach den allgemeineren, außerhalb der politischen Ideologie liegenden Ursachen für den sich schließlich durchsetzenden Terror geradezu auf. Gegenüber einer Sichtweise, die den Terror in deterministischer, neorevisionistischer Weise zu begreifen versucht als wjene Modalität, in der sich die Entdeckung der Politik abspielen mußte, da die Gesellschaft noch keine moderneren Techniken zum Umgang mit ihren Widersprüchen entwickelt hat-

277 Vgl. L. Boroumand, La Guerre des Principes. Les assemblées révolutionnaires face aux droits de l'homme et à la souveraineté de la nation, mai 1789-juillet 1794, Paris 1999; L. JAUME, Le discours jacobin et la démocratie, Paris 1989; N. HAMPSON, Will and Circumstance. Montesquieu, Rousseau and the French Revolution, Duchworth 1983; DERS., From Regeneration to Terror, in: N. O'SullivaN, Terrorism, Ideology, and Revolution, Brighton 1986, S. 49-66; L. ABDOUL-MELLEK, D'un choix politique de Robespierre: La Terreur, in: C. HAYDEN, W. DoYle (Hg.), Robespierre, Cambridge u. a. 1999, S. 191-203. 
te $\ll^{278}$, sind diese Ursachen nach der hier vorgelegten Analyse des politischen Diskurses wesentlich in der Verbindung mit einem Krieg zu finden, dessen Interpretation als revolutionärer Bürgerkrieg die Grenzen zwischen der äußeren und inneren Revolutionsfeindschaft verschwimmen ließ und so dazu führte, daß sich die kriegerisch-revolutionäre Massenmobilisierung gleichermaßen gegen den äußeren wie gegen den inneren Feind richtete und dabei zunehmend terroristische Formen gewann. Zweifellos ist es sinnvoll, diese Entwicklung mit dem späten Furet auch auf die unbewußten Prägungen zurückzuführen, die die Revolution durch die gewalttätige gesellschaftliche Praxis der alten Ordnung erhalten hatte ${ }^{279}$. Gestaltungsfähigkeit konnten diese Prägungen aber erst in einem Kontext gewinnen, der zutiefst geprägt war von der Vorstellung eines revolutionären Krieges an zwei Fronten, gegen die äuBere und innere Konterrevolution.

Die hier vorgetragene Deutung ist also zwischen Orthodoxie und Revisionismus angesiedelt, weil sie einerseits die kriegsspezifischen Umstände in Rechnung stellt, den Terror andererseits jedoch weder aus den Umständen selbst, noch aus der allgemeinen revolutionären Ideologie oder aus unbewußten Prägungen hervorgehen sieht, sondern aus den spezifischen Deutungsmustern, die sich im Diskurs über den revolutionären Bürgerkrieg schon lange herausgebildet hatten. Demgegenüber hat Mona Ozouf in einen sehr einflußreichen Aufsatz die Auffassung vertreten, daß Krieg und Massenmobilisierung einerseits, der Terror andererseits, gerade im zeitgenössischen Diskurs kaum in einem inhaltlichen Zusammenhang miteinander gestanden hätten ${ }^{280}$. Ihr Versuch, die jakobinisch-marxistische Rechtfertigung des Terrors diskursanalytisch zu hinterfragen und zugleich zu widerlegen, zeichnet sich jedoch durch eine Reihe gravierender Probleme aus. Einmal abgesehen davon, daß die Frage nach der Bedeutung des Terrors für die Landesverteidigung diskursanalytisch letztlich gar nicht geklärt werden kann, tendiert ihre punktuell auf drei jeweils einen Monat umfassende Phasen der terroristischen Radikalisierung (September 1792; August/September 1793; Mai/Juni 1794) eingeengte Perspektive, verstärkt noch durch die Beschränkung auf den halboffiziösen Moniteur als alleinige Quellengrundlage dazu, sowohl die Breite als auch die Dynamik des revolutionären Diskurses auszublenden. Dabei ist Ozouf neben den durchaus vorhandenen, instrumentell-kriegsbezogenen Begründungen des Terrors vor allem entgangen, wie sehr nicht nur der innere und der äußere

${ }^{278}$ So die Charakterisierung von M. MIDDELL in seiner Besprechung von J.-C. MARTIN, Révolution et contre-révolution en France 1789-1989. Les rouages de l'histoire, Rennes 1996, in: Francia, 28/2 (1998), S. 302-304.

${ }^{279}$ Vgl. FURET, Terreur, in: DERS., Ozouf, Dictionnaire Critique, S. 156-169; P. HIGONNET, Goodness beyond Virtue. Jacobins during the French Revolution, Cambridge $u$. London 1998, S. 2.

${ }^{280}$ OzOUF, Guerre et terreur dans le discours révolutionnaire. 
Feind, Krieg und Bürgerkrieg, sondern auch kriegerische Massenmobilisierung und terroristische Radikalisierung im revolutionären Diskurs zunehmend auch unabhängig von allen instrumentellen Bezügen miteinander verschmolzen. Der von Albert Soboul, und vor ihm von vielen anderen Historikern vorgetragene "discours d'identification«, in dem Ozouf wesentlich nur eine geschickte, der Rechtfertigung des Terrors dienende Lösung von chronologischen Abfolge- und rationalen Ursache-Wirkungs-Analysen sieht, findet im zeitgenössischen revolutionären Diskurs tatsächlich eine Entsprechung, deren Analyse keineswegs notwendig einen apologetischen Charakter haben muß. Die wesentlich vom Krieg bestimmten Umstände, so könnte die hier vertretene Position zusammenfassend charakterisiert werden, ließen den Terror nicht zu einer objektiven Notwendigkeit werden, doch ihre spezifische Deutung im revolutionären Diskurs führte mit innerer Notwendigkeit zum Terror.

Insbesondere die selbständige, die Revolution noch einmal radikalisierende Mobilisierung der Pariser Sansculotten hat lange vor allem im Zentrum marxistisch inspirierter Revolutionsforschung gestanden ${ }^{281}$. Ihre grundlegenden Erkenntnisse, daß diese Politisierung wesentlich in sozialen Problemen und Konflikten wurzelte und daß die unter einer akuten Krise der Lebensmittelversorgung leidenden unteren Bevölkerungsschichten gegen die revolutionäre bürgerliche Elite vor allem die Abkehr von liberalen Wirtschafts- und Gesellschaftsprinzipien durchzusetzen versuchten, sollen hier nicht infrage gestellt werden. Vielmehr wird es im folgenden darum gehen zu zeigen, wie sehr und in welcher Weise der Krieg, auch unabhängig von seiner ursächlichen Verknüpfung mit der Teuerungskrise, in die zeitgenössische Deutung und Austragung dieser sozialen Konflikte eingewoben war und dadurch in spezifischer Form die terroristische Radikalisierung des Jahres 1793 geprägt hat. Viele der uns schon bekannten Muster der Verknüpfung von innerer und äußerer Revolutionsfeindschaft, von Krieg und Bürgerkrieg werden dabei erneut eine wichtige Rolle spielen; sie gewannen im Proze $B$ der Radikalisierung, den sie selbst begründeten, zugleich eine neue, zugespitzte Gestalt. In den Mittelpunkt der politischen Diskursanalyse wird nun aber die Verbindung von kriegerischer Massenmobilisierung und terroristischer Politik rücken, wie sie bereits im August/September 1792 einen ersten, spontanen Höhepunkt erreicht hatte.

Die zunehmende Identifikation des revolutionären Kampfes gegen alle, sowohl gegen die äußeren als auch die inneren Feinde der Revolution, wurde zweifellos zum zentralen Strukturprinzip eines revolutionären Diskurses, der zunehmend terroristische Qualität gewann; »exterminer tous les ennemis de

${ }^{281} \mathrm{Vgl}$. bes. A. SoBoul, Les Sans-Culottes de l'an II. Mouvement populaire et gouvernement révolutionnaire, Paris 1958; DERS., Les Soldats de l'an II, Paris 1959; MATHIEZ, La Vie chère. 
l'intérieur et du dehors ${ }^{282}$, diese Aufgabe wurde so zum zentralen Inhalt einer mit dem Krieg identifizierten, terroristischen Revolution, die sich jeweils unter dem Eindruck der forcierten militärischen Bedrohung im Sommer 1792, im Frühjahr und im Sommer 1793 weiter radikalisierte, bis Krieg und Revolution letztlich $z \mathfrak{u}$ einem nicht mehr unterscheidbaren, zugleich das Feindbild immer stärker ausweitenden Kampf gegen alle möglichen Feinde der Revolution verschwammen. Im August 1793, am Vorabend von levée en masse und terreur, erschien in Paris ein Flugblatt, das diese Vermengung in beispielhafter Form zum Ausdruck brachte. Es sei, so hieß es da, wfait de nous, si nous n'exterminons sans délai tous les conspirateurs qui veulent nous détruire ou nous faire redevenir esclaves (...) il faut que la guillotine sera permanente, que l'infâme, le scélérat, la sanguinaire Médicis-Antoinette, les généraux traîtres qui ont vendu Condé, Valenciennes, les députés infidèles qui ont entretenu des correspondances avec les tyrans coalisés, les rebelles de la Vendée et des départements fédéralisés, les administrateurs infidèles, les juges prévaricateurs, les prêtres contre-révolutionnaires, les accapareurs, les agitateurs, les intrigants, les conspirateurs (...) soient jugés sur-le-champ et aillent expier leurs forfaits à l'aimable guillotine (...), car, n'en doutez pas, mes amis, tant que ces scélérats existeront, la république sera en danger et le sang des patriotes ne cessera de couler ${ }^{233}$.

Doch beginnen wir mit der Erbschaft der Septembermassaker, die von den radikalen Revolutionären keineswegs nur, wie Ozouf meint, verschämt verschleiert, sondern auch als wjournée si essentiellement liée avec celle du 10 août, qu'elle a non moins contribué que celle-ci à sauver la République« gefeiert wurden ${ }^{284}$. Schon am 3. September 1792 hatten radikale Vertreter der

${ }^{282}$ Père Duchesne, Nr. 227.

${ }^{283}$ Vgl. MATHIEZ, La Vie chère, S. 264f. Vgl. neben Père Duchesne, Nr. 267, auch J. RouX, Discours sur les Causes des Malheurs de la République Française, abgedr. in: Scripta et Acta, S. 102-139, hier S. 127f.: "Voulez-vous donc mettre fin aux trahisons, à l'anarchie, à la terreur, rétablir les finances, l'esprit public, rendre l'âme et la vie au corps politique, imitéz l'exemple que vous donna le sénat romain; suspendéz les loix envers quiconque s'est déclaré contre la cause du peuple. L'ennemi est à vos portes. (...) Sauvez le capitole, arrêtéz, incarceréz les hommes suspects, les nobles, les prêtres réfractaires, les banquiers, les agents de change, les accapareurs, les ci-devant privilégiés, les étrangers connus par leur incivisme, les supports de la faction contre-révolutionnaire, tous ceux enfin qui depuis quatre ans principalement ont fait une fortune immense, qui ont acheté et vendu l'argent, qui tenaient par principe à l'ancienne cours (sic), qui ont retardé les progrès de la liberté, et qui voyent dans le gouvernement républicain, le tombeau de leur espérance. En séparant les chairs gangrenées pour sauver le reste du corps, en frappant ainsi les serpents qui sont dans votre sein, vous couperéz les vivres à l'ennemi, vous briseréz l'anneau des conspirations; les émigrés perdent leur appuy, (...) vous termineréz, dans peu de temps, cette guerre qui dévore les terres, le commerce, les arts, la population et la liberté«.

${ }^{284}$ Rundschreiben des Pariser Jakobinerklubs an die angeschlossenen Volksgesellschaften, 30.11.1792, abgedr. in: AULARD, Société jacobine, Bd. 4, S. 534-540, hier S. 538. 
Pariser Stadtverwaltung, unter ihnen Marat, die Provinzen dazu aufgefordert, dem Beispiel der Pariser Septembermassaker zu folgen, weil dies ein notwendiger Schritt im Kampf gegen die miteinander verbundene innere und äußere Konterrevolution sei: »La commune de Paris se hâte d'informer ses frères de tous les départements qu'une partie des conspirateurs féroces détenus dans les prisons a été mise à mort par le peuple, actes de justice qui lui ont paru indispensables pour retenir par la terreur ces légions de traîtres cachés dans ses murs au moment où il allait marcher à l'ennemi, et sans doute la nation entière, après la longue suite de trahisons qui l'ont conduite sur les bords de l'abîme, s'empressera d'adopter ce moyen si nécessaire de salut public, et tous les Français s'écrieront comme les Parisiens: Marchons à l'ennemi, mais ne laissons pas derrière nous ces brigands pour égorger nos enfants et nos femmes ${ }^{285}$. Auch die Révolutions de Paris feierten nicht nur die Volksjustiz, sondern sie sahen darin zugleich ein wesentliches Element des revolutionären Kampfes gegen die innere und äußere Konterrevolution: "... la hâche du peuple a fait justice des conspirateurs du dedans; bientôt leur coupable chef tombera sous la hâche des loix; plus tôt encore les armées des despotes conjurés seront repoussées ou taillées en pièces. Le peuple va rester en insurrection permanente jusqu'au parfait établissement de la liberté universelle « ${ }^{286}$.

In der Folgezeit betonte nicht nur ein Robespierre immer wieder den unauflöslichen Zusammenhang von Revolution, Landesverteidigung und Terror ${ }^{287}$. Selbst ein so vergleichsweise gemäßigter jakobinischer Konventsabgeordneter und Militärfachmann wie Dubois-Crancé, der sich scharf von Radikalen wie Marat und Robespierre abzusetzen wußte, sah nicht nur im Sturz der Monarchie, sondern auch im spontanen Terror eine Voraussetzung der revolutionären Stabilisierung: "La Révolution du 10 août a tout calmé, le monstre de la royauté est abattu, la France sera constituée en république, les armées étrangères ont fuit de notre territoire«, stellte er in einer politischen Bestandsaufnahme zum Jahresende 1792 fest, um dann fortzufahren: "et la terreur des vengeances populaires a fait rentrer dans le néant l'ennemi de l'intérieur « ${ }^{288}$. Für Vertreter des Pariser Radikalismus wie Collot d'Herbois und Billaud-

${ }^{285}$ Aufruf vom 3. September, zit. n. Wiedergabe Louvets im Nationalkonvent am 5.11.1782. AP 53, S. 189.

${ }^{286}$ Révolutions de Paris, 1.-8.9.1792, Bd. 13, S. 437. Vgl. auch die Ausgabe vom 6.13.10.1792, Bd. 14 S. 118: "la perfidie de la cour, le succès des armées prussiennes qu'elle avait évidemment favorisé, la résolution que prirent en ce moment tous les citoyens, de mourir ensevelis sous les ruines de la patrie, l'indignation jetée dans tous les cours, tout commanda au courage la nécessité, sans doute affreuse, de purger la patrie d'une foule d'assassins, de brigands, de traîtres fanatiques «.

${ }^{287} \mathrm{Vgl}$. Rede im Nationalkonvent vom 5.11.1792. AP 53, S. 158-165.

${ }^{288}$ Coup-d'œil sur la situation de la Convention nationale, in: Révolutions de France et de Brabant, seconde partie, Nr. 34, S. 279ff., hier S. 280. 
Varenne stand gar fest, daß der Terrorismus nicht nur den inneren Feind in die Schranken gewiesen, sondern auch den militärischen Sieg gegen den äußeren Feind begründet hatte: "Cette vengeance terrible arrêta le roi de Prusse pendant six jours. La crainte de voir la famille royale tomber sous les coups d'un peuple justement irrité a arrêté la marche des Prussiens, et les patriotes se sont ralliés ${ }^{289}$. Und in der populären Diktion des Père Duchesne verschwammen diese rationalen Argumentationsversuche schon Ende 1792 in der allgemeinen terroristischen Propaganda für »la guerre à outrance» gegen den äußeren wie den inneren Feind, den es gleichermaßen zu vernichten gelte: "C'est glorieux de foutre le tour aux Autrichiens, mais il serait plus heureux d'exterminer tous les traîtres dans l'intérieur « ${ }^{200}$.

Auch wenn sich viele radikale Jakobiner, selbst Marat, später von den Massakern distanzierten, ging es ihnen dabei doch weniger um eine grundsätzliche Ablehnung des Terrors als vielmehr um die unkontrollierte Form seiner Ausführung. Der Sinn und Zweck einer terroristischen, Einschüchterung und Vernichtung miteinander verbindenden Politik gegen die inneren Feinde der Revolution wurde dadurch keineswegs infrage gestellte. "C'est donc parce que les conspirateurs étaient soustraits au glaive de la justice, qu'ils sont tombés sous la hâche du peuple«, lautete die zukunftsweisende, auf den justiziellen Terror abzielende Lehre Marats aus dem »événement désastreux « der Septembermassaker ${ }^{29}$. Als im März 1793 erneut gravierende militärische Niederlagen hingenommen werden mußten und zugleich antirevolutionäre Aufstände in der Bretagne und in der Vendée begannen, wurde damit nicht nur der von Robespierre beschworene, erst einmal gegen die Gironde zielende Eindruck bestärkt, "que c'est dans l'intérieur qu'est la source du mal «"92. Danton leitete zugleich auch die offizielle Verabschiedung der ersten Maßnahmen einer terroristischen Politik des salut public, die Einrichtung des Revolutionstribunals, der Überwachungsausschüsse und des Wohlfahrtsausschusses, mit dem auf den September 1792 bezogenen, die Unterscheidung Marats aufgreifenden Argument ein: „Faisons ce que n'a pas fait l'Assemblée législative; soyons terribles pour dispenser le peuple de l'être ${ }^{293}$. Das war keineswegs rein taktisch motiviert, denn Danton, der ja bereits unmittelbar vor den Septembermassakern aktive Gewaltmaßnahmen gegen den inneren Feind propagiert hatte, trat neben der allgemeinen Volksbewaffnung nun zugleich vehement dafür ein, "que nous déclarions la guerre à nos ennemis intérieurs.

${ }^{289}$ So Billaud im Jakobinerklub am 10.1.1793. AULARD, Société des Jacobins, Bd. S, S. 22.

${ }^{290}$ Père Duchesne, Nr. 189.

291 Journal de la République Française, 6.10.1792.

${ }^{292}$ Rede im Konvent am 10.3.1793, abgedr. in: Guvres Bd. 9, S. 306-313.

${ }^{293}$ AP 60, S. 63, 10.3.1793. 


\section{(...) Je demande qu'avant tout, il nous faut tuer l'ennemi de l'intérieur «294.}

Dieser Zusammenhang verdient eine genauere Betrachtung. Auf die Bildung der ersten antifranzösischen Koalition aller europäischen Großmächte reagierte der Konvent im Februar 1793 mit der "grande levée«, der Aushebung von 300.000 weiteren Soldaten, die zugleich den Anstoß für die Aufstände in der Vendée und in anderen Landesteilen gab. Die auf die Mobilisierung der Bevölkerung zielende Beschwörung, "que la France (...) ne soit qu'un camp, et la nation une armée «295, war zuerst, ähnlich wie diverse ähnlichlautende Forderungen besonders aus den Reihen der Gironde ${ }^{29}$, noch getragen vom Pathos der inneren Einheit. Doch dieses Pathos war im revolutionären Diskurs längst aufs engste verbunden mit dem Kampf gegen den sich außerhalb des Kreises der Revolutionäre stellenden sinneren Feind, dem schon hier auch von den gemäßigten Revolutionären deutlich gedroht wurde: "Si l'ennemi triomphe, malheur à ceux qui auront des torts envers la patrie. Riches, remplissez vos devoirs envers elle, si vous voulez qu'elle soit généreuse envers vous ${ }^{297}$. Als sich die Niederlagen dann tatsächlich einstellten, kam es, angetrieben von um sich greifenden Ängsten, wie selbstverständlich zu einer Radikalisierung der Wendung gegen den sinneren Feindk. An die Stelle des "comité autrichien" von 1792 trat nun die Verschwörung von "Pitt et ses agents $\ll^{298}$. Die seit Kriegsbeginn immer wieder beschworene Bereitschaft, für die Verteidigung von Vaterland und Revolution mit dem eigenen Leben einzustehen, fand dabei zu ihren innenpolitischen Wurzeln zurück, freilich in einer durch den Krieg nachhaltig veränderten Form: „vous avez juré d'être libres ou de mourir« hieß es Anfang April 1793 in einem Aufruf, wjurez maintenant de vivre, pour exterminer les traîtres et les perfides ${ }^{299}$.

Zuerst wurde das von der Pariser Bevölkerung geforderte Revolutionstribunal geschaffen. Die Begründung war dieselbe wie beim spontanen Terror Anfang September 1792. "Ils nous ont dit«, so erstattete Jeanbon-Saint-André, getragen von lebhaftem Beifall, dem Konvent am 9. März Bericht über die Stimmung in den Sektionen, wnous combattons les ennemis du dehors, mais combattez et terrassez les ennemis du dedans. (...) Enfin, une demande à laquelle ils tiennent très fort, est celle-ci: que pendant le temps que nos frères combattent au dehors les ennemis de la République, un tribunal spécialement établi, veille au-dedans pour punir les traîtres, les conspirateurs et les

${ }^{294}$ AP 60, S. 603-605, 27.3.1793.

${ }^{295}$ Erklärung des Konvents an das französische Volk, 24.2.1793. AP 59, S. $161 \mathrm{ff}$.

${ }_{296}$ Vgl. etwa Brissots Forderung, »que la grande famille des Français ne soit plus qu'une armée, que la France ne soit plus qu'un camp où l'on ne parle que de guerre, où tout tend à la guerre, où tous les travaux n'ayent pour objet que la guerre«. AP 58, S. 113, 1.2.1793.

${ }_{297}$ AP 59, S. 162, 24.2.1793.

${ }^{298}$ Révolutions de Paris, 16.-23.3.1793, Bd. 15, S. 526.

299 Journal des hommes libres, 6.4.1793. 
perturbateurs $\aleph^{300}$. Diese Intiative fand im Konvent trotz des erbitterten Widerstands von Lanjuinais und anderen Girondisten schließlich eine große Mehrheit, nachdem Léonhard Bourdon sie mit dem Argument unterstützt hatte, das Revolutionstribunal sei notwendig »afin que lorsque nos frères combattent aux frontières, ils ne soient pas inquiets des conspirateurs et des actes commis par les ennemis de l'intérieur «301. Die kriegspolitisch begründete Agitation für die Verschärfung des Kampfes gegen den inneren Feind kam damit aber noch nicht zum AbschluB; »il faut de grandes mesures pour faire le tirage entre les bons et les méchants«, propagierte Varlet ein paar Tage später im Jakobinerklub, "la ligne de démarcation doit être tracée entre les patriotes et les aristocrates avant d'ouvrir une campagne qui, dans l'état actuel livrerait les amis de la liberté à la merci de nos ennemis« ${ }^{302}$.

Schon im März, als nicht nur die Erhebung in der Vendée bekannt wurde, sondern auch in Paris Léonhard Bourdon nur knapp einem Attentat entging, waren weitere, konkretisierende Forderungen nach "plusieurs mesures de sûreté générale« laut geworden ${ }^{303}$. Am 21. März beschloß der Konvent die Bildung von Überwachungsausschüssen, "considérant qu'à l'époque où des despotes coalisés menacent la République, plus encore par les efforts de leurs intrigues, que par le succès de leurs armes, il est de son devoir de prévenir les complots liberticides $\ll^{304}$. Es gehe darum, so hatte Débry diese Initiative ganz kriegsbezogen begründet, durch den Schlag gegen den inneren Feind auch den europäischen Mächten zu beweisen, "que la République est invincible « ${ }^{305}$. Und Anfang April schließlich führte der Abfall von General Dumouriez, der erneut die Verbindung von äußerer und innerer Konterrevolution $\mathrm{zu}$ bestätigen schien, zur Bildung des ersten Wohlfahrtsausschusses. Marat begründete seine

${ }^{300}$ AP 60, S. 3, 9.3.1793. Vgl. auch den ebd. wiedergebenen Beschluß der Generalversammlung der Sektion Louvre, die angesichts der Aufforderung »à voler à la défense de la patrie« die Auffassung vertrat, »que les ennemis intérieurs sont les plus dangereux«.

${ }^{301}$ Ebd.

302 Journal des débats, 14.3.1793, Sitzung vom 11.3.

${ }^{303} \mathrm{Vgl}$. die Rede Barères im Konvent am 18.3.1793. AP 60, S. 290-294. Neben im Text angesprochenen Maßnahmen sind ferner zu nennen: am 19. März die Bestimmung, daß alle bewaffneten Rebellen innerhalb von 24 Stunden hinzurichten seien, und daß Pressegesetz vom 29. März, nach dem auf das öffentliche Eintreten für die Monarchie die Todesstrafe stand.

${ }^{304}$ Aus der Einleitung zum Dekret über die Überwachungsausschüsse. AP 60, S. 389. Am 27.3.1793 wurde ferner dekretiert, da $B$ alle früheren Adeligen, Priester und andere Verdächtige entwaffnet und ein Register aller als solche denunzierten Personen angelegt werden sollte. Die Sektion Réunion hatte dies mit folgender Begründung gefordert: "Il existe, dans cette ville immense, un repaire caché d'émigrés, de valets d'émigrés, de prêtres et de contre-révolutionnaires, qui n'attend que le premier signal et le moment où le danger sera devenu plus pressant, pour se répandre dans les différents quartiers, pour piller et égorger les meilleurs patriotes «. Journal des hommes libres, 1.4.1793.

${ }^{305}$ AP 60, S. 389, 21.3.1793. 
fundamental gegen demokratische Prinzipien verstoßenden Sondervollmachten mit dem Argument, es gehe um die Einsetzung einer »autorité provisoire«, die alle nationalen Kräfte in Bewegung setzen müsse »à les précipiter sur les ennemis du dedans et du dehors et à les écraser tous à la fois $\mathbf{~}^{306}$.

Bereits im Herbst 1792 war auch eine konkretisierende Vorstellung davon entstanden, wie der Terror gegen den inneren Feind zum Instrument der Landesverteidigung werden sollte. So hatte der revolutionäre Priester Roux nicht nur die Inhaftierung aller Ex-Adeligen bis zum Ende des Krieges gefordert, sondern darüber hinaus propagiert: $»$ Prenez en otage les femmes, les enfants des traîtres à la patrie; qu'ils répondent des événements de la guerre que la race nobiliaire et sacerdotale a provoqué au-dedans, au-dehors: qu'enchaînés, ils soient exposés, les premiers, au feu de l'ennemi, ou plutôt au fer des assassins qu'ils ont recrutés: que les maisons de ces lâches habitants, qui ont livré nos places fortes, soient rasées et démolies $\aleph^{307}$. Das Konzept der Geiselnahme als Instrument der Kriegsfuhhrung im Kampf »contre l'ennemi et les traitres ${ }^{308}$ wurde im Frühjahr 1793 unter dem Eindruck des Abfalls von General Dumouriez und der scheinbar bevorstehenden Invasion von den radikalen Kräften erneut propagiert und von der Pariser Volksbewegung aufgegriffen. Marat wollte "s'assurer de tous les parents, femmes \& enfants des émigrés, des rebelles, des généraux, des officiers suspects ou traîtres $\aleph^{309}$, und der Père Duchesne spitzte weiter zu: "Avant que leurs bayonnettes arrivent jusqu'à moi, il faudra qu'ils immolent les restes de la ci-devant noblesse; car je vais m'emparer des femmes, des enfants des émigrés, et de tous les jean-foutres qui ne veulent pas la république; je les fous sur la première ligne, et ils essuieront la première bordée ${ }^{310}$. Im Konvent schlug eine Bürgerin dementsprechend "comme mesure qui peut sauver Paris« nicht nur vor, die Frauen und Kinder der unter Zwang an die Front geschickten adeligen Konterrevolutionäre als Geiseln zu nehmen, um diese so zum Kampf für die Verteidigung der Revolution zu zwingen, sondern sie forderte zugleich: »à la

${ }^{306}$ AP 61, S. 380, 6.4.1793. Vgl. auch Publiciste de la République française, 5.4.1793: „Une grande mesure préalable, doit être prise, sans laquelle tous nos moyens de défense seront sans succès: c'est d'organiser sur-le-champ, un comité de sûreté-générale, \& un comité de défense-générale« mit den folgenden Aufgaben: »l'un, toutes les mesures de sûreté contre les ennemis cachés du dedans, jusqu'à l'arrestation des personnes \& la saisie des propries; l'autre à concerter tous les moyens de défense contre les ennemis armés du dedans et du dehors«.

${ }^{307}$ J. Roux, Discours sur les moyens de sauver la France et la Liberté. Prononcé dans l'Eglise Métropolitaine de Paris, abgedr. in: Scripta et Acta, S. 49-78, hier S. 73.

${ }^{308}$ Adresse der Sektion Théâtre-Français an den Konvent, 3.4.1793. AP 61, S. 277.

${ }^{309}$ Publiciste de la République française, 5.4.1793.

${ }^{310}$ Père Duchesne, Nr. 227. 
moindre trahison de ces pères et de ces époux, leurs enfants et leurs femmes soient égorgés $\aleph^{311}$.

Zwar reagierte der Konvent mit einem »mouvement général d'horreur« auf diesen Vorschlag, doch auf Antrag des Girondisten Lasource faßte man immerhin den Beschluß, die Angehörigen aller Offiziere der Armee von Dumouriez in Geiselhaft zu nehmen, um die Armeeführung zur Freilassung der vier inhaftierten Konventskommissare zu zwingen ${ }^{312}$. Wenige Tage später konnte Marat im Konvent bereits unter lautem Beifall von den Tribünen und ohne Proteste des Konvents fordern, "que cent mille des parents et amis des émigrés seront pris en otages, afin que s'il arrivait la moindre chose à vos commissaires la tête de ses scélérats pût en répondre ${ }^{313}$. Als im Sommer 1793 die Forderung nach einer allgemeinen «levée en masse« als »conséquence naturelle de la marche progressive de l'action révolutionnaire $\mathbf{~}^{3 / 4}$ dann immer weitere Verbreitung fand, trat nicht nur, verstärkt durch den vermeintlichen Verrat General Custines, die Wendung gegen die »ci-devants« in der Militärführung wieder hervor. Vielmehr verband sich damit auch wie selbstverständlich wieder das viel weiterreichende Projekt, alle der inneren Feindschaft, ja sogar der Neutralität Verdächtigen unmittelbar in die Kriegsführung zu integrieren und dabei zu vernichten. Der Père Duchesne formulierte die dann von den Urwählervertretern aufgenommene Forderung: "Nous ferons ensuite marcher devant ces vils égoistes qui, pendant la révolution, n'ont été ni chair ni poisson, nous leur ferons porter le bagage; nous mettrons à la gueule du canon tous les accapareurs, les financiers, les avocats, les calotins et tous le bougres qui n'ont vécu jusqu'à présent que pour le malheur public« «115.

Wenn wir nun genauer die besonders von der marxistisch inspirierten Forschung in den Mittelpunkt gerückten sozialen Grundlagen der terroristischen Radikalisierung und ihre Bedeutung für die diskursive Begründung des Terrors betrachten, so wird schnell deutlich daß auch hierfür der Krieg eine zentrale Rolle spielte. Die vielleicht erste ssozialistische` Erklärung über die Notwendigkeit zur Auflösung des privaten Eigentums überhaupt findet sich in den Révolutions de Paris, die im Zusammenhang der nationalen Mobilmachung Ende August/Anfang September 1792 die Auffassung vertraten: „Dans la circonstance où nous vivons, la promiscuité de biens est de droit, tout appartient à tous; la propriété de l'homme est la liberté; toutes les propriétés particulières doivent être employées à la conservation de celle-là $\aleph^{316}$. Das war

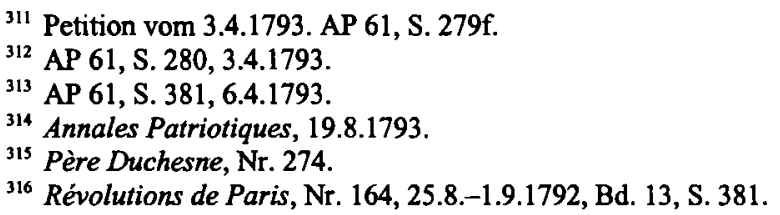


zweifellos ein sehr weitreichender Gedanke, der in dieser Zuspitzung nur selten formuliert wurde. Die Struktur der Verbindung von Landesverteidigung und Aufhebung der Eigentumsrechte aber war stilbildend. Und es war zweifellos mehr dieser auf Krieg und Massenmoblisierung bezogene Ansatz als eine grundsätzliche, im zeitgenössischen Diskurs kaum auffindbare Kritik an privatkapitalistischen Eigentumsstrukturen, der dazu führte, da $B$ »la vie chère» einen terroristischen Kampf gegen »les riches« hervorbrachte. Man fordere, so berichtete Bentabole am 9. März 1793 im Konvent über die Pariser Volksstimmung, "que les citoyens riches qui ne veulent pas aller aux frontières, indemnisent ceux qui vont verser leur sang pour la défense de la patrie $\aleph^{317}$. Die vom wroten Priester« Roux geführte Sektion Gravilliers verabschiedete zur selben Zeit eine Petition an den Konvent, in der die rhetorische Frage aufgeworfen wurde: »Eh quoi! pendant que vos bataillons déploient au-dehors l'étendard de la vengeance nationale, souffririez-vous plus longtemps, que les femmes, les enfants de nos braves volontaires gémissent et expirant sous les

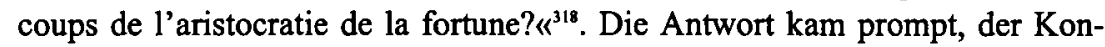
vent verabschiedete einhellig "d'imposer sur cette classe d'hommes, jusqu'à présent inutile, pour ne pas dire nuisible à la Révolution, une taxe de guerre, dont une partie soit affectée au soulagement des femmes, pères, mères et enfants des défenseurs de la patrie $\ll^{319}$.

Im wesentlichen ging es also zuerst darum, die Vermögenden durch eine Kriegssteuer zur Finanzierung der kriegerischen Mobilmachung und ihrer sozialen Folgen heranzuziehen. "Que les gens riches, et sur-tout les impitoyables banquiers et ex-financiers soient tenus de fournir abondamment aux frais de la guerre dans chaque département, qu'eux-mêmes soient forcés de marcher comme les sans culottes ${ }^{320}$. Im Laufe von Frühjahr und Sommer 1793 kam allerdings noch ein zweiter, für die terroristische Radikalisierung besonders wichtiger Aspekt hinzu. Die Wohlhabenden wurden bald nicht mehr nur als egoistisch kritisiert, sondern sie schienen auch, wie die Aristokraten, im Bunde mit dem äußeren Feind zu stehen und schließlich für alle Übel von Krieg und Revolution verantwortlich zu sein. Roux entwickelte in seinem Entwurf zu einer Rede "Sur les Causes des Malheurs de la République Française«, der zur Grundlage des ob seiner sozialistischen Tendenzen berühmten Manifestes der Enragés wurde, seine Kritik an den Reichen dement-

${ }^{317}$ AP 60, S. 2, Bericht aus der Sektion Oratoire.

${ }^{318}$ Abgedr. in: Scripta et Acta, S. 97-99, hier S. 99.

319 So der ohne jeden Widerspruch verabschiedete Wortlaut einer von Chaumette verlesenen Adresse der Pariser Kommune, in der es einleitend hieß: "Citoyens, assez et trop longtemps le pauvre a fait seul le plus grand sacrifie; il n'a rien épargné: tout, jusqu'à son sang et celui de ses enfants, tout a été prodigué de sa part pour le salut de l'Etat; il est temps que le riche égoïste, qui s'isole et se cache derrière ses trésors, en soit amaché, et contraint d'en laisser échapper une portion pour les besoins de la République«.

${ }^{320}$ Annales Patriotiques, 29.4.1793. 
sprechend wesentlich aus einer Analyse der kriegspolitischen Problematik der Revolution: "Qu'est-ce qui a favorisé la déroute et la désorganisation de nos troupes, qu'est-ce qui a fait manquer l'expédition de la Holande et de la Belgique; qu'est-ce qui a empêché la Savoie, l'Irlande et la Prusse d'adorer le soleil naissant de la liberté? C'est le riche. Qu'est-ce qui a désapprovisionné nos places fortes et nos ports maritimes, qu'est-ce qui a vomi des féroces millions de brigands sur nos côtes, qu'est-ce qui a livré des peuples infortunés aux fers de leur implacables tyrans? C'est le riche. C'est lui qui a mis obstacle à l'explosion volcanique des principes de l'égalité et qui ne cesse de colporter le mensonge et l'imposture. C'est par lui que l'Autriche s'est emparé de nos munitions, de nos vivres, et a fait la campagne à nos dépens. Enfin ce n'est que dans la classe des riches que vous trouverez les factieux, les anarchistes, les assassins nationaux et les supports de la contrevolution (sic!). Le riche vous a toujours trahi; toujours il vous trahira: à la guerre il conduira vos armées à la boucherie, dans la capitale, il vendra les droits du peuple; dans le temple des lois, il sacrifira l'innocent. En un mot, il n'est pas de crime que la soif de l'or et de richesses ne lui ait fait commettre; républicains, c'est à vous de lever une juste vengeance des fléaux que le riche a attiré sur la patrie. L'opulence servit à river le fer des peuples; que l'opulence serve à les briser «32!

Konkret schienen die Reichen im Sommer 1793 einen "plan de famine dirigé contre Paris $\aleph^{322}$ zu verfolgen, wie die radikalen Enragés argumentierten: "Qui pourra douter que ceux qui ont fait arrêter nos subsistances, ne soient ceux qui ont provoqué la foudre des puissances étrangères; qui ont absolus le tyran et qui ont constamment retardé la marche de la volonté nationale«. Und da dieser Plan auch im Konvent und seinem Komitee für Handel und Landwirtschaft Unterstützung finde, forderte Roux nun zur revolutionären Selbsthilfe auf: "... il n'est qu'un parti à prendre, c'est de lever une force imposante pour aller au secours des subsistances«. Diese Sicherung der Subsistenzgrundlagen zielte allerdings keineswegs nur auf die mittelbar mit dem Krieg verknüpften sozialen Bedürfnisse der Pariser Bevölkerung. Vielmehr gewann sie im Zusammenhang mit der nun immer intensiver geforderten "levée en masse« auch eine unmittelbare kriegspolitische Begründung. "Comment faire marcher à la fois plusieurs millions d'hommes? comment les armer, les approvisionner«, fragte der Père Duchesne treffend. Seine Antwort wies den Weg zum sozialen Terror: "Il faut, avant toutes choses, nous assurer de toutes les subsistances de la république«. Da diese allerdings »dans les mains des

${ }^{321}$ Abgedr. in: MARKov, Scripta et Acta, S. 102-139, hier S. 131. Ebd., S. 140-150, das Manifest mit dem zentralen kriegspolitischen Argument: »La force armée est à la disposition des corps administratifs, comment les subsistances ne seraient-elles pas à leur réquisition?«. ${ }^{322}$ Le Publiciste de la République française par l'ombre de Marat, 29.7.1793; hier auch die folgenden Zitate. 
contre-révolutionnaires ${ }^{323}$ seien, schien nur der Krieg gegen die Reichen die Revolution retten zu können. "Il faut se lever en masse«, stellte Roux fest, "pour voler aux frontières, confisquer au profit des volontaires les biens de ceux qui refusent sous d'autre prétexte que celui des infirmités, leurs bras $\aleph^{324}$.

Wie dies konkret geschehen solle, auf diese Frage gab es seit Monaten im revolutionären Diskurs eine Antwort, die nun auch begrifflich die Identifikation des Kampfes gegen den inneren Feind mit dem Krieg gegen den äußeren Feind anzeigt. Wenn sich im Zuge dieser Gleichsetzung die Auffassung verbreitete, "que tous les citoyens soient soldats « ${ }^{325}$, dann war es zugleich auch konsequent, militärische Organisationsformen auf den Kampf im Innern zu übertragen. Bereits Anfang April hatte Robespierre so vor dem Hintergrund lokaler Initiativen die Bildung einer »armée révolutionnaire « für den Krieg gegen den inneren Feind propagiert ${ }^{326}$. Sie sollte aus bezahlten Sansculotten zusammengesetzt sein, und es lag bald nahe, Ausrüstung und Entlohnung durch »taxes révolutionnaires« von den Vermögenden bezahlen zu lassen, wie es in Lyon schon Anfang Mai beschlossen worden war ${ }^{327}$. Davon ausgehend war es nur noch ein kleiner Schritt, die »armées révolutionnaires« als Instrument eines kriegspolitisch begriffenen Klassenkampfes gegen die Reichen zu begreifen. »Nous demandons«, forderten die Cordeliers und der Club der revolutionären Republikanerinnen gemeinsam mit den Jakobinern Mitte Mai vom Konvent, "que vous établissez dans chaque ville des armées révolutionnaires composées de sans-culottes (...) Législateurs, frappez les agitateurs, les accaparateurs et les égoistes marchands. Il existe un complot affreux de faire mourir de faim le peuple, en partant les denrées à un prix énorme. A la tête de ce complot est l'aristocratie mercantile d'une caste insolente qui veut s'assimiler à la royauté et accaparer toutes les richesses (...) Exterminez tous ces scélérats: la patrie sera assez opulente s'il lui reste les sans-culottes et leurs vertus $\aleph^{328}$.

Wie bis hierhin gezeigt werden konnte, waren im Frühjahr und Sommer 1793 die Intensivierung der Verteidigungsanstrengungen und die terroristische Radikalisierung diskursiv auf vielen Ebenen eng miteinander verbunden. Das gilt auch für das Projekt einer »levée en masse« selbst, das bald in den Mittelpunkt der revolutionären Agitation rückte. Kriegerische Massenmobilisierung

\footnotetext{
${ }^{323}$ Père Duchesne, Nr. 274, S. 289.

${ }^{324}$ RouX, Sur les Causes des Malheurs, S. 132, Anm. 9, Kurzfassung des zweiten Teils.

${ }^{325}$ So Albitte, zit. n. Journal des débats, 9.4.1793, Sitzung vom 7.4. Es ging Albitte wesentlich um den Kampf gegen die inneren Feinde, "wcar ce sont ceux qui nous suscitent les ennemis du dehors. (...) Il faut (...) commencer par écraser nos ennemis intérieurs«.

${ }^{326}$ AULARD, Société des Jacobins, Bd. 5, S. 124, 3.4.1793.

${ }^{327} \mathrm{Vgl}$. hierzu wie zum Thema generell: R. COBB, Les armées révolutionnaires, instruments de la terreur dans les départements, 2 Bde. Paris 1961/63.

${ }^{328}$ AULARD, Société des Jacobins, Bd. 5, S. 198f., Sitzung vom 19.5.1793.
} 
und innerer Terror waren dabei unauflöslich ineinander verwoben. Schon im April 1793 rief der Pariser Jakobinerklub unter der Präsidentschaft von Marat auf: »Levons-nous!, oui, levons-nous tous! Mettrons en état d'arrestation tous les ennemis de notre révolution, et toutes personnes suspectes. Exterminons sans pitié, tous les conspirateurs, si nous ne voulons être exterminés nousmêmes « ${ }^{329}$. Anfang Mai 1793 formulierte Châles hier dann die stilbildende Forderung »de nous lever tous en masse au nombre de trois ou quatre millions d'hommes« und verband damit erstmals auch das Projekt, die Feinde der Revolution gegen ihren Willen in die Schlacht zu treiben: "Une mesure qui nous dispenserait de l'embarras de garder nos ennemis, ce serait de suivre le système que nous ont tracé nos ennemis. Qui nous empêcherait de lier nos prisonniers ramassés dans les différents départements, et de les mettre sur la première ligne ${ }^{330}$. Als Anfang Juli die Pariser Kommune dann erstmals die Forderung nach einer bislang noch auf die Hauptstadt begrenzten slevée en masse« an den Konvent richtete, ging es gar überhaupt nicht um den äußeren Krieg, sondern allein um den Bürgerkrieg gegen aufständische Départements; der terroristische Charakter der Initiative wurde in der Zielvorstellung deutlich, "qu'il est temps que ces monstres politiques disparaissent ${ }^{331}$. Anfang August, vor dem Hintergrund um sich greifender Gerüchte über "projets de septembrisade«, propagierte der Publiciste de la République française von Roux in einem "moment où Paris est entre le fer des Autrichiens et le feu des rebelles«, die wiederum kriegerische Mobilisierung und inneren Terror verbindene Perspektive, "yde se lever en masse pour défendre les frontières et exterminer les rebelles ${ }^{332}$. Vor diesem Hintergrund kann es kaum noch überraschen, wenn die schließlich von den Vertretern der französischen Urwählerversammlungen erstmals auch im Konvent erhobene Forderung nach einer allgemeinen »levée en masse« am 12. August wie selbstverständlich die Landesverteidigung mit dem terroristischen Projekt verband, "que l'aristocratie devienne entre nos mains l'instrument de sa propre destruction ${ }^{333}$.

Vieles spricht dafür, daß im Juli 1793 besonders die Ermordung von Marat, kurz darauf gefolgt von der Hinrichtung Chaliers in Lyon, dem Gedanken an ein wretournement de la terreur« gegen die ursprünglich des Terrors bezichtigten Konterrevolutionäre weiter Auftrieb gab, zumal mit Hébert, Roux und

${ }^{329}$ La Société des amis de la liberté et de l'égalité de Paris, à leurs frères des départements, 11.4.1793, abgedr. in: AULARD, Société des Jacobins, S. 198f.

${ }^{330}$ Journal des débats, 12.5.1793, über die Sitzung vom 9.5.

${ }^{331}$ AP 68, S. 316, 6.7.1793.

${ }^{332}$ Le Publiciste, par l'ombre de Marat, 3.8.1793.

${ }^{333}$ Adresse der Vertreter der französischen Urwählerversammlungen an den Nationalkonvent, 12.8.1793, in: AP 72, S. 103. 
Leclerc gleich drei radikale Journalisten das publizistische Erbe von Marat anzutreten und ihn in seinem terroristischen Eifer noch zu übertreffen versuchten $^{334}$. Doch die terroristische Konzeption revolutionärer Politik blieb keineswegs auf die Enragés begrenzt. Barère etwa gelangte nun zu der Auffassung, "que le moment est arrivé où vous devriez prendre l'attitude fière de la justice nationale, et frapper indistinctement tous les conspirateurs $\aleph^{335}$. Und es war kein anderer als Robespierre, der am 12. August die Initiative der Urwähler folgendermaßen aufnahm: "Que le glaive de la loi plane avec une rapidité terrible sur la tête des conspirateurs, frappe de terreur leurs complices, inspire la terreur à tous les ennemis de la patrie $\aleph^{336}$.

Während Robespierre hier noch abgestufte Bedeutungsebenen des Terrors unterschied, begannen im terroristischen Diskurs zunehmend die Grenzen zwischen Abschreckung und Vernichtung der Feinde zu verschwimmen. "Citoyens, ce n'est qu'en jetant la terreur dans l'âme des traitres que vous assurerez l'indépendance de la patrie«, stellte Roux fest, um dann im Zeichen der kriegerisch konzipierten Revolution wie selbstverständlich von der Abschreckung zur Vernichtung der Feinde überzugehen: »En fait de révolution, le seul moyen de la consolider, c'est d'écraser les traîtres dans la fureur de la guerre $«{ }^{337}$. Die entscheidenden Voraussetzungen für eine positive Umwertung des Terror-Begriffs wie für seine von der Abschreckung zur Vernichtung übergehende Bedeutungserweiterung hatte indes vor allem der Krieg geschaffen, in enger Verbindung mit dem Bürgerkrieg. So wie das Vokabular der Vernichtung sich ursprünglich gegen die feindlichen Tyrannen und ihre Armeen gerichtet hatte, so fand auch der positive Begriff des Terrors im Krieg seine konkrete Begründung: La terreur bezeichnete erst einmal den erschreckenden Eindruck, den die neuen, militärisch schlecht ausgebildeten, unorganisiert und undiszipliniert, aber auch massenhaft und motiviert agierenden Revolutionsarmeen auf ihre Feinde ausüben sollten. "Allez! braves soldats, allez! la victoire vous attend«, hieß es etwa im März 1793 zur Verabschiedung der neu ausgehobenen Truppen, »la terreur de vos armes a déjà devancé votre arrivée« « ${ }^{338}$.

${ }^{334} \mathrm{Vgl}$. J. GuILhaumou, La formation d'un mot d'ordre: »Plaçons la terreur à l'ordre du jour« (13 juillet 1793 - 5 septembre 1793, in: Bulletin du Centre d'Analyse du Discours, Bd.5, 1981, S. 149-196; ähnlich VAN DEN HEUVEL, Terreur, S. 106-116.

${ }^{335}$ AP 69, S. 631, 28.7.1793.

${ }^{336}$ AP 72, S. 103.

${ }^{337}$ Le Publiciste, par l'ombre de Marat, 27.7.1793.

${ }^{338}$ Républicain Français, 17.3.1793. Vgl. etwa auch den Chant du départ nach Texten von Marie-Joseph Chenier: »Tremblez, ennemis de la France,/Rois ivres de sang et d'orgueil;/Le peuple souverain s'avance:/Tyrans, descendez au cercueil«. Zit. n. J. TULARD u.a., Histoire et dictionnaire de la Révolution française, Paris 1987, S. 637f.; zur differenzierteren Wahrnehmung auf gegnerischer Seite vgl. E. SCHNEIDER, Das Bild der französischen Revolutionsarmee (1792-1795) in der zeitgenössischen deutschen Publizistik, in: J. VosS (Hg.), Deutschland und die Französische Revolution, München 1983. 
Die Verbindung von Krieg und Bürgerkrieg trug dann entscheidend dazu bei, daß sich die inhaltliche Füllung des Begriffes gewissermaßen verdoppelte, neben den feindlichen Truppen zunehmend auch auf den Feind im Innern zielte. "Tremblez, tyrans et vous perfides, / (...) de tous les partis:/Tremblez, vos projets parricides/Vont enfin recevoir leur prix", so hieß es schon in der Marseillaise, und neben die Abschreckung trat bald immer deutlicher auch die aktive Vernichtung der Feinde. "Citoyens, accourez, le tocsin sonne dans la Vendée, la patrie vous y appelle«, so verabschiedete die Pariser Kommune im Mai 1793 Truppen, die den Aufstand in der Vendée unterdrücken sollten, um dann fortzufahren: "portez-y votre patriotisme et vos bras. Point de grâce, point de quartier envers les rebelles: ce sont les ennemis de la liberté qu'il faut anéantir, ce sont les complices de Dumouriez, qu'il faut exterminer. (...) Parisiens, votre nom seul vaut une armée; il inspire la terreur aux ennemis de la libertée ${ }^{339}$. Aus diesem kriegerischen Geist entstammte schließlich das Dekret zur Vernichtung der Vendée, das Barère bezeichnenderweise in einer auBenpolitischen Rede über die Lage der Republik und über die "grande conjuration dont la France est enveloppé par les puissances étrangers, notamment par le gouvernement anglais", vortrug. "Nous aurons la paix le jour que l'intérieur sera paisible«, so begründete er die »mesures qui tendent à exterminer cette race rebelle, à faire disparaître leurs repaires, à incendier leurs forêts, à couper leurs récoltes, et à les combattre autant autant par des ouvriers et des pionniers que par des soldats $\aleph^{340}$.

Im Sommer 1793 erreichte die terroristische Zuspitzung des revolutionären Diskurses ihren Höhepunkt, als nach der Initiative der Urwählervertreter die "masse terrible de tous les sans-culottes de la république« eine umfassende revolutionäre levée en masse gegen die äußeren wie gegen die inneren Feinde der Revolution durchfuihren und zugleich den Terror auf die Tagesordnung setzen sollte. Massenmobilisierung und Terror waren keineswegs nur für die radikalen Kräfte der Pariser Volksbewegung unmittelbar miteinander verbunden, sondern auch für die von den Jakobinern und der Bergpartei geprägte Revolutionsführung. "Avant de fondre sur les barbares aux ordres des tyrans coalisés«, mit dieser vom Montagnard Bayle formulierten Aufforderung an die

\section{Zit. n. Journal des hommes libres, 1.5.1793.}

${ }^{340}$ AP 70, S. 90-103, hier S. 101, 1.8.1793. Es soll hier nicht verschwiegen werden, daß Barère zugleich betonte, »les vieillards, les femmes, les enfants seront traités avec les égards exigés par la nature et la société«. Sie sollten ins Landesinnere gebracht werden, doch für ihre Versorgung wurde keinerlei Vorkehrung getroffen, und zwei Monate später erklärte Barère die ganze Bevölkerung der Vendée unter Einschluß von Kindern ab 10 Jahren für schuldig. Als Carrier und Tourreau schließlich im Dezember $1793 \mathrm{ihr}$ allgemeines Mordprogramm entwickelten, stimmten Wohlfahrtsausschuß und Konvent zwar nicht förmlich zu, sie wandten sich aber auch nicht dagegen. Zur hier nicht weiter verfolgten Tragödie der Vendée vgl. A. GeraRD, ,Par principe d'humanité ... La Terreur et la Vendée, Paris 1999; L.-M. CLENET, Les colonnes infernales, Paris 1993; E. FOURNIER, Turreau et les colonnes infernales, ou l'échec de la violence, Paris 1985. 
Nation stimmten im Spätsommer 1793 fast alle Revolutionäre überein, vil faut purifier ton sol, et le jour auquel tu auras la paix dans l'intérieur, sera celui auquel les tyrans couronnés te la demandent ${ }^{344}$. Wir sind, so fügte Gaston im Konvent hinzu, "tous d'accord qu'il faut réunir tous les moyens pour anéantir les ennemis; qu'il faut que le peuple se lève pour la dernière fois. Mais nous différons sur les moyens d'exécution « ${ }^{342}$.

Tatsächlich lagen hier, in der Form der Durchführung, die wesentlichen, vorerst in den Hintergrund rückenden Differenzen, und sie waren längerfristig deshalb nicht weniger bedeutsam. Sie basierten auf unterschiedlichen, mit der doppelten Bedeutung des Begriffs »levée«, nämlich revolutionäre Erhebung und militärische Aushebung, verbundenen Vorstellungen darüber, in welchen Formen sich die Mobilisierung zum Kampf gegen die äußere und innere Konterrevolution vollziehen sollte. Es handelte sich auch nicht einfach um einen Konflikt zwischen Jakobinern und Volksmassen, die Bruchlinie verlief vielmehr innerhalb des Jakobinerklubs. Die hier ebenso wie die gemäßigteren Kräfte präsenten radikalen Vertreter der Volksbewegung stellten sich unter dem Begriff der »levée« einen allgemeinen, revolutionären Aufstand der Massen >von unten` vor, wie er im Sommer 1793 vor allen von den Cordeliers immer wieder propagiert wurde ${ }^{343}$. "Peuple souverain «, so lautete der Aufruf von Roux, wlève-toi donc pour la dernière fois! Imprime sur le front des conspirateurs le sceau de ta sainte colère; fais éclater la foudre de l'égalité sur les monstres qui t'ont enchaînés au millieu des victoires et des triomphes; et bientôt se viendront écraser contre les rochers de la liberté, les satellites du despotisme $\ll^{344}$. Es ging mit den Worten von Royer darum, »que le mouvement révolutionnaire sera organisé, que le tocsin sonne dans toutes les communes de la république $\aleph^{345}$, und diese revolutionäre Bewegung sollte nicht von oben geleitet werden, sondern selbstbestimmt agieren: »on doit regarder la France entière comme un comité général, qui s'occupe exclusivement du bonheur du peuple $\ll^{346}$.

Die bürgerlich geprägte, aus den Reihen der Bergpartei stammende Revolutionsführung verfolgte dagegen das Ziel, die Massen in organisierter Form, gewissermaßen svon oben zu mobilisieren und zu dirigieren. Der Kreis um

${ }^{341}$ Konventsmitglied Bayle, Aufruf $» A$ tous les sans-culottes de la France«, in: Journal des hommes libres, 22.8.1793. Der Gedanke an eine »Reinigung« war weit verbreitet, vgl. etwa auch Père Duchesne, Nr. 274: „d'abord il faut purger la France des tous les traîtres, établir des tribunaux dans toutes les places publiques, pour y juger tous les scélérats qui ont conspiré contre leur patrie «.

${ }^{342}$ AP 72, S. 489, 20.8.1793.

${ }^{343}$ Vgl. GuilhaumoU, La Formation d'un mot d'ordre, S. 166-169.

344 Discours Sur les Causes des Malheurs de la République Française, S. 103.

${ }^{345}$ Journal des débats, 18.8.1793, Sitzung vom 16.8 .

${ }^{346}$ AULARD, Sociétés des Jacobins, Bd. 5, 19.8.1792, S. 364. 
Robespierre lehnte so die von der Volkbewegung geforderte allgemeine levée en masse zuerst einmal sogar prinzipiell ab, während sowohl Robespierre als auch Danton die damit verbundene sinitiative de la terreur contre les ennemis de l'intérieur« schon am 12. August positiv aufgriffen, wobei sie bezeichnenderweise zugleich aber betonten, "que ce soit avec ordre « ${ }^{347}$. Als Barère am 20. August seinen ersten Entwurf zum Dekret über die "levée en masse« vorstellte, richtete er sich nicht zuletzt gegen die "mouvements qu'y ont excité les contre-révolutionnaires ${ }^{348}$. Und fast alle Kommentatoren betonten in noch deutlicherer Form die Verbindung von Massenmobilisierung und Terror. "Je demande que la première mesure que vous preniez soit de chasser tous les aristocrates de la République«, stellte Chabot fest, um dann die Forderung der Urwählervertreter aufzugreifen: „Mon projet est simple, c'est d'envoyer au delà des frontières tous ceux qui ne respirent qu'après la contre-révolution«. Tallien nahm die Angst vor dem inneren Feind auf und betonte: "Les peuples anciens, avant d'aller combattre les ennemis extérieurs, purgeaient leur territoire des ennemis intérieurs; il faut, quand ils vont combattre les Autrichiens, que les patriotes sachent si leurs femmes et leurs enfants seront en sûreté«. Amar schließlich stellte etwas zurückhaltender fest, es sei endlich an der Zeit »de faire justice de tous ces conspirateurs qui depuis si longtemps nous trahissent. Je demande que tous les aristocrates et les gens suspects soient renfermés jusqu'après la paix«.

Das Dekret wurde allerdings noch einmal an den Wohlfahrtsausschuß zurückverwiesen, weil Danton angesichts der enormen Menschenmassen, die nicht nur in Bewegung gesetzt, sondern auch ausgerüstet und ernährt werden müßten, eine intensiver durchdachte Aufgabenverteilung und Organisation forderte. Das Ergebnis dieser Initiative war schließlich das berühmte, von Carnot und Barère formulierte Dekret über die »levée en masse « vom 23. August 1793, das eine totale Mobilmachung der gesamten Bevölkerung verordnete. Seinem Pathos nach zielte es auf das Engagement der Massen, doch in der konkreten Form sah es eine arbeitsteilige, staatlich dirigierte Mobilisierung der Massen vor: "Dès ce moment jusqu'à celui où les ennemis auront été chassés du territoire de la République; tous les Français sont en réquisition permanente pour le service des armées. Les jeunes gens iront au combat, les hommes mariés forgeront les armes et transporteront les subsistances, les femmes feront des tentes, des habits et serviront dans les hôpitaux, les enfants mettront le vieux linge en charpie, les vieillards se feront porter sur les places publiques

${ }^{347}$ So Danton, ähnlich auch Robespierre, in Reaktion auf die in Anm. 272 genannte Adresse der Urwählervertreter: AP 70, S. 102f.

${ }^{348}$ AP 72, S. 488; die folgenden Zitate ebd. 
pour exciter le courage des guerriers, prêcher la haine des rois et l'unité de la République $\ll^{349}$.

Zwar wurde bereits in $\$ 3$ des Dekrets auch ein bewaffneter wservice de l'intérieur" angeordnet, doch den Vertretern einer revolutionären Massenerhebung war dies nicht genug. Wenn Sie nun immer schärfer die Ergänzung durch terroristische Maßnahmen forderten, so handelte es sich dabei im Grunde um den Versuch, ihr vom Konvent tatsächlich in dieser Form nicht umgesetztes Konzept einer revolutionären, selbständig organisierten Massenerhebung gegen die äußere und innere Konterrevolution noch zu retten. Royer stellte Ende August enttäuscht fest, "que la levée en masse ne produira aucun effet $\iota^{350}$. Die Forderung nach dem Terror wurde so zum Hauptinhalt des Versuchs, der »levée en masse« doch noch eine revolutionäre Form zu geben. Royer prägte schließlich im Jakobinerklub die berühmte, die Pariser Volksmassen noch einmal zum Aufstand anstachelnde Phrase: "Qu'on place la terreur à l'ordre du jour! C'est le seul moyen de donner l'éveil au peuple et de le forcer à se sauver lui-même « ${ }^{351}$. Die Quintessenz dieser Initiative faßten die Révolutions de Paris etwas später rückblickend folgendermaßen zusammen: "Nous sommes en guerre, malheur aux lâches, aussi bien qu'aux traîtres! (...) Tout est en réquisition; que tout soit aussi en révolution! ( $^{352}$.

Die Unruhen, die am 4. September 1793 Paris erschütterten und konkret zur Inaugurierung des Terrors führten, hatten zweifellos soziale Ursachen und zielten intentional auf eine rigide Politik gegen »les riches« zur Beseitigung der unmittelbaren Not. Doch der Krieg und die Identifikation von innerer und äußerer Konterrevolution waren dabei, erneut angestachelt durch das Bekanntwerden der Übergabe Toulons an die Engländer, ebenso präsent wie die Anbindung an die »levée en masse«, insbesondere in den Äußerungen der politischen Wortführer. "C'est ici la guerre ouverte des riches contre les pauvres. Ils veulent nous écraser, eh bien! Il faut les prévenir, il faut les écraser nous-mêmes; nous avons la force en main «, mit dieser Stellungnahme gelang es Chaumette, dem Protest eine politische Stoßrichtung zu geben ${ }^{353}$. Und als die Pariser Sektionen am folgenden Tag bewaffnet vor den Konvent zogen, wurde der geforderte Terror gegen die Reichen noch enger an den Krieg und die "levée en masse « gebunden. Unterstützt von Plakaten mit den Aufschriften "Guerre aux tyrans, guerre aux aristocrates, guerre aux

\footnotetext{
${ }^{349}$ AP 72, S. 688.

${ }^{350}$ AULARD, Société des Jacobins, Bd. 5, S. 382, 28.8.1793.

351 So Royer am 30. August im Pariser Jakobinerklub, zit. n. ebd., S. 383f.; fünf Tage später fand erneut Royer im Jakobinerklub eine Mehrheit für seinen Vorschlag, die Sitzung aufzuheben und "aller dans les rues inviter le peuple à nous suivre pour presser la Convention des mesures révolutionnaires«. Ebd., S. 398.

${ }^{352}$ Révolutions de Paris, 7.-14. Brum. IL/28.10.-4.11.1793, Bd. 18, S. 131.

${ }^{353}$ Journal de la Montagne, zit. n. GUILHAUMOU, La Formation, S. 187.
} 
accapareurs«, verband Chaumette als Vertreter der Pariser Kommune in seiner Ansprache an den Konvent wie üblich die "tyrans de l'Europe» mit den "ennemis domestiques de l'Etat", deren gemeinsames Ziel es sei, "d'affamer le peuple français pour le vaincre et le forcer à échanger honteusement sa liberté, sa souveraineté, contre un morceau de pain $\kappa^{334}$. Die Delegation der Jakobiner rückte zwar den sozialen Aspekt stärker in den Hintergrund, doch änderte sich mit ihrem Erscheinen deshalb noch keineswegs »tout«, wie Ozouf meint ${ }^{355}$. Vielmehr bezogen sich die wesentlich von Royer inspirierten Jakobiner einleitend explizit auf die "levée en masse«, um dann für den ihrer Auffassung nach noch wichtigeren Kampf gegen »les traittres qui nous agitent dans l'intérieur" ähnliche »remèdes extrêmes" zu fordern; der spezifisch kriegspolitische Charakter wurde nicht zuletzt darin deutlich, daß der Terror besonders gegen die ex-adelige Militärführung zur Anwendung kommen sollte $^{356}$. Nur durch die "punition des traîtres et des conspirateurs" schien es angesichts der allgemeinen Bedrohung noch möglich zu sein, wie die Sektion Unité in einer Adresse an den Konvent argumentierte, "que vous pouvez achever la Révolution et affirmer la République«.

Das Programm zur Ergänzung der Massenmobilisierung durch den Terror wurde vom Konvent schließlich verabschiedet. Billaud-Varenne gab seinen Einstand in den erweiterten Wohlfahrtsausschuß mit der nach innen wie nach außen zielenden Erklärung: „Ecrasons les ennemis de la révolution, et, dès aujourd'hui, le gouvernement prend l'action, les lois sont exécutés, le sort du peuple est affermi, la liberté est sauvée « ${ }^{357}$. Der Père Duchesne sah mit der Verabschiedung des Terrors ebenfalls den Sieg einer mit dem Krieg identifizierten Revolution gesichert: "Voilà le coup de grâce de l'aristocratie et de la royauté. Tremblez, scélérats, qui avez voulu enchaîner le peuple, il tient entre ses mains la masse qui va vous écraser. Tremblez, muscadins, qui n'avez pas voulu être des hommes libres; l'heure de votre mort va sonner. Tremblez, riches égoistes engraissés du sang des pauvres, le jour est arrivé. Vous, SansCulottes, qui avez tant fait dans un jour, ne vous rebutez pas; n'abandonnez pas le fer dont vous vous êtes armés jusqu'à ce que tous vos ennemis soient exterminés $\aleph^{358}$. Und Jacques Roux jubelte: "... la Convention nationale vient de s'élever à la hauteur de ses fonctions. Les décrets qui purifient les autorités constituées, souillées par le fédéralisme, qui ne mettent à la tête de nos phalanges républicaines, que des officiers plébéiens, qui promènent la hache de la loi sur la tête des conspirateurs de toutes les classes, de l'organisation de l'armée révolutionnaire, les grandes mesures qui ont été adoptés pour assurer

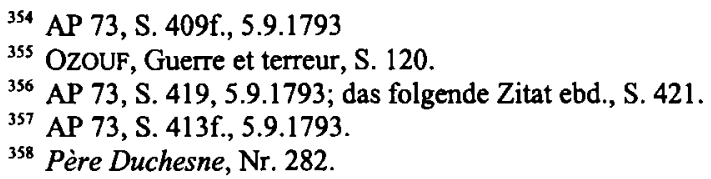


les subsistances dans les départements, tout nous annonce que la patrie sera bientôt sauvée « ${ }^{359}$.

Der Jubel muß dem "roten Priester" allerdings im Halse stecken geblieben sein, denn er selbst wurde noch am 5. September verhaftet. Auch wenn die Verabschiedung der "levée en masse" zuerst wie ein Erfolg der Pariser Sektionsbewegung aussah, war dieser Vorgang doch bezeichnend für die weitere Entwicklung, die der Terror in der Folgezeit unter der Führung der großen Ausschüsse, des Allgemeinen Wohlfahrtsausschusses und des Allgemeinen Sicherheitsausschusses nehmen sollte. Zwar wurden die revolutionären Armeen im Winter 1793/94 zu wesentlichen Trägern des Terrors gegen den inneren Feind, wobei die Massenhinrichtungen durch ihr Kanonenfeuer in Nantes wohl der deutlichste Ausdruck für die militärischkriegerisch geprägte Konzeption des inneren Terrors waren. Doch nicht das tatsächlich kaum konkretisierte, letztlich auf Forderungen an den Konvent zusammenschrumpfende Konzept einer allgemeinen, selbstorganisierten, revolutionären Massenerhebung gegen alle Feinde der Revolution wurde schließlich verwirklicht, sondern die terroristische Kriegsdiktatur der großen Ausschüsse, die sich bald auch gegen die Pariser Sektionsbewegung richtete. 


\section{Krieg und terroristische Diktatur 1793/94}

Die sich seit September 1793 herausbildende terroristische Diktatur der groBen Ausschüsse, insbesondere des Wohlfahrtsausschusses unter informeller Führung von Robespierre, wird in der Literatur wesentlich unter drei Aspekten analysiert: Sie erscheint, überwiegend mit republikanisch-apolegetischem Einschlag, als eine Kriegsdiktatur, die den unabweisbaren Notwendigkeiten der Landesverteidigung geschuldet sei; sie wird in umgekehrter Weise, unter ideologiekritischen, den Krieg in den Hintergrund rückenden Vorzeichen, als eine Tugenddiktatur gedeutet, die rousseauistisch geprägte philosophische Maximen einer ganz anders strukturierten Gesellschaft habe aufzwingen wollen; oder aber sie wird in der marxistisch geprägten Tradition als eine spezifische Form des komplexen sozialen und politischen Spannungsverhältnisses zwischen den städtischen Volksmassen einerseits, der bürgerlichen Revolutionsführung andererseits begriffen, deren Hauptzweck die letztlich an den inneren Widersprüchen scheiternde Durchsetzung sozialer Reformprogramme gewesen $\operatorname{sei}^{360}$. Auch wenn der virulente, die revolutionäre Dynamik antreibende Charakter der sozialen Probleme und Konflikte hier keineswegs geleugnet werden soll, konzentriert sich die Analyse doch auf die beiden ersten Aspekte, die im politischen Diskurs zweifellos eine wichtigere Rolle spielten als die doch weit mehr als Mittel zum Zweck der Integration der Volksmassen denn als eigenständiges Ziel hervortretenden sozialen Umgestaltungstendenzen.

Bereit Robert R. Palmer hat in seiner klassischen Analyse der Diktatur des Wohlfahrtsausschusses nicht nur den revolutionären Krieg und die republikanisch-demokratische Tugend in den Mittelpunkt gerückt, sondern zugleich auch die engen Verbindungen und Abhängigkeiten zwischen beiden Aspekten betont: "The Revolutionary Government existed to win the war. But it existed also to found the democratic and constitutional Republic, to which the chief danger was internal faction. Peace, by ending the Revolutionary Government, would destroy the narrow pathway to a democratic and moral world. War and democracy were joined by an iron bond, fused in the essential dualism of the Revolutionary Government itself. History is full ironic situations, and this surely is one of them: the war, begun in 1792 against the opposition of Robespierre and the sincerest democrats, became indispensable in 1794 to the fulfilment of their program .... ${ }^{361}$.

${ }^{360} \mathrm{Vgl}$. A. MATHIEZ, La Terreur, instrument de la politique sociale des Robespierristes. Les décrets de ventôse et leur application, in: DERS., Girondins et Montagnards, S. 109-138.

${ }^{361}$ PaLmer, Twelve who Ruled, S. 277. 
Im folgenden soll vor allem gezeigt werden, daß diese in vielem zutreffende Analyse doch einen zentralen, in der politischen Diskursanalyse deutlich hervortretenden Aspekt verkennt. Die terroristische Diktatur basierte tatsächlich weniger auf dem hier anvisierten, wesentlich zweckrational konstruierten Abhängigkeitsverhältnis zwischen dem revolutionären Krieg und der demokratischen Erneuerung als vielmehr auf einer aus der kriegspezifischen Formierung des revolutionären Diskurses hervorgehenden, nur dadurch auch zweckrational erscheinenden, de facto aber doch in zunehmendem $\mathrm{MaBe}$ irrationalen Identifikation von Krieg und Revolution. Es waren wesentlich drei eng miteinander verwobene Prozesse, in denen diese die terroristische Diktatur begründende Identifikation ihren Ausdruck fand: Die Ausbildung des Konzeptes der revolutionären Regierung als einer straff zentralisierten Kriegsdiktatur; der Kampf gegen ein zunehmend allgegenwärtig erscheinendes "complot de l'étranger«; und schließlich die Hybris des totalen Krieges nach innen wie nach außen in der "grande terreur «.

Ihrer eigenen Begründung nach basierte die revolutionäre Regierung von Anfang an auf dem Krieg. "Nous y serons encore votre avant-garde contre les tyrans coalisés«, stellte Barère fest, als sich der Wohlfahrtsausschuß, dessen Herrschaft formal immer an das Votum des Konvents gebunden blieb, bereits Ende September 1793 erstmals gegen Bestrebungen aus dessen Reihen zur Wehr setzen mußte, seine Zusammensetzung $\mathrm{zu}$ ändern ${ }^{362}$. Zugleich wurde deutlich, wie fundamental das Selbstbild der Revolutionsregierung von der Vorstellung geprägt war, einen nicht nur unauflöslich miteinander verbundenen, sondern auch allumfassenden Kampf an zwei Fronten, gegen den äußeren, nun vor allem mit England identifizierten, wie gegen den damit verbundenen inneren Feind zu führen. Robespierre charakterisierte die Tätigkeit des Wohlfahrtsausschusses dementsprechend so: "11 armées à diriger, le poids de l'Europe entière à porter, partout des traîtres à démasquer, des émissaires soudoyés par l'or des puissances étrangères à déjouer, des administrateurs infidèles à surveiller, à poursuivre; (...) tous les tyrans à combattre, tous les conspirateurs à intimider, eux qui se trouvent presque tous dans une caste si puissante autrefois par ses richesses, et encore par ses intrigues: telles sont nos fonctions. Croyez-vous, sans unité d'action, sans secrets dans les opérations, sans certitude de trouver un appui dans la Convention, le gouvernement puisse triompher de tant d'obstacles et de tant d'ennemis? «.

Diese Argumentation war offenbar überzeugend, der Wohlfahrtsausschuß wurde vom Konvent in seiner Zusammensetzung bestätigt. In der Folgezeit war er dann intensiv darum bemüht, seine auf der Suspendierung der neuen, demokratischen Verfassung basierende Regierungs- bzw. Herrschaftsform 
politisch-konzeptionell zu begründen. In den Mittelpunkt rückte dabei ihr besonderer, revolutionärer Charakter, der zugleich immer deutlicher mit dem Krieg identifiziert wurde. "Un peuple n'a qu'un ennemi dangereux, c'est son gouvernement«, stellte Saint-Just im ersten Rechtfertigungsbericht des Wohlfahrtsausschusses über die weitere Notwendigkeit einer außerverfassungsmäBigen, revolutionären Regierung in total kriegsbezogener Weise fest, "le votre vous a fait constamment la guerre avec impunité.(...) Il est possible que les ennemis de la France fassent occuper en trois mois tout votre gouvernement par des conjurés ${ }^{363}$. Aus diesem Grunde sei es notwendig, daß der Konvent selbst, d.h. durch seine Ausschüsse, den Kampf des Gesetzes gegen das Verbrechen ausführe und somit in direkter, revolutionärer Form die Regierung ausübe, denn: »Il est impossible que les lois révolutionnaires soient exécutés, si le gouvernement lui-même n'est constitué révolutionnairement«: Ausgehend von dieser Argumentation ließ Saint-Just dann ein Dekret über die Regierung verabschieden, daß die Dauer der zuerst wesentlich auf der Überwachung der Regierung basierenden, zugleich unmittelbar mit einem Vorstoß zur Ausweitung und Verschärfung des Terrors ${ }^{364}$ verbundenen Herrschaft des Wohlfahrtsausschusses durch seinen ersten Artikel in direkter Weise an den Krieg band: "Le gouvernement provisoire de la France est révolutionnaire jusqu'à la paix«.

Diese indirekte Identifikation von Revolution und Krieg griff Robespierre gut zwei Monate später in seinem grundlegenden Bericht über die Prinzipien der revolutionären Regierung auf und gestaltete sie in positiver Weise aus ${ }^{365}$. Durch die Konstruierung der revolutionären Regierung als Kriegsdiktatur wurden die Revolution und der Krieg nun auch inhaltlich miteinander identifiziert. Es sei, so Robespierre, das Ziel der revolutionären Regierung, durch den Krieg gegen alle Feinde der Freiheit die Voraussetzungen für eine verfassungsmäßige Regierung erst einmal zu schaffen: "La Révolution est la guerre de la liberté contre ses ennemis; la constitution est le régime de la liberté victorieuse et paisible«, stellte er kategorisch fest. Um dieses Ziel erreichen zu können, sei es vorerst aber notwendig, daß die Regierung der im Krieg befindlichen Republik über »une activité extraordinaire«, d.h. über revolutionäre bzw. diktatorische Vollmachten verfügen müsse, "précisement parce qu'elle est en guerre«.

Ein weiteres grundlegendes Element der kriegsdiktatorischen Ausprägung der Revolution bestand darin, daß sich der nun zunehmend zentralisierte Terror seit Herbst 1793 nicht mehr nur gegen Vertreter der alten Ordnung rich-

${ }^{363}$ AP 76, S. 313-317, hier S. 313, 10.10.1793; hier auch die folgenden Zitate.

${ }^{364} \mathrm{Vgl}$. ebd., S. 313: "Il n'y a point de prospérité à espérer, tant que le dernier ennemi de la liberté respirera. Vous avez à punir non seulement les traîtres, mais les indifférents même; vous avez à punir quiconque est passif dans la République, et ne fait rien pour elle«.

${ }^{365}$ AP 82, S. 209-303, 25.12.1793. 
tete, sondern immer mehr auch gegen abweichende Meinungen und Gruppierungen im revolutionären Lager selbst. Die Revolution begann mit der Hinrichtung der Girondisten im Oktober und November 1793 tatsächlich - mit Vergniauds berühmten Worten -, wie Saturn ihre eigenen Kinder zu fressen, und sie fand daran offensichtlich Geschmack. Revolutionäre aber waren, um im Bild zu bleiben, nur schmackhaft, wenn sie mit der wesentlich kriegspolitisch angesetzten Soße des Revolutions- und Landesverrates gewürzt waren, die seit dem Herbst 1793 allen politischen Auseinandersetzungen beigegeben wurde. Als im März und April 1794 die verfeindeten "factions« der wultras« und "citras«, der "exagérés" und "modérés«, der radikalen Hébertisten und gemäßigten Dantonisten oder wie immer man sie mehr oder weniger unzulänglich charakterisieren mag, nacheinander vor das Revolutionstribunal zitiert und auf das Schafott geschickt wurden, wurde ihnen bezeichnenderweise nicht nur derselbe Vorwurf von Agententätigkeit und Landesverrat gemacht, sondern ihre gegeneinandergerichteten Tätigkeiten wurden auch noch zu einer gemeinsamen, allgegenwärtigen "conspiration de l'étranger" miteinander verbunden.

Auf den ersten Blick muß es absurd erscheinen, daß führenden Protagonisten der radikalen Revolution wie Danton und Desmoulins oder Chaumette und Hébert ernsthaft der Vorwurf einer - trotz ihrer schroffen Feindschaft auch noch gemeinsam betriebenen - antirevolutionären Spionagetätigkeit gemacht werden konnte. War dies nur bloße Rhetorik, oder entsprach es gar doch der Realität? Über diesen lange im Zentrum der Debatten stehenden Gegensat $\mathrm{z}^{366}$ hat vor allem Albert Soboul die Diskussion hinausgetrieben, als er die Realität des "complot de l'étranger « treffend in der Mentalität der revolutionären Regierung ausmachte ${ }^{367}$. Die politische Diskursanalyse bestätigt diesen Befund nachdrücklich. Damit sollen die interessengeleiteten Hinter-

${ }^{366}$ Bereits Mathiez hat in seiner durch den Weltkriegsnationalismus bestärkten Besessenheit, mit Danton den Héros seines Lehrers und späteren Gegners Aulard zu demontieren und durch Robespierre zu ersetzen, die kriegspolitischen Aspekte des Konflikts der factions zurecht in den Mittelpunkt gerückt, freilich distanzlos die zeitgenössischen Vorwürfe gegen Danton reproduzierend, nicht kritisch analysierend. Vgl. neben MATHIEZ, Danton et la paix sowie DERS., Le Complot de l'étranger. Études robespierristes II, zuletzt O.BLANC, Les Hommes de Londres, histoire secrète de la terreur, Paris 1989. Die Forschung rückt sonst in der Regel unterschiedliche Positionen gegenüber innenpolitischen Fragen wie der Dechristianisierung und dem Terrorsystem in den Mittelpunkt der Analyse des Konfliktes zwischen 'gemäßigten` Dantonisten und ‘radikalen` Hébertisten und sieht so im Vorwurf des "complot de l'étranger« ein mehr oder weniger vorgeschobenes Konstrukt. Vgl. etwa B. VINOT, Saint Just, Paris 1985, S. 244.

${ }^{367}$ A. Soboul, Précis d'histoire de la Révolution française, 2 Bde., Paris 1962, hier Bd. 2, S. 67, wobei bezeichnenderweise politische Gegensätze noch immer wie selbstverständlich als Intrigen gegen die kriegspolitische Einheit der Nation gedeutet werden: "Le Comité de salut public crut à la réalité du complot de l'étranger ..., les comités virent la main de l'étranger et l'or de Pitt dans toutes intrigues pour diviser les patriotes«. 
gründe der wechselseitigen Denunziationen in der "murky underworld of the terror $\ll^{368}$ keineswegs geleugnet werden. Doch konnten sie in dieser Form nur deshalb wirken, weil sie in die Grundmuster des politischen Diskurses eingepaßt waren und so problemlos Glaubwürdigkeit gewinnen konnten.

Vor dem Hintergrund der Konstruktion eines universellen, Krieg, Bürgerkrieg und Revolution zu einem einzigen antagonistischen Konflikt verbindenden Kampfes zwischen neuer und alter Ordnung, zwischen Republik und Monarchie, wurde es geradezu selbstverständlich, alle realen oder vermeintlichen Feinde der Revolution mit dem feindlichen Ausland in Verbindung zu bringen, zumal nachdem mit den Girondisten erstmals führende Revolutionäre als englische Agenten >enttarnt، worden waren. Und angesichts der nun dominierenden Beschwörung einer vereinheitlichten, zentralisierten Revolutionsführung als notwendigem Mittel der Kriegsführung wurde bald jede Opposition gegen die revolutionäre Regierung, deren Stärkung doch »l'intérêt le plus cher du peuple et de la liberté« zu sein schien ${ }^{369}$, nicht nur als Infragestellung der Revolution schlechthin, sondern im Zeichen der Identifikation von Krieg und Revolution auch wie selbstverständlich als subversive Tätigkeit im Interesse der feindlichen Kriegskoalition gedeutet. "Ainsi nous dévoilerons tous ces complots«, formulierte Barère dementsprechend die Perspektive der Revolutionsregierung, "nous mettrons au jour tous ces plats conspirateurs et ces aveugles motionnaires, qui ne peuvent être conduits que par l'aristocratie restée en France et les gouvernements étrangers. Car à quoi peuvent servir ces divisions, ces mouvements, ces désorganisations brutales de l'état social? Elles ne peuvent servir qu'à l'étranger, elles ne peuvent servir qu'au tyrans « ${ }^{370}$.

Doch betrachten wir zuerst genauer den Konflikt zwischen den factions, in dem es inhaltlich bereits von Anfang an wesentlich um gegensätzliche kriegspolitische Perspektiven ging. Dieser Konflikt hatte bereits im Sommer 1793 seinen Ausgang genommen, als es angesichts der militärischen Bedrohung des erst kurz vorher in die Republik eingegliederten Savoyen im Konvent zu scharfen Auseinandersetzungen über die Notwendigkeit der Verteidigung zwischen dem radikalen Hérault einerseits, dem gemäßigten, der Gironde nahestehenden Mecier andererseits kam ${ }^{37 !}$.

${ }^{368}$ GoUGH, The Terror, S. 95. Vgl. auch A. DE LESTAPIS, La ‘Conspiration de Batzı (17931794), Paris 1969.

${ }^{369}$ So Saint-Just am 23. Vent. IU13.3.1794. AP 86, S. 439.

${ }^{370}$ AP 86, S. 129, 16. Vent. II/6.3.1794.

${ }^{371}$ Vgl. hier Kap. IV.1. In den Annales Patriotiques, 12.7.1793, die Mercier gemeinsam mit dem kurz darauf als Girondist verhafteten Carra herausgab, vertrat dieser sein altes Projekt einer Verständigung mit Preußen, wobei zugleich die enge Verbindung zwischen außen- und innenpolitischen Positionen überdeutlich hervortrat: "Si le Roi de Prusse, dont l'intérêt véritable est de se détacher au plus tôt de la coalition, montre un désir sincère de faire la paix avec la République, nous verrons alors quels seront les partisans assez osés de l'Autriche 
Im Herbst 1793 spitzten sich die Konflikte über Begrenzung oder Ausweitung des Krieges weiter zu, und es war wesentlich diese zu Anfang, angesichts der bedrohten militärischen Situation der Republik, noch verdeckt ausgetragene Auseinandersetzung, die zur Bildung der factions führte. Es steht jedenfalls außer Zweifel, daß Hérault, zu diesem Zeitpunkt außenpolitischer Sprecher des Wohlfahrtsausschusses, eine Politik verfolgte, die auf die Revolutionierung der neutralen Schweiz abzielte. Auf der anderen Seite war der Kreis um Danton darum bemüht, die Möglichkeiten für einen Verständigungsfrieden offenzuhalten. Beide tatsächlich jeweils nur in einem sehr lockeren Zusammenhang stehende Gruppierungen verbanden dabei zugleich in gegensätzlicher Weise Krieg und Revolution miteinander: Während die Dantonisten mit der Begrenzung oder Beendigung des Krieges zugleich die revolutionäre Radikalisierungsdynamik zu einem Ende bringen wollten, ging es den Hébertisten im Einklang mit radikalen Emigranten aus dem Umkreis der Cordeliers wie Cloots umgekehrt darum, die Radikalisierung des »guerre à outrance« mit dem Weitertreiben der Revolution nach außen und innen zu verbinden.

»Depuis quelque temps«, so argumentierte die wesentlich von Cloots inspirierte Emigrantenzeitung Le Batave im September 1793 gegen die Friedensbestrebungen, "on parle beaucoup de paix. Tous nos modérés, nos feuillants et nos royalistes, car tous ces hommes sont très fort d'accord, s'efforcent à nous persuader que les puissances coalisées, lasses de la guerre, ne seraient pas éloignées d'entrer en négociations avec la France pour rendre la tranquillité à l'Europe (les bons apôtres!), pourvu seulement qu'elles fussent assurées que les Français se prêteraient à des conditions raisonnables; mais ils ne nous disent pas quelles seraient ces conditions; et peu nous importe; nous savons très bien que les despotes conjurés contre la liberté française sont très las de la guerre; que leurs finances sont fort embarassées pour trouver les moyens de subvenir aux frais immenses qu'occasionne cette nouvelle croisade contre la sainte Egalité « ${ }^{372}$. Statt dessen gehe es darum, so stellte Cloots etwas später fest, den Krieg bis zur letzten Entscheidung zu führen, denn das französische Volk wne veut pas recevoir la paix, il veut la dicter. Car l'homme le moins

pour s'y opposer«. Carra ordnete zugleich die innenpolitischen Gruppierungen in Frankreich auf politisch in vieler Hinsicht absurde, zugleich aber für die alles bestimmende Bedeutung des Krieges und die Verbindung von Innen- und Außenpolitik bezeichnende Weise ausländischen Mächten zu, er unterschied zwischen Parteigängern Österreichs wie den Radikalen »Pa(che), Bou(chotte), Aud(oin), Has(sefratz) et consorts de la Commune de Paris«; den «instruments aveugles ou clairvoyants du parti anglais: Dan(ton), Mar(rat), La(croix), Rob(espierre) (!,WK) et consorts des Ja(cobins)«; schließlich einen "parti espagnol: Jus(mann), Pi(lo), Per(reira) et consorts des Cor(deliers)«. Ob Carra sich selbst, wie oft betont wird, als Parteigänger Preußens sah, ist nicht überliefert.

${ }^{372}$ Le Batave, 16.9.1793, zit. n. MATHIEZ, Danton et la paix, S. 188f. 
versé dans la diplomatie européenne prévoit une série d'agitations internes, et de calamités universelles dans un désarmement précoce, dans un accommodement qui laisserait subsister une puissance aristocratique entre le Rhin et nous. Un traité pareil serait la honte des républicains, la gloire des presseurs et le désespoir des opprimés. Non, la France perdra avec honneur, ou nous dicterons la paix aux tyrans $\aleph^{373}$.

Die gegensätzliche Position der Dantonisten trat am deutlichsten hervor, als Desmoulins im Dezember seine Zeitschrift Le Vieux Cordelier herausbrachte. Sie wird in der Literatur zumeist vor allem als Plädoyer gegen die Fortsetzung des Terrors begriffen, doch war sie tatsächlich mit dem treffenden Urteil von Marc Dufraisse wautant une ode en faveur de la paix qu'une élégie en faveur de la clémence « ${ }^{374}$. Die Beendigung des Krieges und die Beendigung der Revolution, beides war im politischen Diskurs der Dantonisten in der Tat unauflöslich miteinander verbunden: "Je pense bien différemment de ceux qui vous disent qu'il faut laisser la terreur à l'ordre du jour«, so die durchaus naiv anmutende, die revolutionären Kräfte in England weit überschätzende Grundüberzeugung des Vieux Cordelier: "Je suis certain au contraire que la liberté serait consolidée, et l'Europe vaincue, si vous aviez un comité de clémence. C'est ce comité qui finirait la révolution. (...) Etrange bizarrerie! En Angleterre (...), c'est Pitt, en un mot, qui demande à grands cris la continuation de la guerre; et c'est tout ce qu'il y a de patriotes, de républicains et de révolutionnaires, qui votent pour la paix, qui n'espèrent que de la paix un changement dans leur constitution. En France, tout au rebours. Ici ce sont les patriotes et le révolutionnaires qui veulent la guerre, et il n'y a que les modérantins, les feuillants, si l'on en croit Barère; il n'y a que les contre-révolutionnaires et les amis de Pitt qui osent parler de paix «" ${ }^{375}$.

Lassen wir die hier angesprochene Position des Wohlfahrtsausschusses erst einmal beiseite und konzentrieren uns auf die wechselseitigen Zuweisungen

${ }^{373}$ Diplomatie révolutionnaire. Adresse d'Anacharsis Cloots aux Sans-Culottes bataves, vorgetragen am 5.10.1793 im Pariser Jakobinerklub, abgedr. in: Ecrits révolutionnaires, S. 608-616, hier S. 615. Wie zentral zugleich der Bezug von Cloots auf Belgien war, wird in den folgenden Zeilen, S. 610, deutlich: »Gardons-nous de professer l'hérésie brissotine en calomniant les Belges, en conseillant de les fédéraliser ou de faire un désert de leur pays. Ne cherchons pas à nous concilier Pitt, l'ennemi du genre humain. Les Belges sont plus dignes de la liberté que beaucoup de nos anciens départements.. (...) Est-ce pour exciter les PaysBas à se lever en masse contre nous? Est-ce pour désorganiser nos armées victorieuses, que l'on insinue à nos soldats de se livrer à la crapule, de tout piller et brûler dans un pays où nous avons trois milliards de biens nationaux; dans un pays où le nom français est en recommandation ...«.

${ }^{374}$ Zit. n. MATHIEZ, Danton et la paix, S. 251.

${ }^{375}$ Vieux Cordelier, Nr. 4, 30. Frim. II/20.12.1793, S. 56, u. Nr. 7, 5. Pluv. II/24.1.1794, S. 129. 
zwischen den factions, die sich, nach dem Muster der Auseinandersetzungen zwischen Gironde und Montagne sowie vor dem Hintergrund vielfailtiger geheimer Denunziationen, wechselseitig offen der Tätigkeit im Auftrag oder zumindest im Interesse Englands beschuldigten. »O Pitt! je rends hommage à ton génie!«, so lautete der erste Satz der ersten Nummer des Vieux Cordelier, und gemeint waren damit die Angriffe der Hébertisten gegen die Dantonisten, die Ausdruck einer neuen, erfolgversprechenden Taktik der englischen Regierung seien: "Tu as compris que ce sont ceux qui t'ont toujours vaincus qu'il fallait craindre; qu'il fallait faire accuser de corrumption, précisement ceux qui tu n'avais pu corrompre et d'attiédissement ceux qui tu n'avais pas attiédir « ${ }^{376}$. Die Radikalen seien deshalb generell wévidement en coalition au moins indirecte avec Pitt « ${ }^{377}$, in Hébert aber sah Desmoulins einen "conspirateur payé par Pitt«, den er genau wie Brissot - eine Anspielung auf seine Broschüre "Jean-Pierre Brissot démasqué« - entlarven werde: "Tes numéros, et tes contradictions à la main, je suis prêt à prouver que tu es un avilisseur du peuple français et de la Convention, et un scélérat, déjà aux yeux des patriotes et des clair-voyants, non moins démasqué que Brissot dont les agents de Pitt t'avaient fait le continuateur, et entrepreneur de contre-révolution par un autre extrême « ${ }^{378}$.

Während sich die Dantonisten gegen den nach außen wie nach innen gerichteten Militarismus der »exagération en moustaches«, d.h. der sansculottischen armées révolutionnaires mit ihrem militärischen, die zivilen Autoritäten gering achtenden Gehabe wandten, "qui ont cherché à éterniser la guerre pour se prouver des généralats lucratifs et d'autres places ${ }^{379}$, attackierten die Radikalen umgekehrt die »endormeurs (...), qui oseraient nous proposer de mettre les pouces au moment de la victoire ${ }^{380}$. Es handele sich dabei, so der umgekehrte Bezug auf Brissot, um "les mêmes viédases qui voulaient la guerre quand nous n'étions pas en force pour la soutenir et qui demandent aujourd'hui la paix à hauts cris pour nous arrêter au milieu de nos victoires $\aleph^{381}$. Vor allem Desmoulins' Vorschlag zur innenpolitischen Versöhnung veranlaßte Hébert zu der Frage, "scombien l'infâme Pitt a-t-il payé cette bougre de motion de Coblentz?«. Denn schließlich habe gerade der Terror, so wieder die

\footnotetext{
376 Vieux Cordelier, Nr. 1, 5. Frim. II/25.11.1793, S. 1.

377 Vieux Cordelier, Nr. 7, 5. Pluv. II/24.1.1794, S. 163.

${ }^{378}$ Vieux Cordelier, Nr. 5, 5. Niv. II/26.12.1793, S. 79.

${ }^{379}$ So Tallien im Jakobinerklub, 24. Vent. II/14.3.1794, zit. n. AULARD, Société des Jacobins, Bd. 5, S. 687; gemeint war auch das Kriegsministerium, in dem der radikale Cordelier Vincent ein Machtzentrum aufgebaut hatte. Vgl. H. G. BROWN, War, Revolution, and the Bureaucratic State. Politics and Army Administration in France, 1791-1799, Oxford 1995, S. 65-150.

${ }^{380}$ Père Duchesne, Nr. 320.

${ }^{381}$ Père Duchesne, Nr. 337.
} 
Verbindung von Krieg und Revolution, das Wunder der militärischen Stabilisierung ermöglicht: "Comment avons-nous fait tant de miracles en si peu de temps? C'est en nous relissant contre tous les jean-foutres qui nous trahissaient à la journée; c'est en exterminent tous les coquins. Ce n'est que depuis que nous avons mis les gens suspects à l'ordre, ce n'est que depuis la terreur est à l'ordre du jour, ce n'est que par la vertu de la sainte guillotine que nous nous sommes sauvés, foutre. Si nous faisions un seul pas à reculons, nous serrions foutus $\ll^{332}$.

Wenden wir uns nun der Wahrnehmung dieser Konflikte durch die Revolutionsführung zu. Furet und Richet haben die Politik der großen Ausschüsse gegenüber den factions am Beispiel von Robespierre wesentlich als taktisch begründetes Verhalten mit dem Ziel gedeutet, die trotz aller diktatorischen Tendenzen weiterhin notwendige Mehrheitsfähigkeit der revolutionären Regierung im Konvent $\mathrm{zu}$ bewahren ${ }^{383}$. In der Tat ist eine wesentliche Voraussetzung für den Sturz der factions darin zu sehen, daß sie jeweils in unterschiedlicher Weise von der nun immer stärker von Robespierre personifizierten Position des revolutionären Zentrums abwichen und damit die kriegspolitisch notwendig erscheinende Einheitlichkeit der revolutionären Regierung zu gefährden schienen. Das den Wohlfahrtsausschuß dominierende Zentrum stimmte mit den Radikalen darin überein, daß der Krieg "à outrance " geführt werden müsse, lehnte andererseits aber die von diesen im Zeichen der Dechristianisierung und des Terrors betriebene Basisradikalisierung ebenso vehement ab wie die allgemeine Ausweitung des Krieges. Während die Revolutionsführung darin mit den Gemäßigten einig war, erfuhr die von diesen vertretene Politik der äußeren und inneren Befriedung jedoch eine schroffe Ablehnung.

In dieser politisch prekären Situation lag zweifellos eine wesentliche Voraussetzung für die Politik der Revolutionsführung gegenüber den factions. Doch sie allein kann nicht hinreichend erklären, wieso in der Beurteilung beider Richtungen wie selbstverständlich die negativen Aspekte in den Vordergrund rückten, warum ihre jeweiligen Aktivitäten als feindliche Agententätigkeit begriffen wurden, und wie es schließlich möglich war, ihre gegeneinander gerichteten Aktivitäten auch noch als Ausdruck einer gemeinsamen Verschwörung zu deuten. Dies war nur deshalb möglich, weil es in der Logik eines politischen Diskurses lag, der abweichende politische Tendenzen wie selbstverständlich als im Bunde mit dem feindlichen Ausland stehende "faction anglo-prussienne" oder "faction autrichienne" erscheinen lassen konnte $^{384}$, deren Ziel es sei, die Einheitlichkeit der Revolutionsführung und

382 Ibid.

${ }^{383}$ FURET, RICHET, La Révolution Française, Bd. 1, S. $340 \mathrm{f}$.

${ }^{384}$ So Robespierre, AP 76, S. 642, 16.10.1793. 
damit die Substanz der militärischen Landesverteidigung zu unterminieren. »Il existe«, so argumentierte Barère bereits im September 1793 gegen die ersten Angriffe auf den Wohlfahrtsausschuß, wun grand plan parmi les ennemis intérieurs; il existe un petit parti d'ambitieux ou d'étrangers, qui a pour objet de diviser la Convention, de faire des sectes de patriotisme, afin que, ne formant plus une masse, la République ne soit plus défendue «. Und Robespierre fügte noch eindeutiger hinzu: "Quelle est donc la cause de ces dénonciations? Ah! cette journée a valu à Pitt, j'ose le dire, plus de trois victoires. A quel succès en effet peut-il prétendre, si ce n'est à anéantir le gouvernement national que la Convention a établi, à nous diviser, à nous faire déchirer de nos propres mains? $\aleph^{385}$.

Hatten sich diese Attacken noch gegen Vorstöße aus dem Umkreis von Danton gerichtet, die auf einen Wechsel in der Zusammensetzung des Wohlfahrtsausschusses drängten, um bessere Voraussetzungen für die Eingrenzung des Krieges zu gewinnen ${ }^{380}$, rückten bald erst einmal die radikalen Kräfte in den Mittelpunkt der Kritik. Dazu trugen nicht zuletzt die von Fabre d'Eglantine, Chabot und Bazire im Oktober und November 1793 vorgebrachten Denunziationen einer besonders von ausländischen Emigranten in den Reihen der Hébertisten getragenen Konspiration bei, die von den Vertretern der beiden großen Ausschüsse offensichtlich für glaubwürdig befunden wurden $^{387}$. Schon im November 1793 wendete sich Robespierre nun gegen "faux patriotes « und »émissaires stipendiés par les cours étrangères«, deren Ziel es sei, durch den Propagandakrieg letztlich eine Stärkung der antifranzösischen Koalition zu bewirken. "La politique de nos ennemis", stellte er fest, "a jusqu'ici épuisé toutes ses ressources pour les armer contre nous; l'imprudence, l'insouciance, la perfidie ont concouru à les seconder; quelques violations de territoire, des chicanes inutiles, des injures gratuites, insérées dans certains journaux et une intrigue très active, dont les principaux foyers sont Genève, le Mont-Terrible et certains comités ténébreux, qui se tiennent à Paris, composés de banquiers, d'étrangers et d'intrigants couverts d'un masque de patriotisme; tout a été mis en usage pour les déterminer à grossir la ligue de nos ennemis « $^{38}$. Zielte dies nicht zuletzt gegen die Aktivitäten von Hérault, so attackierte Robespierre einige Wochen später offen den »baron allemand«, den "prussien Cloots«, dessen Propaganda für die Weltrevolution tatsächlich nur darauf ziele, die Welt gegen Frankreich zu mobilisieren: »Eh!

\footnotetext{
${ }^{385}$ AP 75, S. 130, 132, 25.9.1793.

${ }^{386} \mathrm{Vgl}$. MATHIEZ, Danton et la paix, S. 172-199.

${ }^{387} \mathrm{Vgl}$. A. MATHIEZ, Fabre d'Eglantine, inventeur de la conspiration de l'étranger, in: DERS., La Conspiration de l'étranger, S. 1-38; N. HAMPSON, François Chabot and his Plot, in: Transactions of the Royal Historical Society, 5. Serie, Bd. 26, 1976, S. 1-14.

${ }^{388}$ AP 79, S. 402, 17.11.1793.
} 
s'il eût été bon Français, eût-il voulu que nous tentessions la conquête de l'univers? Eût-il voulu que nous fissions un département français du Monomotapa? Eût-il voulu que nous déclarassions la guerre à toute la terre et à tous les éléments? (...) Jamais il ne fut le défenseur du peuple français, mais celui du genre humain. Hélas! malheureux patriotes, que pouvons-nous faire, environnés d'ennemis qui combattent au milieu de nos ranges! Ils se couvrent d'un masque, ils nous déchirent, et nous sentons les plaies sans savoir d'où partent les traits meurtriers $\ll^{389}$.

Als patriotisch maskierte Verräter erschienen bald auch die radikalen Kräfte im Umkreis der Cordeliers, die die Revolution von unten weitertreiben wollten. Selbst Billaud, der doch als Vertreter der Cordeliers in den Wohlfahrtsausschuß gelangt war, wandte sich nun gegen die "Anarchie«, die schließlich nur in die Sklaverei zurückführe ${ }^{30}$. Robespierre attackierte die Volksgesellschaften, weil »la tartufferie contre-révolutionnaire y domine. Les agents de la Prusse, de l'Angleterre et de l'Autriche veulent par ce moyen anéantir l'autorité de la Convention et l'ascendant patriotique de la Société des jacobins « ${ }^{391}$. Die terroristischen Exzesse, vor allem aber die Dechristianisierungsbewegung ${ }^{392}$ wurden als Versuch gedeutet, die Revolution zu diskreditieren und zu einem inneren Zusammenbruch zu führen. "Le fanatique couvert de scapulaires, et le fanatique qui prêche l'athéisme ont entre eux beaucoup de rapport«, so verband Robespierre die Dechristianisierer mit den eidverweigernden Priestern zu einer gemeinsamen Verschwörung gegen die Republik ${ }^{393}$. Vor allem aber denunzierte er die antichristlichen Aktivisten der Volksgesellschaften und die Agitatoren des universellen Krieges gemeinsam als Vertreter eines überzogenen Radikalismus, der tatsächlich nur den Interessen der Konterrevolution diene: »Tel appelait la France à la conquête du monde, qui n'avait d'autre but que d'appeler les tyrans à la conquête de la France. L'étranger hypocrite qui, depuis cinq années proclame Paris la capitale du globe, ne faisait que traduire, dans un autre jargon les anathêmes des vils fédéralistes qui vouaient Paris à la destruction. Prêcher l'athéisme, n'est qu'une manière d'absoudre la superstition et d'accuser la philosophie; et la guerre déclarée à la divinité, n'est qu'une diversion en faveur de la royauté. Quelle autre méthode reste-t-il de combattre la liberté? « $^{394}$.

Es ist allerdings bezeichnend für die Wahrnehmungsweise der Revolutionsführung, $\mathrm{da} B$ die Wendung gegen den revolutionären Radikalismus nie alleine

\footnotetext{
389 AULARD, Société des Jacobins, Bd. 5, S. 555f., 12.12.1793.

390 AP 79, S. 451, 18.11.1793.

${ }^{391}$ AULARD, Société des Jacobins, Bd. 5, S. 578, 26.12.1793.

${ }^{392} \mathrm{Vgl}$. M. VoVELLE, Réligion et révolution, La déchristianisation de l'an II, Paris 1976.

${ }^{393}$ AP 82, S. 301, 25.12.1793.

${ }^{394}$ Robespierre, 5.2.1794 vor dem Konvent. AP 84, S. 334 f.
} 
stand, sondern prinzipiell mit einer ähnlich strukturierten Kritik am sogenannten "modérantisme « verbunden war. "Le gouvernement anglais ne désire rien tant que de nous inspirer une modération qui ralentirait la ferveur populaire, ou des mesures extravagantes qui perdraient l'Etat«, argumentierte Saint-Just bereits im Oktober 1793, kurz nachdem er erstmals die Notwendigkeit einer revolutionären Regierung begründet hatte ${ }^{395}$. Robespierre fügte zwei Monate später mit derselben Intention hinzu: "Les tyrans ont constamment cherché à nous faire reculer vers la servitude, par les routes du modérantisme; quelquefois aussi, ils ont voulu nous jeter dans l'extrémité opposée. Les deux extrêmes aboutissent au même point. Que l'on soit en deça ou au delà du but, le but est également manqué «39.

Es war nach Jahren der Agitation gegen die gemäßigten Kräfte tatsächlich wohl kaum möglich, die Politik der Revolutionsführung nun allein durch die Absetzung vom Radikalismus zu legitimieren. Doch entsprach es auch grundsätzlich der auf Einheitlichkeit abzielenden Konstruktion der revolutionären Kriegsregierung, ihre Position jenseits bzw. oberhalb aller partikularen politischen Strömungen und Konflikte zu verorten, so daß sich die Kritik am Moderantismus als Parallele zur Wendung gegen den Radikalismus geradezu aufzwang. In der Perspektive der Revolutionsführung wurden so schließlich alle von ihr abweichenden inhaltlichen Positionen wesentlich als Bedrohung aufgefaßt, inhaltlich nivellierte und als Teil einer antirevolutionären Verschwörung gedeutet. "Ceux qui sont d'un génie ardant et d'un caractère exagéré proposent des mesures ultra-révolutionnaires; ceux qui sont d'un esprit plus doux et plus modéré proposent des moyens citra-révolutionnaires«, so charakterisierte Robespierte die unterschiedlichen Richtungen im Januar 1794 durchaus zutreffend, um sie dann folgendermaßen zu qualifizieren: »Ils se combattent entre eux, mais que l'un ou l'autre partie soit victorieuse, peu leur importe; comme l'un ou l'autre système doit également perdre la République, ils obtiennent un résultat également certain, la dissolution de la Convention nationale $\aleph^{397}$. Wenige Tage später argumentierte er vor dem Konvent: "Les ennemis intérieurs du peuple français ne sont divisés en deux factions, sinon en deux corps d'armée. Elles marchent sous des bannières de différentes couleurs et par des routes diverses; mais elles marchent au même but; ce but est la désorganisation du gouvernement populaire, la ruine de la Convention, c'est à dire, le triomphe de la tyrannie. (...) La double tâche des

${ }^{395}$ AP 76, S. 641, 10.16.1793.

${ }^{396}$ AP 82, S. 300f., 25.12.1793. Schon am 9.12. hatte Robespierre im Jakobinerklub erklärt: "Le modérantisme (...) est une arme plus dangereuse que la baionnette, et c'est contre cette perfidie que nous devons nous armer de courage et de force«. AULARD, Société des Jacobins, Bd. 5, S. 550.

397 AULARD, Société des Jacobins, Bd. 5, S. 601f., 8.1.1794. 
modérés et des faux révolutionnaires est de nous ballotter perpétuellement entre ces deux écueils « ${ }^{398}$.

Für Saint-Just stand so schon bald außer Zweifel, daß hinter den politischen Auseinandersetztungen der factions tatsächlich »une secte politique« stand, "qui joue tous les partis«. In seinen Erläuterungen wurde zugleich deutlich, wie sehr diese Deutung geprägt war von dem kriegspolitisch begründeten Führungsanspruch der revolutionären Regierung, der sich durch abweichende, gar oppositionelle Tendenzen grundsätzlich bedroht fühlte: „Parlez-vous de terreur, elle vous parle de clémence; dévenez-vous cléments, elle vous vante la terreur; elle veut être heureuse et jouir; elle oppose la perfection au bien, la prudence à la sagesse. (...) Eprouvons-nous des revers, les indulgents prophétisent les malheurs; sommes-nous vainqueurs on en parle à peine. (...) On distrait l'opinion des plus purs conseils et le peuple français de sa gloire pour l'appliquer à des querelles polémiques (...), les principes de la liberté publique peu à peu s'effacent, ceux du gouvernement se relâchent, et c'est ce que l'on veut pour accélérer notre perte « ${ }^{399}$. Und Barère machte etwas später, zu Beginn der Frühjahrskampagne 1794, noch einmal explizit deutlich, daß diese Betrachtungsweise in der Tradition eines Diskurses stand, der seit Kriegsbeginn den Kampf gegen den inneren Feind zur Voraussetzung des äuBeren militärischen Sieges gemacht hatte: "Vous ne pouvez vous dissimuler qu'avec l'Europe diplomatique et militaire coalisée, qu'avec les rois ennemis naturels de la République, nous devons être agités au-dedans, corrompus dans ce qui nous entoure, (...) divisés dans nos opinions et traversés dans nos projets. (...) Il faut surveiller la faction des indulgents et des pacifiques, autant que celle des prétendus insurgés (...) Citoyens, la campagne va s'ouvrir, déblayons le sol de l'intérieur de tant d'intrigues afin que nous puissons ne plus nous occuper que de combats et de victoires contre les ennemis étrangers $\aleph^{400}$.

Trotzdem ist es nicht unverständlich, wenn Danton und seine Anhänger sich anfangs von der Kritik am Moderantismus nicht getroffen fühlten. Gemeint waren zuerst eindeutig die gerade erst auf das Schafott geführten Girondisten, während Robespierre das Hauptaugenmerk zweifellos auf die Radikalen richtete: "Savez-vous que les puissances étrangères vous cernent ici? Elles vous ont placés entre deux écueils: entre le modérantisme qui est abattu pour jamais (!, WK), et la perfidie prussienne de ces hommes qui veulent la république universelle ou plutôt l'incendie universel « ${ }^{401}$. In der Ablehnung revolutionärer Kriegsausweitung und hébertistischer Basisradikalisierung

\footnotetext{
${ }^{398}$ AP 84, S. 334ff., 17. Pluv. II/5.2.1794.

${ }^{399}$ AP 85, S. 517, 8. Vent. II/26.2.1794.

${ }^{400}$ AP 86, S. 126, 129, 16. Vent. IV/6.3.1794.

${ }^{401}$ AULARD, Société des Jacobins, Bd. 5, S. 576, 23.12.1793.
} 
stimmte man ja tatsächlich weitgehend überein, und Robespierre hatte die ersten Nummern des Vieux Cordelier für seinen alten Freund Desmoulins gar vor der Veröffentlichung abgesegnet. Doch sowohl in der Friedensfrage als auch in der von den Dantonisten immer offener infragegestellten Notwendigkeit der revolutionären Regierung ergaben sich bald wieder so gravierende Differenzen, daß auch sie immer stärker als Bedrohung erscheinen mußten. Vor allem nachdem mit Fabre d'Eglantine ein enger Vertrauter von Danton immer tiefer in die ursprünglich von ihm selbst denunzierte, untrennbar mit der Vorstellung eines »complot de l'étranger« verbundene Korruptionsaffäre verwickelt wurde, wurden sowohl die Friedensbestrebungen als auch ihre damit verbundenen Bemühungen zur Beendigung des Terrors nun immer nachdrücklicher ebenfalls als Projekte im Interesse des feindlichen Auslands gedeutet, der Politik der Hébertisten gleichgestellt, ja schließlich damit verbunden.

"Qui ose parler de paix?«. Auf diese rhetorische Frage gab Barère als außenpolitischer Sprecher des Wohlfahrtsausschusses im Januar 1794 dem Konvent eine eindeutige Antwort: »Ceux qui espèrent ajourner la contrerévolution à quelques mois, à quelques années, en donnant aux étrangers, aux tyrans le temps de se restaurer, les moyens de sucer les peuples, de refaire leurs approvisionnements et de recruter leurs armées ${ }^{402}$. Und Saint-Just wies etwas später die Initiative der Dantonisten zum Abbau des Terrorregimes folgendermaßen zurück: "Il s'éleva, dans le commencement de la Révolution, des voix indulgentes en faveur de ceux qui la combattaient; cette indulgence, qui ménagea pour lors quelques coupables, a depuis coûté la vie à deux cent mille hommes dans la Vendée; cette indulgence nous a mis dans la nécessité de raser des villes; elle a exposé la patrie à une ruine totale; et si aujourd'hui vous vous laissiez aller à la même faiblesse, elle vous coûterait un jour trente ans de guerre civile $\ll^{403}$.

Die offene Wendung der Revolutionsführung gegen den Moderantismus führte im Spätwinter 1794 nicht zuletzt dazu, daß der Radikalismus neuen Auftrieb bekam. Als die Cordeliers im März 1794 jedoch offen von einem Aufstand gegen den Konvent zu sprechen begannen, mußte sich die Revolutionsführung geradezu in ihrem Verdacht bestätigt sehen, daß die ranarchischer Radikalisierung tatsächlich »révolutionnaire contre le peuple«, gegen die Revolution selbst bzw. gegen ihre gewählte Führung gerichtet sei, wie Saint-Just am 13. Mai die Notwendigkeit der Anklageerhebung vor dem Konvent begründete ${ }^{4 a 4}$. Besonders gefährlich schienen die Cordeliers auch deshalb zu

${ }^{402}$ AP 83, S. 562, 22.1.1794.

${ }^{403}$ AP 85, S. 516-520, hier S. 518, 26.2. (8. Vent.) 1794.

${ }^{404} \mathrm{Vgl}$. den zur Anklageerhebung führenden Bericht von Saint-Just, AP 86, S. 434 441, 13.3.1794; das Zitat S. 439. Zu den tatsächlich kaum organisierten Absichten der sog. 
sein, weil sie sich mit der Pariser Revolutionsarmee unter Führung von Ronsin auf eine bewaffnete, schon lange militaristischer Tendenzen verdächtige Macht stützen konnte, wodurch die Angst der Revolutionäre vor der Militärherrschaft erneut Nahrung bekam. Die Ausschaltung der radikalen Hébertisten erschien dann aber doch in ganz kriegsbezogener Weise vor allem als eine Maßnahme, die mit dem Schlag gegen den sinneren Feind den militärischen Sieg vorbereiten sollte. "Un succès important vient d'ouvrir la campagne de d'intérieur«, so kommentierte die revolutionäre Öffentlichkeit die Aburteilung, "nos éclaireurs ont surpris et détruit l'avant-garde ennemie: c'étaient des conspirateurs; ils ne sont plus, le glaive de la loi en a fait justice hier. Ce nouveau triomphe de la liberté prépare à ceux qu'elle remportera à l'extérieur « ${ }^{405}$.

Schon in Saint-Justs Anklagerede gegen die Hébertisten zeichnete sich deutlich ab, daß die Revolutionsführung sich anschickte, mit den factions insgesamt abzurechnen, wenn er erklärte, daß wtous les complots sont unis: ce sont les vagues qui semblent se fuir, et qui se mêlent cependant: La faction des indulgents, qui veulent sauver les criminels, et la faction de l'étranger, qui se montre hurlante parce qu'elle ne peut faire autrement sans se démasquer, mais qui tourne la sévérité contre les défenseurs du peuple, toutes ces factions se retrouvent la nuit pour concerter leurs attentats du jour; elle paraissent se combattre pour que l'opinion se partage entre elles; elles se rapprochent ensuite pour étouffer la liberté entre deux crimes $\aleph^{406}$. Gut zwei Wochen später bègründete Saint-Just dann die Anklageerhebung gegen Danton und seine Anhänger mit dem umgekehrten Argument, sie seien wie Hébert »tous complices du même attentat. Tous vous avez tenté le renversement du gouvernement révolutionnaire et de la représentation (...) tous, vous avez travaillez pour l'étranger, que jamais ne voulut autre chose que le renouvellement de la Convention, qui eût entraîné la perte de la République «07.

Ein letzter wichtiger Aspekt in der diskursiven Wendung gegen die factions bleibt zu analysieren: der Kollektivsingular "l'étranger«, der in der Verbindung mit "complot« oder "conspiration" keineswegs nur das (feindliche) Ausland bezeichnete, sondern zugleich auch dessen Agenten, ja in typischer Identifikation schließlich sogar alle inneren Feinde der Revolution umfaßte. Zweifellos war es für die Wendung gegen die factions auch wichtig, daß in beiden Gruppierungen, vor allem aber im Kreis der Hébertisten ausländische Emigranten aus den Ländern vertreten waren, gegen die die Republik Krieg führte. Doch war dies nur eine unter mehreren Voraussetzungen für die Kon

Hébertisten vgl. M. SLAVIN, The Hébertists to the Guillotine. Anatomy of a »Conspiracy « in Revolutionary Francy, Baton Rouge und London 1994.

${ }^{405}$ Journal des hommes libres, 6. Germ. II/26.3.1794.

${ }^{406}$ AP 86, S. 434-441, hier S. 437, 23. Vent. IV17.3.1794.

${ }^{407}$ AP 87, S. 629-639, hier S. 636, 11. Germ. II/31.3.1794. 
struktion eines "complot de l'étranger«. Sophie Wahnich hat in einer beeindruckenden Diskursanalyse gezeigt, wie wichtig das Verhältnis zu den »Fremden« für die Revolution tatsächlich war ${ }^{08}$. Zwar geht es ihr vor allem um die in der Revolution grundsätzlich angelegten, die Moderne auszeichnenden, miteinander verbundenen Ambivalenzen von Gastfreundschaft und Verdacht, Freundschaft und Verrat, Brüderlichkeit und Ausschluß im Verhältnis der revolutionären Gesellschaft zu den »Fremden«. Doch wird in Wahnichs Darlegungen zugleich immer wieder deutlich, wie sehr gerade die Situation und die revolutionäre Konstruktion von Krieg und Bürgerkrieg den universellen Anspruch der Revolution zur nationalistischen Exklusion pervertiert haben. Die im Spätsommer 1793 beschlossenen Überwachungsmaßnahmen gegen die Ausländer richteten sich dementsprechend wesentlich gegen »les étrangers des pays qui sont en guerre avec la République « ${ }^{409}$.

Für die hier behandelte Themenstellung von noch größerer Bedeutung ist es aber, daß unter dem Eindruck von Krieg und Bürgerkrieg im Jahre 1793 eine enorme Ausweitung der bereits vielfach hervorgehobenen Denkfigur des mit dem feindlichen Ausland verbundenen inneren Feindes der Revolution stattfand. Bereits im Frühjahr 1793, als angesichts der kriegspolitischen Krisensituation erstmals auch gesetzliche Maßnahmen gegen die Ausländer diskutiert worden waren, hatte sich statt dessen letztlich der weniger nationalistisch konzipierte Generalverdacht gegen alle möglichen Feinde der Revolution durchgesetzt, neben den noch keineswegs generell ausgeschlossenen »étranger « trat der sich selbst aus der Nation ausschließende »étranger de l'intérieur ${ }^{10}$. Man hatte es nun also auch zu tun mit dem französischen »étranger qui vive au milieu de vous, affublé d'un bonnet rouge, pour vous percer le cœur«, wie Robespierre im Dezember 1793 urteilte $^{41}$. Einige Monate später, als der Kampf gegen die factions seinem Höhepunkt zusteuerte, argumentierte er dementsprechend folgendermaßen für eine terroristische Politik: »il n'y a de citoyens dans la République que les républicains. Les royalistes, les conspirateurs ne sont, pour elle, que des étrangers, ou plutôt des ennemis. Cette guerre

${ }^{408}$ WAHNICH, L'impossible citoyen, S. 206; vgl. auch E. DUCOUDRAY, "La main de l'étranger « en l'an II: Fantasmes populaires et paranoïa gouvernementale, in: J.P. BERTAUD (Hg.), Mélanges Michel Vovelle, Paris 1997, S. 243-252.

${ }_{409}$ Dekret vom 1.8.1793. AP 70, S. 107. Zur weiteren Ausgestaltung vgl. WAHNICH, L'impossible citoyen, S. 44-55.

410 Jean DEBRY, Rapport sur la police extraordinaire à exercer à l'égard des étrangers. AP 60, S. 386-389, hier S. 388, 21.3.1793: "Ces considérations nous ont fait penser que le décret relatif aux étrangers devait s'appliquer encore dans la République aux hommes que personne n'avouerait: tout homme doit aux magistrats de lui faire connaître par quels moyens il existe (...); dans des temps orageux, l'individu qui n'offre pas une caution suffisante de ses intentions civiques est justement suspect, et les mesures que dicte l'intérêt général sont réclamées par la liberté et par l'humanité«.

${ }_{411}$ AULARD, Société des Jacobins, Bd, 5, S. 550, 9.12.1793. 
terrible que soutient la liberté contre la tyrannie, n'est-elle pas indivisible? les ennemis du dedans ne sont-ils pas les alliés des ennemis du dehors? « $^{412}$.

In Verbindung mit der Gleichsetzung aller realen oder scheinbaren inneren und äußeren Feinde der Revolution in der Wahrnehmung der Revolutionsführung lag es nun nahe, aus dem Plural einen kollektiven Singular werden zu lassen. "L'étranger«, das waren nicht einzelne Ausländer, und es war auch nicht das feindliche Ausland, sondern es war ein so umfassendes wie ungenaues Synonym für alle Feinde der Revolution, ja für wtout le champ des valeurs, morales, sociales et politiques qui s'opposent a l'établissement de la République. L'étranger est alors conjointement un désignat abstrait et une figure polymorphe de tout ce qui s'oppose à la Révolution de l'an II ${ }^{433}$. Die Konsequenz daraus war der unnachgiebige Kampf gegen alle Abweichungen vom Kurs der revolutionären Regierung. "Il faut que le peuple et le gouvernement les répriment", proklamierte Saint-Just, "par la seule raison qu'ils sont favourables aux projets de l'étranger $\aleph^{414}$.

Der Kollektivsingular brachte einerseits das zunehmend allgegenwärtige Bedrohungsgefühl der Revolutionsführung zum Ausdruck, bewirkte andererseits aber auch eine Erweiterung des Feindbildes, die über den Kampf gegen die factions hinaus zu einer Triebkraft der weiteren terroristischen Radikalisierung wurde. Man hatte es nun zu tun mit »l'étranger qui attise ces factions, qui les fait se déchirer, par un jeu de sa politique et pour tromper l'œil observateur de la justice populaire; par-là il s'établit une sorte de procès devant le tribunal de l'opinion; l'opinion bientôt se divise, la république en est bouleversée. (...) L'étranger créera donc le plus de factions qu'il pourra; peu lui importe quelles elles soient, pourvu que nous ayons la guerre civile; l'étranger soufflera même, comme je l'ai dit, la discorde entre les partis qu'il aura fait naître, afin de les grossir et de laisser la révolution isolée. Tout parti est donc criminel, parce qu'il est un isolement du peuple et des Sociétés populaires et une indépendance du gouvernement. Toute faction est donc criminelle, parce qu'elle tend à diviser les citoyens«.

Der mit dem Feind gleichgesetzte sétranger" schien so überall zu wirken, und zugleich gewann der aus der Nation ausgegrenzte "étranger de l'intérieur" immer unschärfere Konturen; er schien selbst im Zentrum der revolutionären Bewegung präsent zu sein, zugleich aber auch unsichtbar zu werden. Je weniger man ihm nachweisen konnte, desto gefährlicher mußte er sein. Da gerade darin aber sein eigentliches Wesen erkannt wurde, schien eine klare Beweisführung nicht mehr notwendig, denn sie wäre gar nicht möglich. So konzentrierte sich die Anklage gegen die factions schließlich wesentlich darauf, die

${ }^{412}$ AP 84, S. 333, 17. Pluv. II/5.2.1794.

413 WAHNICH, L'impossible citoyen, S. 207.

${ }^{414}$ AP 86, S. 440, 23. Vent. II/13.3.1794; hier S. 439f. auch das folgende Zitat. 
Allgegenwart von Verschwörungen in der Revolution generell nachzuweisen. ${ }^{415}$ Der Präsident des Revolutionstribunals Dumas erklärte in seiner Rechtfertigungsrede vor den Jakobinern dementsprechend gleich auch alle, die das "complot de l'étranger« bezweifeln würden, zu Komplizen der Verschwörer: "Ils sont donc bien perfides ceux qui ont feint de ne pas croire à un parti de l'étranger; ceux qui ont affecté de méconnaître ce bras perfide; ceux qui n'ont voulu voir dans les résultats, que les effets ordinaires des passions locales? Celui qui n'est pas frappé de l'horreur du crime ne sent pas le prix de la vertu; celui qui veut dérober à nos yeux les crimes de nos ennemis, les a partagés dans son cœur, il est leur complice ${ }^{416}$. Es lag in der Logik dieser Verallgemeinerung des Feindbildes, daß der »große Terror» des Frühsommers 1794 der Revolution erst noch bevorstand.

Nach dem Sturz der factions standen im Frühjahr 1794 zwei letztlich einander ausschließende politische Projekte unvermittelt nebeneinander: die nun möglich erscheinende, siegreiche Beendigung des Krieges und damit - diese Verbindung erschien so selbstverständlich, daß sie gar nicht mehr zur Debatte stand - auch der Revolution einerseits, die Weiterführung des revolutionären Kampfes gegen den äußeren und inneren Feind, die Radikalisierung von Krieg und Terror andererseits. Obwohl die innere und äußere Befriedung durchaus ernsthaft angestrebt wurde, setzte sich doch die terroristische Radikalisienung schließlich durch, weil ihre Begründung in der Logik des revolutionären Diskurses so tief verankert war, da $\beta$ die Befriedung vorerst keine Chance besa $\beta$.

Das Ziel, mit dem Krieg auch die Revolution siegreich zum Abschluß zu bringen, rückte zuerst einmal jedoch immer nachdrücklicher in den Mittelpunkt der Verlautbarungen des nun den politischen Diskurs uneingeschränkt dominierenden Wohlfahrtsausschusses. Schon im Februar hatte Robespierre zu diesem Zusammenhang grundlegende Überlegungen vorgetragen, als er die Demokratie, »la jouissance paisible de la liberté et de l'égalité; le règne de cette justice éternelle«, als Ziel der Revolution bestimmte, dann aber fortfuhr: "Mais pour fonder et pour consolider parmi nous la démocratie, pour arriver au règne paisible des lois constitutionnelles, il faut terminer la guerre de la liberté contre la tyrannie, et traverser heureusement les orages de la révolution; tel est le but du système révolutionnaire que vous avez régularisé ${ }^{417}$. Im April bereitete Billaud den Konvent dementsprechend vor auf eine militärische "campagne qui sera terrible, car il est temps de terminer cette lutte révoltante

${ }^{415} \mathrm{Vgl}$. den Bericht von Saint-Just, AP 87, S. 629-6t39, 11. Germ. II/31.3.1794.

${ }^{416}$ Rapport fait à la société des amis de la liberté et de l'égalité, séante aux Jacobins à Paris, sur la conspiration dont Hébert, Ronsin, Vincent, Momoro, etc. Danton, Lacroix, Fabre, Chabot, Hérault, etc. Chaumette, Gobel, Dillon, etc. ont été complices, par Dumas, 21.Germ IV10.4.1794, abgedr. in: Le Père Duchesne, Bd. 11, S. 149-161.

417 AP 84, S. 331, 17. Pluv. IV/5.2.1794. 
de la royauté contre la république«, um sich dann den im Vergleich zum Beginn einer Revolution unendlich schwierigeren Problemen zuzuwenden, "pour la terminer ' $^{418}$.

Als sich der siegreiche Ausgang der Frühjahrskampagnen immer deutlicher abzuzeichnen begann, konnte es einen Moment so scheinen, als würde nun für Frankreich tatsächlich das Zeitalter des Friedens, der Demokratie und der Tugend anbrechen. Der "moment où le bruit de nos victoires retentit dans l'univers est donc celui où les législateurs de la République française doivent veiller avec une nouvelle sollicitude sur eux-mêmes et sur la patrie, et affirmer les principes sur lesquels doivent reposer la stabilité et la félicité de la République«, so leitete Robespierre Anfang Mai seinen Vorschlag für die Feier eines Festes des »Höchsten Wesens« ein. »C'est en vain que nous porterions au bout de l'univers la renommée de nos armes, si toutes les passions déchirent impunément le sein de la patrie. Défions-nous de l'ivresse même des succès; soyons terribles dans les revers, modestes dans nos triomphes (on applaudit), et fixons au milieu de nous la paix et le bonheur par la sagesse et par la morale. Voilà le véritable but de nos triomphes « ${ }^{419}$.

Das Fest des Höchsten Wesens erweckte dann in der Tat kurzzeitig den Eindruck, "que Robespierre allait fermer l'abîme de la Révolution", wie der zumeist gut unterrichtete Mallet du Pan im schweizerischen Exil meinte ${ }^{420}$. Doch obwohl das Ziel, Krieg und Revolutionen zu einem friedvollen, demokratischen, tugendhaften Ende zu bringen, zweifellos ernst gemeint war, setzte sich das gegenläufige Projekt der Radikalisierung von Krieg und Terror weiterhin durch, wie bereits zwei Tage später die Verabschiedung der sogenannten Prairial-Gesetze deutlich machte, die erst »la grande terreur « einleiteten ${ }^{421}$.

Als Argument gegen eine kriegsbezogene Begründung des Terrors ist oft darauf hingewiesen worden, daß er erst im Frühjahr und Sommer 1794 seinem Höhepunkt zustrebte, zu einem Zeitpunkt also, als die militärische Bedrohung der Republik im Innern und von Außen gestoppt worden war und die französischen Armeen zunehmend wieder die Offensive übernahmen. In einem engen instrumentellen Sinne spricht dies zweifellos dafür, den Terror nun definitiv von der Bindung an die Notwendigkeiten der Landesverteidigung zu lösen. Im revisionistischen Paradigma war er deshalb nun endgültig »moins partie de l'arsenal de la victoire que d'une ambition de régénération«, wie Furet unter

${ }^{418}$ AP 89, S. 95f., 1. Flor. II/20.4.1794.

${ }^{419}$ AP 90, S. 132, 140, 18. Flor. II/7.5.1794.

${ }^{420}$ Zit. n. A. MATHIEZ, Le culte de l'être suprême, in: DERS., Autour de Robespierre, Paris 1925, S. 93-128, hier S. 126.

${ }^{421} \mathrm{Vgl}$. zu den Hintergründen: M. EUDE, La loi de prairial, in: Annales Historiques de la Révolution Française, 55. Jg. 1983, S. 544-559; G. LEFEBVRE, Sur la loi du 22 prairial, in: DERS., Etudes sur la révolution française, Paris 1954, S. 67-89. 
Berufung auf Ozouf urteilt ${ }^{422}$. Die letzten Monate der von Robespierre dominierten Herrschaft des Wohlfahrtsausschusses werden so als eine terroristische Tugenddiktatur gedeutet. Beides aufs engste miteinander verbindend, erscheint sie geprägt von der Inszenierung der Moral, der Tugend und des Höchsten Wesens einerseits, der weiteren Radikalisierung des Terrors als unabtrennbares Pendant des Tugendstaates andererseits. Der Terror war demnach wesentlich ein Instrument der moralischen Erneuerung, die einer widerstrebenden Gesellschaft gewaltsam aufgezwungen werden mußte.

Doch so überzeugend diese Analyse auf den ersten Blick zu sein scheint, unter der hier eingenommenen Perspektive kann tatsächlich nur eine Nuancenverschiebung im revolutionären Kriegsdiskurs festgestellt werden. Es wurde oben bereits gezeigt, da $\beta$ die Grundmuster des politischen Diskurses mit ihrer Beschwörung eines unausweichlichen Entscheidungskampfes zwischen Revolution und Ancien Régime, zwischen Republik und Monarchie, über die erfolgreiche Landesverteidigung hinaus zur Radikalisierung des Vernichtungskrieges gegen den äußeren Feind führten. Untrennbar damit verbunden war zugleich die weitere terroristische Radikalisierung im Innern, die erst im Sommer 1794 in der "grande terreur « ihre Hybris fand. Schon zum Jahresbeginn 1794 hatte Barère, als er nach ersten französischen Siegen jeden Gedanken an einen baldigen Friedensschluß zurückweisen wollte, zugleich den Krieg und damit auch den Terror zum Wesenselement nicht mehr nur der Revolution, sondern gleich auch der Republik erklärt: "Il faut la paix aux monarchies, il faut l'énergie guerrière à la République; il faut la paix aux esclaves, il faut la fermentation de la liberté aux républicains; il faut la paix aux gouvernements de l'Europe, il faut de l'activité révolutionnaire à la République française « ${ }^{423}$.

Es ist so nicht erstaunlich, daß Barères berühmte "apologie de la terreur" vor dem Konvent vom 4. Juli $1794^{424}$ wiederum wesentlich dazu diente, die Notwendigkeit der Fortsetzung des Krieges auch nach der nunmehr vollständigen Befreiung aller französischen Territorien zu begründen. Und längst waren nicht nur Krieg und Terror im revolutionären Diskurs untrennbar miteinander verbunden, sondern auch die revolutionäre Erneuerung war in diese Verbindung unauflöslich eingewoben. »La guerre, qui semblait devoir consommer notre ruine, est pourtant ce qui nous a sauvé«, so stilisierte Billaud, als er zu Anfang der Frühjahrskampagnen eigentlich das Ende von Krieg und Revolution anvisieren und sich den Problemen des demokratischen Aufbaus zuwenden wollte, den Krieg in tautologischer, nur vor dem Hintergrund der bisherigen Entwicklung des revolutionären Diskurses verständlicher Form zum

${ }^{422}$ FURET, Terreur, in: DERS., OzOUF, Dictionnaire critique, S. 156-169, hier S. 167.

${ }^{423}$ AP 83, S. 562, 3. Pluv. II/22.1.1794.

${ }^{424}$ Vgl. etwa TULARD u. a., Histoire et dictionnaire de la Révolution française, S. 369. 
Motor von Terror und revolutionärer Erneuerung: »La guerre, en enflammant tous les esprits, en agrandissant tous les cœurs, en inspirant comme passion dominante la gloire de sauver la patrie, a rendu le peuple constamment éveillé sous ses dangers, sans cesse exaspéré contre les forfaits de la monarchie et du fanatisme, toujours aussi ardant pour combattre les despotes jusqu'au dernier qu'inexorable envers les traîtres méditant le massacre de nos armées et l'avertissement de la France«. Wenn Billaud dann in einer Rede, die eine kriegsentscheidende militärische Kampagne begründen sollte, wune action forte, une impulsion véhémente, propre à développer les vertus civiques et a comprimer les passions de la cupidité et de l'intrigue« als Voraussetzung für die innere demokratische Erneuerung forderte, so bezog sich dies auch weiterhin auf einen Krieg, der nicht nur den Frieden erst auf den Ruinen der Königreiche Österreich, Spanien und England errichtet sehen wollte, sondern dessen terroristische Konzeption »en soi la source de votre splendeur« trage ${ }^{425}$.

Die Basis für die sich hier abzeichnende Ausweitung des Terrors indes schuf die im politischen Diskurs vorgezeichnete Unfähigkeit der Revolutionsführung, aus dem Schreckbild der Bedrohung durch den äußeren und inneren Feind, aus dem Zirkel von Krieg, Bürgerkrieg und Terror herauszufinden. Die wesentliche Grundlage für die Radikalisierung des Terrors lag zweifellos weiterhin in der revolutionären Beschwörung des Kampfes an zwei Fronten. »Cette guerre terrible que soutient la liberté contre la tyrannie«, so Robespierre im Februar 1794, "n'est-elle pas indivisible? Les ennemis du dedans ne sont-ils pas les alliés des ennemis du dehors? Les assassins qui déchirent la patrie dans l'intérieur; les intrigants qui achètent les consciences des mandataires du peuple; les traitres qui les vendent; les libellistes mercenaires soudoyés pour déshonorer la cause du peuple, pour tuer la vertu publique, pour attirer le feu des discordes civiles, et pour préparer la contrerévolution politique par la contre-révolution morale; tous ces gens-là sont-ils moins coupables ou moins dangereux que les tyrans qu'ils servent? Tous ceux, qui interposent leur douceur parricide entre ces scélérats et le glaive vengeur de la justice nationale, ressemblent à ceux qui se jeteraient entre les satellites des tyrans et les baionnettes de nos soldats « ${ }^{426}$.

Dieser Grundauffassung entsprechend, verband sich der Beginn der Frühjahrskampagnen wie selbstverständlich mit der Verschärfung des Kampfes gegen den sinneren Feind. »Les armées extermineront les soldats de la

${ }^{425}$ Am 19. Germ. II/20.4.1794 im Konvent. AP 89, S. 94-100, hier S. 95. Vgl. auch ebd. die historische Parallele: »Rome encore à son adolescence trouva même dans cette guerre le principe de sa grandeur. Ce fut la nécessité de défendre qui, électrisant son énergie et son courage, centupla ses forces, et qui la rendit bientôt un colosse ayant pour piédestal l'univers asservic.

${ }^{426}$ Ebd., S. 333. 
tyrannie, et nous ferons tomber les traîtres sous la masse du peuple«, so verband etwa Collot den Kampf nach außen und innen. "Je vous le répète, citoyens, surveillons au dedans pendant que nos guerriers combattent aux dehors ${ }^{427}$. Zumeist aber wurde sogar der Vorrang des Kampfes gegen den inneren Feind beschworen, der Sieg an der inneren Front galt als notwendige Voraussetzung des militärischen Sieges. "Nous sommes" so argumentierte etwa Tallien im März 1794 für die Radikalisierung des Terrors, "au commencement d'une campagne dans laquelle toutes les cohortes étrangères amenées du fond de l'Europe pour détruire la liberté vont être elles-mêmes anéanties; il est instant de détruire l'armée auxiliaire que la tyrannie soudoie dans le sein de la France ${ }^{428}$. Barère forderte: „Citoyens, la campagne va s'ouvrir, déblayons le sol de l'intérieur de tant d'intrigues afin que nous puissons ne plus nous occuper que de combats et de victoires contre les ennemis étranger ${ }^{429}$. Und Le Bas fügte Anfang Mai als Präsident des Jakobinerklubs hinzu: »Les ennemis de la liberté ne sont pas tous au-delà des Alpes et du Rhin; il en est dans l'intérieur, qui sont plus perfides que les autres; ce sont ceux-là que vous devez poursuivre avec courage, en songeant que les succès que la République doit espérer contre les ennemis de l'extérieur dépendent des avantages que vous obtiendrez sur ceux de l'intérieur. Ne laissons aux traîtres aucun asile sur le sol de la France, et les tyrans seront anéantis « ${ }^{30}$. Wenn er nun zugleich feststellte, daß ganz Frankreich »une seule armée« sei und es »ni paix ni trêve« für seine Feinde geben könne, denn »il faut leur faire la guerre jusqu'à la mort", so zeichnete sich darin trotz der wachsenden militärischen Erfolge auch die weitere Radikalisierung des Terrors deutlich ab.

Im ersten Kapitel dieses Teils konnte gezeigt werden, daß die Beendigung des Krieges angesichts eines prinzipiellen, auf die totale Vernichtung des Gegners abzielenden Kriegsbegriffs nur in der Form einer totalen, trotz aller Siege noch lange nicht erreichbaren Niederwerfung der Staaten der Koalition denkbar schien, die Revolution somit außenpolitisch aufs engste an die Fortdauer des Krieges gebunden wurde. Da es so nicht gelingen konnte, die Revolution durch die Beendigung des Krieges einzuhegen, ergab sich parallel zur Fortsetzung und Radikalisierung des Krieges mit innerer Notwendigkeit auch die Radikalisierung des Terrors gegen den inneren Feind, der inzwischen zu einer allgegenwärtigen Bedrohung geworden zu sein schien. "Aussi les cours étrangères ont-elles dès long-temps vomi sur la France tous les scélérats habiles qu'elles tiennent à leur solde«, so hatte Robespierre schon Ende 1793

${ }^{427}$ Rede am 9. Germ. II/10.4.1794 im Jakobinerklub. AULARD, Société des Jacobins, Bd. 6, S. $60 \mathrm{f}$.

${ }^{428}$ AULARD, Société des Jacobins, Bd. 6, S. 5, 29. Vent. II/19.3.1794.

${ }^{429}$ AP 86, S. 129, 6.3.1794.

${ }^{430}$ AULARD, Société des Jacobins, Bd. 6, S. 108, 13. Flor. II/2.5.1794. 
die Allgegenwart des sinneren Feindes ‘ beschworen. "Ils rôdent autour de nous; ils surprennent nos secrets; ils caressent nos passions; ils cherchent à nous inspirer jusqu'à nos opinions; ils tournent contre nous nos résolutions (...), les cohortes impies des émissaires étrangers se recrutent chaque jour $^{433}$. Und gerade angesichts der militärischen Überlegenheit der republikanischen Truppen schien es nun naheliegend zu sein, daß die noch nicht endgültig besiegten Feinde nun umso stärker auf die Kriegführung an der inneren Front setzen würden. "Soyez plus que jamais sur vos gardes«, argumentierte Robespierre im Jakobinerklub, »les hommes pervers emploient tous les sacrifices (sic) imaginables pour anéantir la Convention et égorger en détail les défenseurs de la patrie. Ne vous endormez point dans une fausse sécurité; n'abandonnez pas la Convention et le gouvernement dont elle est le centre ${ }^{432}$.

Insbesondere vor dem Hintergrund einiger obskurer Mordanschläge gegen Robespierre und Collot war die Revolutionsführung nun umso mehr überzeugt, daß »la faction de l'étranger s'agite en tout sens«, wie Couthon im Jakobinerklub die terroristischen Prairial-Gesetze begründete. „Pitt a encore ici une multitude d'agents, dont les uns sont chargés de corrompre, les autres de poignarder, les autres enfin de diviser et d'épouvanter, en disant que le Comité veut usurper les pouvoirs et opérer le plus grand de tous les malheurs $\aleph^{433}$. Wenige Tage zuvor hatte er im Konvent die terroristische Energie beschworen, "qui, dans ces derniers temps, nous a donné les moyens de vaincre nos ennemis étrangers, en arrêtant l'audace de nos ennemis intérieurs. Comment«, so fuhr er rhetorisch fragend fort, "croire à la République ou à la victoire, quand la ligue des tyrans et des traîtres dominait dans l'état, et se jouait impunément des destinées du peuple français«. Um dies zu verhindern, sei es nun notwendig, die Feinde der Republik nicht nur zu bestrafen, sondern endgültig auszulöschen, denn, wie Couthon in Umkehrung einer von Robespierre geprägten Formel betonte: „Une révolution comme la nôtre n'est qu'une succession rapide de conspirations, parce qu'elle est la guerre de la tyrannie contre la liberté, du crime contre la vertu. Il n'est pas question de donner quelques exemples, mais d'exterminer les implacables satellites de la tyrannie $\ll^{434}$.

Wenn auch eher beiläufig eingeführt, haben wir hier nun endlich auch das

\footnotetext{
${ }^{431}$ AP 82, S. 302, 25.12.1793.

432 AULARD, Société des Jacobins, Bd. 6, S. 174, 23. Prair. IV/11.6.1794.

${ }^{433}$ Ebd., S. 178, 26. Prair. II/14.6.1794.

${ }^{434}$ AP 91, S. 485-487, 22. Prair. IV/10.6.1794. Wie sehr die Vorstellung vorherrschte, durch den Terror im Inneren die militärischen Erfolge erst ermöglicht zu haben, verdeutlicht etwa auch die Argumentation, mit der Vadier am 27.7.1794 die Tätigkeit des Allgemeinen Sicherheitsausschusses rechtfertigte: "Le comité de gouvernement qui dirige les armées a fait son devoir, et les victoires que la République remporte sont aussi le fruit de la compression des ennemis de l'intérieur, et cette compression est l'ouvrage du comité de sûreté générale«. AP 93, S. 553.
} 
Motiv der mit der Revolution identifizierten »vertu«, der Tugend vor uns, wobei der Kampf der Tugend gegen das Verbrechen jedoch eindeutig als Bestandteil der Verbindung von Krieg und Revolution erscheint. Zweifellos ist es angemessen, darin »un dérivé de l'imaginaire par rapport au réel« zu erkennen $^{43}$. Doch folgt daraus wirklich, daß angesichts der trotz ihrer Siege weiterhin und umso mehr allseitig bedroht erscheinenden Revolution »le thème du danger extérieur peut être rhétoriquement traité«, wie Ozouf argumentiert? Tatsächlich habe gar nicht mehr der Krieg im Zentrum des politischen Diskurses gestanden, sondern das Verbrechen. Damit soll erklärt werden, daß die Republik in jakobinischer Logik gar nicht habe gerettet werden können, weil nicht der Kampf um den Sieg, sondern um die Tugendhaftigkeit ihr eigentliches Wesen ausgemacht habe. Doch welchen Sinn kann es machen, militärischen Sieg und tugendhafte Erneuerung gegeneinanderzustellen, wenn doch der unendliche Krieg, nach innen wie nach außen, zweifellos die beide Aspekte verbindende Essenz des jakobinischen Diskurses ausmachte? Als Robespierre am 5. Februar 1794 tatsächlich erstmals Tugend und Terror miteinander verband, trat die kriegspolitische, auf der Identifikation von Krieg und Revolution fußende Grundlage bereits mehr als deutlich hervor: "Au dehors tous les tyrans vous cernent; au dedans tous les amis de la tyrannie conspirent: ils conspireront jusqu'à ce que l'espérance ait été ravie au crime. Il faut étouffer les ennemis intérieurs et extérieurs de la république, ou périr avec elle; or, dans cette situation, la première maxime de votre politique doit être qu'on conduit le peuple par la raison, et les ennemis du peuple par la terreur. Si le ressort du gouvernement populaire dans la paix est la vertu, le ressort du gouvernement populaire en révolution est à-la-fois la vertu et la terreur; la vertu, sans laquelle la terreur est funeste, la terreur sans laquelle la vertu es impuissante ${ }^{436}$.

Nicht als Inhalt der Republik, sondern als Antriebskräfte der revolutionären Regierung wurden Tugend und Terror hier gedeutet. Beide erschienen wesentlich als Mittel zum Zweck, und während der Terror der mit der Revolution identifizierten Kriegsführung nach außen und innen dienen sollte, war die Tugend dazu bestimmt, die destruktiven Kräfte des Terrors zu kontrollieren. Erst vor diesem kriegspolitischen Hintergrund gewann die Tugend auch noch aus einem anderen Grunde ihre zentrale politische Bedeutung, denn sie firmierte wesentlich als Gegenpol zu der Konspiration, dem Verrat, der Unmoral, dem Verbrechen, wie sie schon seit langem als Mittel der inneren Destabilisierung durch den äußeren Feind gedeutet worden waren und nun, angesichts der militärischen Überlegenheit der revolutionären Armeen, noch stärker in den Mittelpunkt der feindlichen Aktivitäten zu rücken schienen.

${ }^{435}$ Ozouf, Guerre et terreur, S. 124; ebd., S. 125, das folgende Zitat.

${ }^{436}$ AP 84, S. 333, 17. Pluv. II/5.2.1794. 
"L'étranger n'a qu'un moyen de nous perdre; c'est de nous dénaturer et de nous corrompre, puisqu'une République ne peut reposer que sur la nature et sur les mœurs «, analysierte Saint-Just schon Anfang Februar $1794^{437}$, um dann einen Monat später gegen die factions vorzubringen, ihre Tätigkeit sei wcriminelle, parce qu'elle neutralise la puissance de la vertu publique«; die Anklage lautete: "Il y a dans la république une conjuration ourdie par l'étranger, dont le but est d'empêcher par la corruption que la liberté ne s'établisse. Le but de l'étranger est de créer des conjurés de tout les hommes mécontents, et de nous avilir, si c'était possible, dans l'univers par les scandales des intrigues, on commet des atrocités pour en accuser le peuple et la révolution (...) Partout où l'étranger trouve un homme faible et corrompu, il le caresse, il lui promet tout: peu lui importe, pourvu que (...) cet empire tombe au pied de l'Europe asservie ${ }^{438}$. Und als Robespierre zwei Monate später scheinbar das Wesen der Tugendrepublik bestimmte, trat der kriegspolitische Hintergrund des Kampfes zwischen Tugend und Verbrechen wiederum unübersehbar zutage: „L'immoralité est la base du despotisme, comme la vertu est l'essence de la République. La révolution, qui tend à l'établir, n'est que le passage du règne du crime à celui de la justice; de là résultent les efforts continuels des rois ligués contre nous et de tous les conspirateurs pour perpétuer chez nous les préjugés et les vices de la monarchie ${ }^{439}$.

Was Robespierre und seinen Anhängern vorschwebte, das war nur an der Oberfläche ein allgemeiner, durch den Terror zu erzwingender Tugendstaat. Sie waren tatsächlich keine "prisoners of an ideology that had made them responsible for the regeneration of everyone else $\ll^{440}$, sondern sie waren Gefangene eines Diskurses, der Krieg, Bürgerkrieg und Revolution unauflöslich miteinander verbunden und so verewigt hatte. Ihre Vorstellungen zielten wesentlich auf die Ausbildung eines vom revolutionären Kampf an zwei Fronten geprägten, terroristischen Kriegsstaates. »En vain les armées de la République triompheraient des ennemis du dehors, si nous n'arrachions à leurs émissaires, tous les moyens d'assassiner la liberté jusque dans son plus cher asile«, so begründete Robespierre Ende Juni 1794 vor den Jakobinern die Notwendigkeit des verschärften Terrors. "Voilà pourquoi les tyrans et leurs suppôts s'agitent encore dans tous les sens, pour semer parmi nous les divisions, les discordes, et la désorganisation. Ils savent trop bien qu'un peuple ne peut combattre avec

\footnotetext{
${ }^{437}$ AP 85, S. 516-520, 8. Vent. II/ 26.2.1794.

${ }^{438}$ AP 86, S. 434-442, hier S. 434, 13.3.1794.

${ }^{439}$ AP 90, S. 133, 18. Flor. II/7.5.1794. Vgl. auch die letzte von Robespierre inspirierte Adresse des Jakobinerklubs an den Konvent, in der es hieß: »Les amis de la Liberté et de l'Egalité, viennent dénoncer à la Convention nationale les complots que l'étranger forme dans son désespoir (...) l'étranger a placé sa dernière ressource dans le crime«. AULARD, Société des Jacobins, Bd. 6, S. 242f.

${ }^{440}$ So HAMPSON, From Regeneration to Terror, S. 64.
} 
succès ses ennemis conjurés qu'avec cet accord, cet ensemble et ce point de ralliement que seul doit être l'âme de toutes ses victoires et de ses triomphes. Ce plan de division est donc continuellement suivi dans ses ramifications infinies«. Aus dieser Situationsanalyse leitete Robespierre auf dem Höhepunkt seiner Macht das Programm eines unendlichen, ebenso kriegerischen wie terroristischen Kampfes gegen alle Feinde der Revolution ab: "Tant que nous existerons, nous démasquerons, nous combattons les tyrans, les traîtres, et tous les scélérats! «44!

Bleibt zu klären, wieso es trotzdem zum Sturz Robespierres und damit zum Ende der terroristischen Radikalisierung kommen konnte. Zweifellos gibt es eine Reihe von Ursachen, die von der wachsenden Selbstisolierung Robespierres über die Vielzahl der sich bedroht fühlenden Revolutionsführer bis zum Verlust der sozialen Basis der revolutionären Regierung in der stillgestellten Pariser Volksbewegung reichen ${ }^{42}$. Von besonderer Bedeutung jedoch scheint zu sein, daß die Koalition höchst unterschiedlicher politischer Kräfte, die den sTyrannen ‘ am 9. Thermidor 1794 stürzte, zweifellos nicht die Absicht verfolgte, auch das Terrorregime zu Fall zu bringen. Sein Zusammenbruch ergab sich eher beiläufig, und ein Hauptgrund ist wohl darin zu sehen, daß der terroristische Kriegsdiskurs nach den großen Siegen der französischen Armeen im Frühsommer 1794 mit der de facto eben doch schwindenden äußeren Bedrohung seine wesentliche Grundlage verlor. Nur so ist zu erklären, weshalb unmittelbar nach Bekanntwerden des Sieges bei Fleurus im Wohlfahrtsausschuß vorher kaum denkbare, zum inneren Zerwürfnis führende Vorwürfe gegen Robespierre laut werden konnten, er bereite eine persönliche Diktatur vor ${ }^{43}$.

Trotzdem aber schien die Überzeugungskraft des kriegspolitisch begründeten staatsterroristischen Diskurses noch am 9. Thermidor so groß zu sein, daß die Verschwörer Robespierre im Konvent nicht mehr zu Worte kommen lieBen und jeden seiner Versuche, die Stimme zu erheben, gezielt niederschrien $^{44}$. Und nach getaner Tat wurde der Sturz des $>$ Tyrannen selbstverständlich mit dem gängigen Argument begründet, auch er habe im Dienste des feindlichen Auslandes gestanden. "Le rapport d'un déserteur apprend que les puissances étrangères étaient liguées avec Robespierre et ne voulaient traiter qu'avec lui«, so lautete die typische, äußere und innere Revolutionsfeindschaft >amalgamierender Formel, mit der Billaud die Hinrichtung

\footnotetext{
${ }^{441}$ AULARD, Société des Jacobins, Bd. 6, S. 183ff., 3. Mess. II/21.6.1794.

${ }_{442}$ Vgl. allg. F. BRUNEL, Thermidor. La chute de Robespierre, Brüssel 1989.

${ }^{443}$ Vgl. PALMER, Twelve who Ruled, S. 361-372.

444 Vgl. AP 93, S. 553f.; zur Position Robespierres vgl. seinen hier die Mehrheit überzeugenden Vortrag der Rede im Jakobinerklub am 8. Therm. II/26.7.1794. AULARD, Société des Jacobins, Bd. 6, S. 246-282.
} 
Robespierres und seiner Vertrauten vor dem Jakobinerklub begründete ${ }^{445}$. $» \mathrm{La}$ France est libre enfin«, so wurde den Soldaten an der Front mitgeteilt. »Et vous, braves guerriers, intrépides défenseurs de la patrie! n'avez-vous jamais vu comment il cherchait à terminer l'éclair de vos succès? Comment au milieu des victoires et des triomphes de la république, il essayait de semer l'alarme et la terreur dans toutes les âmes par des idées de conspiration, dont lui seul avait été le chef, puisqu'elles étaient son ouvrage? N'avez-vous jamais vu comment il essayait de faire oublier votre courage, votre vertu et votre dévouement, en vous disant que ce n'était pas par des victoires, qu'on sauvait la patrie, mais en s'acharnant avec lui à la ruine de ceux dont il redoutait l'œil et l'énergie, et qu'il transformait en conspirateurs? $\ll^{446}$.

Doch angesichts der Tatsache, daß die Agitation gegen Robespierre im Konvent zuvor auf jeden kriegspolitischen Bezug verzichtet und allein die Kritik an der Tyrannei beschworen hatte ${ }^{447}$, müssen diese Argumente nun in der Tat wesentlich als rhetorische Mittel erscheinen. Auffällig ist dabei auch, $\mathrm{da}$ im ersten Beispiel nicht mehr die Kriegsführung, sondern vielmehr Friedensverhandlungen in den Mittelpunkt der Argumentation rückten, während das zweite Beispiel die Konspiration in der Beschwörung von Konspirationen erkennen wollte. Alles dies weist letztlich auf die zentrale Voraussetzung für den Sturz Robespierres hin, nämlich darauf, daß die terroristische Diktatur, deren Inhalt die Führung des Überlebenskampfes einer allseits bedrohten Republik gewesen war, mit der kriegerischen Bedrohung auch ihre herrschaftskonzeptionelle Begründung eingebüßt hatte. Und daß nun mit der Herrschaft Robespierres und seiner engeren Gefolgsleute auch die terroristische Kriegsdiktatur selbst an ihr Ende gelangt war, wurde unmittelbar deutlich. Denn als der Konvent schon zwei Tage nach dem Sturz Robespierres, ganz gegen die Intentionen seiner Protagonisten, den Beschluß faßte, die Mitglieder des Wohlfahrtsausschusses fortan regelmäßig auszuwechseln und damit de facto seine Diktatur zu beenden, ließen sich die Abgeordneten nun auch durch das Argument nicht mehr beirren, man brauche eine starke Regierung, um die Armeen zu führen ${ }^{488}$.

\footnotetext{
${ }^{445}$ AULARD, Société des Jacobins, Bd. 6, S. 299, 11. Therm. II/29.7.1794; ebd., S. 300, das folgende Zitat.

${ }^{446}$ Abgedr. in: Journal des hommes libres, 11 Therm. II/29.7.1794.

${ }^{447} \mathrm{Vgl}$. auch die nachträgliche Rechtfertigung durch Barère: AP 93, 10. Therm. IU/28.7.1794, S. 611-614.

${ }^{448}$ Vgl. AP 93, 11. Therm. II/29.7.1794, S. 647-650.
} 
